\title{
Assessment of Government Tribology Programs
}

September 1985

Prepared for the U.S. Department of Energy under Contract DE-AC06-76RLO 1830

Pacific Northwest Laboratory Operated for the U.S. Department of Energy by Battelle Memorial Institute 


\title{
DISCLAIMER
}

This report was prepared as an account of work sponsored by an agency of the United States Government. Neither the United States Government nor any agency thereof, nor any of their employees, makes any warranty, express or implied, or assumes any legal liability or responsibility for the accuracy, completeness, or usefulness of any information, apparatus, product, or process disclosed, or represents that its use would not infringe privately owned rights. Reference herein to any specific commercial product, process, or service by trade name, trademark, manufacturer, or otherwise, does not necessarily constitute or imply its endorsement, recommendation, or favoring by the United States Government or any agency thereof. The views and opinions of authors expressed herein do not necessarily state or reflect those of the United States Government or any agency thereof.

\author{
PACIFIC NORTHWEST LABORATORY \\ operated by \\ BATTELLE \\ for the \\ UNITED STATES DEPARTMENT OF ENERGY \\ under Contract DE-AC06-76RLO 1830
}

\begin{tabular}{|c|c|}
\hline \multirow{2}{*}{\multicolumn{2}{|c|}{ Printed in the United States of America }} \\
\hline & \\
\hline \multicolumn{2}{|c|}{$\begin{array}{l}\text { Available from } \\
\text { National Technical Information Service }\end{array}$} \\
\hline \multicolumn{2}{|c|}{$\begin{array}{l}\text { National Technical Information Service } \\
\text { United States Department of Commerce }\end{array}$} \\
\hline \multirow{2}{*}{\multicolumn{2}{|c|}{$\begin{array}{c}5285 \text { Port Royal Road } \\
\text { Springfield, Virginia } 22161\end{array}$}} \\
\hline & \\
\hline \multirow{2}{*}{\multicolumn{2}{|c|}{$\begin{array}{l}\text { NTIS Price Codes } \\
\text { Microfiche } A 01\end{array}$}} \\
\hline & \\
\hline \multicolumn{2}{|c|}{ Printed Copy } \\
\hline & Price \\
\hline Pages & Codes \\
\hline 001-025 & $A 02$ \\
\hline $026-050$ & $\mathrm{~A} 03$ \\
\hline $051-075$ & A04 \\
\hline 076-100 & A05 \\
\hline $101-125$ & 106 \\
\hline $126-150$ & A07 \\
\hline $151-175$ & 108 \\
\hline $176-200$ & $A 09$ \\
\hline $201-225$ & $A 010$ \\
\hline $226-250$ & A011 \\
\hline $251-275$ & A012 \\
\hline $276-300$ & A013 \\
\hline
\end{tabular}


ASSESSMENT OF GOVERNMENT

TRIBOLOGY PROGRAMS

M. B. Peterson

Wear Sciences Corporation

T. M. Levinson

DOE/ECUT Program Manager

September 1985

Prepared for

Energy Conversion and Utilization

Technologies Division

Office of Energy Systems Research

Conservation and Renewable Energy

U.S. Department of Energy

under Contract DE-AC06-76RLO 1830

Pacific Northwest Laboratory

Richland, Washington 99352 

Experts estimate that in 1978 over four quadrillion Btu of energy were lost in the United States because of simple friction and wear--enough energy to supply New York City for an entire year. This translates to a $\$ 20$ billion loss, based on oil prices of about $\$ 30$ per barrel. (a) Because of the enormity of this energy loss, the Energy Conversion and Utilization Technologies (ECUT) Program in the U.S. Department of Energy (DOE) initiated a program in 1983 to study tribology--the science of friction and wear--to learn more about the causes of these energy losses (or tribological

"sinks") and how to reduce them.

The ECUT Program itself was started in 1980 to encourage research to improve energy conversion and utilization efficiency. The enormous energy loss in tribological sinks has been targeted by the ECUT program as having significant potential for energy conservation. One goal of the ECUT Tribology Program is to reduce these energy losses by developing improved lubricants and more durable materiais.

To support initial Tribology Program planning, ECUT conducted six surveys to gather three types of information about the current tribology problem in the U.S.:

1. The identification of typical industrial sinks

2. A survey of current U.S. Government tribology projects

3. The identification of tribology R\&D needs based on industry perceptions.

The six ECUT-sponsored surveys are listed in Table ES.1. Each survey is being published as a separate volume with its own summary. This executive summary, which also appears in each of the six volumes, presents an overview of results from the six surveys and their implications for energy conservation. The results of these six surveys and theír implications for energy conservation are presented in this summary. These results will be used to support further research planning for the ECUT Tribology Program.
TABLE ES.1. ECUT Surveys Reviewed in this Summary

1. A Review of Tribological Sinks in Six Major Industries. Imhoff, et a). PNL-5535, Pacific Northwest Laboratory, Richland, Washington.

2. Reduction in Tribological Energy Cosses in the Transportation and Electric Utilities Sectors. Pinkus and Wi Tcock, Mechanical Technology Incorporated. PNL-5536; Pacific Northwest Laboratory, Richland, Washington.

3. Identification of Tribological Research and Development Needs for Lubrication of Advanced Heat Engines. Fehrenbacher, Technology Assessment and Transfer, Incorporated. PNL -5537 , Pacific Northwest Laboratory, Richland, Washington.

4. Energy Conservation Potential of Surface Modification Technologies. Le Khac, DHR, Inc. PNL-5538, Pacific Northwest Laboratory, Richland, Washington.

5. Assessment of Government Tribology Programs. Peterson, Hear Sciences Corporation. PNL-5539, Pacific Northwest Laboratory, Richland, Washington.

6. Assessment of Industrial Attitudes Toward Generic Research Needs in Tribology. Sibley and Zlotnick, Tribology Consultants Incorporated. PNL -5540 , Pacific Northwest Laboratory, Richland, Washington.

IDENTIFYING TYPICAL TRIBOLOGICAL SINKS AND RECHANISINS

ECUT's first step in collecting information about tribology was to identify significant tribological sinks and mechanisms. This information was needed to focus research on key technological problems. Because the industry, transportation, and utilities sectors account for most of the

(a) Calculations in this summary are based on a $\$ 30$ f1gure. 
energy consumed in the U.S., ECUT concentrated first on the tribological energy sinks and mechanisms found in these three sectors. The report by Imhoff, et al., describes the most important tribological sinks typically found in industry, and the report by Pinkus and Wilcock describes tribological energy losses in the transportation and utilities sectors. Two specific studies assessed tribological problems in the metalworking industry and in the advanced diesel engine.

To identify areas in which tribology has a significant impact, the authors examined the energy consumed, the fuels used, and the primary products and processes found in the transportation, industrial, and utflities sectors. Once energy losses were 1 dentified, their magnitude was estimated. The estimates include both friction losses (direct losses) and material wear losses (indirect losses). The authors also estimated the energy savings potential in each sector and recommended some specific R\&D programs to help achieve these energy savings.

\section{The Industrial Sector}

Tribological energy losses are pervasive throughout industry. Because revilewing all industries and industrial processes in detail would be impossible, the Imhoff, et al. survey, instead chose six representative industries (Mining, Agriculture, Primary Metals, Chemicals/Refining, Pulp and Paper, and Food Processing) that appeared to have the most significant tribological sinks and energy losses. These industries were selected because of their 1) major, nonthermal energy streams (such as machine drives); 2) high material wear rates and friction; 3) significant material transportation/alteration processes; and 4) total energy use.

The study identified important tribological sinks in each selected industry, based on both friction and material wear energy losses and on the tribological mechanisms and materials involved. Figure ES.1 and Table ES.2 show the key results for each of the six industries.

The first conclusion from this study confirmed earlier claims that losses from material wear are greater than energy losses from friction; the wear losses in five of the industries were found to be more thap twice as large as the friction lasses. (a) The study also concluded that reducing material wear rates to improve equipment life

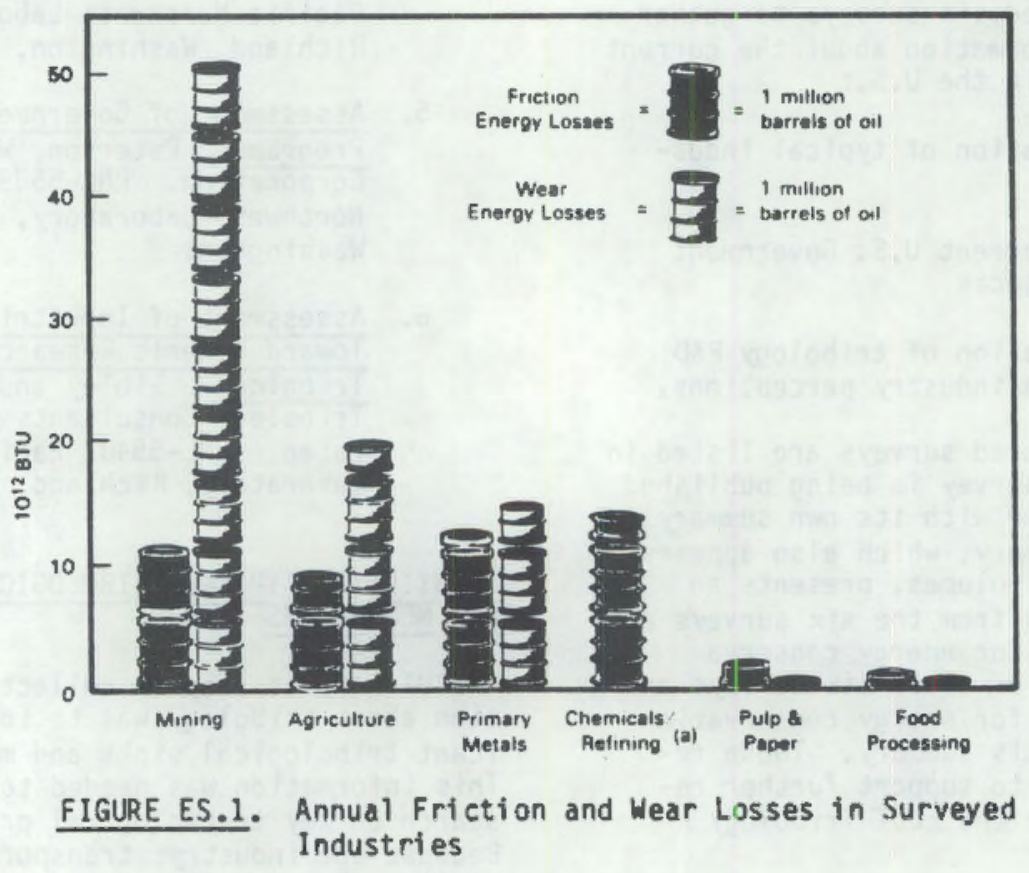

(a) These five industries had estimates of both friction and material wear losses; the sixth, Chemicals/Refining, did not have estimates of wear losses. 
TABLE ES.2. Primary Mechanisms in Friction Energy Losses and Principal Materials Involved in Wear Energy Losses

\begin{tabular}{|c|c|c|}
\hline Industry & Mechanisms & Materials \\
\hline Mining & $\begin{array}{l}\text { 3-body Abrasion } \\
\text { Friction }\end{array}$ & $\begin{array}{l}\text { Iron, Steel alloys, } \\
\text { Alumi num, Rubber }\end{array}$ \\
\hline Agriculture & $\begin{array}{c}\text { 3-body Abrasion } \\
\text { Frlction }\end{array}$ & Steel, Rubber, Lubricants \\
\hline Primary Metals & $\begin{array}{l}\text { Hot Rolling } \\
\text { Inefficiencies }\end{array}$ & Steel \& alloys \\
\hline Chemicals/Refining & $\begin{array}{l}\text { Friction, Erosion } \\
\text { Abrasion }\end{array}$ & Not studied \\
\hline Pulp \& Paper & Friction & $\begin{array}{l}\text { Steel \& alloys, Chromi um- } \\
\text { Molybdenum ailoys } \\
\text { Grinding stones }\end{array}$ \\
\hline Food Processing & Erosion, Abrasion & Steel \& alloys \\
\hline
\end{tabular}

and reliability would also significantly improve industrial productivity. The industry representatives interviewed strongly emphasized the positive impacts that tribological research could have on operational productivity.

\section{Tribology in the Metalworking Industry}

In addition to the general review of tribological sinks in industry, ECUT sponsored a more specific study of tribology in the netalworking industry by Le Khac at DHR, Inc. The study estimated the energy conservation potential of using advanced surface modification technologies in this industry. These surface modification technologies are thermal, chemical, or mechanical treatments that reduce friction and wear at a material's surface without changing its bulk properties. The advanced surface modification technologies considered were ion implantation, laser surface hardenting, electron beam surface hardening, and wearresistant coating deposition. The author studied 70 percent of the metal-forming and metal-cutting machines used in the United States (except those associated with primary metals processing), identified tribological mechanisms, and estimated friction and wear energy losses. Potential energy savings from using surface-modified tools were also estimated.

The metal-forming machines studied were punches, presses and forges, and the metalcutting machines studied were turning, drilling, mlling, broaching, and sawing machines. Models were developed to estimate friction and wear energy losses and potential savings. The friction losses were estimated by adding friction losses at the motor drive system and at the tool-workpiece interface. Estimates of energy consumption were based on standard operating conditions (known friction coefficients, total working time, etc.) The indirect losses from wear were estimated based on the replacement costs of all metalworking tools used and discarded in one year.

Based on actual experimental or production data, the author estimated that the friction losses in all U.S. petalworking machines amount to $20.2 \times 10^{12}$ Btu per year, or $\$ 104.5$ million. of this energy loss, $1.8 \times$ $10^{12}$ Btu per year, or $9 \%$, could be saved using surface modification technologies to reduce friction. The wear loss was estimated to be $7.7 \times 10^{12}$ Btu per year. (a) Possible energy savings using surface modification technologies to reduce wear could conserve $5.5 \times 10^{12}$ Btu per year, or $71 \%$.

Finally, the author estimated that tribological energy losses in all U,S. metalworking machines total $27.9 \times 10^{12}$ Btu, equivalent to 4.8 million barrels of oil or $\$ 144 \mathrm{million}$ annually. More than a quarter of this loss could be saved using surface modification technologies to reduce friction and wear. These results are shown in Figure ES.2.

(a) Using 19.2 million Btu per ton as the embodied energy in steels. 


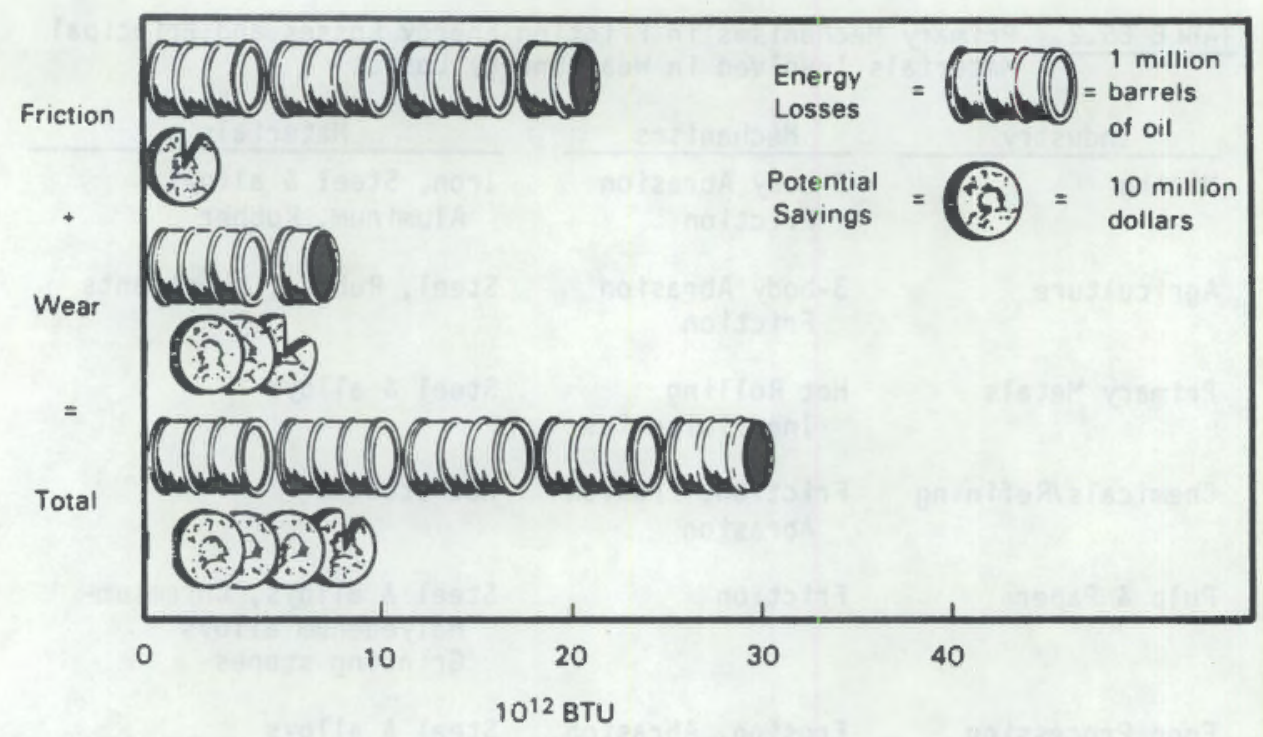

FIGURE ES.2. Annual Friction and Hear Energy Losses in the Metalworking Industry, and Potential Savings from Surface Modification Technologies

\section{The Transportation Sector}

The transportation sector is important both in terms of its energy consumption (26\% of total U.S. annual energy consumption, or $19 \times 10^{15} \mathrm{Btu}$, equivalent to $\$ 98$ billion), and because of the high level of tribological losses. The Pinkus and Wilcock study primarily focused on the hi ghway fleets (passenger cars, buses and trucks), which consume $77 \%$ of the total energy used in the transportation sector. The survey primarily addressed the conventional otto cycle engine. However, other concepts were also considered, such as the adiabatic diesel, the gas turbine, and the Stirling engine; in addition, the Fehrenbacher report evaluated tribological activity in advanced diesel engi nes.

Figure ES. 3 shows the principal automotive tribological sinks and the estimated energy savings. The principal automotive energy sinks are caused by the mechanical inefficiency of the engines and drive trains; most of the energy losses are due to friction.

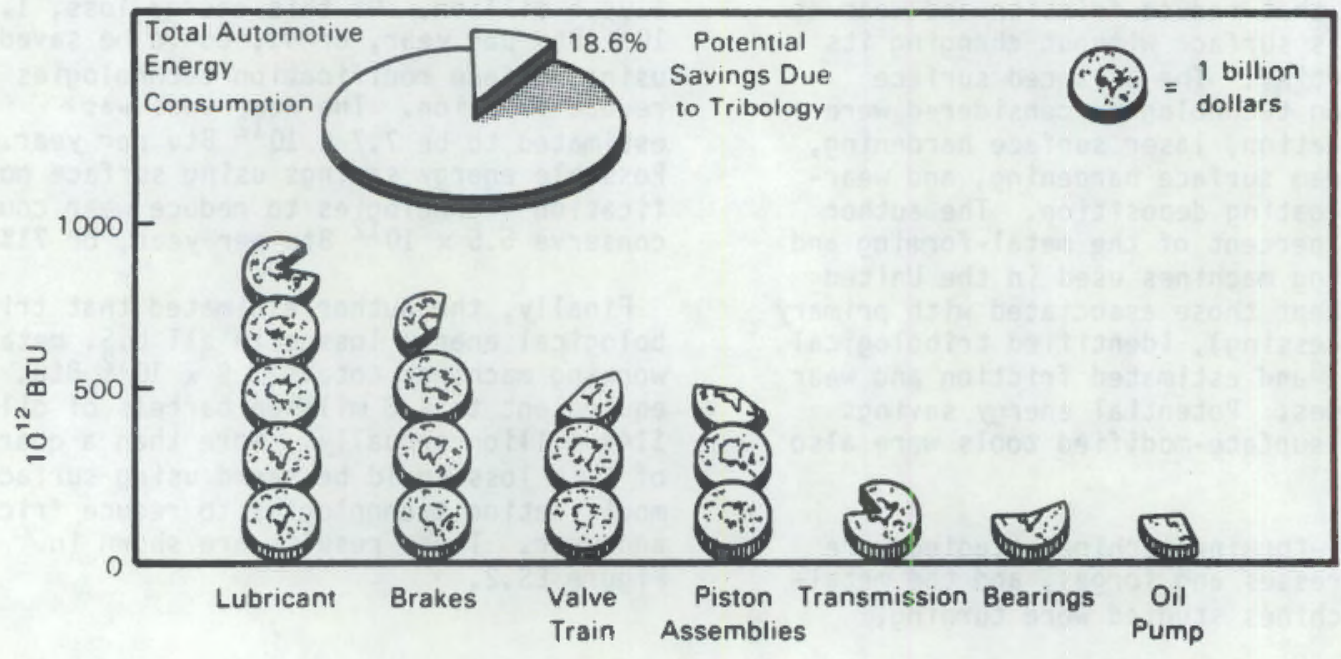

FIGURE ES.3. Potential Energy Savings Per Year for the Conventional Engine (Based on highway fleet size in 1976) 
The survey by Pinkus and Wilcock revealed several tribological areas of particular concern for conventional engines, such as the piston ring assembly and the long-range effect of low-viscosity oil on engine wear. As shown in Figure ES.3, tribological improvements could save $18.6 \%$ of the total annual energy consumed by automobiles, or $\$ 14.3$ billion.

Research on conventional engines often applies to unconventional engines as well. Except for the adiabatic diesel, the energy savings possible from tribological improvements to unconventional engines are less significant than those of the conventional otto cycle engine. The major problems in unconventianal engines are related to hightemperature tríbological problems. Introducing adiabatic and mi nimum friction engines into the bus and truck fleets of the U.S. could save up to $2.9 \%$ of total U.S. energy consumption.

This survey also revealed the difficulties with devising adequate performance tests to quantify energy losses and evaluate new designs and products. Laboratory tests that accurately reflect real-world conditions are badly needed. The ability to test entire systems is vital, since tribological energy losses are often caused by complex interactions between all the components of a system.

\section{Advanced Diesel Engines}

Because of the great potential for energy savings, the ECUT study by Fehrenbacher examined the lubrication of advanced diesel engines in detail. The efficiency of these engines could be improved by about $10 \%$; however, higher operating temperatures $\left(1000^{\circ} \mathrm{F}\right.$ and higher in the upper cylinder area) are required to reach this greater efficiency. As a result, the primary development challenge for these engines concerns friction, wear, and lubrication of the upper cylinder region. In fact, tribological advancements in these areas are essential if diesel engine performance and durability goals are to be reached. This study assessed these vital tribological concerns in both current and future technologies and recommended tribology R\&D topics for further advanced engine development.

Both the mechanical design of the upper cylinder and the chemical effects of lubricants and fuel determine the friction and wear characteristics of the upper cylinder region. These two factors interact in a complex and sometimes synergistic manner. The geometry of the piston, piston ring, and cylinder di rectly affect the rate and nature of deposit formation, oil consumption, and friction. Efforts have been made to optimize the upper cylinder geometry in current diesel engine technology; this will also be a critical area in future developments. However, problems with upper cylinder deposits, bore polishing, and oil consumption still exist. This study indicates that these problems are caused by the chemf cal interactions between upper cylinder materials, oil degradation products, and fuel combustion by-products. Therefore, lubricants, oil degradation rates, and mechanisms will continue to be important research areas.

Although a great deal of research has been conducted on liquid lubricants, in most cases the lubricants have been tested without considering the tribological factors specific to the upper cylinder. Since the lubricants interact with the materials and environment of the upper cylinder, they must be developed and tested under similar conditions.

The ECUT study also pointed out that future advanced engine concepts will requitre ceramic upper cylinder materials able to withstand the higher operating temperatures. New lubricants will have to be developed, and solid lubricants are likely to play a major role. A major research effort will be needed in this area; again, the research must be conducted on a total system basis to be most effective.

The study concluded that many problems with current diesel engines wll continue to exist in advanced diesel engines. Tribological problems in the upper cylinder region will be most critical in terms of engine performance and wear. Lubricant R8D is still a major research area in current technology, but total system materials and design considerations should be emphasized. Advanced diesel concepts will require new design approaches, but the tribology of the upper cylinder region will still be critical and may even be the 11 miting factor in achieving higher engine efficiencies. Extensive materials R\&D -111 be required for advanced designs as well, especially in ceramics, ceramic composites and solid lubricants.

\section{The Utilities Sector}

The utilities sector was also reviewed for significant tribology sinks. This sector accounts for roughly $28 \%$ of total U.S. energy consumption. ECUT's revi ew revealed that tribological improvements in efficiency and reliability could save $2.3 \%$ of the total energy annually consumed by utilities, or about $\$ 2.5$ billion. As in the transportation sector, efficiency is a major factor. 
However, reliability (especially in generating units) is just as important for energy conservation.

The data used in these studies were primarily for the utilities' power plants. The average power plant operates at an efficiency (output energy/input energy) between 30 and $40 \%$. Mechanical losses account for $17-26 \%$ of the total energy used. Reliability problems that lead to generator shutdown require using standby equipment, which generally has less efficient fuel consumption. This causes losses both in terms of fuel economy, and revenue and labor costs. Tribological problems are estimated to cause as much as $5 \%$ of the reliability problems that requile shutdown. Furthermore, tribology-caused shutdowns increase wh the size of the power generating unit.

The ECUT survey found several tribological areas with significant energy savings potential, including gas path leakage, seals, and bearings on both the main turbine generator and on the various accessories. Different forms of bearing and lubricant problems (contaminated oil 1s, pump problems, etc.) and vibrations are the leading causes of the plant shutdowns.

Figure ES.4 summarizes potential savings from improving tribological problems in the electric utilities. For accessories, the major concern is sealing problems with feedwater pumps. Friction and wear are implicated in much of the seal and bearing losses. The major problens identified in this study wll requi re research on lubrication theory and advanced materials and coatings developments.

\section{CURRENT U.S. GOVERNMENT PROGRAMS}

The second part of ECUT's information collecting efforts involved identifying tribology R\&D currently being sponsored or conducted by the U.S. Government. This information was needed to avoid duplicating existing research and to locate those areas that need more research support. The Peterson study identified 215 current projects sponsored by 21 different government organizations. The study classified these projects by subject, objective, energy conservation relevance, type of research, phenomena and variables being investigated, materials, and applications. The principai government sponsors include the Department of Defense (DOD), the National Aeronautics and Space Administration (NASA), National Science Foundation (MSF), National Bureau of Standards (NBS), and DOE.

The study located these tribology projects initially by using information from literature searches. Data bases used included the Smithsonian Science Information Exchange, the Defense Technical Information Center's Research and Technology Work Unit Information System, and the Materials Science Abstracts of the National Technical Information Service (NTIS). The study located a

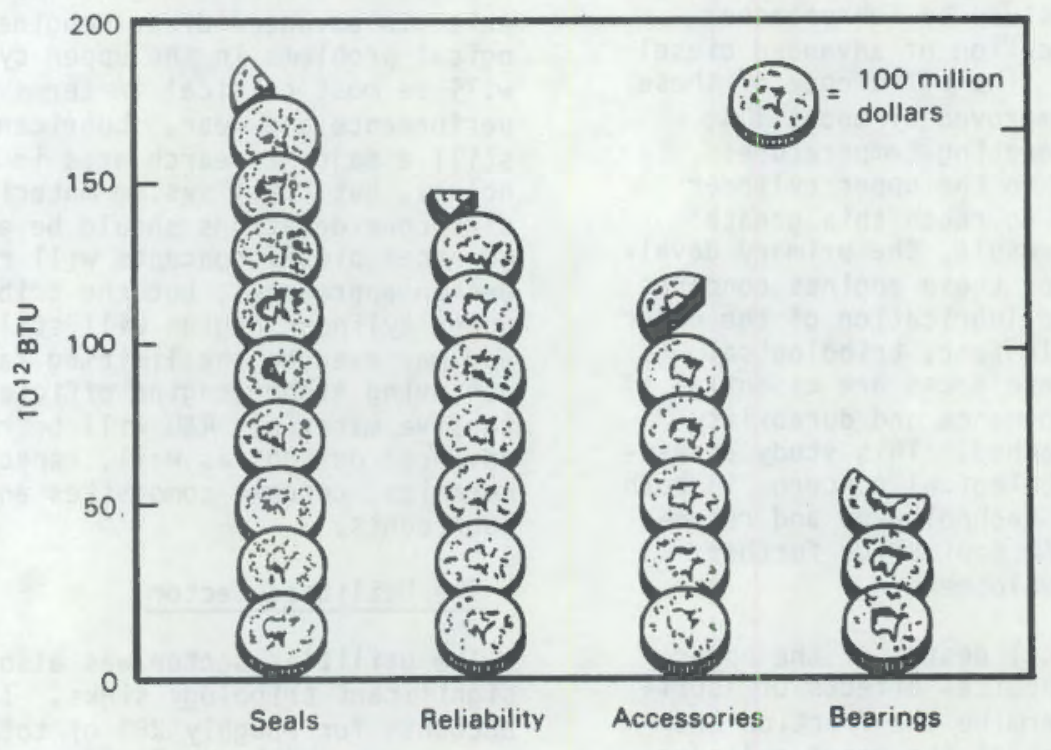

FIGURE ES.4. Potential Energy Savings for the Utilities (Based on estimates of installed capacity in 1983 and on an energy cost of $\$ 30$ per barrel.) 
total of 640 government-sponsored projects covering the fiscal years 1978-1983. These organizations were then contacted by mail, followed by visits and/or phone discussion. Of the original 640 projects, 215 were found to be current. A detailed description of each project is included in the report.

According to this study, until several years ago tribology research emphasized component development, fluid film and elastohydrodynamic lubrication, and concentrated contacts. Since then the emphasis has shifted dramatically, and research efforts now concentrate on lubricants, materials and coatings, and friction and wear mechanisms. There is still considerable interest in rolling contact bearings and seals, as well as in early failure detection in maintenance technology.

The study also concluded that most current tribology research is related to 000 objectives of longer $11 \mathrm{fe}$, low maintenance/ failure-free machinery, and the basic understanding of friction, wear, materials, and coatings. High-temperature lubrication also continues to be a major objectlve in tribology research; the effects of new materials and solid lubricants on current temperature limitations are also being studied. Coatings are receiving the most attention in general materials development. Figure ES.5 shows a breakdown of the materials considered in the 215 projects.

The author also concluded that current programs generally do not emphasize energy or materials conservation. Design predictability and composite materials are other areas that are receiving little attention. Finally, the study concluded that current
U.S. Government high-temperature lubrication work is the most applicable to energy conservation goals.

INDUSTRY PERCEPTIONS OF GENERIC RESEARCH NEEDS IN TRIBOLOGY

Because transferring information to industries is a major part of the ECUT program, ECUT conducted a survey of industry perspectives on tribology Red needs. This survey, conducted by Sibley and Zlotnick, involved interviewing industry contacts to discover what research results are needed.

The authors held in-depth discussions wt th engineers and managers from 27 companies. These companies were chosen by defining different tribological categories (such as transportation, power plants, seals, gears, aerospace, etc.). At least one company was then selected for each category, and two or three were chosen for categorles that are particularly important to the ECUT program. The purpose of this study was not to produce statistically significant findings, but rather to represent many different viewpoints and a variety of interests.

The authors' main emphasis was on determining the engineering 11 mitations imposed by tribology considerations. They also tried to determine the type and funding level of current generic tribology R\&D in each company, al though only pon-proprietary information was available. (a)

Based on the levels of generic tribology R 80 in the 27 individual companies, the authors then estimated total tribology R\&D in each industrial segment. Although this approach is obviously limited, reasonably

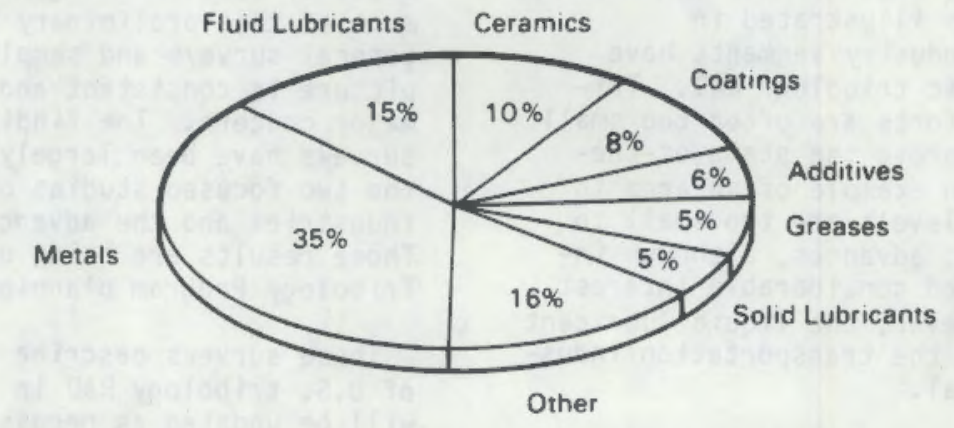

FIGURE ES.5. Materials Under Consideration in the 215 Current Government-Sponsored Tribology Projects

(a) "Generic" R\&D in this case is basic research that is not di rected toward a specific end use or product. 
TABLE ES.3. Estimate of Generic Tribology R\&D and Total R\&D Budget for Representative Industries (In SM)

\begin{tabular}{|c|c|c|c|}
\hline Classification & Company & $\begin{array}{l}\text { Total } \\
\text { R\&D }(a) \\
\end{array}$ & $\begin{array}{c}\text { Generic } \\
\text { Iribology R\&D (b) }\end{array}$ \\
\hline Liquid Lubricants & Mobil1 & 188 & 1 \\
\hline Transportation & Ford & 1764 & 1 \\
\hline Aerospace & Pratt \&hitney & 835 & 0 \\
\hline Powerplants & Caterpillar & 234 & 0 \\
\hline Seals & Crane & 10 & $<1$ \\
\hline Rolling Elements & TRH & 109 & $>0$ \\
\hline Gears & Eaton & 100 & $\times 0$ \\
\hline Silding Bearings & Tribon & 0 & $>0$ \\
\hline Filters & Pall & 7 & 0 \\
\hline Small Mechantcal & Xerox & 565 & $>0$ \\
\hline Ceramics & Norton & 26 & $<1$ \\
\hline Coatings & Union Carbi de & 240 & $<1$ \\
\hline \multirow[t]{2}{*}{ Forming } & Bethlehem & 46 & $\leq 1$ \\
\hline & & 4124 & 6 \\
\hline
\end{tabular}

(a) From the report to the Securities and Exchange Commlssion for 1982. (Source: "Business Week," June 20, 1983.)

(b) Based on discussions with research staff and referring to only company-funded generic tribology R\&D.

accurate estimates were developed of the amounts of generic tribology $R \& D$ being conducted in each of the industrial segments. The results for the individual compantes are summarized in Table ES.3.

These authors concluded that industry funds only a very limited amount of generic tribology research. Some 'hidden' generic $R \& D$ is incorporated into the companies' design manuals, but much of this information is proprietary. As lllustrated in Table ES.3, some industry segments have little or no generic tribology R\&D. Tribology research efforts are often too small to be likely to improve the state-of-theart; ceramics is an example of an area in which the funding levels are too small to promote significant advances, although industry has expressed considerable interest in this area. However, the liquid lubricant research budget in the transportation industries is substantial.

The industry representatives expressed interest in the ECUT Tribology Program, and also in obtaining a fundamental physical understanding of tribological mechanisms. The industry contacts also requested more effective presentations of research results, especially results in a form that design and development engineers could readily use.
Another industry concern involved develaping more realistic laboratory tests and more rational performance standards.

\section{CONCLUSIONS}

The six ECUT surveys summarized here were conducted to provide an overview of the major tribological sinks and the current state of U.S. tribology research. Although much of this preliminary ECUT work involved general surveys and samplings, the overall picture is consistent and reveals areas of major concern. The findings in the general surveys have been largely substantiated by the two focused studies on metalworking industries and the advanced diesel engine. These results are being used to support ECUT Tribology Program planning.

These surveys describe the current status of U.S. tribology R\&D in 1984; the findings will be updated as necessary. Much of the information is necessartly somewhat speculative and theoretical, and many of the general findings have not yet been fully corroborated. This is due in part to the lack of previous research; improving this intial information should be an important goal of current research. In particular, identifying tribological mechanisms should 
the emphasized in order to define specific research projects. Further discussion with industry representatives is also needed.

The five key results from these ECUT studies are listed below:

1. Advanced tribo-materials, coatings, and luoricants must be developed to further improve energy efficiency. Although tribo ogical improvements can be made with the current technology, new and innovative materials and designs (such as the: advanced diesel engine) are needed to significantly increase energy efficiency.

2. Tribological mechanisms that shorten equipment life and cause excesstve downtime and repair should be identified and studied. Initial research shows that these indirect energy losses from material wear are often greater than the di rect energy losses from friction. In addition to the energy conservation impacts, reducing these losses could also significantly improve industrial productivity.

3. Generic tribological research will affect: all three major sectors, since similar tribological mechantsms are found in many different processes. Although the transportation sector has the largest tribological energy loss and the greatest potential for energy savinus, there is significant energy savinus potential in all sectors. Thus resea"ch results must be effectively trans"erred to all sectors.

4. Meani igful performance tests and standards must be developed so that new desigits and products can be accurately evaluated. Laboratory tests that accurately reflect real-world conditions are badly needed. Total system testing is vital, since tribological energy losses are often caused by complex interactions between all the components of a system.
5. Continuing communication with industry is critical to ensure that industry research needs are addressed and that the results are adequately transferred.

These results supported the development of the ECUT Tribology Program plan for 1985. The research program is divided into two parts. The Mechanisms component includes such areas as advanced tribo-materials R\&D, identifying and characterizing tribological mechantsms, and developtng perfomance test requil rements. Projects in this area include developing new tribologtcal materials, and modeling and experimental efforts to determine physical and chemical interactions and processes in tribological systems. Liquid and solid lubricants, tribological coatings and surface modifications, and ceramic and cermet materials are specific topics to be considered. The Mechantsms area also 1 ncludes efforts to develop novel characterization and testing procedures and diagnostic tools and equipment to assess the performance of tribological systems.

The second part of the research program, Destgn, includes such topics as design and reliability modeling of components, systems, and system assemblies. Industry is di rectly involved in these projects. The Design area will also establish a data center to gather and disseminate information on tribology. These projects concentrate on generfic tribology R\&D, including energy losses from material wear.

Clearly, tribology research can have a major impact on energy use and conservation in the U.S. Much of the needed research identified in these studies is innovative and high-risk, which makes tribology a vital and appropriate area for ECUT support. Thus the ECUT Tribology Program, wth industry participation and cooperation, wll continue its efforts to reduce the enormous energy losses caused by friction and wear. 



\section{CONTENTS}

EXECUTIVE SUMMARY OF TRIBOLOGY SERIES $\ldots \ldots \ldots \ldots \ldots \ldots \ldots \ldots \ldots \ldots \ldots \ldots \ldots$ i $\ldots \ldots$

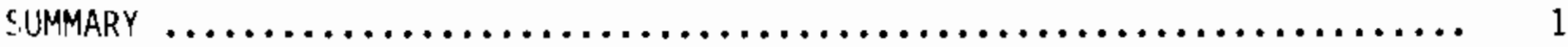

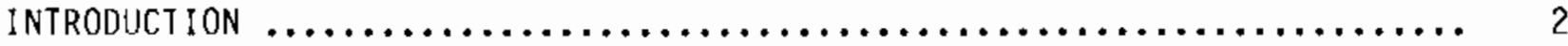

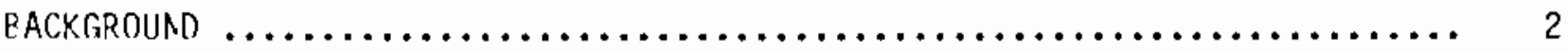

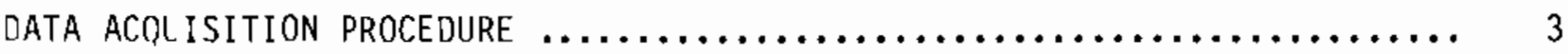

TRIBOLOGY CLASSIFICATION $\ldots \ldots \ldots \ldots \ldots \ldots \ldots \ldots \ldots \ldots \ldots \ldots \ldots \ldots \ldots \ldots \ldots \ldots$

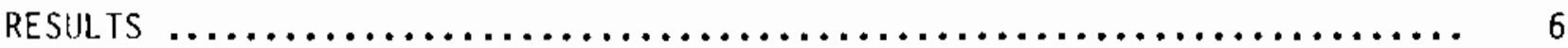

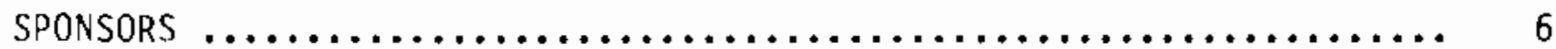

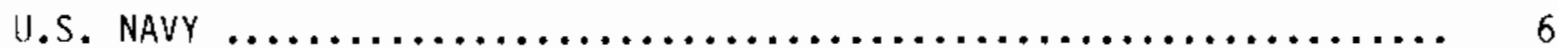

U.S. AIR FORCE $\ldots \ldots \ldots \ldots \ldots \ldots \ldots \ldots \ldots \ldots \ldots \ldots \ldots \ldots \ldots \ldots \ldots \ldots \ldots$

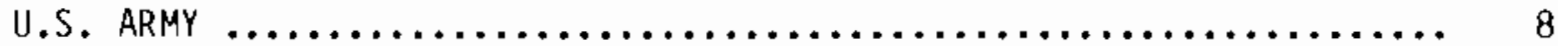

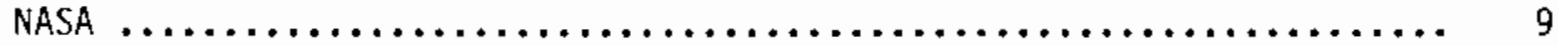

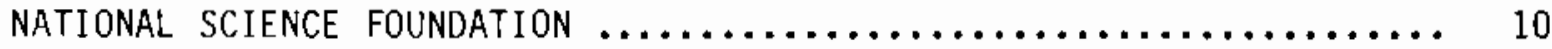

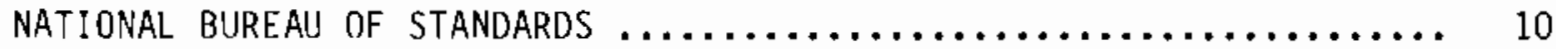

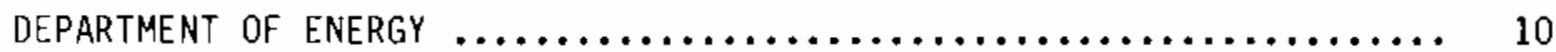

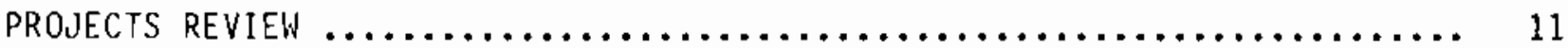

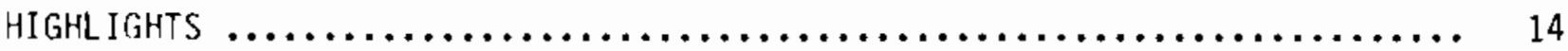

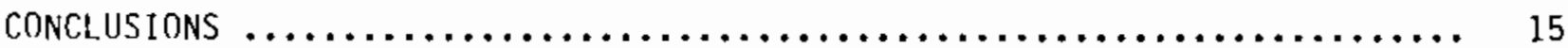

REFERENCES $\ldots \ldots \ldots \ldots \ldots \ldots \ldots \ldots \ldots \ldots \ldots \ldots \ldots \ldots \ldots \ldots \ldots \ldots \ldots \ldots \ldots$

APPENDIX 1 - PROJECT DESCRIPTIONS $\ldots \ldots \ldots \ldots \ldots \ldots \ldots \ldots \ldots \ldots \ldots \ldots \ldots \ldots$ 


\section{TABLES}

1 Tribological Subjects $\ldots \ldots \ldots \ldots \ldots \ldots \ldots \ldots \ldots \ldots \ldots \ldots \ldots \ldots \ldots, 18$

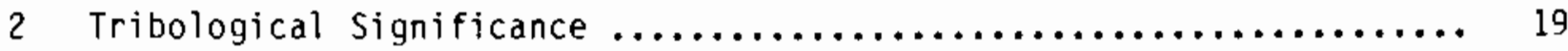

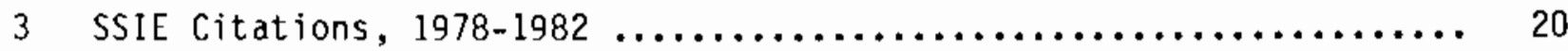

4 Subject Search Terms $\ldots \ldots \ldots \ldots \ldots \ldots \ldots \ldots \ldots \ldots \ldots \ldots \ldots \ldots \ldots, 21$

5 Major Sponsors $\ldots \ldots \ldots \ldots \ldots \ldots \ldots \ldots \ldots \ldots \ldots \ldots \ldots \ldots \ldots \ldots \ldots, 22$

6 Organizations Conducting Tribology Research $\ldots \ldots \ldots \ldots \ldots \ldots \ldots . . \ldots 23$

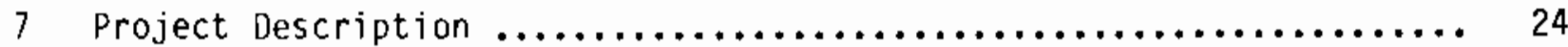

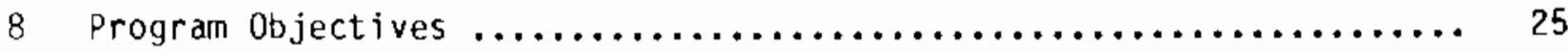

9 Energy Relevance $\ldots \ldots \ldots \ldots \ldots \ldots \ldots \ldots \ldots \ldots \ldots \ldots \ldots \ldots \ldots, 26$

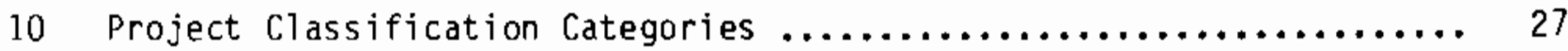

11 Office of Naval Research-Tribology Projects $\ldots \ldots \ldots \ldots \ldots \ldots \ldots \ldots . . . \ldots 28$

12 Naval Research Laboratory-Tribology Programs $. . . . \ldots . \ldots . \ldots . \ldots . .29$

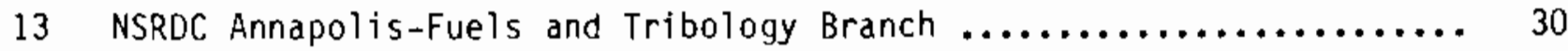

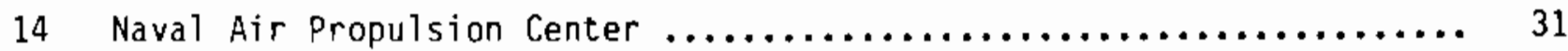

15 Naval Air Development Center-Tribology Programs $\ldots \ldots \ldots \ldots \ldots \ldots \ldots . . . \ldots . .32$

16 Naval Air Engineering Center $\ldots \ldots \ldots \ldots \ldots \ldots \ldots \ldots \ldots \ldots \ldots \ldots \ldots \ldots \ldots \ldots \ldots \ldots \ldots, 33$

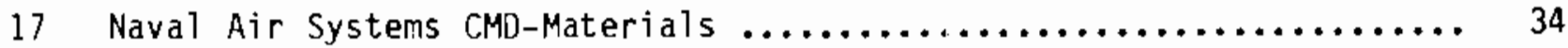

18 AF Office of Scientific Research-Chemistry Division............$\quad 35$

19 AF Aeropropulsion Lab $\ldots \ldots \ldots \ldots \ldots \ldots \ldots \ldots \ldots \ldots \ldots \ldots \ldots \ldots \ldots, \quad 36$

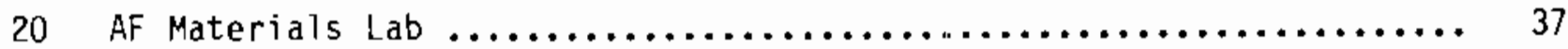

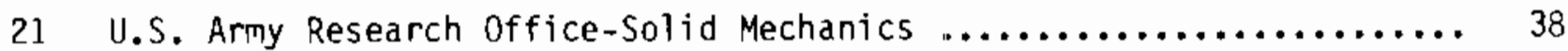

22 Army Research Office-Material Sciences Division $\ldots . . . \ldots \ldots \ldots \ldots . .39$

23 Army Mechanics and Materials Research Center $\ldots \ldots \ldots \ldots \ldots \ldots \ldots \ldots . . . \ldots 40$

24 MERADCOM-Belvoir Fuels and Lubricants division $\ldots \ldots \ldots \ldots \ldots \ldots \ldots$.......... 41 
27 Aviation Research and Development CMD-Ft. Eustis .............. 44

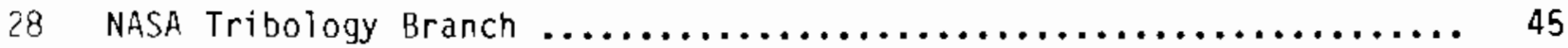

29 National Science Foundation-Engineering Science ............... 46

$30 \quad$ National Science Foundation-Materials Research Division ......... 47

31 Recommendations to NSF ........................... 48

32 National Bureau of Standards-Metallurgy Division .............. 49

33 National Bureau of Standards-Inorganic Materials nivision ......... 50

$\therefore$ Department of Energy-0ffice of Energy Research $\ldots \ldots \ldots \ldots \ldots \ldots \ldots \ldots$

35 Department of Energy-0ffice of Conservation and

Renewable Energy ................................ 52

S6 Profosed Elements ECuT Tribology Program ................... 53

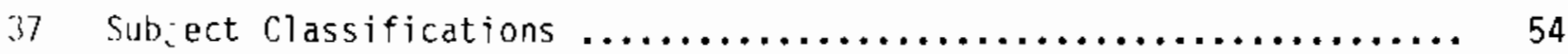

38 Program objectives $\ldots \ldots \ldots \ldots \ldots \ldots \ldots \ldots \ldots \ldots \ldots \ldots \ldots \ldots \ldots \ldots \ldots$

$39 \quad$ Energy Relevance $\ldots \ldots \ldots \ldots \ldots \ldots \ldots \ldots \ldots \ldots \ldots \ldots \ldots \ldots \ldots \ldots \ldots \ldots \ldots$

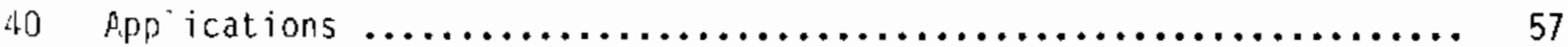

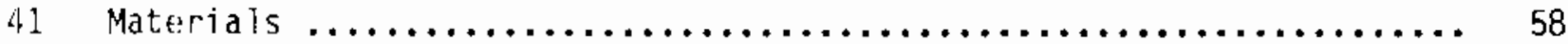

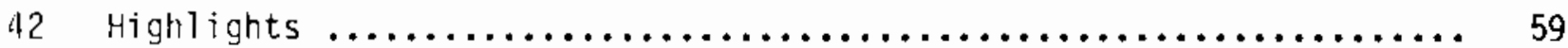





\section{SUMMARY}

An assessment has been made to determine current tribology research and development work sponsored or conducted by the government. Data base surveys and discussions were conducted to isolate current projects sponsored primarily by 21 different government organizations. These projects were classified by subject, objective, energy relevance, type of research, phenomenon being investigated, variables being studied, type of motion, materials and application. An abstract of each project was prepared which included the classification, sponsor, performing organization and a project description. It was found that current work is primarily materials oriented to meet military requirements. Other than the high temperature programs very few of the tribology projects accomplish energy related objectives. 


\section{INTRODUCTION}

The Department of Energy established the Energy Conversion and Utilization Technologies (ECUT) Program to develop and promote utilization of an expanded technology base and advanced concepts in energy conversion and utilization. In 1983 the ECUT Tribology Project was established within the ECUT program to explore innovative lubrication and material concepts for mitigating friction and wear in order to save $11 \%$ of the total U.S. annual energy consumption. Beginning in 1983 the Tribology Project under the direction of $\mathrm{Dr}$. Joseph A. Carpenter, Jr. began supporting research in two areas: Mechanisms and Design. To support this research, certain assessments were also undertaken. Wear Sciences was funded under P0 $86 \mathrm{X}-47967 \mathrm{~V}$ from Oak Ridge National Laboratory to conduct one such assessment, "Identification of Tribological Research and Development Supported by the U.S. Government". This is the fina? report of that assessment.

\section{BACKGROUND}

Tribology is defined as the science and technology of interacting surfaces in relative motion and the practices related thereto. Principal subjects included within the scope of tribology are listed in Table 1. As can be seen, the field covers surface phenomenon, materials and lubricants, mechanical components, and their application to major systems such as metal working, engine design and operation, transmissions, etc. Tribology is not only an important consideration in the design of equipment but in its maintenance. Tribological problems, either scheduled or unscheduled, represent (along with corrosion and fatigue) one of the primary reasons for removal of equipment from service. Costs for such removals could include repair costs, machine down time, loss of production, loss of mission, and depleted resources.

Historically the government's role in tribology was mainly limited to its ownership of a large variety of mechanical equipment. It provided design requirements, specifications, and maintenance of such equipment and conducted research to upgrade performance and to improve reliability.

However, in the past ten years a variety of social concerns have arisen which have required that the government expand its role in this field of technology. Those concerns are environmental matters, foreign competition and productivity, materials conservation, and energy utilization. Examples of the role of tribology in each of these areas are listed in Table 2. Accordingly, a variety of new research has been initiated with objectives unrelated to equipment ownership. One of the most important of these concerns effective energy conservation and utilization.

Under the auspices of DOE, a workshop was helc in Washington, D.C. on February 7-9, 1977, to assess the possible impact of tribology on energy conservation and to identify those areas where the application of existing or new tribological knowledge would yield majcr benefits. Based upon this workshop, DOE tasked the Research Committee on Lubrication (ASME) to prepare 
a broad tribological R\&D plan for possible implementation by government. $\mathrm{RCL}$ organized task forces in various industry sectors which considered how various tribological research programs could reduce energy consumption. A summary report was published by ASME (1). This report was updated in 1981 (2). As part of its early program DOE made a substantial contribution to the preparation of the Wear Control Handbook (3), a project of the Research Comititee on Lubrication of ASME.

In 1981 at the request of $\mathrm{Dr}$. Joseph A. Carpenter, Jr. Of Oak Ridge National Laboratory ASME's Research Committee on Lubrication appointed a task force to review the recommended projects and assign priorities. The task force report (4) submitted in November 1982 gave priority to the following projects:

\author{
Tribology Utilization \\ Adiabatic Diesel Requirements \\ Viscometrics and Friction Modifiers \\ Bearings for Bottoming Cycles \\ High Speed Rolling Bearings \\ Metal Processing Friction and Lubrication \\ Traction Drives
}

The Tribology Project is part of the ECUT division of the Office of Energy Systems Research. This office is assigned to the Deputy Assistant Secretary for Conservation of DOE. Tribology work was initiated in FY 1980 under the ECUT Materials Program. In October 1982, tribology was elevated to project status within ECUT with Dr. Joseph A. Carpenter, Jr. serving as acting project manager. In 1984, Terry Levinson was appointed ECUT Tribology prograin manager and the project assigned to Argonne National Laboratory under the di rection of $\mathrm{Dr}$. Manfred Kaminsky. A long-range program is currently being developed. The overall objective of this program is to explore innovative lubrication and materials concepts for mitigating friction and wear in energy conversion and utilization devices in order to save $11 \%$ of the tota? U.S. annual energy consumption. This study was initiated to assist in the long-range planning process. An assessment was conducted of current government projects in tribology in order to gain an understanding of the nature of this research, to avoid duplication and to identify existing programs which have energy saving potential.

\title{
DATA ACQUISITION PROCEDURE
}

To iniziate this project several data base searches were conducted to identify tribology projects.

A search was made of the Smithsonian Science Information Exchange (research in progress) using the indexing terms listed in Table 3 . These indexing terms were selected from a review of the thesaurus for that data base. The number of unique projects contained in this data base for each term is listed in Table 3 . From this, 480 tribology projects were identified.

A second search was made using the Defense Technical Information Center's Research and Technology Work Unit Information System using the search terms 
listed in Table 4. A total of 768 abstracts were received and reduced to 180 projects by elimination of nonrelevant ard duplicate ones in the SSIE.

A third search was made using the Material Science Abstracts of NTIS. A collection was made of abstracts of reports covering the calendar years 1982, 1993, and 1984. These were collected to identify completed projects and to provide abstract material for current projects. This search also identified ongoing programs which were not ertered into the previous data bases.

From these searches, a total of 640 projects were selected which covered the years FY 78 to FY 83. These were then reviewed to identify the major sponsoring (Table 5) and performing organizations (Table 6). A letter was written to each of the listed organizations requesting information on current tribology projects. Follow up visits and phone discussions were held to obtain detailed information.

All of the above information was used to prefare a detailed listing of projects which were then used to assess current government tribology research.

\section{TRIBOLOGY CLASSIFICATION}

Table 7 shows the project description form used for each project. Projects are described by titie, investigators, performing organization, sponsor, schedule and funding, objective, abstract description, and a classification scheme which includes subject, objective, type research, type motion, variables being studied, the phenomenon or process being considered, the materials, and the application.

The subjects are those listed in Table 1. This list prepared by winer at Georgia Tech is used by ASME in its classification of papers submitted for publication. This list was found to be satisfactory and complete but did not uniquely classify projects. Projects could usualiy have two subjects, e.g. solid lubricants for rolling contact bearings. However, wherever possible this was reduced to one by deciding whether it was really a study of solid lubricants or bearings. This could be done since both solid lubricants and bearings appeared under the materials and application classification. The subject classification was primarily an overview.

The program objectives (Table 8) were not predetermined but selected based upon a review of the stated project objectives. The first objective, "Long Life etc.", covers that research and development carried out to improve design and performance to meet new requirements. Much of the current work falls within this category. Fundamental understanding covers the basic type of research. Although "High temperature Tubrication" can be a design requirement, this category covers that research or development where no design requirement is stated. The same condition hclds for materials development. An investigator may be working on a wear resistant coating (e.g. filled anodizing) with no specific application or requirement in mind. "Design predictability" is listed as the objective when efforts are being made to establish techniques to predict life, wear, failure, load capacity, etc. of 
tribological components. The "energy or materials conservation" objective identifies ongoing projects whose stated objective is to conserve energy or materials. The final three objectives (cost effectiveness, quiet operation, and improved health and safety) are self-explanatory.

The "energy and materials conservation" objective is intended for specific conservation projects. However, other research may contribute to energy objec:ives. To identify such projects, the classification of "energy relevance" was established. Energy relevant categories are listed in Table 9 along with examples of specific projects which might be included in each category.

Advances in "High Temperature Lubrication" allows heat engines to operate more efficiently and reduces energy losses in cooling. Improved high temperature lubricants would also allow selection of optimum operating or processing conditions without the current thermal barriers.

Mater:als selection and development has previously ignored energy considerations; energy intensive materials and heat treatments have been widely used when low energy coatings could meet the application requirements. Product lives could also be extended with improved materials which would conserve both the materials and their embodied energy. Studies of failure prevention would accomplish the same objectives.

Friction reduction would yield direct energy savings. Thus, any study which leads to a better understanding of frictional processes would accomplish energy objectives. In addition, any project to develop friction reducing addit ves would be of significant value for energy saving. Of particular interest is the hydrodynamic to boundary transition where friction increases onehundred times. Any additives, materials, or conditions which enhanced fiuid film lubrication would be very significant.

Like naterials, designs have not necessarily been energy efficient. Studies such as low energy approaches to power transmission and friction reduction in ma :erial processing would serve energy objectives. Process fluid lubrication proposes to use other working fluids as lubricants and eliminate conventional lubrication systems. This action would reduce weight and improve efficiency. Improved sealing would also have positive energy impacts. Reducion of gas path leakage and reduction of seal friction are particularly imporant.

A more detailed classification for the selected tribology projects is shown in Table 10. The purpose of this classification is to learn more about the project scope and how it was carried out.

Each of the projects were classified according to the system described above and that classification used in an analysis of the current government research. 


\section{RESULTS}

The basic project data used in this assessment are contained in Appendix 1 which lists current projects. Broad interpretation should be given to the term current since some of the 1 isted projects have been concluded and some are projects not yet under way. The purpose here is not precision but an attempt to obtain a general understanding of current tribology research and where it is carried out. In the following paragraphs various aspects of tribological research is discussed.

\section{SPONSORS}

A list of the major government organizations which sponsor tribology projects is shown in Table 5. This table lists the organizations in order of the number of citations found in the data bases for FY 78 to FY 33 . From year to year the order will change; furthermore, certain organizations like NASA or NSRDC Annapolis have many projects listed uncler one citation. A list of current projects was prepared for each of the listed sponsors. These are given in Tables 11-35. Information on current projects was obtained from discussions with the Program Manager and from the data bases.

\section{U.S. NAVY}

The Navy carries out a wide range of tribology programs from basic research to demonstration projects in support of both ship and aircraft activities. Basic research is supported by the Office of Naval Research (Table 11) and conducted by the Naval Research Lab (Table 12). The Office of Naval Research supports research primarily through longer term university grants. Current work (Table 11) is heavity concentrated in the areas of materials, wear, and failure processes. The Naval Research Laboratory has several groups working in the tribology area with major effarts in advanced Tubricant development and coatings (Table 12). Current lubricant research is devoted to evaluating the potential of deuterated lubricants. In deuteration heavy hydrogen replaces normal hydrogen, improving the lubricant stability. NRL has also set up ion implantation facilities and is conducting research on the friction and corrosion properties of ion implanted metals.

Several of the Navy laboratories do a wide range of tribology work. Although much of this work is concerned with new requirements and specifications, a large amount of basic research is also undertaken. Major programs in the Fuels and Tribology Branch of the Naval Ship Research and Development Center in Annapolis are listed in Table 13. Areas of major concern are rolling contact bearings, main shaft seals, and lubricant properties. NSRDC also administers the Marine Tribology Block program for NAVSEA. In this program a "block" of money is provided yearly to this laboratory with broad mission objectives. NSRDC defines specific projects and funds them in-house, in other Navy laboratories, or by contract.

The Nava? Air Propulsion Center and the Naval Air Development Center conduct tribology projects to support the Naval Air Systems Command requirements. The Propulsion Center at Trenton is involved primarily in programs to meet 
The Aeropropulsion Laboratory conducts in house and contract research in all aspects of propulsion system tribology. This includes bearings, gears, seals, lubricants and tribological materials. A list of current and future projects is shown in Table 19. Much of their work is applied research concerned with new turbine engine requirements and evaluation of new lubrication techniques. For the past 35 years, operating temperatures and rotative speeds of the aircraft gas turbine engine have increased. This laboratory has had the responsibility of providing the appropriate tribological advancements. New programs include solid lubrication of bearings and gears, improved $0 i 1$ analysis techniques, improved rolling contact bearing materials and 600F lubricant capability. Close cooperation is reported between this laboratory and NAPC-Trenton and the AF Materials Laboratory.

Examples of Air Force Materials Laboratory Programs are shown in Table 20. Much of this work is concerned with the development of lubricants and hydraulic fluids and seals for the 500-600F temperature range. The current fluids (diesters) are limited to a bulk oil temperature of approximately 375F. The perfluoroalkyl ethers and the polyalphaolefins will extend this range somewhat. Major emphas is however is being placed into the development of the silahydrocarbons. Work recently concluded was a major effort to develop the technology of untubricated and solid lubricated high temperature. rolling contact bearings and life prediction techniques. Reports summarizing the results of this DARPA/HUGHES program are listed in references 6-14. A new space related activity concerned with bearing lubrication in hard vacuums for 10-15 year life is under consideration. On a more fundamental basis a lubricant modeling program is being prepared using dynamic models which predicts the needed properties of lubricants to achieve optimum bearing performance for a given set of bearing operating parameters. Such a model could be used to tailor fluids for minimum friction in a given application.

A major new effort is in the area of solid lubricants. A new DARPA/HUGHES program will study solid lubricant/ceramic materials interactions. Another effort will be to develop solid lubricants and solid lubricant application techniques for rolling contact bearings.

\section{U.S. ARMY}

The Army Research Office began a major research program in tribology in 1979 supported by the Solid Mechanics Division. This program has been carried out in the Mechanical Engineering and Mechanics Department of RPI under the direction of Professor F. F. Ling, Department Chairman. A I ist of current projects is shown in Table 21 . This is basic research undertaken to gain a better quantitative and fundamental understanding of wear in boundary and micro-elastohydrodynamic lubricated systems.

The Materials Sciences Division supports the work atiRPI and also sponsors additional research. A new three year program has recently been started with Professor Furey at Virginia Polytechnic Institute. It is concerned with the polymers formed in the contact area during lubricated sliding and how they affect lubrication. 
the new turbine engine requirements. This includes bearings, seals, and lubricants. Some recent projects are listed in Table 14. One recent major program has been the development of corrosion resistant bearings by ion implantation. This program began with simple bench tests several years ago and has progresses to field tests in the 379 and T58 engines. Since corrosion is one of the major reasons for bearing removal, this development could significantly reduce maintenance costs. NAPC also conducts a program on new lubricants and materials for advanced propulsion systems where new ideas are evaluated. Current work under this program is involved with ceramic bearing materials and lubricant preconditioning for gears.

Table 15 illustrates the programs being conducted by the Lubricants laboratory at the Naval Air Development Center. Most of the work is either basic or applied research but they also are responsible for the airframe lubricant military specifications and have developed lubricants and qualified products to meet those specifications. A new research program to study the mechanisms of corrosion with oil wetted surfaces has recently been started. The Naval Air Engineering Center at Lakehurst had until recently a major tribology program concerned with oil analysis, wear particle analysis, and ferrography. Most of this work has been successfutly concluded. One program is currently under way (Table 16) which is involved with the sensitivity of spectrometers used by the Navy in its fleet oil analysis program.

The Naval Air Systems Command, Materials and Processes Branch, sets lubricant requirements and supports projects at the various Navy laboratories and through contracts to meet those requirements. A number of the programs previously listed were sponsored by this group. One contractual program on ceramic bearings has been under way for a number of years at SKF Industries. In this project a silicon nitride bearing has been run with a graphite cage at 50,000 RPM and 1000F for 30 minutes. New efforts with ceramic bearings involve hostile environments such as salt water.

The Naval Air Systems Command, Maintenance Engineering Division has in the past supported tribology projects related to reducing maintenance and increasing the service life of aircraft. Tribological problems were shown to be one of three major reasons for removal of aircraft from service; the others being corrosion and fatigue. Major problem areas identified, based upon maintenance man-hours were leakage of actuators, bearing corrosion and wear, excessive lubrication requirements, surface erosion and daily inspections for early fajlure detection of tribological components. No current efforts were reported.

\section{U.S. AIR FORCE}

Basic tribology research is limited at the Air Force Office of Scientific Research; that function being carried out at Wright-Patterson AFB. The Chemistry Division does support basic synthesis work on high temperature fluids which can be considered for lubricants and hydraulic fluids (Table 18). Most of the tribology work in the Air Force is the responsibility of the Materials Laboratory and the Aeropropulsion Laboratory at Wright-Patterson AFB Ohio. 
The Army Mechanics and Materials Research Center in Watertown, Mass, has no formal tribology group. However, research and development projects are carried out in several different sections (metals, ceramics, etc.). A list of current projects is given in Table 23 .

The Fisels and Lubricants Laboratory of the U.S. Army Mobility Equipment Research and Development Command has technical responsibility within the Department of the Army for fuels, lubricants, power transmission/functional fluids, greases, and corrosion preventatives.

In support of their mission, this laboratory carries out basic and applied research as well as exploratory RDTE programs. The program primarily addresses the specific needs of Army combat/tactical equipment. Research work is carried out at Fort Belvoir, Va., and at a unique government-owned, contractoroperated facility located at Southwest Research Institute in San Antonio, Texas. This facility, which was established in 1958, is known as the U.S. Army Fuels and Lubricants Research Laboratory and is considered an "in-house" facility of MERADCOP. Major programs under way are listed in Table 24. A major new program just getting under way is the development of lubricants and lubrication systems for advanced Army engine systems which includes the adiabatic diesel. A new improved grease has been developed and is currently undergoing field trials in preparation for its introduction into the system.

Research is also under way at several other Army laboratories in support of their specific missions. At Watervilet Arsenal, Dr. R. Montgomery has been conducting tribology research for many years on subjects related to armaments. Recent research has been concerned with gun tube erosion; current projects are listed in Table 25. The Armament Command also sponsors research in tribology at Picatinny Arsenal (Table 26). Aviation-type research is carried out at Fort Eustis. The Fort Eustis work represents the closing effort on a major program to develop diagnostic capability for helicopter engines and transmissions.

\section{NASA}

The Lewis Flight Propulsion Laboratory of NASA has conducted tribology research for the past 40 years. Efforts were first directed to piston engines then gas turbine engines, rocket engines, space lubrication, and currently advanced engine concepts. A list of current projects is shown in Table 28 . Recent research has focused on obtaining a basic understanding of the frictional behavior of well-characterized materials in accurately controlled environments. Correlations are established between the frictional behavior and the measurable material properties. As shown in Table 28 , current efforts cover a wide range of phenomena including friction, wear failure mechanisms, lubrication, coatings, fretting, abrasion, erosion, cavitation, adhesion, and solid lubricants. Emphasis has been on high temperatures and a number of solid lubricant films and composites have been developed to meet engine and a rcraft requirements. A major program of the Bearing Section headed by Erwin Zaretsky is in Advanced Power Transmission Technology. Current efforts include studies of advanced transmission techniques such as traction drives and appropriate components development. 


\section{NATIONAL SCIENCE FOUNDATION}

Two groups within the National Science Foundation support tribology research: The Mechanical Systems Branch of the Engineering Science Division, and the Materials Research Division. Current projects are listed in Tables 29 and 30. A recent study (5) carried out under a llational Science Foundation grant to ASME recommended tribology research to be carried out in five areas: Modeling of Tribo-Systems, Materials Behavior in Tribo-Elements, TriboSystem Diagnostics, Tribo-Technology Transfer, and Novel Concepts in Tribology. A description of these areas taken from reference 5 is given in Table 31. More recently, tribology has been given program status at NSF.

\section{NATIONAL BUREAU OF STANDARDS}

Two groups within the National Bureau of Standards conduct research in tribology: The Metallurgy Division and the Inorganic Materials Division. Research in the Metallurgy Division is listed in Table 32. The activities of this group address the measurement and stândards needs concerned with the application of metals including metallic coatings to wearing situations. Principal emphasis in the various projects 7 isted in Table 32 concerns the effects of metallurgical parameters, the need for better understanding of basic mechanisms involved, and better wear measurement methodology including standards and reference materials.

The Tribo Chemistry group has recently completed a major study to establish standards for recycled oil. The base technology developed in that program is now being expanded into other areas primarily to an understanding of friction mechanisms in fluids (Table 33). Key components in base oils that affect friction and wear are being identified. The ultimate goal is to assess the effects of molecular structure on friction and wear. Such an understanding will provide a basis for optimizing frictional behavior in mechanical components. A new effort just beginning concerns the frictional behavior of ceramic materials at elevated temperatures.

\section{DEPARTMENT OF ENERGY}

DOE has, in the past, supported tribology research and development through its various departments originally to support materials for nuclear applications and more recently through its Office of Enercy Research (Table 34). Tribology investigations are currently being conducted by the Fossil Energy Materials program on mechanisms of galling and abrasive wear in connection with coal gasification and on materials and lubrication for the adiabatic diesel program. References 15-20 are reports of research programs sponsored by the Office of Vehicle and Engine R\&D.

In 1981, tribology research was conducted as part of the ECUT Materials program. Since achieving project status, a number of research and assessment programs have been initiated (Table 35). Research has been primarily in two areas: fluid friction mechanisms and the sliding behavior of ceramics. In preparation for a much expanded tribology program a number of assessments 
have been conducted to determine major energy losses in mechanical equipment and identify current tribological research being conducted which could reduce these losses.

One of the assessment recommendations to the ECUT Tribology Program was to prepare a long-range plan covering the next 10 years. Such a plan is currently being prepared by Dr. Manfred Kaminsky at Argonne Nationa] Laboratory. Proposed elements being considered for incorporation in the plan are 1 isted in Table 36.

The ECUT Tribology Program is a program in the Office of Energy Systems Research which is under the Deputy Assistant Secretary for Conservation. Terry Levinson is the program manager. This program is described in more detail in reference 21 .

\section{PROJECTS REVIEW}

The classification system used allows a review to be made of the current projects shown in Appendix 1. The subjects under study are listed in Table 37. By far, the most emphasis is being placed on lubricants, materials and coatings, and friction and wear mechanisms. This emphasis is quite different than several years ago when more work was being done in component development, fluid film and elastohydrodynamic lubrication, and concentrated contacts. There are no obvious reasons for this change except the natural cycle of events which turns to new unknowns when solutions to current problems are achieved. The major new emphasis has been in the field of wear. Ten years ago there was no work and little interest in this subject. The first work in this country was sponsored by the Office of Naval Research and then material scientists became interested. New techniques of surface analys is allowed wear mechanisms to be accurately defined and classified. With this understanding, new techniques for wear reduction have been proposed and are being evaluated. There is still considerable interest in the subject as evidenced by the excellent response in both papers submitted and attendance at the International Wear Conference held every two years.

There is continuing interest in rolling contact bearings and seals. Much of this interest arises from the increasingly severe temperature and life requirements of the aircraft gas turbine engines. Leaking seals, however, are a perennial problem in most machinery and are, at least for aircraft, the major reason for service removals.

Early failure detection has received major emphas is in maintenance technology and that emphasis has prompted renewed interest in tribological failures. Hork in this area centers on appropriate failure detection instrumentation for rolling and sliding contacts and obtaining an understanding of thermomechanical failures.

Objectives of current R\&D are listed in Table 38. Most of the programs are conducted to obtain longer life, low maintenance, faiture free machinery or 
a fundamental understanding (friction, wear, materials, coatings). The improved machinery category is the most obvious objective since it includes new designs to meet new requirements and proslem oriented developments.

Fundamental research in tribology is conducted on a continuing basis since this is the mission of a number of government organizations. Demand for improved performance and increased severity for operation of equipment has intensified the need for a better understanding of lubricating mechanisms. This is particularly evident in certain areas such as frictional behavior, solid lubrication and wear, where little proyress can be made without additional research. This fundamental research could well lead to important advances relevant to energy use. A great deal of work is being done to define wear mechanisms but very little on friction and solid lubrication.

High temperature lubrication has been a major objective in tribology for the past forty years and will continue to be in the future. The primary driving force has been the aircraft gas turbine engine but space power, metal working of super alloys, higher temperature automotive engines, and metal cutting have also contributed. Past research has been evolutionary as incrementa] improvements were made in rolling contact bearing materials, synthetic lubricants, piston ring and seal materials, solid lubricants, and wear resistant coatings. Current research driven by the needs of advanced heat engines such as the adiabatic diesel and the sma?l gas turbine appears to be more revolutionary in nature. New materiais (ceramics, composites) are being considered as well as new solid lubricants (intercalated layer lattice compounds, new dichalcogenides, oxides and double oxides). New techniques for supplying solid lubricants are being considered and evaluated. These new approaches may provide the necessary breakthrough to allow major temperature increases in propulsion systems and machinery. Temperature limitations on the lubricant has always been a major obstacle.

General materials development has proceeded with coatings receiving the most attention. A wide variety of techniques have been developed for applying controlled compositions and controlled thicknesses. This has allowed coatings to be used in close tolerance applications such as rolling contact bearings and spool valves. Mixed metals and ceramics can be applied as required

One of the most interesting developments has been in the area of composite coatings which use electroplating and electroless plating technologies. This includes both hard particles and lubricating particles in a variety of metal substrates. This technology has great potential since it allows tailoring of the surfaces to meet the requirements of the application in regard to both friction and wear characteristics. In fact, it appears feasible to transfer many of the additive functions (extreme pressure, antiwear, anticorrosion, friction modification, etc.) from the lubricant to the bearing surface. With this approach, efiorts could be concentrated on high temperature fluid stability.

Very few of the current government programs have design predictability as their objective. Obviously the need exists to make rational choices of materials and designs to achieve a given life or load capacity. Although the government does not design the equipment it uses, it has a vested 
interest in machinery reliability. Industry, even more than government, needs improved design techniques for tribological applications. Much work needs to be done in this area, particularly in the materials area.

As yet, tribology has not been specifically addressed to energy or material conservation objectives. The ten programs listed in Table 38 are primarily those currently supported by ECUT.

The energy relevance of the work is listed in Table 39. This table identifies those programs which are not conducted for improved energy utilization; they may, however, contribute to that end. It can be seen that if the $32 \mathrm{high}$ temperature lubrication programs are subtracted, only 43 of programs make some contribution. There is much room for new energy-significant research in a variety of subject areas.

An applications breakdown is shown in Table 40. Almost all of the work is involved in bearing and seals for machinery and their lubrication. Other component work is limited.

The materials involved in the tribology studies are listed in Table 40. Obviousty, the most interest is in metals and fluid lubricants for current applications. However, because of the higher temperatures anticipated in new propulsion systems, most research organizations are beginning to look at ceramics and solid lubricants. New rigs are being constructed at several different laboratories to study the frictional behavior of ceramics to $1500 \mathrm{C}$. In addition, new research is being contemplated to gain a better understanding of solid lubricant mechanisms and to apply them to tribological components.

As shown in Table 41, very little development work is being carried out with either polymer or metal composites for tribological applications. However, significant advances have been made in the past 20 years in improving the wear rates and temperature capabilities of such materials. 


\section{HIGHLIGHTS}

Table 41 lists some of the highlights of the current research efforts. For each subject category there is listed some of the major efforts which are currently under way in a variety of laboratories. In fundamentals, work is under way to gain a better understanding of both fluid friction under boundary lubricating conditions and solid friction. The major effect, however, is to better define wear and surface damage machanisms which occur in sliding and rolling contacts. Lubrication transitions are also being studied, especially the trans"tion from fluid film to boundary lubrication. Analytical and experimental work is being conducted to mode? this process in terms of the surface topography, fluid properties, and materials properties. A new wave of interest has developed in high temperature operation which has prompted new interest in ceramic friction and wear. Many of the laboratories surveyed are constructing new friction and wear test devices for operation to 1500C. The increasingly severe requirements of the gas turbine engine has prompted renewed efforts to find 600F synthetic 0ils. The Amy is also interested in higher temperature engine oils for tactical vehicles as well as improving current oils. Solid Tubricant studies have been almost nonexistant since space research received less government emphasis. However, new programs are planned to identify new solid lubricants with broad temperature range capability and to find new ways to use them. What is also needed is systems work which will define the capability of solid lubrication in a broad range of components such as bearings, gears, etc. The application of solid lubricants in coatings and polymers has continued with significant improvements being made in the wear Tives of such materials. Coating technology has made significant advances in recent years and this is now being applied to wear resistant coatings. The significant development is that controlled thickness, composition, and structured coatings can be applied which makes them much more practical for use in close tolerance machinery and components.

In order to develop more reliable, higher speed rolling contact bearings, new fracture and corrosion resistant materials have been developed which are now being introduced into service. Improved bearing designs are also being evaluated to meet the higher speed and load requirements of advanced engines and transmissions. Of particular significance is the research which demonstrates that power loss can be reduced significantly with appropriate technology. 


\section{CONCLUSIONS}

1. Over the past six years approximately 650 tribology projects have been conducted under government sponsorship. Approsimately are current programs sponsored by 21 different government organizations.

2. Other than high temperature lubrication projects, very few of the current tinibology research and development programs accomplish energy related objectives. Tribology has not been adequately addressed to energy objectives.

3. Almost all of the tribology work is related to the objectives of the Department of Defense. Of the 21 major sponsors, 15 are DoD organizations. of the remaining 6 , two carry out either sponsored or similar work. Industrial tribology areas are receiving very little attention.

4. Past work has been primarily evolutionary in nature with little exploratory work being carried out with novel tribological systems.

5. Most of the projects are either basic or applied research in friction, wear, materials, and coatings. Wear research has increased from almost no effort several years ago to a major effort today. In contrast, work on improved tribological components is decreasing.

6. Work on high temperature lubrication continues with emphas is on materials (engine oils, rolling contact bearing materials, high temperature, corrosion resistant greases, extended wear life dry bearing materials, controlled property coatings, and ceramic friction and wear).

7. These materials developments along with the components research conducted in previous years has set the stage for significant advancements to be made in the development of high temperature systems.

8. New techniques for applying controlled property and controlied thickness coatings are being applied to improve the performance and reliability of tribological components.

9. Many organizations are assembling test equipment and personnel for a major emphasis on ceramic friction and wear studies at high temperatures.

10. Tribology areas which are receiving little attention are design predictability and composites materials. Fundamental work on friction and solid lubrication is also needed to achieve energy objectives. 


\section{REFERENCES}

1. 0. Pinkus and D.F. Wilcock, "Strategy for Energy Conservation Through Tribology", ASME 1977.

2. Research Committee on Lubrication, "Strategy for Energy Conservation Through Tribology - Second Edition", ASME 1931.

3. M.B. Peterson and W.0. Winer, Wear Control Handbook, ASME 1980.

4. Research Committee on Lubrication, "Workshop Report on Tribology Program Plan", ASME 1982.

5. Anon, "Research Needs in Mechanical Systems", Journal of Tribology, ASME January 1984.

6. Solid Lubricated Rolling Element Bearings. Part I: Gyro Bearings and the Associated Solid Lubricant Research. AFWL-TR-83-4129.

7. Solid Lubricant Rolling Element Bearings. Part 1 - Vol 1. Summary AFWL-TR-33-4129.

8. Solid Lubricant Rolling Element Bearings. Part 1 - Vol 2. Appendix A-J AFWL-TR-83-4129.

9. Solid Lubricant Rolling Element Bearings. Part 1 - Vol 3. Appendix J-? AFWL-TR-83-4129.

10. Solid Lubricated Rolling Element Bearings. Part II: Turbine Bearings and the Associated Solid Lubricant Research. AFWL-TR-83-4129.

11. Solid Lubricated Rolling Element Bearings. Part II - Vol 1. Summary AFWL-TR-83-4129.

12. Solid Lubricated Rolling Element Bearings. Part II - Vol 2. Appendix A-P AFWL-TR-83-4129.

13. Solid Lubricated Rolling Element Bearings. Part II - Vol 3. Appendix Q-CC AFWL-TR-83-4129.

14. Solid Lubricated Rolling Element Bearings. Part II - Vol 4. Appendix dd- $i \mathrm{i}$ AFWL-TR-83-4129.

15. J. Lankford, "Sliding Seal Materials for Adiabatic Engines. Phase 1 Interim Report". NASA CR-174893. Apr 85.

16. L.J. Lindberg, "High Temperature Ceramic Interface Study". NASA CR-174728. Aug 84 . 
17. W. Shapiro, "Development of Gas-Lubricated Pistons for Heavy Duty Diesel Engine Technology Program. NASA CR-174746. Jul 84.

18. R.C. Wagner and H.E. Sliney, "Effects of Silver and Group II Fluorides Additions to Plasma Sprayed Chromium Carbide High Temperature Solid Lubricant for Foil Gas Bearings to 650C. NASA TM-86895 (1985).

19. B.B. Aggarwal, T.M. Yonushonis, and R.L. Bovenkeric, "Solid lubrication Design Methodology". NASA CR-174690. May 84.

20. T. Morel, P.N. Blumberg, E.F. Fort, and R. Keribar, "Methods for Heat Analys is and Temperature Field Analys is of the Insulated Diesel". INASA CR-174783. Aug 84.

21. T.M. Levinson, "Status of Tribology in the US - Part II" in "Economic l.osses Due to Friction and Wear - A Workshop Report". National Research Council of Canada. 
Table 1

TRIBCLOGICAL SUBJECTS

1. Boundary Lubrication

2. Friction and Wear Mechanisms

3. Surface Mechanics, Thermal Behavior, \& Modeling

4. Surface Anatysis \& Test Techniques

5. Concentrated Contact Phenomenon

6. Lubricants/Greases/Hydraulic Fluids

7. Solid Lubricants

B. Tribologica? Materials \& Coatings

9. Component Failure Analysis \& Diagnostics

10. Erosion/Cavitation/Abrasion

11. Sliding Bearings \& Bushings

12. Power Transmission \& Traction Devices

13. Gears

14. Meta] Working Tribology

15. Engine Tribology

16. Filtration

17. Fluid Film Bearings

18. Rolling Element Bearings

19. Seals

20. Brushes \& Electrical Contacts

21. Miscellaneous Components \& Studies 
Table 2

TRIBOLOGICAL SIGNIFICANCE

\section{ENVIRONMENT}

Utilization or Disposal of Used 0 ils Wear Due to Lead Remova? from Gasoline Sea] Leakage of Contaminating Chemicals Removal of Heavy Metal Coatings

\section{FOREIGN COMPETITION AMD PRODUCTIVITY}

Reduced Maintenance in Both Manufacturing and Products Improved Too? Life through use of Hard Coatings Deve lopment of High Speed Data Processing Equipment Innovative Tribological Component Designs

\section{MATERIALS CONSERVATION OF CRITICAL MATERIALS}

Removal of Cobalt from Wear Resistant Alloys

Substitution for Chromium in Bearing Steels

Replacement of Tungsten in Tool Steels

Increased Product Lives through Improved Tribological Components lse of Nonmetallic Coatings for Corrosion and Wear Resistance

\section{ENERGY CONSERVATION}

Higher Efficiency through High Temperature Lubrication Utilization of Tribological Materials with Low Embodied Energy Reduced Friction in Mechanical Components and Metal Working Lubrication with Process Fluids Loss of Engine Efficiency through Seal Leakage Substitution of Coatings for High Temp Wear Resistant Heat Treatments Loss of Efficiency through Component Wear 


\section{Table 3 \\ SSIE CITATIONS \\ 1978-1982}

\begin{tabular}{|c|c|}
\hline Lubricity, Lubrication & 11 \\
\hline Friction & 316 \\
\hline Wear & 431 \\
\hline Lubricants & 239 \\
\hline Bearings & 83 \\
\hline Seats & 184 \\
\hline Gearing, Power Transmission & - \\
\hline Brakes & 34 \\
\hline Clutches & 1 \\
\hline Valves & 119 \\
\hline Fretting & 15 \\
\hline Wear Reduction & 11 \\
\hline Erosive Wear & 175 \\
\hline Hydraulic Fluids & 33 \\
\hline Greases & 24 \\
\hline Solid Lubricants & 20 \\
\hline FaiTure & 922 \\
\hline Surface Properties & 6,633 \\
\hline
\end{tabular}


Table 4

SUBJECT SEARCH TERMS

DTIC

\begin{tabular}{|c|c|c|}
\hline PHENIMENON & MATERIALS & APPLICATION \\
\hline Friction & Fluid Lubes & Fluid Film Bearing \\
\hline Wear & Solid Lubes & Rolling Bearing \\
\hline Lubrication & Hydraulic Fluids & Gas Bearing \\
\hline Fretting & Greases & Bushing \\
\hline Erosion & Additives (Lubricant) & Rings \\
\hline Adhesion & Bearing Materials & Spline \\
\hline Abrasion & & Coupling \\
\hline \multirow[t]{8}{*}{$0 i t$ Analys is } & & CTutch \\
\hline & & Valve \\
\hline & & Seals \\
\hline & & Gears \\
\hline & & Brakes \\
\hline & & Brushes \\
\hline & & Cams \\
\hline & & Filters \\
\hline
\end{tabular}


Table 5

MAJOR SPONSORS

ORGANI ZATION

Office of Nava] Research

AF Propulsion Lab

MF Materials Lab

Army Research Office

AF Office of Scientific Research

MERADCOM. Ft. Belvoir

National Science Foundation (Materials)

Army Materials \& Mechanics Research Center

DOE Office of Energy Research

NASA Cleveland

Naval Mir Propulsion Center, Trenton

Waterv]iet Arsenal

National Science Foundation (Engineering)

Naval Air Systems Command, Washington DC

DOE Office of Conservation

National Bureau of Standards

Nava] Research Lab, Washington DC

Applied Technology Lab, Ft. Eustis

NSRDC, Annapolis

Naval Air Development Center

Pitcatinny Arsenal
NAMES

W. Ruff

H. Jones

B. McConnell

F. Schmedeshoff

G. Mayer

A. Matuszko

M. LePera

J. Thomas, Jr.

P.R. Smoot

R. Middleton

0. Manley

D. Buckley

A. D'Orazio

R. Valori

R. Montgomery

R. Marsh

P. Weinberg

T. Levinson

14. Ruff

S. Hsu

J. Murday

B. Poteate

J. Dray

N. Reibuck

W. Ebihara 
Table 6

ORGANIZATIONS CONDUCTING TRIBOLOGY RESEARCH

\section{GOVERNMENT}

Nava! Research Laboratory

Naval Ship Research and Development Center - Annapolis

U.S. Army Fuels and Lubricants Laboratory, Ft. Belvoir

Army Mechanics and Materials Research Center

National Bureau of Standards

AF Propulsion Laboratory

AF Materia?s Laboratory

NASA - Cleveland

Naval Air Propulsion Test Center

Naval Air Development Center

Waterviiet Arsenal

Picatinny Arsenal

Oak Ridge National Laboratory

Argonne Nationa! Laboratory

Lawrence Berkeley Laboratory

UNIVEPSITIES

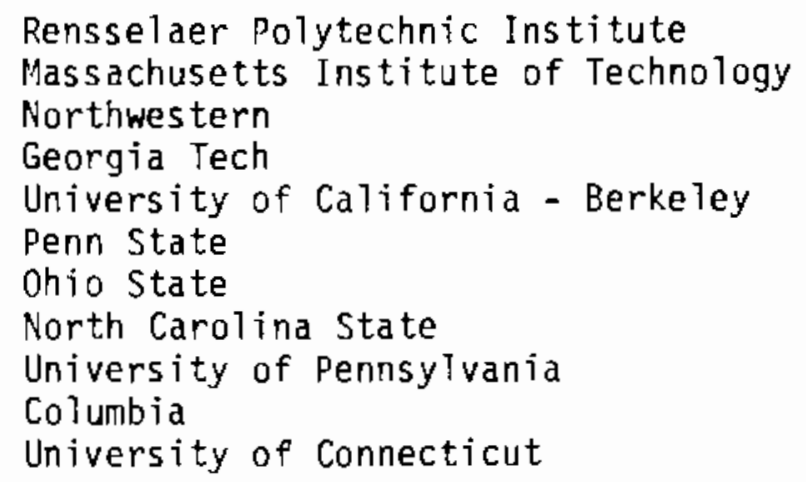

INST ] TUTES

Battelle

Southwest Research Institute

Midwest Research Institute

CORPOIRATIONS

Pratt and Whitney Aircraft Mechanical Technology Inc. SKF Industries

General Electric - Evendale Westinghouse Research

Teledyne

Geo-Centers

U? trasys tems

\author{
Virginia \\ Virginia Polytechnic Inst. \\ Cornell \\ New Mexico \\ Missouri \\ Dartmouth \\ Oklahoma State \\ Minnes ota \\ Delaware \\ Illinois \\ Vanderbilt
}

Franklin Institute

Dayton Research Institute

Draper Labs

Ford Research

Advanced Mechanical Technology

Ball Brothers

Sikorsky Aircraft

Cummins

Hughes Aircraft

Effects Technology

Boeing 
Table 7

PROJECT DESCRIPTION

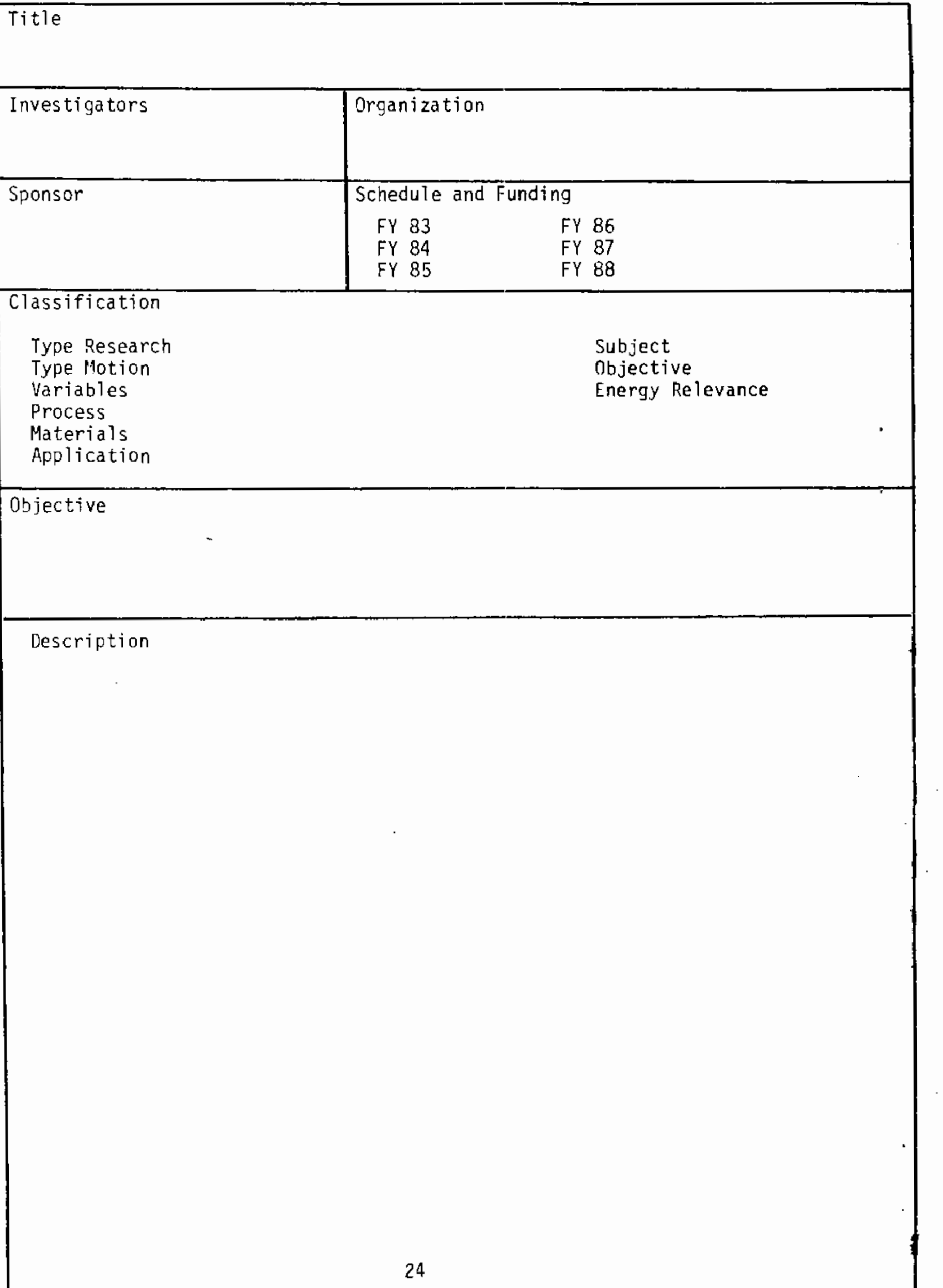


Table 8

PROGRAM OBJECTIVES

1. Long Life, Low Maintenance, Failure Free Machinery

2. Fundamenta 1 Understanding

3. High Temperature Lubrication

4. Materials Development for Improved Performance

5. Design Predictability

6. Energy or Materials Conservation

7. Cost Effectiveness

8. Quiet Operation

9. Improved Health and Safety 
Table 9

ENERGY RELEVANCE

1. HIGH TEMPERATURE LUBRICATION

Materials, Solid Lubricants, Synthetic Lubricants, Lubricant Delivery Systems, Tribocomponent Design \& Operation.

2. DEVELOPMENT OF IMPROVED TRIBOMATERIALS

Materials and Coating with Extendec Wear Life or Low Embodied Energy. Wear Models.

3. STUDIES OF LUBRICATED FRICTION BEMAVIOP:

Friction Reduction Additives, Understanding of Boundary Friction \& Lubrication Processes, Traction, Studies of Boundary to Fliad Film Transition.

4. FAILURE PREVENTION

Transitions, Failure Prediction, Surface Temperatures, Role of Surface Reaction Films.

5. ENERGY EFFICIENT DESIGN \& OPERATION

Component Design for Minimum Frict:on, Low Energy Approaches to Power Transmission, Process Fluid Lubrication, Improved Seals, Friction Reduction in Material Processing. 
Table 10

PROJECT CLASSIFICATION CATEGORIES

\author{
IY IE RESEARCH \\ Bäic \\ Ap:lied \\ Ex: 1 oratory Deve Topment \\ Te :hnology Development \\ De ionstration \\ Comercialization
}

\author{
TYPE MOTION \\ Unlubricated Sliding \\ UnTubricated Rolling \\ Unlubricated Slide/Rol? \\ Impact \\ Reciprocating \\ Lubricated Siiding \\ Lubricated Rolling \\ Lubricated Siide/Roll \\ Oscillating
}

VARIABLES

Load/Pressure

Velocity

Temperature

Environment

Dist/Time/Amp

Geometry

Finish/Lay

Composition

Structure

Physical Properties

Thermal Properties

Chemical Properties

\footnotetext{
DF TIESS OR

가 IICMENON

$\Rightarrow$ intion
}

MATERIALS

APPLICATION

Metals

Ceramics

Polymer

Coatings

Polymer Composites

Metal Composites

Fluid Lubes

Solid Lubes

Hydraulic Fluids

Greases

Additives

Carbons

Elas tomers

Fue 1

Fluid Film Bearing

Rolling Bearing

Gas Bearing

Bushing

Sliding Contact

Rings

Spline

Coupling

Clutch

Valve

Tool/Die

Sea is

Gears

Brakes

Brushes

Cams

Cables

Engine

Transmission 


\section{Table 11 \\ OFFICE OF NAVAL RESEARCH \\ TRIBOLOGY PROJECTS \\ A.W. Ruff}

\section{PROJECT}

1. Trans fer Films/Debris

2. Near-in/Microstructure

3. Therma1 Effects/Brushes

4. Temperature Effects

5. Thermomechanica? Failure

6. Asperity Interactions

7. Seal Materials

8. Mild, Severe Wear Transition

9. Scuffing

10. Surface Additives $\because$ NVESTIGATOR

W. Glaeser (Battelle)

P. Blau (NBS)

-- Dow (N. Carolina State)

D. Wilsdorf (Univ. of Virginia)

F. Kennedy (Dartmouth)

F. Ju (Univ. of New Mexico)

S. Karpe (NSRDC - Annapolis)

1. Ives (NBS)

k. Ludema (Univ. of Michigan)

N. Suh (MIT) 
Table 12

NAVAL RESEARCH LABORATORY

TRIBOLOGY PROGRAMS

J.S. Murday

PROJECT

1. Deuterated Lubricants for

Greater Stability

2. Thin Film Degradation in Instrument Bearings

3. Miniaturized Sensors (in-line) Oxidation Monitor

4. Ion Implantation and Surface Treatments for Wear Resistance

5. Tribology of Ceramics
INVESTIGATOR

J. Capana

R.L. Mowery

R.L. Mowery

I. Singer

C.M. Wu 
Table 13

NSRDC ANNAPOLIS

FUELS AND TRIBOLOGY BRANCH

J. Dray

1. Marine Tribology Block Program

2. Mixed Lubrication Model

3. Asperity Interaction Model

4. Main Shaft Seal Improvement

5. Filter Development for LM 2500 Engine

6. Fiber Optics Bearing Performance Monitor

7. Pump Bearings for Deep Submarines

8. Bearing Condition Monitoring

9. Bearing Stave Materials Studies

10. Marine Corps Tribology Program

11. Synthetic Hydrocarbon Hydraulic Fluids

12. Weapon Lubricant Reduction Program

13. Methods to Determine Lubricant Changes
J. Belt

T. Daugherty

C. Pan

T. Brown

P. Strande11

G. Philips

G. Philips

G. Philips

T. Daugherty

R. Mcquaid

M. Bieberich

J. Taylor

R. Mcquaid 
Table 14

NAVAL AIR PROPULSION CENTER

Trenton

PROJECT

1. Improved Fracture Toughness Bearing

2. Corrosion Resistant Propulsion Bearings

3. Lubricants and Materials for Advanced Propulsion Systems

4. Microtopographic Effects in Tribology

5. Lubricant Preconditioning Effects on Load Capacity

6. High Speed Counter Rotating Cylindrical Roller Bearings

7. Ceramic Bearing Development and Evaluation
INVESTIGATOR

R. Valori/Popgoshev

R. Valori/Popgoshev

A. D'Orazio

A. D'Orazio

A. D'Orazio

R. Valori/Popgoshev

R. Valori/Popgoshev 
Table 15

NAVAL AIR DEVELOPMENT CENTER

TRIBOLOGY PROGRAMS

PROJECT

INVEST IGATOR

1. Fretting Wear, Lubricants Coatings

P. Kennedy

2. Intercalated Solid Lubricants

A. Conti

3. Deuterated Lubricants

N. Reibuck

4. Spline Wear

E. Jewe 1

5. Competitive Additive Adsorption

P. Kennedy

6. Corrosion Resistant Lubricants

L. Stallings

7. Water Base Solid Film Lubes

N. Reibuck

8. Grease Lubricated Helo Transmission

L. Stallings

9. Grease Evaluations/Tactical Vehicles

N. Reibuck 
Table 16

NAVAL AIR ENGINEERING CENTER

PROJECT

1. Spectrometer Sensitivity for 0il Analys is
INVESTIGATOR

P. O'Donell 
Table 17

NAVAL AIR SYSTEMS CMD

MATERIALS

Phi] Weinberg

PROJECT

1. Ceramic Bearing Development and Evaluation
INVESTIGATOR

SKF Industries 


\section{Tabie 18 \\ AF OFFICE OF SCIENTIFIC RESEARCH \\ CHEMISTRY DIVISION}

A.J. Matuszko

PROJECT

1. Fluorocarbon Fluids Synthes is (High Temperature Lubricants)

2. Fluorocarbon Additives

3. High Molecular Weight Elastomers
INVESTIGATOR

R. Lagow (U. of Texas)

K. Pacionek (U]trasystems)

D. Burton (U. of Iowa) 
Table 19

AF AEROPROPULSION LAB

$H$. Jones

PROJECT

1. Foil Bearings for Gas Turbine

2. HiSpeed Cyl Roller Bearings

3. Improved Fracture Toughness Dearing

4. Bearing Research Advanced Concepts

5. Corrosion Resistant Bearings

6. Counter Rot. Roller Bearings

7. Seal Dynamics

8. Improved $T / E$ Camper

9. Taper Roller Bearings

10. Solid Lubricated Bearings

11. Magnetic Bearing Feasibility

12. Dry Lube Gear Technology

13. Expanded Capability

Spectrographic 0il Analys is

14. Lubrication/Analysis Techniques

15. Engine Lubricant Development and Evaluation

16. Fluids Research

17. Lube Life Assessment

18. In-Line 0 il Monitors
INVESTIGATOP

R. Dayton

J. Schrand

J. Dill

R. Dayton

J. Artuso

R. Dayton

S. Drake

R. Dayton

J. Dill

A. Beane

P. Centers

p. Centers

L. Debrohun 
Table 20

AF MATERIALS LAB

B. McConnell

1. High Temperature (600-700F) Gas Turbine

C. Tamborski

oils for Advanced High Performance

L. Gschwender Turbine Engines

2. High Performance Elastomeric Seals

W. Griffin/J. Sieron

3. Wide Temperature Range Lubricants/Seals

L. Gschwender for Advanced Turbine Engines

4. Norflammable Hydraulic Fluids/Seals

C. Snyder

5. Advanced Hydraulic System Materials

L. Gschwender

i. Furdamentals of Solid Lubricated Ceramics

M. Gardos

7. Solid Lubricants for Space Applications

K. Mecklenburg

8. Solid Lubricant Powder Materials/

K. Mecklenburg Technology for Application in Turbine Engine Rolling Element Bearings

9. Surface Modification of Metal/Ceramic Sulstrates via Ion Implantation

K. MeckTenburg

10. Traction Properties of Advanced Aerospace Lubricants

S. Sharma

11. Traction Model Development

3. $\mathrm{McCOOl}$ 
Table 21

U.S. ARMY RESEARCH OFFICE

SOLIO MECHANICS

F. Schmedeshoff

PROJECT

INVESTIGATOR

1. Surface Mechanics - Smooth Surfaces

F. Ling

M. Dawson

2. Surface Mechanics - Finite Roughness

M. Murray

S.F. Murray

3. Observations of Deformation

S.F. Murray and Wear Processes in SElA

S. Calabrese

4. Elastostatic Charging in sliding

S.F. Murray Contacts

W. Holzhauer

5. Analys is of Worn Surfaces with

J. Lauer IEM, LSI, PLIM, and SEM

6. Surface Reaction Kinetics Related

J. Hudwon to Wear Processes

7. Transport Processes in the Contact Line Region

P. Wayner, Jr. 
Table 22

ARMY RESEARCH OFFICE

MATERIAL SCIENCES DIVISION

G. Mayer

PROJEC

1. Meta1/Lubricant/Polymer Interactions
INVESTIGATOR

M. Furey (VPI) 
Table 23

ARMY MECHANICS AND MATERIALS RESEARCH CENTER

PROJECT

1. Advanced Gear and Bearing Materials

2. Ceramic (SiN) Dies for Isothermal Forging

3. Refractory Metal Coatings for Gun Tube Erosion

4. Metal Matrix Composite Abrasion
INVESTIGATOR

R. Middleton

E.N. Kinas

M. Levy

S. Pan

P.R. Smoot 
Table 24

MERADCOM

BELVOIR FUELS AND LUBRICANTS DIVISION

M. LePera

PROJECT

1. Effect of Fuel Components on Engine Wear

2. Relationship Between Grease Thickness and Base 0ils

3. Universal Engine 0ils

4. Lubrication Criteria for Advanced Engine Sys tems

5. Improved Fluids for Helo Transmissions

6. Nonflammable Hydraulic Fluids

7. DOD Long Life Grease

8. User Testing of Improved MIL-G-10924 Grease 
Table 25

ARMAMENT R\&D COMMAND

WATERVLIET ARSENAL

1. Mechanisms of Material Transfer Under Sliding Conditions

2. Design and Materials for Recoil Bearings

R. Montgomery 
Table 26

\section{U.S. ARMY ARMAMENT COMMAND}

\section{PICATINNY ARSENAL}

\section{PROJECT}

1. Wear Resistance of Powder Metallurgy Tool Steels

2. Evaluation of Improved Gear Materials

3. Chromized Coatings for Nickel Alloy Gun Erosion

4. Low Temperature Deposition of Refractory Metals

5. Composite Coatings with Porous Nickel PTate
INVESTIGATOR

J. Burlingame

J. Burlingame

W. Ebihara

W. Ebihara

W. Ebihara 


\section{Table 27}

AVIATION RESEARCH AND DEVELOPMENT CMO

FT. EUSTIS

PROJECT

1. In-line 0it Debris Monitor
INVESTIGATDR

B. Poteate 
Table 28

NASA TRIBOLOGY BRANCH

D. Buckley

INVESTIGATOR

1. Synthetic Lube Structures ( >300C)

M. Meador

2. Additives/ZDP/TCP

3. Lube Thermal Degradation

4. Lube/Metal Catalyzation

5. Plasma Coating Morphology

6. Brake Materials Composites

7. High Temperature Solid Lubes

8. Wear Resistant Sputter Coats

D. Wheeler

F. Morales

W. Jones

T. Spalvins/R. Avni

$R$. Fusaro

H. Sliney

P. Aron

9. New Solid Lube Structures (400C)

B. Good

10. EHL Transitions Theory

11. EHL Roughness

12. Transitions/Experimental

8. Hamrock

J. Tripp

13. Ceramics (Rig \& Theory)

E. Kingsbury

T. Jacobson

14. Amorphous Metal Friction

K. Miyoshi

15. Adhesion Theory

16. Static Friction Correlations

J. Ferrante

17. Fretting

18. Erosion Wear

19. Corrosion Wear

20. Cavitation

21. Gear Materials

22. Transmission Evaluations

23. Hybrid Transmission

24. Traction Drives

S. Pepper

K. Goto

P. Roa

G. Reigsdorf

P. Roa

D. Townsend

E. Zaretsky

S. Loewentha 1

D. Parker 
Table 29

NATIONAL SCIENCE FOUNDATION

ENGINEERING SCIENCE

E. Marsh

\section{PROJECT}

1. Metal Forming with Solid Coatings

2. Wear Behavior of Laser Transformed Cast Iron

3. Three-dimensional Effects in Fluid Film Lubrication

4. Engineering Research Equipment in Tribology

5. Investigation of Multi-facet Drill

6. Metallic Traction Rolling Contact

7. Prediction of Surface Pitting in Gears
INVESTIGATOR

W. Wilson (Northwestern U)

R.A. Molian (Iowa U)

C. Ettles (RPI)

K.M. Marshek (U of Texas)

S.M. Wu (U of Wisconsin)

5. Kumar

H. Cheng (Northwestern U) 
Table 30

NATIONAL SCIENCE FOUNDATION

MATERIALS RESEARCH DIVISION

B. Wilcox

INVESTIGATOR

1. Surface Layer Damage Due to Indentation

T.W. Chow

U. of Delaware

2. Wear Resistance of Hadfield Manganese Stee I

W.C. Leslie

U. of Michigan

3. Basic Mechanisms of Sliding Friction and Wear

D.A. Rigney Ohio state U

4. Role of Structure in Wear Process

J.J. Wert Vanderbilt $U$

5. Role of Chemical Affinity in the N.H. MacMillan Frictional Behavior of Ceramics

Penn State $U$ 
Table 31

RECOMMENDATIONS TO NSF (5)

ASME

\section{MODELING OF TRIBO-SYSTEMS}

Tribo-elements are part of a larger mechanical system and the interactions among the tribo-elements and other components in the system are determining factors in the system performance. This modeling includes dynamic, thermal, chemical, nonlinear material properties, and real surface geometry effects. The modeling should include the full range of lubrication regime behavior (hydrodynamic, elastohydrodynamic, mixed film, boundary, and unlubricated). It should cover not only tribo-element behavior during successful system operation but also the limits of tribo-element behavior in terms of wear and various modes of failure.

\section{MATERIAL BEHAVIOR IN TRIBO-ELEMENTS}

The tremendous range of environmental conditions to which tribo-elements are subjected require a large variety of materials. The environments include thermal, chemical, and stress both steady and unsteady. Material development is a never ending frontier of tribology. Because the near surface region of material is of primary importance to Tribological applications not only the bulk material, but surface layers and surface modifications are important to materials studies in tribology.

\section{TRIBO-SYSTEM DIAGNOSTICS}

Tribo-element failures are often causes of mechanical system failure and downtime. The development of reliable on-line tribo-system performance monitoring techniques can help reduce unscheduled system downtime and therefore system reliability and productivity. On-site methods of monitoring and nondestructive testing in tribology should be developed.

\section{TRIBO-TECHNOLOGY TRANSFER}

Fundamental knowledge in Tribology must be transferred to the design and maintenance personnel to be of value. Computer database systems ("expert systems") should be developed to aid in the trarisfer of new information developed as well as existing tribological knowledge. Tribology as a field has many similarities in its state of developmert with those areas where advances in expert systems have been made (e.g., natural resource exploration and medical diagnostics) and would be a very appropriate field in which to advance the fundamental state of expert systems. 
Table 32

NATIONAL BUREAU OF STANDARDS

METALLURGY OIVISION

A.W. Ruff

PROJECT

INVESTIGATOR

1. Microstructure Effects in the Wear of

P. Blau $\mathrm{cu} / \mathrm{al}$ Alloys

2. Vacuum/Atmosphere Friction Studies

P. Blau

3. Nickel Alloy Tribological Coatings

A.W. Ruff

4. TEM Studies of Worn Microstructures

L. Ives

5. Abrasion Protection with Solid Lubricants

$L$. Ives

6. Mild/Severe Wear Transition

L. Ives

7. Dynamic Mardness Measurement

R. Polvani

8. Properties of Tribological Coatings

A.W. Ruff

9. Effect of Material Properties on Galling

K. Bhansali 


\section{Table 33 \\ NATIONAL BUREAU OF STANIIARDS \\ INORGANIC MATERIALS DIVISION \\ S. Hsu}

PROJECT

1. Standards for Recycled $0 i 1$

2. Friction Mechanisms in Fluids

3. Ceramic Tribology
INVESTIGATOR

S. Hsu

S. Hsu

S. Hsu 


\author{
Table 34 \\ DEPARTMENT OF ENERGY \\ OFFICE OF ENERGY RESEARCH \\ 0. Manley
}

\section{PROJECT}

1. Air Flow and Tire Rolling Resistance

2. Piston Ring Friction and Vehicle Fuel Economy

3. Loss Characteristics of Cord Rubber Composites

4. Characterization of Bearing Surface Roughness

5. Friction Induced Vibrations
INVESTIGATOR

W.J. Rae (CALSPAN)

D.P. Hoult (MIT)

S.K. Clark (U of Michigan)

J.I. McCool (SKF)

V. Aronov (IIT) 
Table 35

DEPARTMENT OF ENERGY

OFFICE OF CONSERVATION AND RENEWABLE ENERGY

J. Eberhardt, T. Levinson, J.A. Carpenter,Jr.

PROJECT

1. Lubrication Qualities of the Constituents of Base Stock 0ils

2. Heats of Adhesion of Separated

Fractions of Base Stock 0il

3. Friction and Wear of Ceramics

4. Ceramic Friction Surface Analys is

5. X-Ray Methods for Analysis of Ceramic Wear Surfaces

6. Hot Spots and the Theory of Ceramic Wear

7. Tribological Coatings

8. Assessment of ECUT Role Tribology

9. Tribology Energy Sinks

Transportation/Utility

10. Tribology Energy Sinks Indus trial

11. Tribology R\&D Private Industry

12. Tribology R\&D in Government
INVESTIGATOR

S.M. Hsu

NBS

F. Lockwood

Martin Marietta Lab

F. Carignan

Advanced Mechanical Technology

C. S. Yust

Oak Ridge

C.R. Hous ka Virginia Polytechnic

W. Winer

Georgia Tech

M. Kaminsky

Argonne

J. A. Carpenter, Jr, ORNL

C.H. Imhoff, PNL

D.F. Wilcock

Mechanical Technology

R. Erickson

Battelle Columbus

L.B. Sibley

M. Zlotnick, Tribology Consultants

M.B. Peterson

Wear Sciences 


\section{Table 36 \\ PROPOSED ELEMENTS \\ ECUT TRIBOLOGY PROGRAM}

High Temperature Liquid and Solid Lubricants

Surface Modification for Improved Tribological Coatings

Exploration of Advanced Lubrication Concepts

Characterization and Testing of Tribosystems

Development of Friction and Wear Models

Diagnostics for Performance Monitoring

Development of a Tribology Data Base 
Table 37

SUBJECT CLASSIFICATIONS

1. Boundary Lubrication 8

2. Friction and Wear Failure Mechanisms 37

3. Basic Mechanics/Thermal Behavior 10

4. Surface Analysis and Test Techniques 7

5. Concentrated Contacts 5

6. Lubricants/Hydraulic Fluids 33

7. Solid Lubricants 14

8. Materials and Coatings 36

9. Failure Analysis/Diagnostics 8

10. Erosion Cavitation 4

11. Sliding Bearings 4

12. Power Transmission/Traction Devices 2

13. Gears 0

14. Meta? Working Tribology 0

15. Engine Tribology 4

16. Filtration 1

17. Fluid Film Bearings 1

18. Rolling Element Bearings 11

19. Seals 6

20. Electrical Contacts 1

21. Misceltaneous Components \& Studies 8 
Table 38

PROGRAM OBJECTIVES

1. Long Life, Low Maintenance Failure-Free Machinery

2. Fundamental Understanding

3. High Temperature Lubrication

4. Materials Development for Improved Performance

5. Design Predictability

6. Energy or Materials Conservation

7. Improved Cost Effectiveness

8. Quiet Operation 1

9. Improved Health and Safety 1 
Table 39

ENERGY RELEVANCE

High Temperature Lubrication $\quad 41$

Studies of Lubricated Friction Reduction 22

Energy Efficient Design and Operation 13

Development of Improved Tribomaterials 11

Understanding Tribological Failures 7 
Table 40

APPLICATIONS

\begin{tabular}{lr} 
Rolling Bearings & 30 \\
Engine Lubrication & 22 \\
Seals & 12 \\
Transmissions & 6 \\
Gears & 5 \\
Fluid Film Bearings & 4 \\
Rings & 4 \\
Tools/Dies & 3 \\
Gas Bearings & 2 \\
Bushings & 2 \\
Sliding Contact & 2 \\
Brakes & 2 \\
Brushes & 2 \\
Tires & 1 \\
Splines & 0 \\
Valves & 1 \\
Cables & 0 \\
Clutch & \\
Cams & \\
\hline
\end{tabular}




\section{Table 41}

MATERIALS

$\begin{array}{ll}\text { Metals } & 74 \\ \text { Fluid Lubricants } & 31 \\ \text { Ceramics } & 22 \\ \text { Coatings } & 18 \\ \text { Additives } & 12 \\ \text { Greases } & 11 \\ \text { Solid Lubricants } & 10 \\ \text { Polymer } & 9 \\ \text { Hydraulic Fluids } & 4 \\ \text { Carbons } & 3 \\ \text { Elastomers } & 3 \\ \text { Polymer Composites } & 2 \\ \text { Metal Composites } & 1 \\ \text { Fuel } & 1\end{array}$


Tabje 42

HIGHLIGHTS

1. FUNDAMENTALS

1. Friction of Fluid Components of 0ils and Solid Surfaces

2. Improved Definition of Wear and Surface Damage Mechanisms

3. Microelastohydrodynamics and Roughness Effects in Lubrication

4. Thermoelastic Surface Models of the Failure Process

2. CERAMICS

1. New Test Rigs to Study Ceramic Friction and Wear

2. Silicon Nitride Rolling Contact Bearings Materials Being Evaluated

3. Structure Effects in Friction and Wear Being Investigated

3. ENGINE OILS

1. Expand Temperature Capabilities to 600F (Silahydrocarbons)

2. Evaluation of Friction Modified Engine 0ils

3. Universal Engine 0ils Being Evaluated

4. Effect of Fuel Components on Engine Wear

4. SOLID LUBRICANTS

1. Double 0xides, Dichalcogenides, Intercalated Layer Lattice Compounds, and Mixed Fluorides Being Considered as High Temperature Solid Lubricants

2. Solid Films, Composites, and Cage Supply Techniques Being Studied; No Efforts on Powder, Stick, or Vapor Lubrication

5. COATINGS

1. Solid Lubricants to $1500 \mathrm{~F}$

2. Controlled Composition/Thickness Ceramics

3. Composite Solid Lube/Wear Resistant Coatings

4. Ion Implanted Corrosion and Wear Resistance Surfaces

6. POLYMER AND METAL COMPOSITES

1. High Temperature, Long Wear Life, Polyimide Composites

7. ROLLING CONTACT BEARING MATERIALS

1. Fracture and Fatigue Resistant Materials

2. Corrosion Resistant Materials and Coatings

8. ROLLING CONTACT BEARINGS

1. 3 Million DN Bearings

2. Solid Lubricated and Dry Operation

9. GAS BEARINGS

1. Foil Bearings for Wide Temperature Ranges 


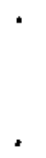


APPENDIX 1

PROJECT DESCRIPTIONS 
Title

A Study of the Chemical Mechanism in Lubrication

\begin{tabular}{|l|lll}
\hline $\begin{array}{l}\text { Investigators } \\
\text { 5. Hsu }\end{array}$ & $\begin{array}{l}\text { Organization } \\
\text { National Bureau of Standards }\end{array}$ \\
\hline Sponsor & Schedule and Funding & \\
Defartment of Energy & FY 83 & FY $86 \quad 90 \mathrm{~K}$ \\
Office: of Basic Energy Sci. & FY 84 50K & FY 87 \\
Engineering Research Program & FY 85 60K & FY 88
\end{tabular}

Classification

Type Research

Type lotion

Variajles

Process

Ma terials

Applization

Objective

Deternine role of chemical reactions in friction and wear.

\section{Description}

Chemical. mechanisms in concentrated contacts under lubricated conditions are langely not understood. This project will study systematically the nature and the extent of influence of chemical reactions in the contact zone on friction and wear. Surface topography of worn surfaces will be characterized to predict oil film thickness under different speed, load ranges in a NBS developed four-ball wear tester. Micro-asperity temperatures and the wear film temperatures of the oil film will be calculated using Archard-Jaeger equations as well as finite-element analysis techniques. Pure model structures will be used as lubricants to test the effects of chemical functional groups on friction and wear. Chemical kinetic studies on tribochemical reaction rate constants for various classes of compounds under wearing conditions will be compiled. A theoretical model linking elastohydrodynamic theories to tribochemical rate constants with materials properties will be attempted to predict lubrication effectiveness a priori. 


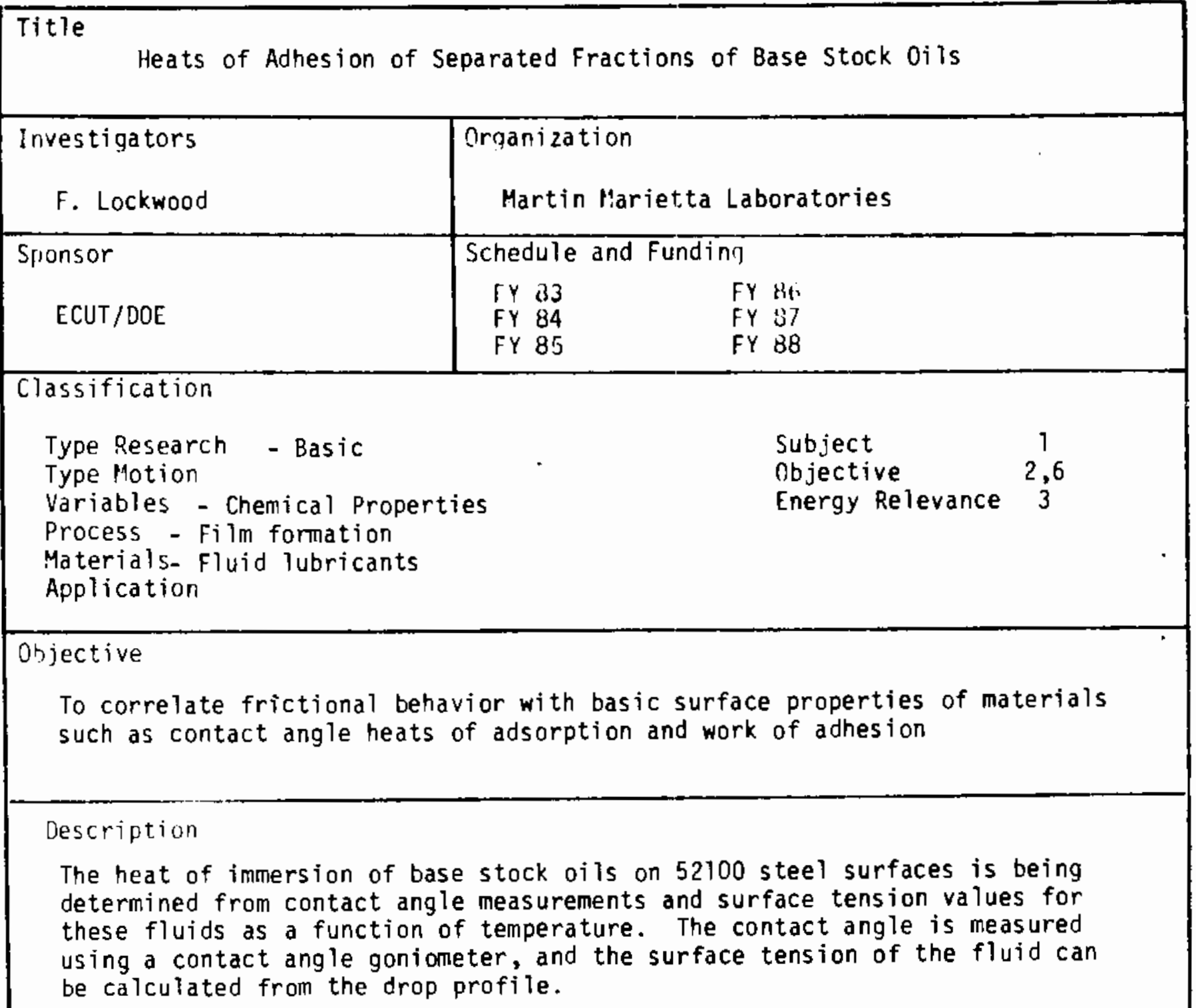




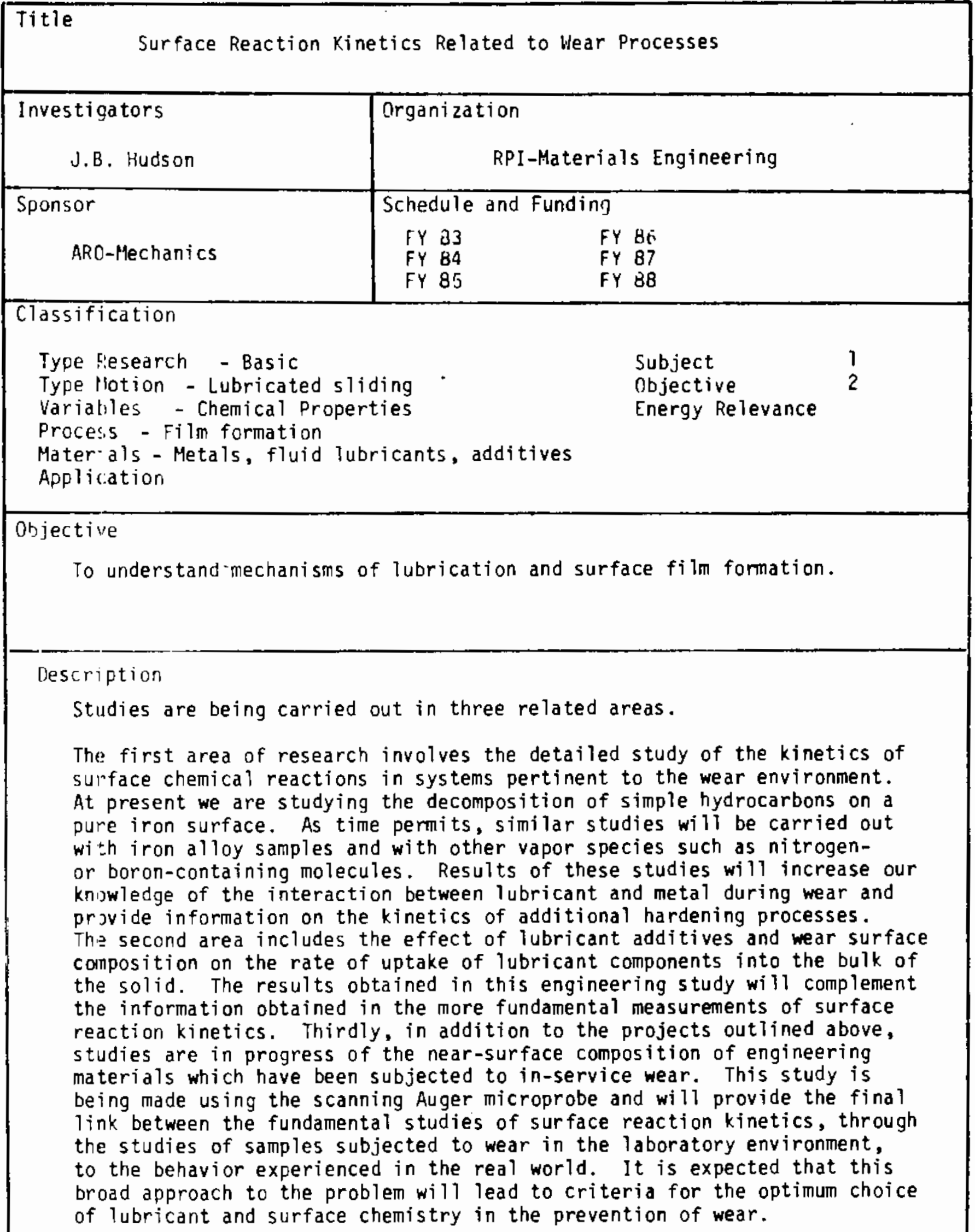


Title

Surface Mechanics - Engineering Sumfaces of Finite Roughness

\begin{tabular}{c|cc}
\hline $\begin{array}{c}\text { Investigators } \\
\text { M.C. Murray }\end{array}$ & \multicolumn{2}{|c}{ Organization } \\
S.F. Murray & \multicolumn{2}{|c}{ RPI Mechanical } \\
\hline Sponsor & Schedule and Funding \\
ARO - Mechanics & FY 33 & FY 83 \\
& FY 84 & FY 87 \\
& FY 85 & FY 88
\end{tabular}

Classification

Type Research

- Basic

Subject

Type Motion - Lubricated sliding

Variables - Finish

Objective 2

Process - Fraction, lubrication

Energy Relevance 3

Materials

- Metais

Application

Objective

To determine the effect of surface texture on mixed film lubrication.

Description

Currently, there is a lack of experimental evidence relating the effect of surface texture to the performance of a sliding system. Theoretical work has produced simple models which assume homogeneous material properties and idealized surface features. However, experimental verification of the validity of these models has not been realized. For this reason, basic slidin tests are being run in the mixed film regime of lubrication using a pinon disc machine in conjunction with computer-aided profilametry (CAP). Through the use of CAP, statistical properties of the surface can be determined and compared with experimental results. In this manner, the important geometric properties of the sliding surfaces can be identified.

Two material combinations,bronze on steel and steel on steel, have been evaluated with two different lubricants, methylphenyl silicone and mineral oil. Because the silicone oil is a poor boundary lubricant for stee? sliding on steel, but is effective in lubricating bronze on steel, the importance of mixed film lubrication is emphasized by the results. The use of CAP also provides a means for discriminating between the effect of initial surface texture and the texture of surfaces developed by run-in. 
Title

Surface Mechanics - Smooth Surfaces

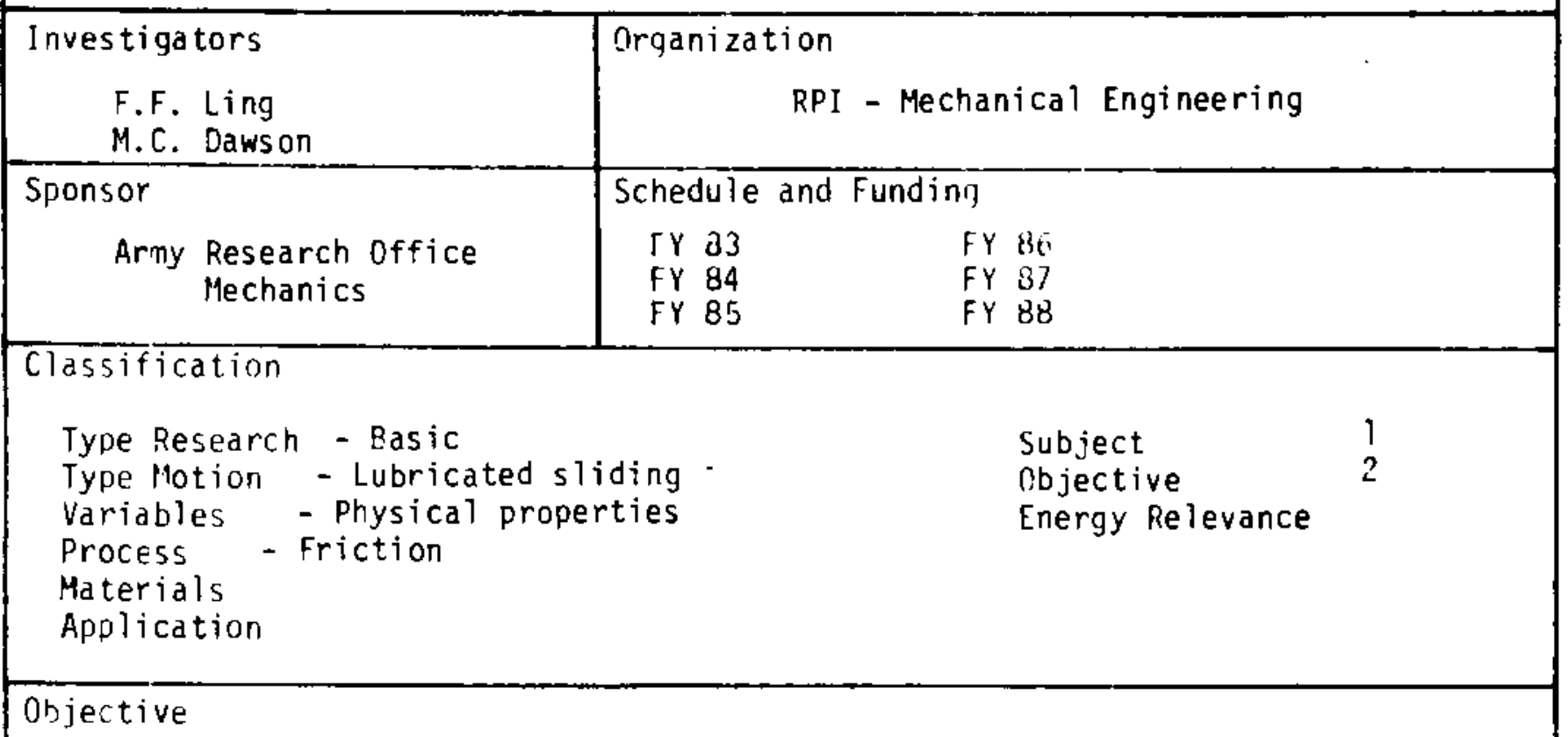

To understand-frictional behavior of smooth surfaces.

Description

Ideally, solid surfaces in relative motion can be visualized as smooth, layered structures. These layers could consist of a top layer of adsorbed or chemisorbed lubricant covering a layer of metal oxide. Below the oxide is a polished Beilby layer which is followed by a region of gross deformation that gradually fades into undeformed metal.

Three aspects of this problem are being investigated: First, being conducted is a systematic study of the complex nonlinear thermoelastic equations with the intent of finding a "boundary layer" set of equations as an approximation. Second, analytic methods of prescribing surface activities are being pursued to include relevant conditions. Third, the role of anisotropy in near surface behavior is being considered with the goal of establishing near-surface approximations that would permit better insight into the physical processes involved in a particular case, say, high speed sliding. 


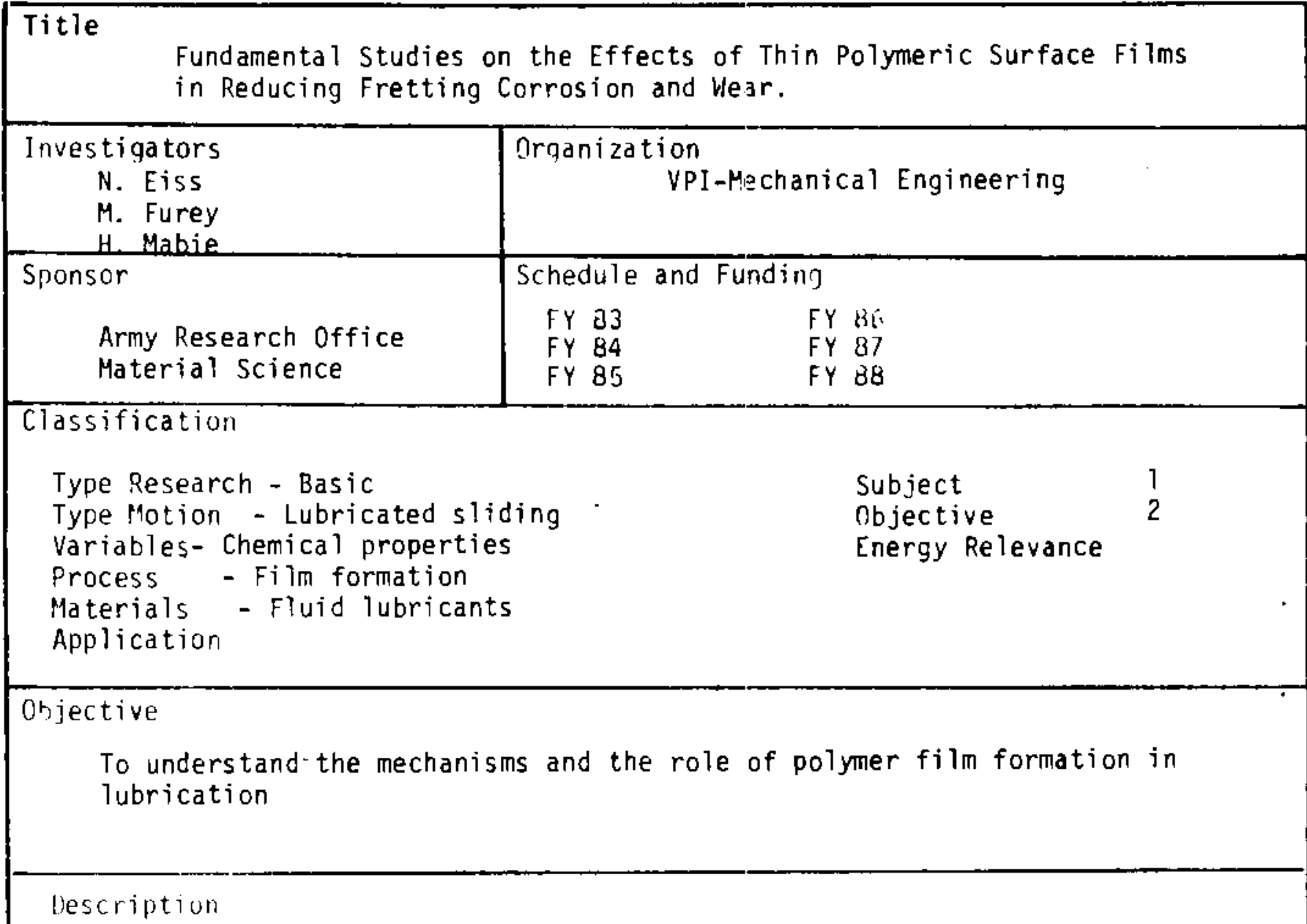

The primary objective of this proposed research is to investigate in a systematic way the effects of thin polymeric surface films on fretting corrosion, metallic contact, and wear under both oscillatory and unidirectional sliding contact; emphasis will be on fretting phenomena in steel-on-steel systems. Variables to be studied will include polymer type and structure, film thickness, and mode of film-formation--including the "in situ" formation of protective polymeric films on rubbing surfaces proposed by one of the principal investigators. 


\section{Title}

Friction Mechanisms in Fluids

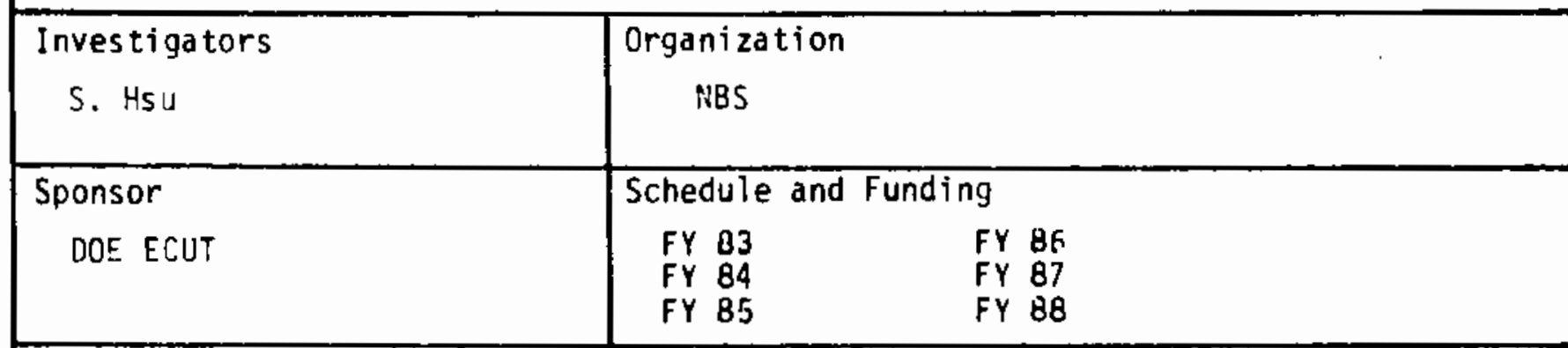

\section{Classification}

Type Research - Basic

Type Motion - Lubricated sliding

Variables-

Process - Friction, wear

Subject

Objective

Energy Relevance

Materials - Metals

Application

Objective - The objective of this study is to develop and standardize measurement methods of friction and wear between interacting surfaces under different conditions (temperatures, surface topography, materials combinations). Through these measurements, it is hoped that the nature of friction and wear mechanisms can be understood and modelled.

Description

State-of-the-art analytical techniques will be used to identify/isolate the key components in base oils that affect the oxidation stability and friction and wear characteristics of lubricants. Model compounds will be used to confirm the identification. An initial correlation model will be used to systematically assess the effects of molecular structures on oxidation stability, and friction and wear. 
Title
Development of a Model for Mixed Lubrication

\begin{tabular}{|c|cc}
\hline $\begin{array}{l}\text { Investigators } \\
\text { T. L. Daugherty }\end{array}$ & $\begin{array}{l}\text { Organization } \\
\text { DT-NSRDC Annapolis }\end{array}$ \\
\hline Sponsor & & \\
& Schedule and Funding \\
NSRDC - Bethesda & FY 83 & FY 86 \\
& FY 84 & FY 87 \\
& FY 85 & FY 88
\end{tabular}

Classification

Type Research - Rasic

Type Hotion - Lubricated sliding

Variables - Finish geometry

Process - Lubrication

Materials - Fluid lubricants

Application- Fluid film bearings

Subject

Objective 2

Energy Relevance 3

Objective

To develop a model for sliding surface bearings which extends hydrodynamic theory into the region of mixed lubrication.

Description

Detailed studies are being conducted to develop a finite element model incorporating solution to Reynolds, the energy, and elasticity equations. This model will be applied to a tilt-pad thrust bearing with longitudinal roughness and will include variable viscosity, side leakage, introduction of various surface shapes, skewed roughness distribution, and roughness on both the bearing and mating surfaces.

Experiments to test the model are being condscted on tilt-pad thrust bearings. 


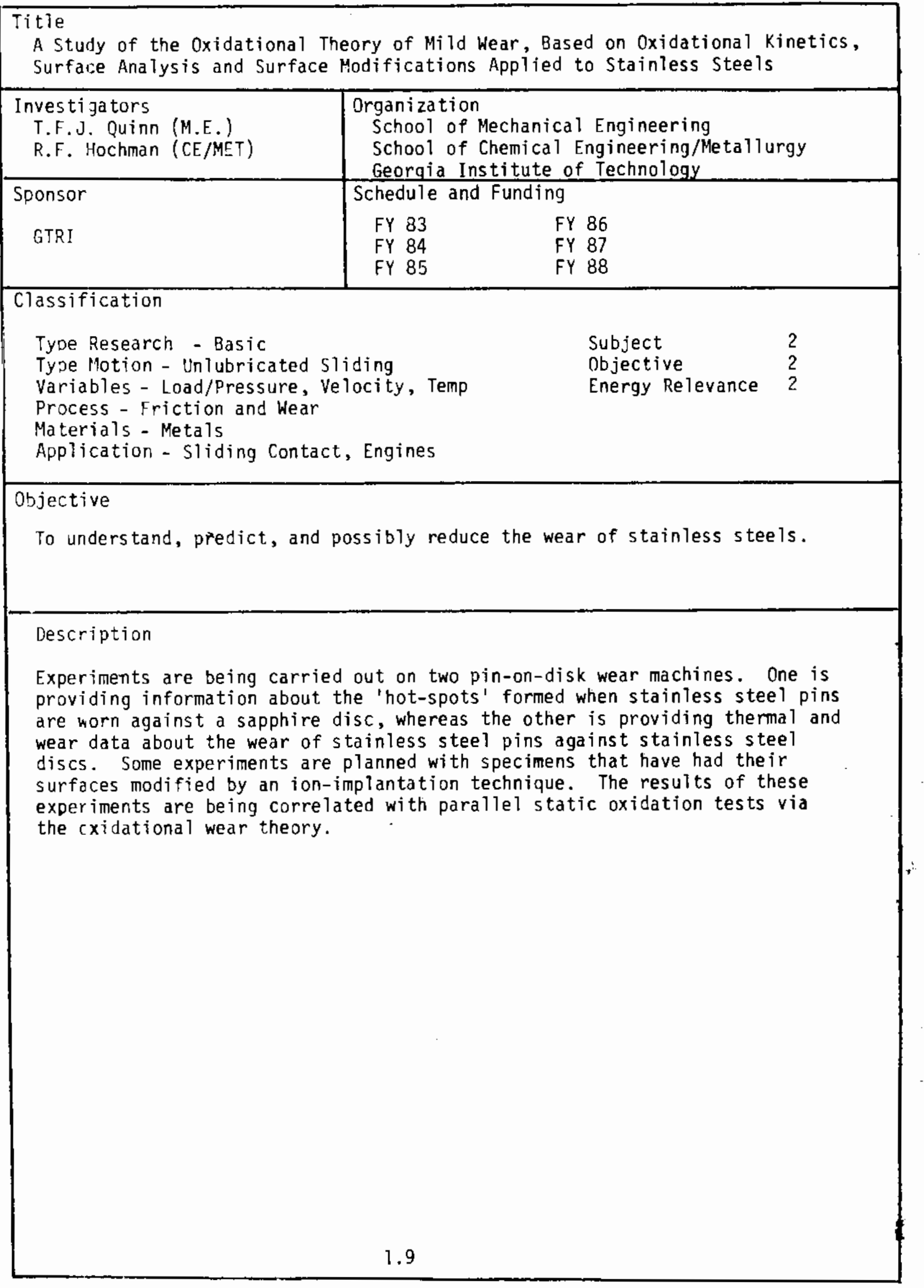




\section{Title}

The Oxidational Wear of Low-alloy Steels at Elevated Temperatures

\begin{tabular}{|c|c|}
\hline $\begin{array}{l}\text { Investigators } \\
\text { T.F.J. Ouinn }\end{array}$ & $\begin{array}{l}\text { Organization } \\
\text { School of Mechanical Engineering } \\
\text { Georgia Institute of Technology }\end{array}$ \\
\hline Sponsor & Schedule and Funding \\
\hline GTRI (E-Funds) & $\begin{array}{ll}\text { FY } & 83 \\
\text { FY } & 84 \\
\text { FY } & 85\end{array}$ \\
\hline
\end{tabular}

\section{Classification}

Type Research - Basic

Type Motion - Unlubricated Sliding

Variables - Load/Pressure, Velocity, Temp

Subject

Objective

2

Process - Friction and Hear

Energy Relevance 1

Materials - Metals

Application - Sliding Contacts

\section{Objective}

To be able to understand and possibiy predict the mild wear behavior of low alloy steels at elevated temperatures.

Description

An elevated temperature pin and disk wear machine is being used to study the wear patterns of low-alloy steels (i.e., the graph of wear rate versus load) as functions of both speed and disc temperature. An oxidational wear theory (modified to allow for oxidation when a given part of the surface is not in contact) is being applied to these results. 
Title

Synthesis and Structure Property Studies of Toughened Epoxy Resins via

- Functionalized Polysiloxanes

\begin{tabular}{|c|c|}
\hline $\begin{array}{l}\text { Investigators } \\
\text { J.E. McGrath } \\
\text { G.L. Wi]kes } \\
\text { N.S.Eiss, Jr. }\end{array}$ & $\begin{array}{l}\text { Organization } \\
\text { Virginia Polytechnic Institute and State Univ }\end{array}$ \\
\hline Sponsor & Schedule and Funding \\
\hline ONR & $\begin{array}{l}\text { FY } 83 \\
\text { FY } 84 \\
\text { FY } 85\end{array}$ \\
\hline
\end{tabular}

Classification

Type Research - Basic

Subject 2

Type "lotion - Unidirection Sliding, Unlubricated

Objective

2

Variables - Load, Distance, Physical Properties

Energy Relevance 2

Process - Friction, Wear, Fatigue

Materials - Polymers

Application - Sliding Contact

\section{Objective}

To determine the friction and wear properties of polysiloxane modified epoxy materials.

Description

The incorporation of rubbers in epoxies has improved the fracture toughness of the epoxies. To improve the temperature range over which the rubber modifiers are effective, polysiloxane curing agents have been used instead of CTZN or ATSN rubbers. During curing the polysiloxane migrates to the surface to create a low surface energy surface.

The friction and wear characteristics of the polysiloxane modified epoxies have been measured in a pin (steel ball)-on-disk (epoxy) experiment in which the surface stress is varied by choosing various combinations of load and ball radius. With surface stresses below the yield strength of the epoxy, the wear track initiates after several hundred disk rotations. Measurements include friction, no. of disk rotations to wear initiation, wear rate after initiation, and the relation of segregated elastomeric domains to the initiation of the wear track. Variables include the percent polysiloxane in the epoxy and the chemical composition of the polysiloxane. 


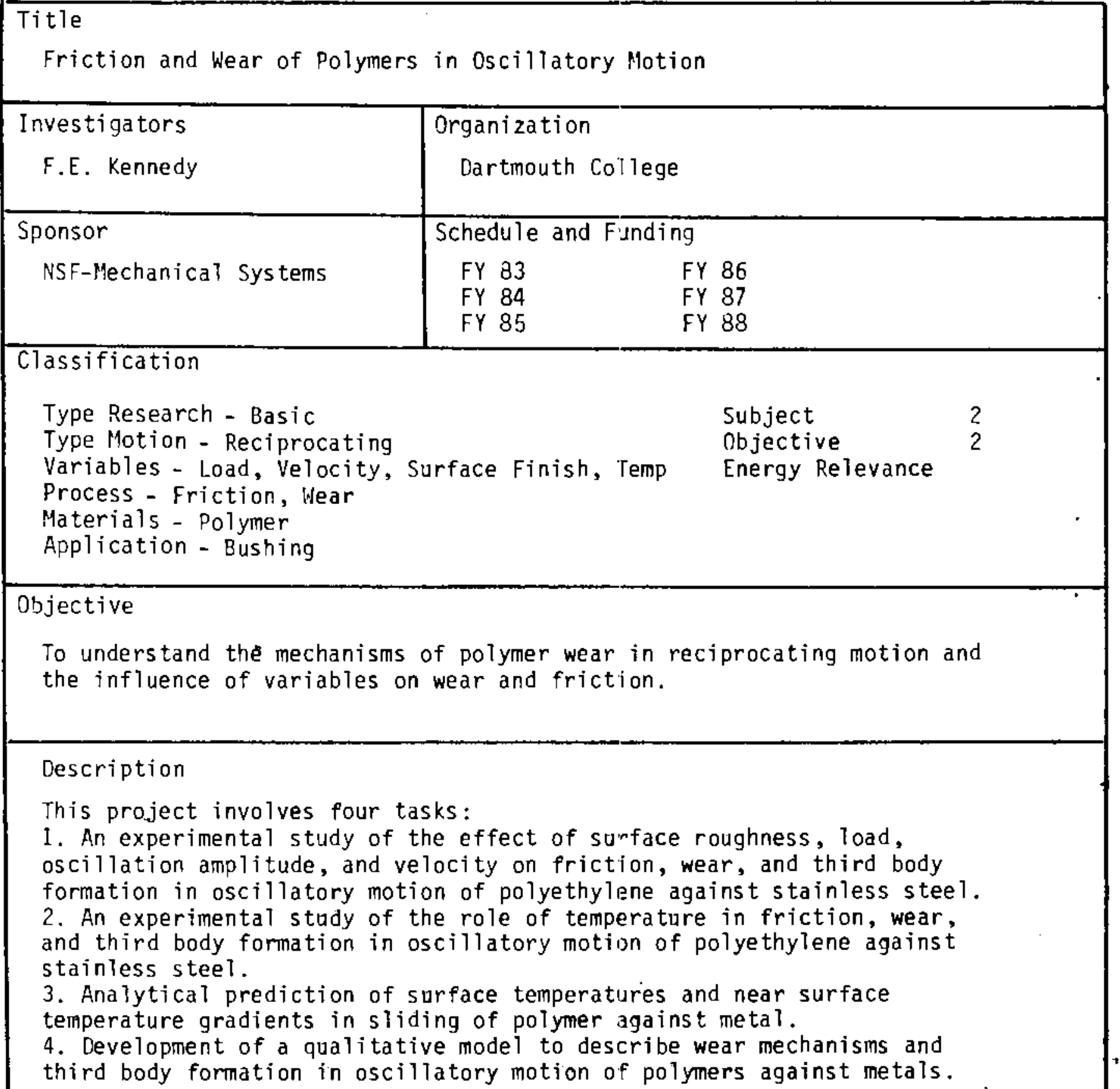




\begin{tabular}{|c|c|c|c|}
\hline \multicolumn{4}{|c|}{$\begin{array}{l}\text { Title } \\
\text { Dynamic Friction of Pletals on Ice }\end{array}$} \\
\hline $\begin{array}{l}\text { Investi jators } \\
\text { F.E. Kennedy } \\
\text { N.P. Huber }\end{array}$ & \multicolumn{3}{|l|}{$\begin{array}{l}\text { Organization } \\
\text { Dartmouth College }\end{array}$} \\
\hline Sponsor & \multicolumn{3}{|l|}{ Schedule and Funding } \\
\hline $\begin{array}{l}\text { U.S. Army Cold Regions } \\
\text { Research \& Engineering Lab }\end{array}$ & $\begin{array}{lll}\text { FY } & 83 & F \\
\text { FY } & 84 & F \\
\text { FY } & 85 & F\end{array}$ & $\begin{array}{l}86 \\
87 \\
88\end{array}$ & \\
\hline \multicolumn{4}{|l|}{ Classification } \\
\hline \multicolumn{4}{|c|}{$\begin{array}{l}\text { Type Research - Basic } \\
\text { Type "otion - Sliding } \\
\text { Variables - Temperature, Surface Finish, Velocity } \\
\text { Process - Friction, Surface Temp } \\
\text { Materials - Metals, Ice } \\
\text { Application }\end{array}$} \\
\hline \multicolumn{4}{|l|}{ Objective } \\
\hline \multicolumn{4}{|c|}{$\begin{array}{l}\text { To increase the anderstanding of the effect of surface finish and } \\
\text { temperature on dynamic friction of metals on ice. }\end{array}$} \\
\hline \multicolumn{4}{|l|}{ Description } \\
\hline \multicolumn{4}{|c|}{$\begin{array}{l}\text { Dynamic friction experiments are being performed using cylindrical metallic } \\
\text { rods of different surface roughnesses pressed against a rotating cylinder } \\
\text { of ice. Temperature is being varied by independently controlling ambient } \\
\text { temperature, metallic bulk temperature, and sliding velocity. Concurrently } \\
\text { with the test program, a numerical thermal analysis is being carried out } \\
\text { to get a better understanding of the sliding surface temperature and its } \\
\text { effect on friction. }\end{array}$} \\
\hline
\end{tabular}




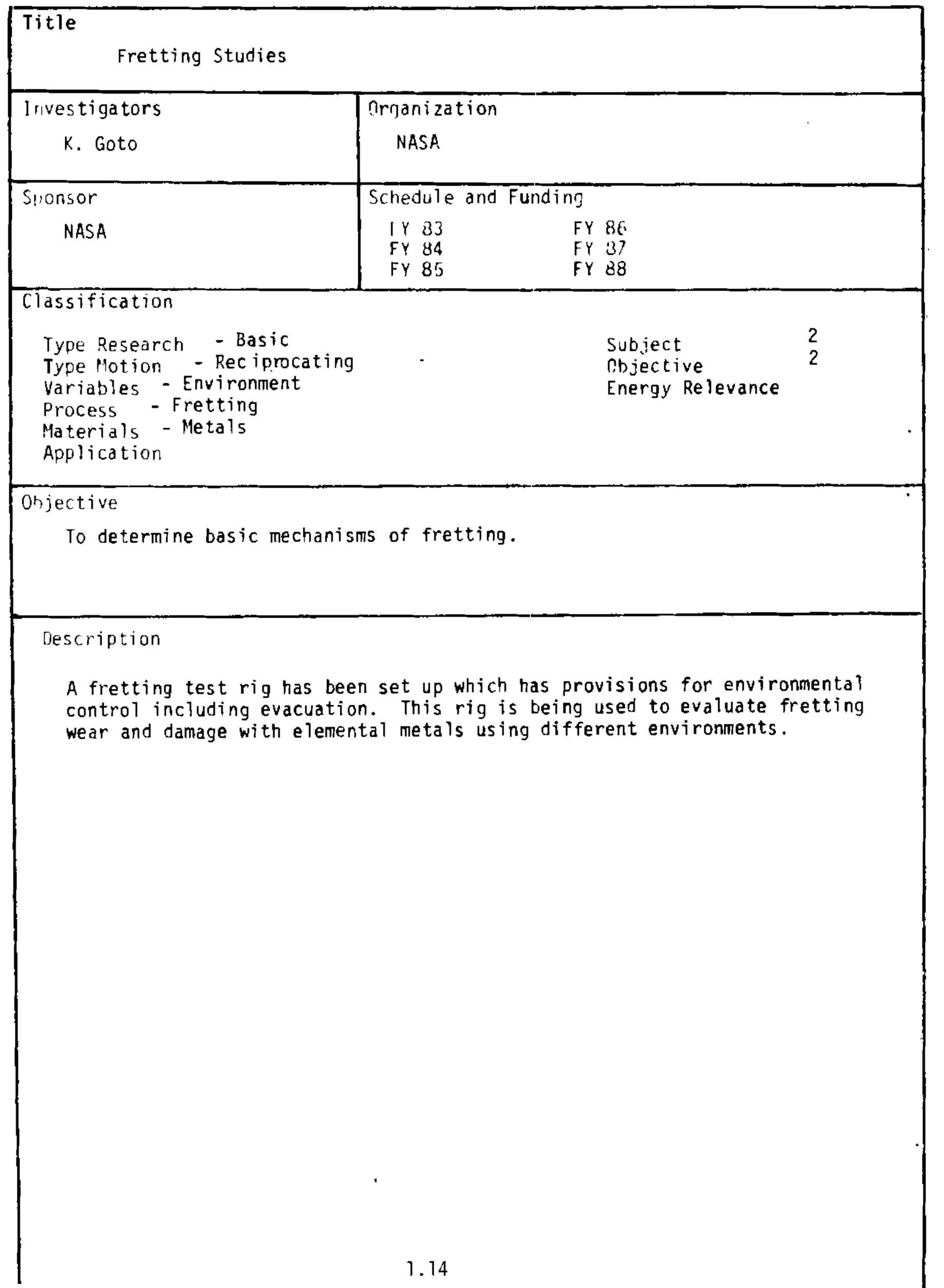




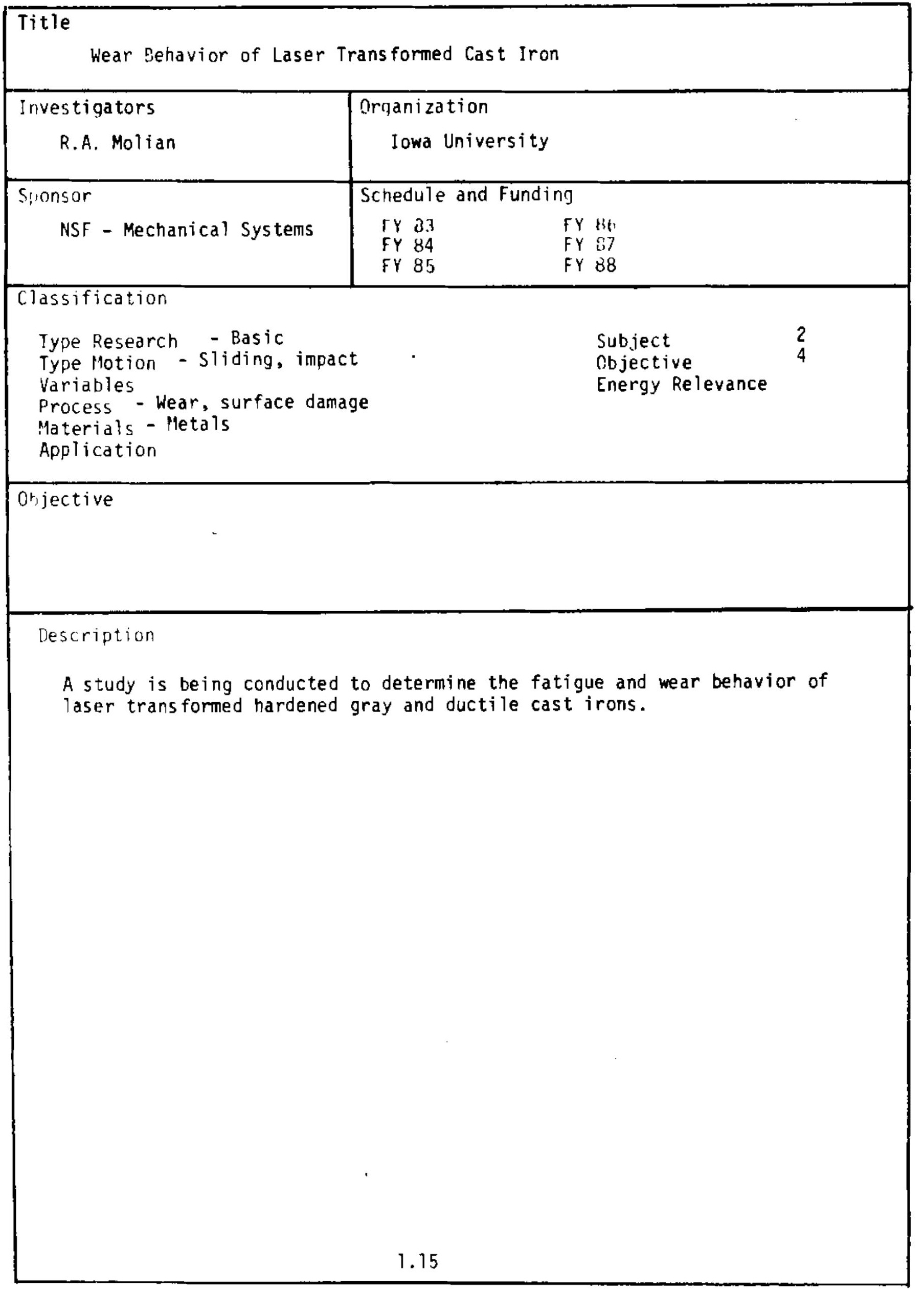




\section{Title}

Investigation of Wear of Ceramics on Ceramics for High Temperature Application

\begin{tabular}{|c|c|}
\hline $\begin{array}{l}\text { Investigators } \\
\text { T.F.J. Quinn } \\
\text { W.O. Winer }\end{array}$ & $\begin{array}{l}\text { Organization } \\
\text { School of Mechanical En } \\
\text { Georgia Instizute of } \mathrm{Te}\end{array}$ \\
\hline Sponsor & Schedule and Funding \\
\hline DOE (ECUT Program) & 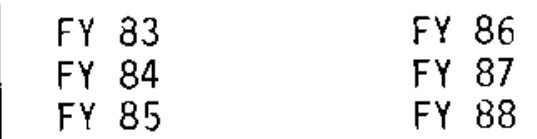 \\
\hline
\end{tabular}

Classification

Type Research - Basic

Type Motion - Unlubricated Sliding

Variables - Load/Pressure, Velocity, Temp

Subject

Objective

2

Process - Friction and wear

Energy Relevance

Materials - Ceramics

Application - Sliding contact, Engines

Objective

To study the wear of selected ceramic materials and its relation to

'hot spot' temperatures.

Description

$\mathrm{Si}_{3} \mathrm{~N}_{4}$, PSZ, and other ceramic pins are being slid against $\mathrm{Al}_{2} \mathrm{O}_{3}$ (sapphire) discs at various loads in order to deduce the wear pattern (i.e., wear rate versus load) as a function of speed. The roles of plastic flow and chemical reaction at the surfaces during sliding are being examined. The direct measurement of 'hot spots' by infrared detection through the transparent sapphire is an important feature of these studies. 


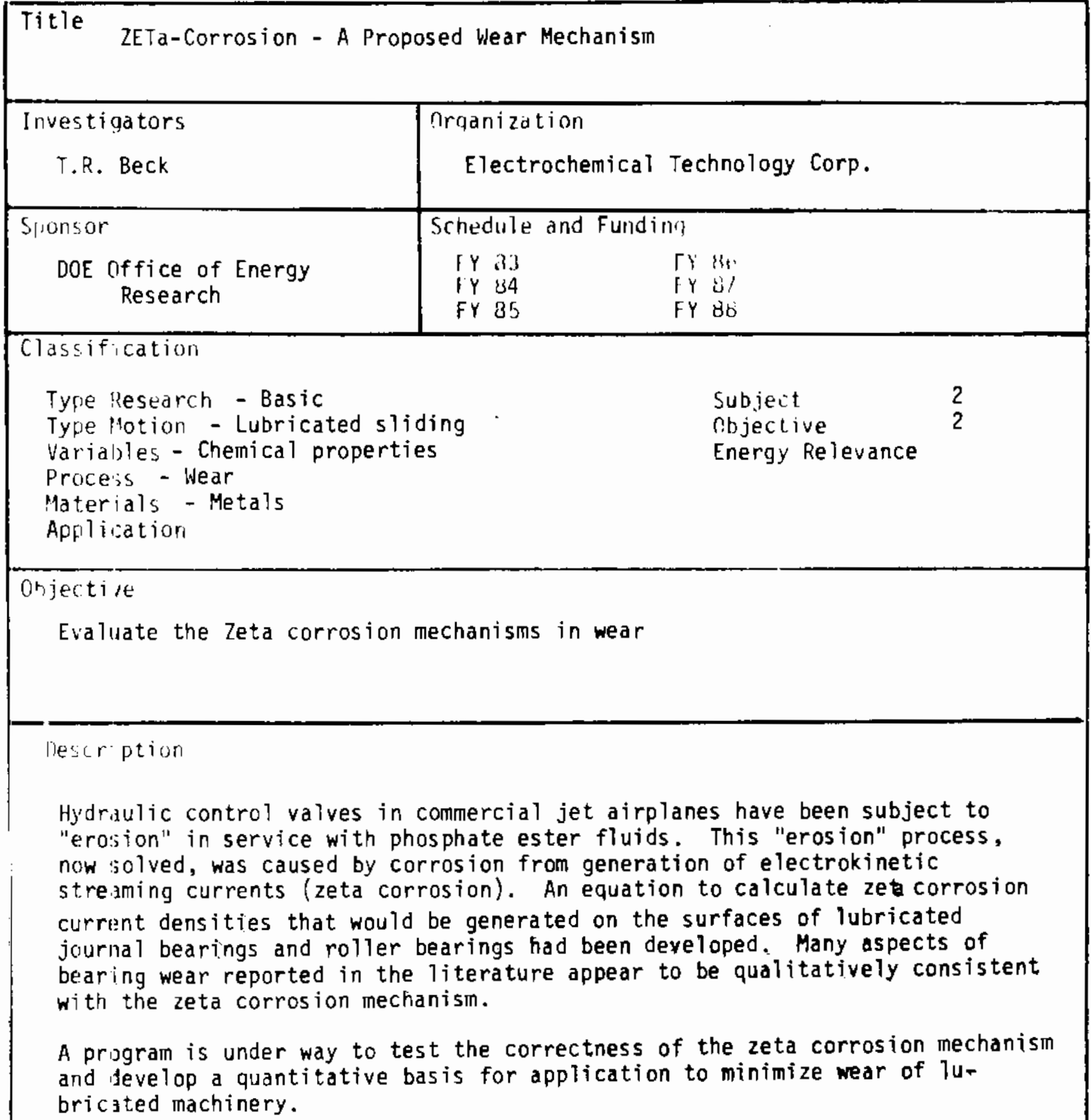




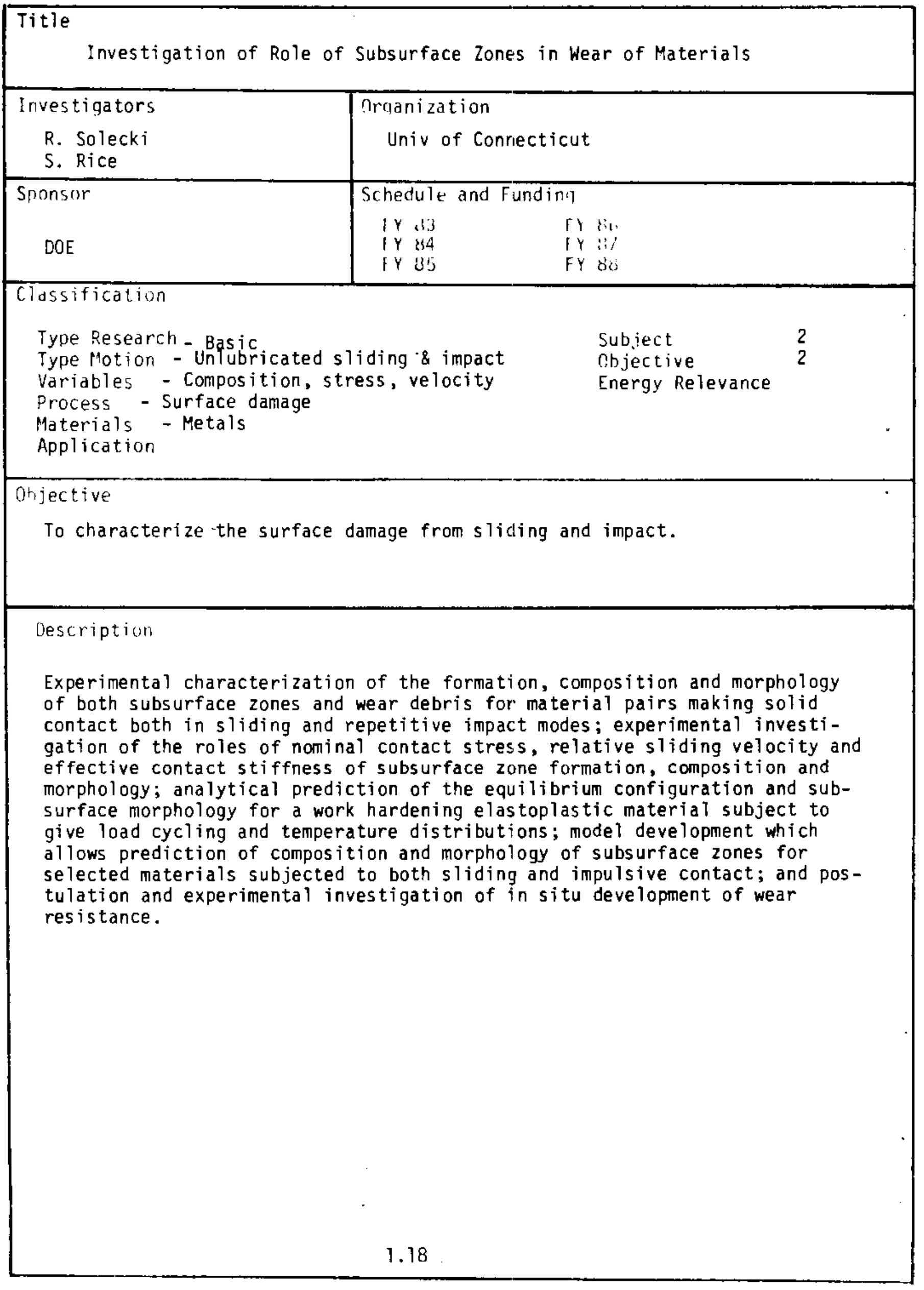




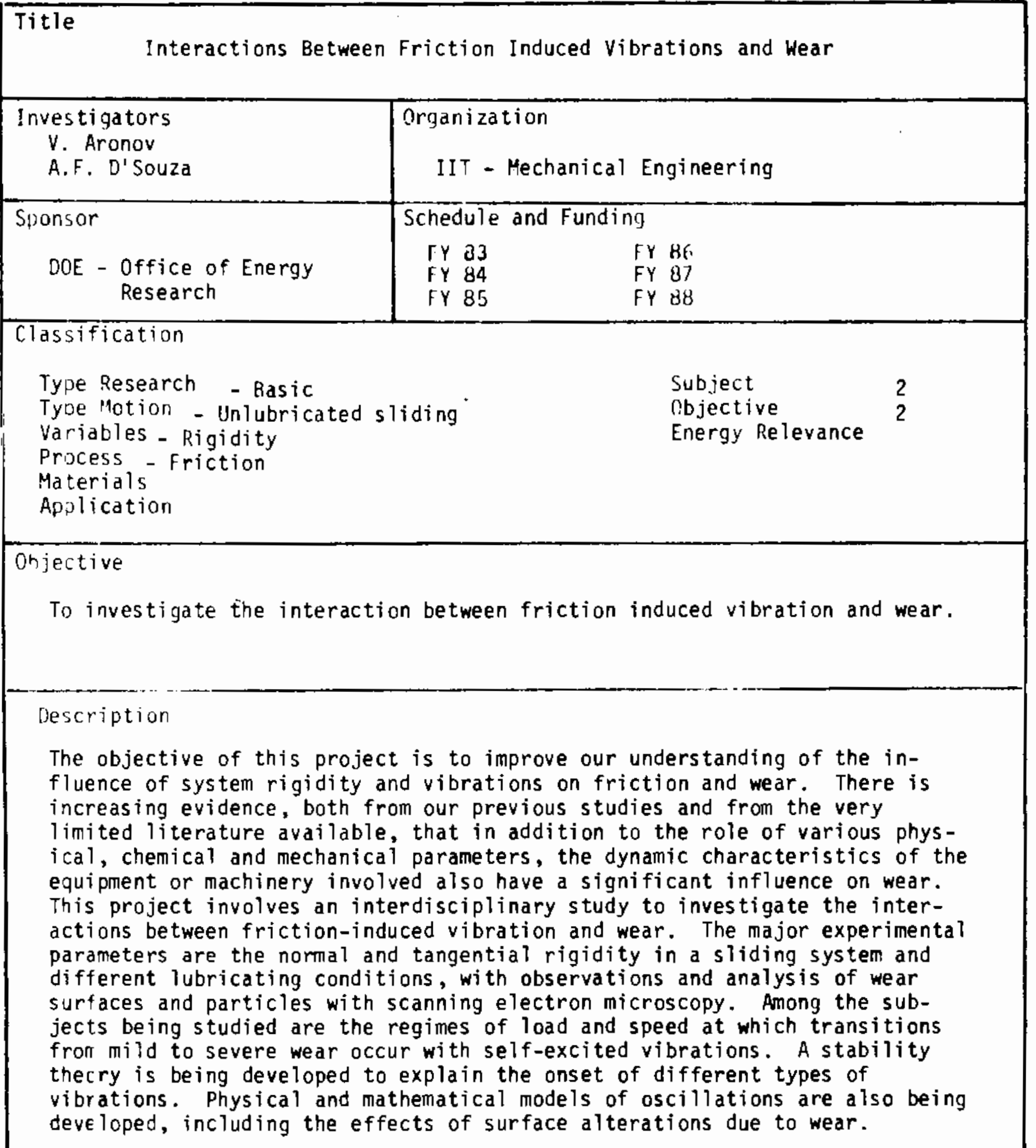




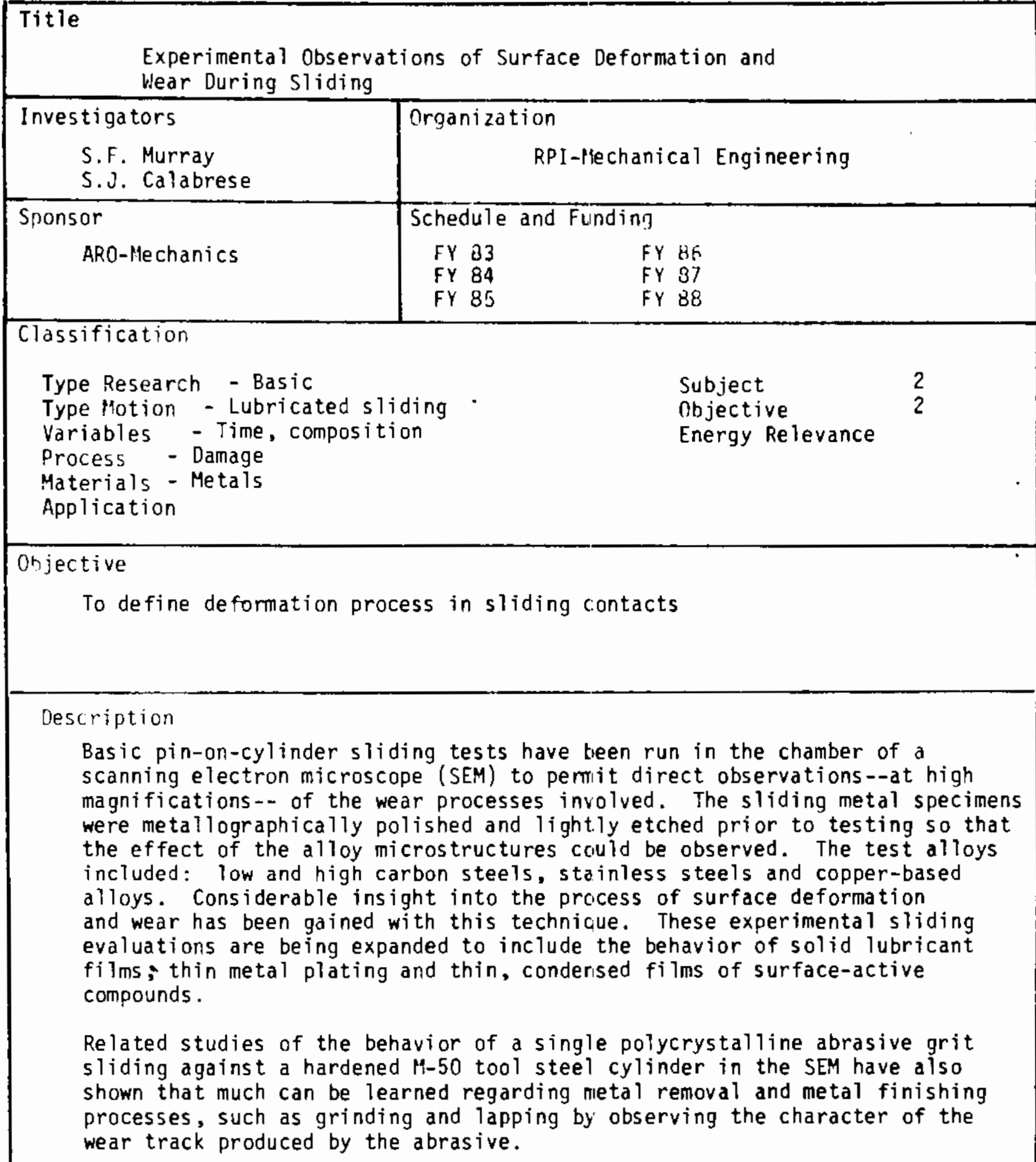




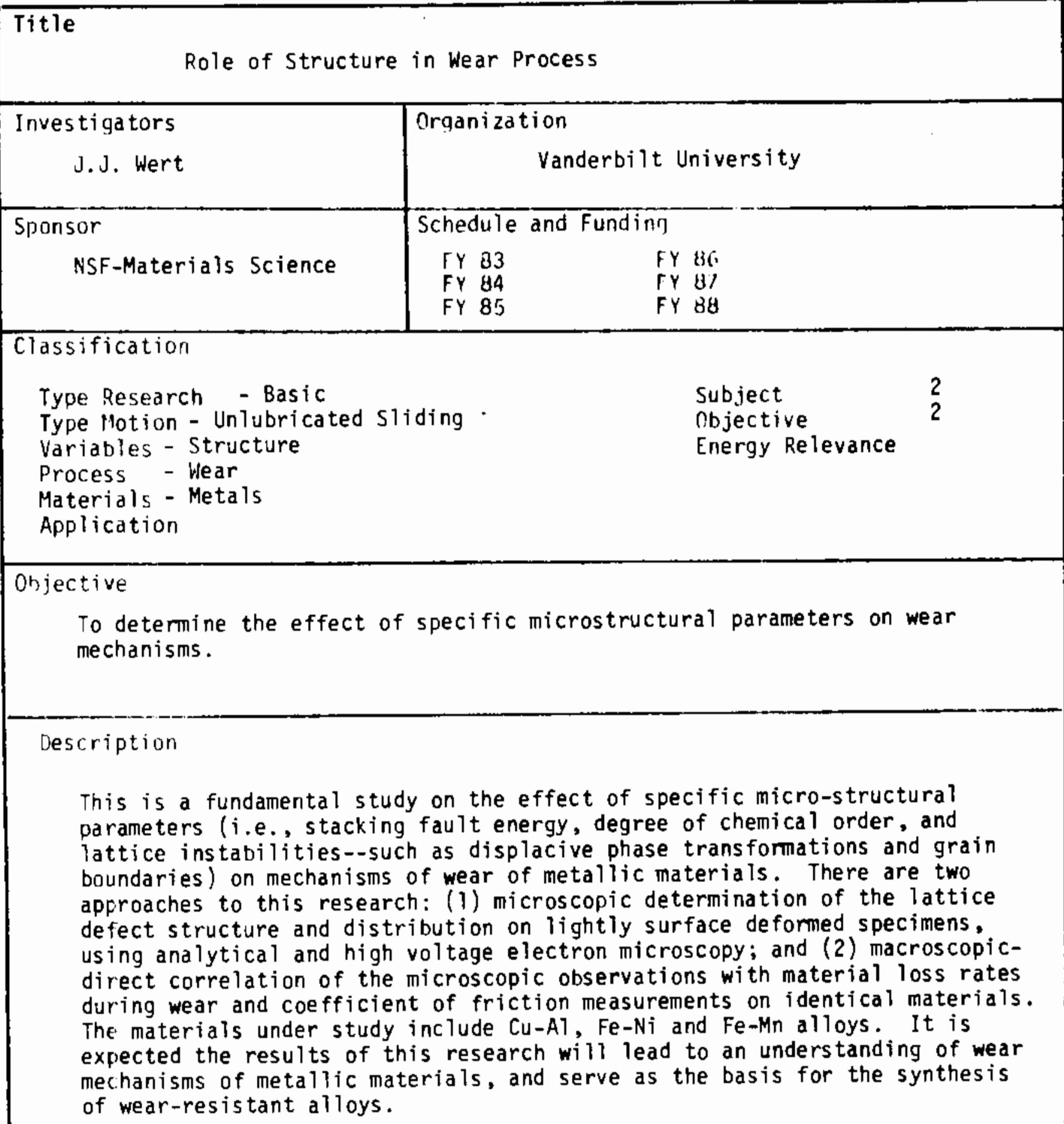


Title

Basic Mechanisms of Sliding Friction and Wear

\begin{tabular}{|c|cc}
\hline $\begin{array}{c}\text { Investigators } \\
\text { D.A. Rigney }\end{array}$ & \multicolumn{2}{|c}{ Organization } \\
& \multicolumn{2}{|c|}{ Chio State University } \\
\hline Sponsor & Schedule and Funding \\
NSF Materials Sciences & FY 83 & FY 86 \\
& FY 84 & FY 37 \\
& FY 85 & FY 88
\end{tabular}

Classification

Type Research - Basic

Type lotion - Unlubricated sliding.

Variables - Physical properties

Process - Friction

Materials - Metals

Application

Ohjective

To establish basic mechanisms of sliding friction and wear.

Description

The materials systems to be tested include Cu-Be (an age-hardening system), $\mathrm{Cu}-\mathrm{Al}_{2} \mathrm{O}_{3}$ and $\mathrm{Cu}-\mathrm{Cu}_{2} \mathrm{O}$ (dispersion-hardened systems), dual phase steels (for comparison with fatigue data), dilute aluminum alloys, and coated systems (e.g. Cd or $\mathrm{Sn}$ on $\mathrm{Cu}$ ). Our successful friction model will be extended so that it can be easily used with experimentally determined stress-strain curves. Worn samples and debris will be studied with the aid of a wide range of analytical techniques, including microhardness tests, $X$-ray diffraction, SEM, TEM, STEM, EDS, and WOS. The actual sequence of the experiments, and the analysis of the results will be guided by the predictions resulting from our energy-based model of friction, and by our recent results on the relation of the accumulation of transfer material to both friction and wear.

Work is being extended to single crystal copper and $\mathrm{HCP}-\mathrm{Co}$, using a method for measuring local orientations changes caused by sliding. The method, which we developed, uses automatic analys is of STEM Kikuchi patterns by a minicomputer. 


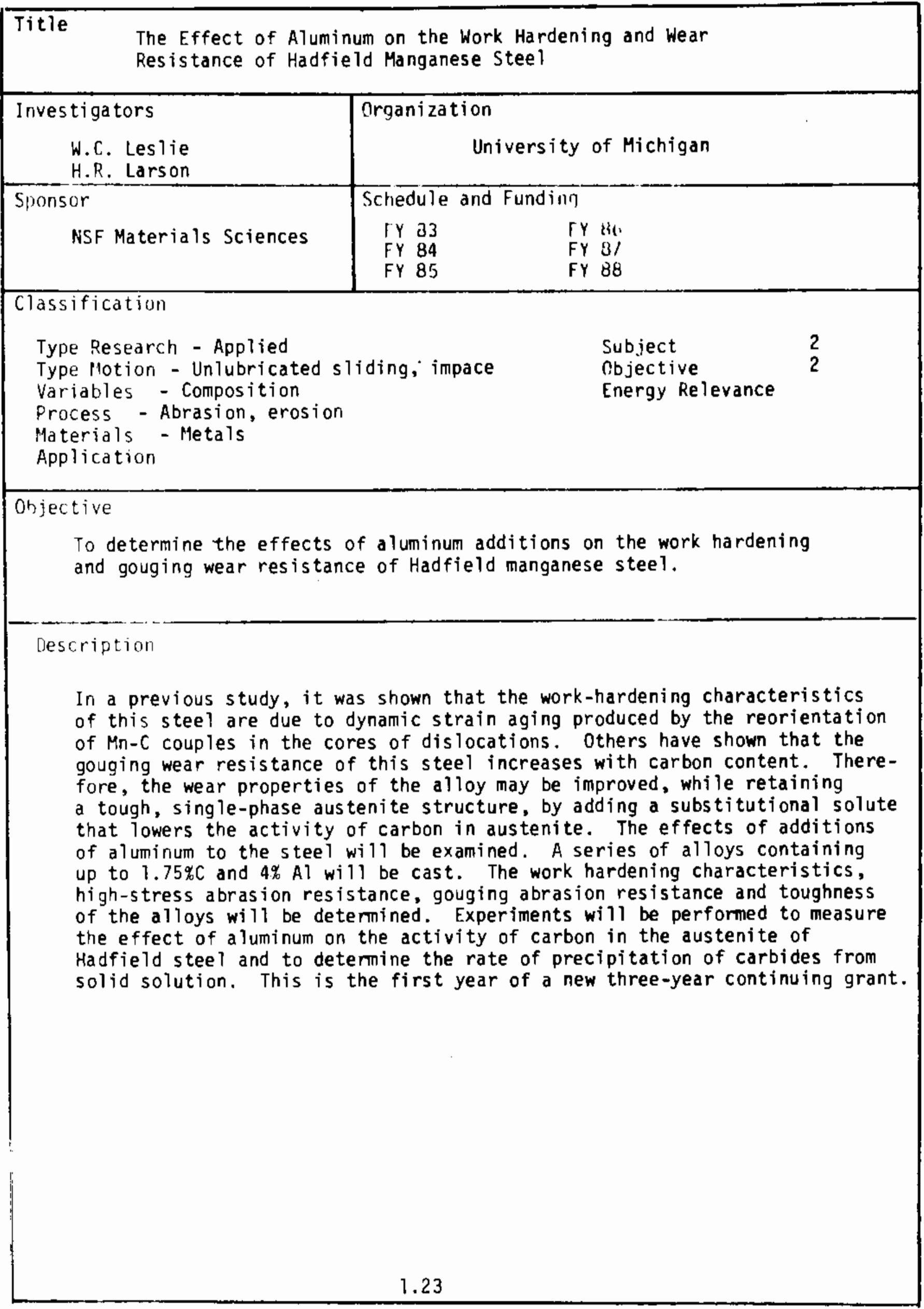




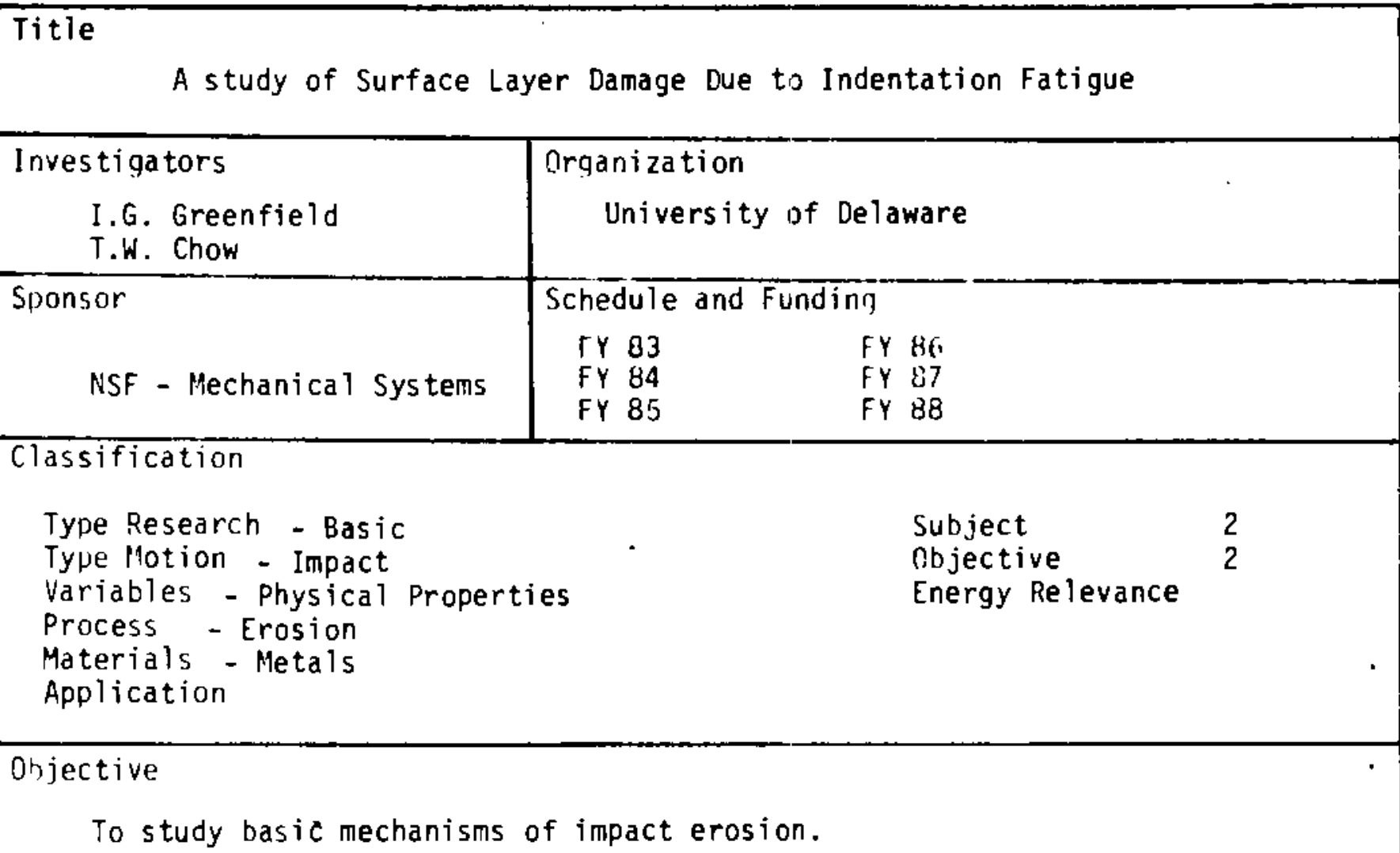

Description

The proposed research during the first two years was intended to gain some fundamental understandings of material fatigue under repeated impact by indenters. A near-rigid indenter was used to repeatedly impact a fixed location on a target material to perform simplified yet highly controlled experimentation. The aim of the research was to understand the complete process of crack initiation, growth and eventually the spalling of the surface layer of the indenter material.

The objective of the following two years' proposed research was to further the understanding of surface layer damage due to indentation fatigue. Both normal and oblique impacts were performed with single and multiple indenters to assess the interactions among neighboring impacts. Key mechanical properties examined were plastic deformation, work-hardening, crack nucleation and propagation, and adiabatic heating during repeated impacts. Particular attention was paid to the synegistic effects of strain-hardening and residue stresses under cyclic loading.

The main goal of the research during the rext year was to combine the physical observations made in the past into a basic model of erosion. 


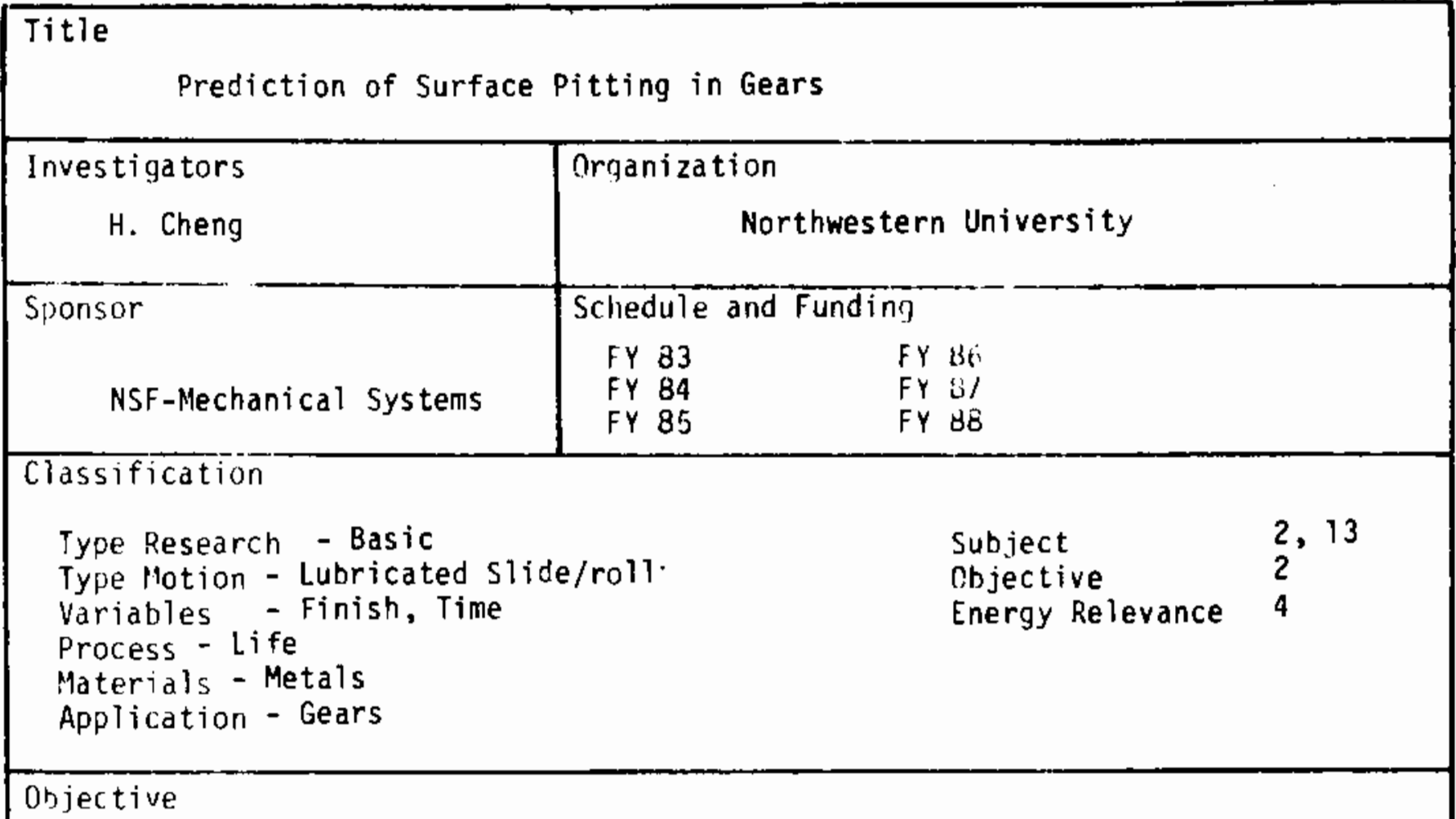

To develop an analytical model which predicts surface pitting.

An analytical model has been set up which predicts life based upon fracture mechanics. Inputs are roughness, lubrication $(n)$ and texture. The probability of pitting is predicted based upon an initial distribution of cracks. 


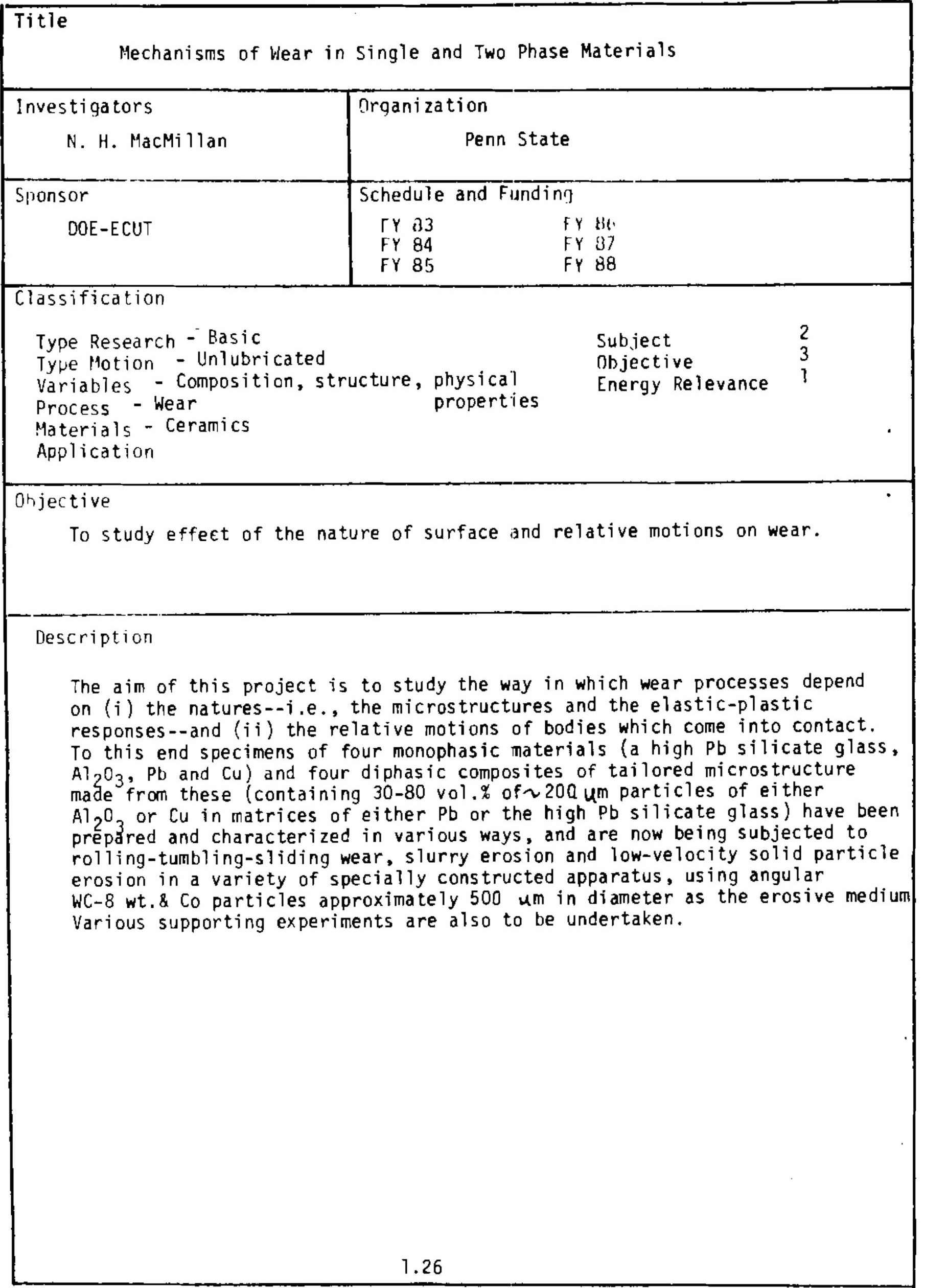




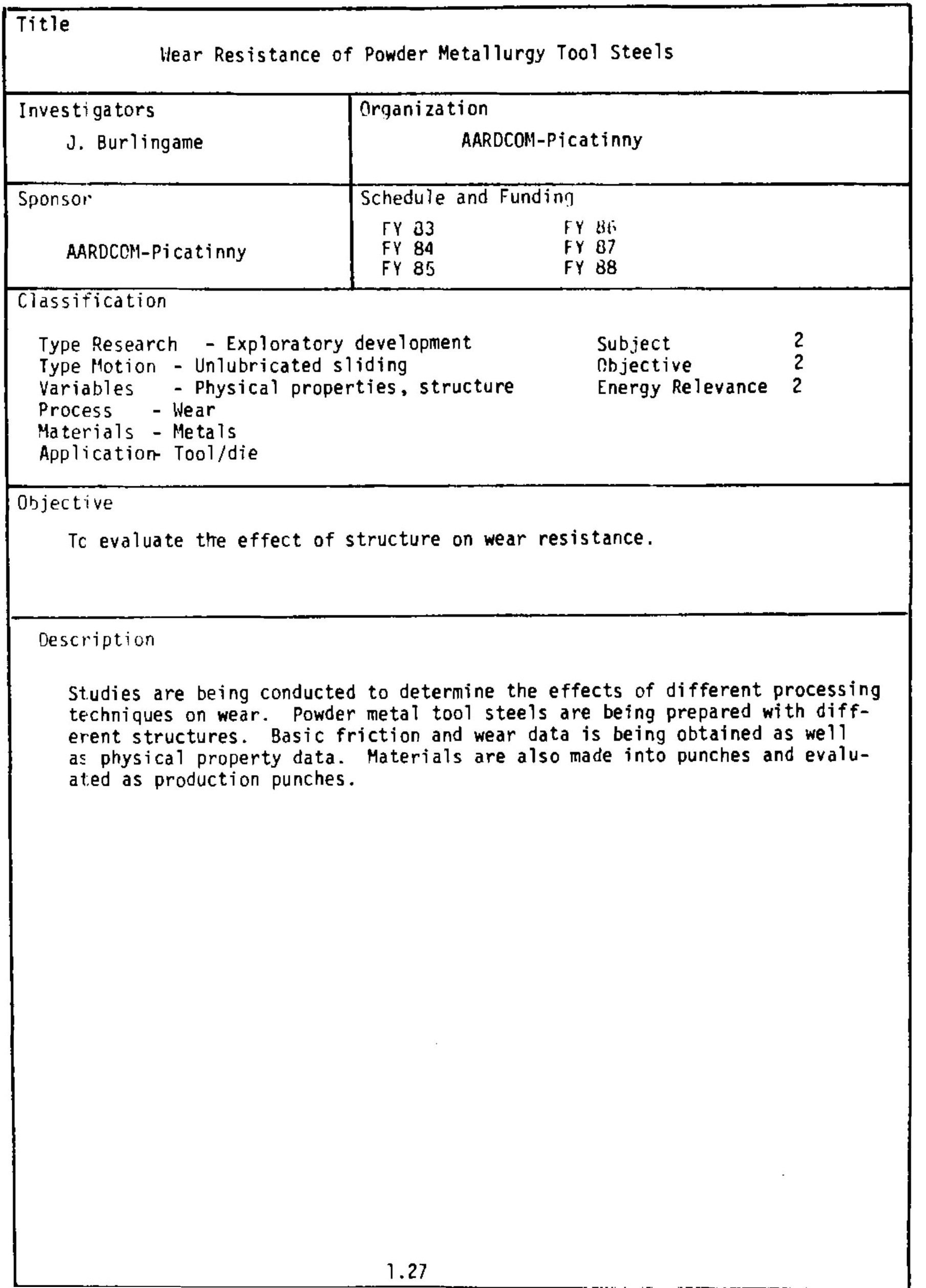




\section{Title}

\section{Mechanisms of Material Transfer During Sliding}

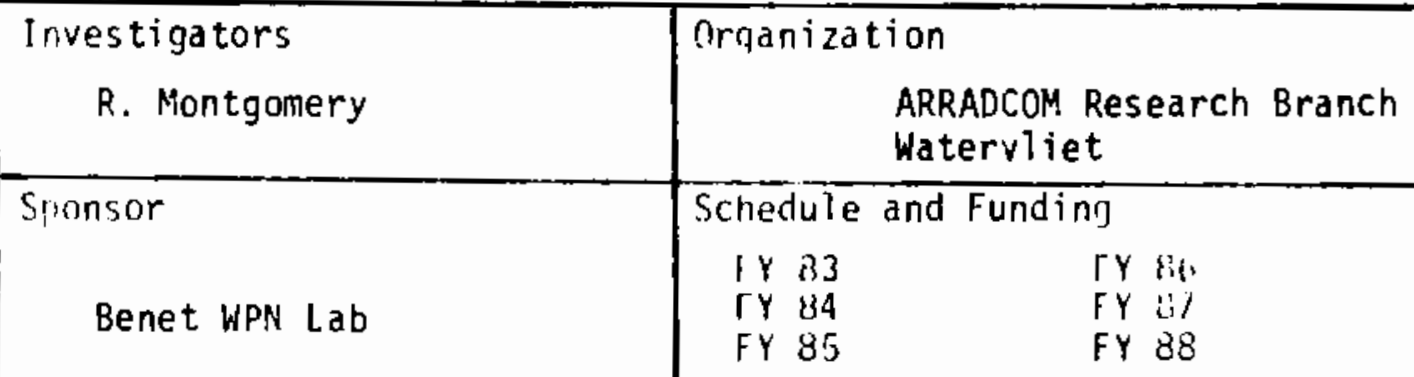

\section{Classification}

Type Research - Basic

Type Motion - Uniubricated sliding

Variables - Composition

Process - Friction, wear, adhesion

Materials - Metals

Application
Subject

Cbjective

Energy Relevance

2

2

Orjective

To understand transfer and adhesion mechanisms

Description

Pin on disk experiments (dry) are being conducted at high velocity and short times $(100 \mathrm{~m} \mathrm{sec})$. Friction, wear, and transfer patterns are recorded for metals and plastics. 


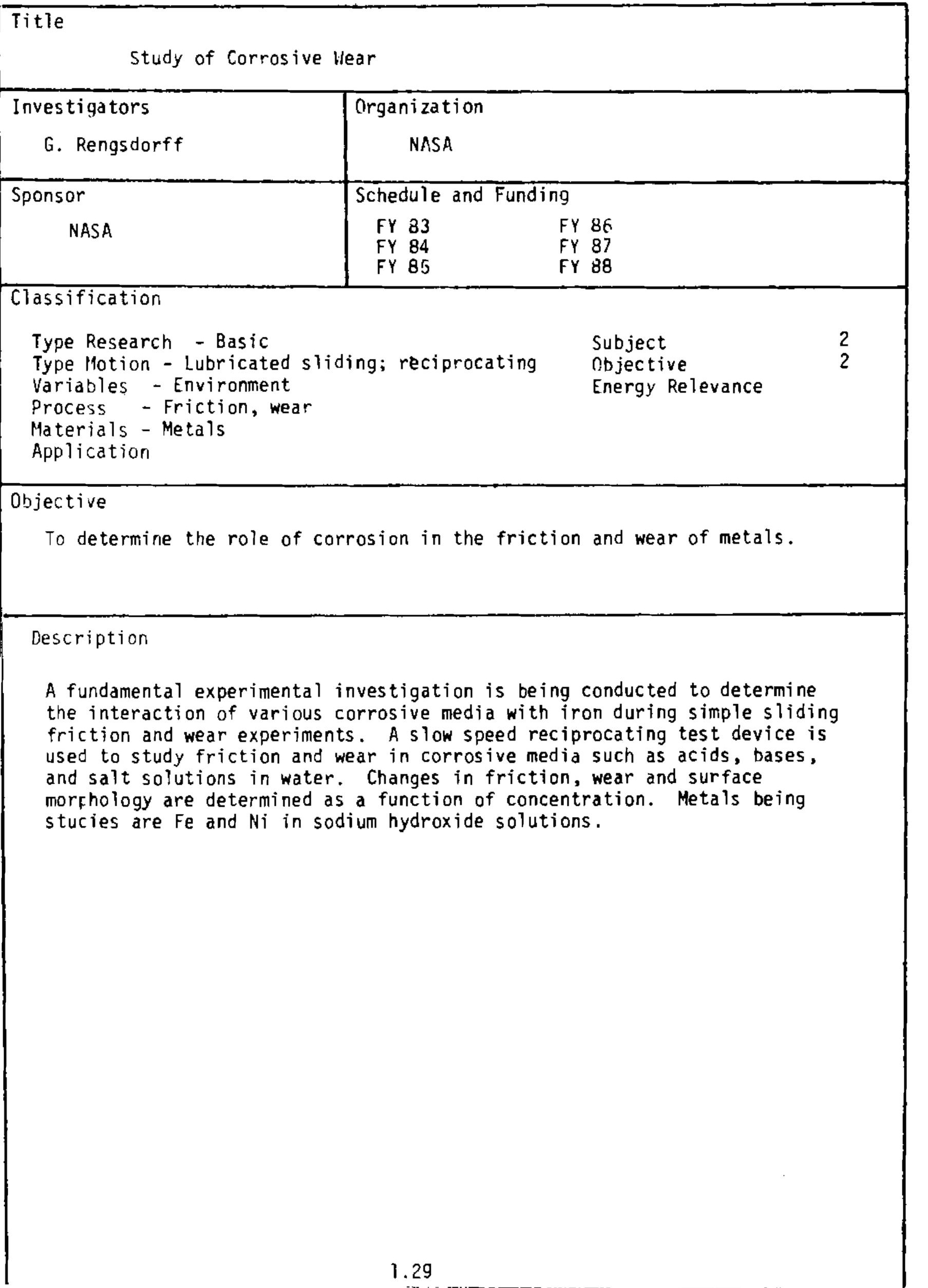


Title

Frictiona? Behavior with Amphorous Metais

\begin{tabular}{|c|cc|}
\hline $\begin{array}{c}\text { Investigators } \\
\text { K. Miyoshi }\end{array}$ & Organization \\
& NASA \\
\hline Sponsor & Schedule and Funding \\
NASA & FY 83 & FY 8 B \\
& FY 84 & FY 87 \\
& FY 85 & FY 88
\end{tabular}

Classification

Type Research- Basic

Type llotion - Unlubricated sliding

Variables - Physical properties, composition

Process - Friction, life

Materials - Metals

Application

Objective

To determine the friction and wear characteristics of metallic glasses.

Description

A. variety of studies have been conducted on metallic glasses. This improved friction behavior of such materials is due to their better mechanical properties. Friction coefficients are related to oxide species on the surface. For example, at temperatures above $500 \mathrm{C}$ the low friction is due to formation of $B N$ films. At lower temperatures other oxide films are formed which change the friction and wear behavior.

The work of Miyoshi has covered a broad scope of materials. In addition to the ferrites and silicon carbide, he is studying the performance of both oxide and nonoxide ceramics, amorphous metals, and interfacial adhesion of plasma deposited coatings. 


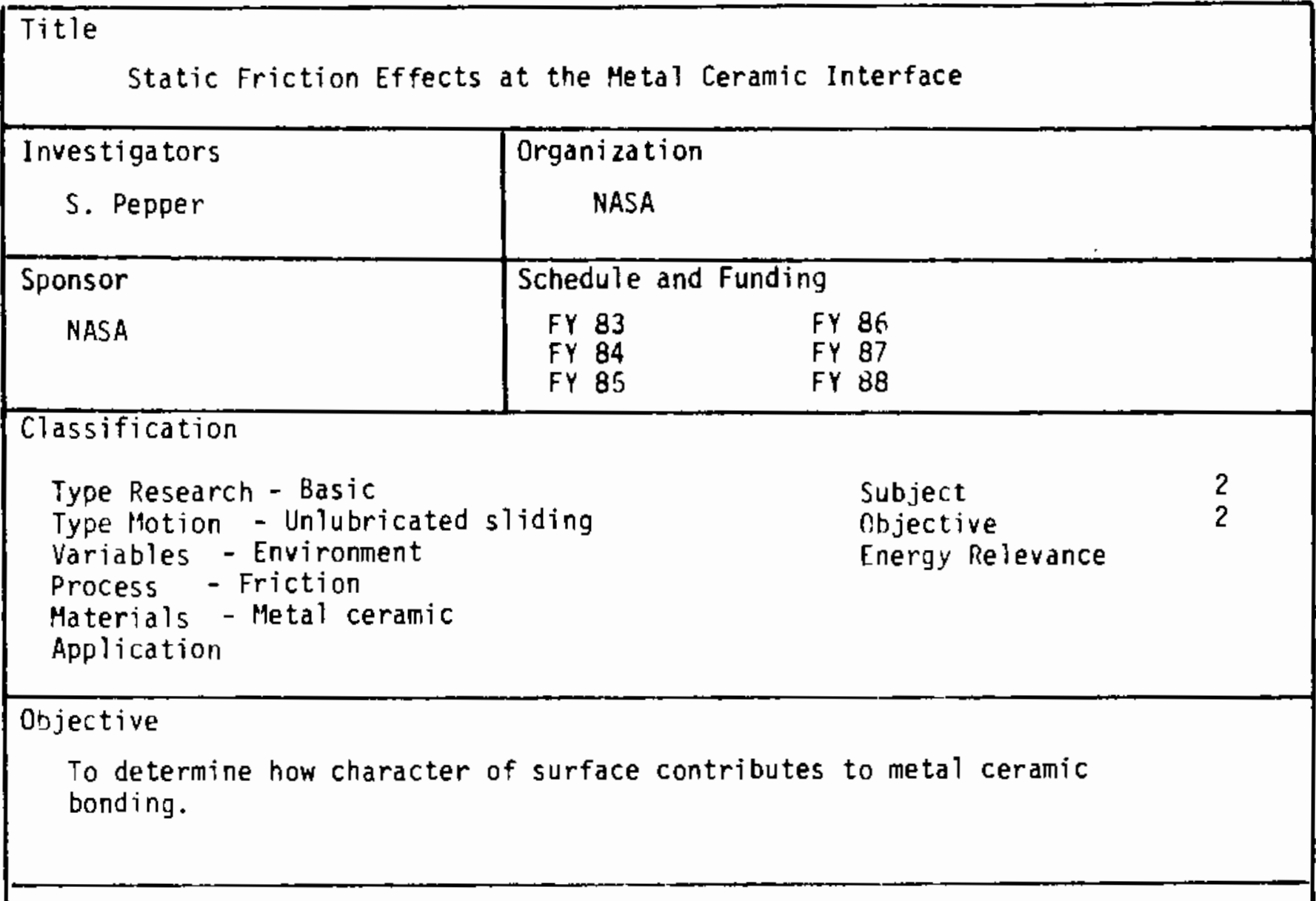

Descreption

Static friction studies in controlled atmospheres are being used to measure the bond strength between metals and ceramics. Adsorbed species such as $\mathrm{H}_{2}$ or $\mathrm{H}_{2} \mathrm{O}$ are found to lower friction substantially. Friction is reduced more on $\mathrm{SiO}_{2}$ than on $\mathrm{Al}_{2} \mathrm{O}_{3}$. 


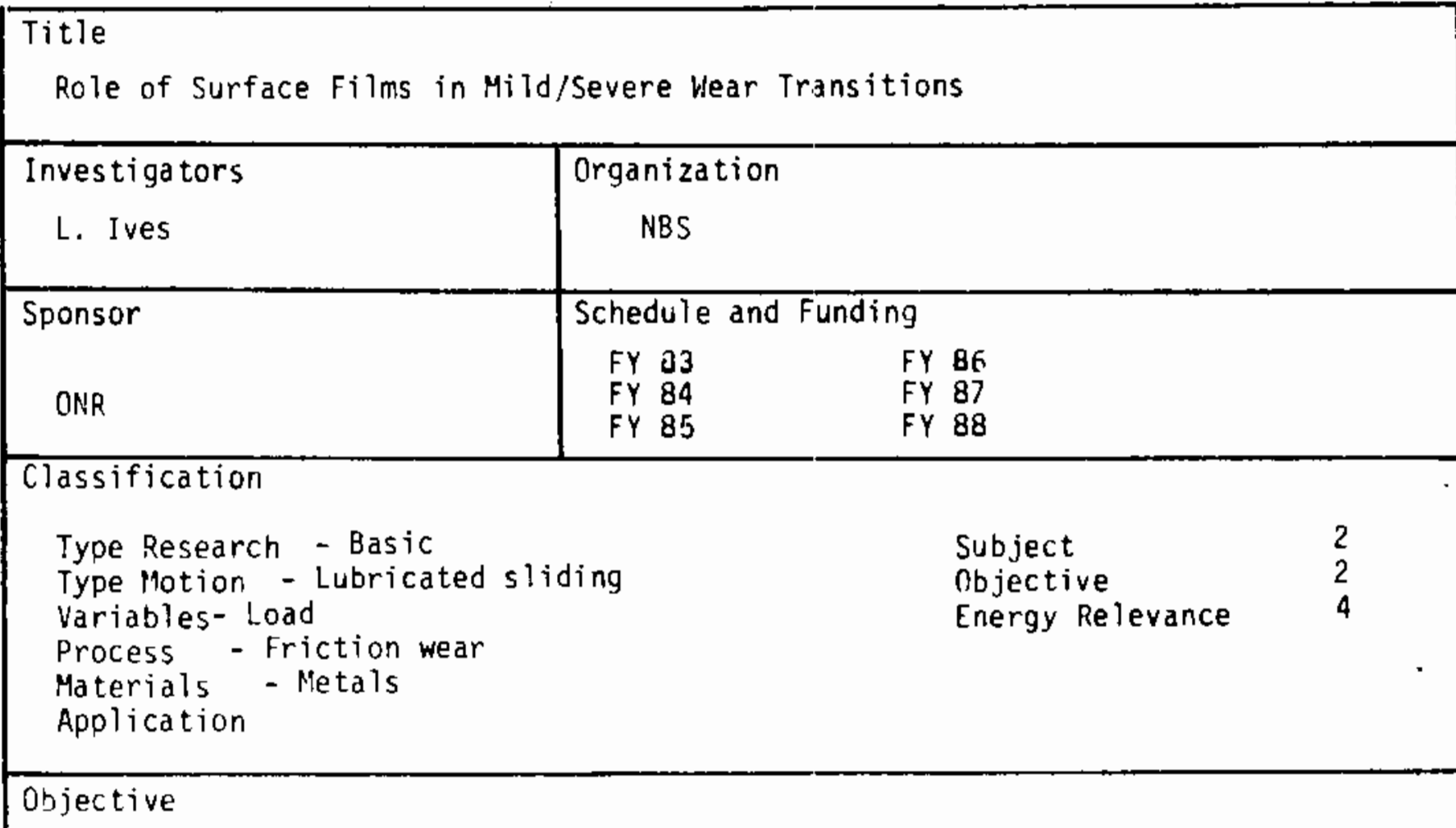

To study the effect of materials properties on transitions

Description

SEM and TEM are being used to study microstructure effects which occur at the mild/severe wear transition and how material properties affect it. 


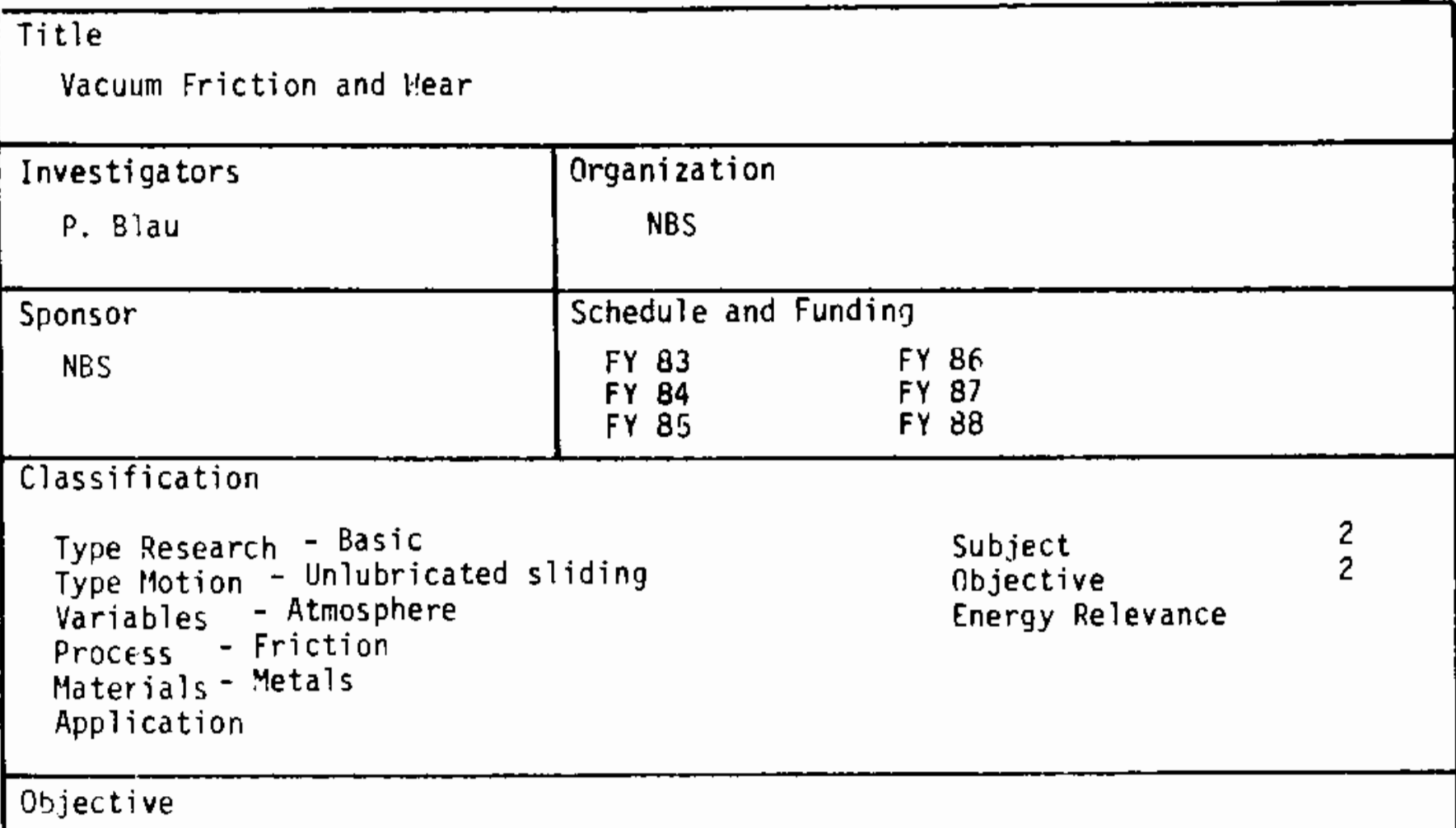

To study the effect of controlled environments on friction and wear problems.

\section{Description}

Work is nearing completion on construction of a controlled atmosphere tribometer with high vacuum capabilities. Hithin the next four months, computer interfacing of the device should be completed. Studies of surface contamination effects and controlled atmospheres on 1ong-term transitions in wear mode and on running-in behavior are planned, to isolate the influence of combinatory factors responsible for net friction and wear values. Changes in the contact conditions during the tests (particularly the gas atmosphere composition) are also planned for systematic study. 


\section{Title \\ Effects of Coatings on Hardness/Friction Relationships}

\begin{tabular}{|c|cc|}
\hline $\begin{array}{c}\text { Investigators } \\
\text { P. Blau }\end{array}$ & Organization & \\
& NBS & \\
\hline Sponsor & Schedule and Funding \\
NBS & FY 83 & FY 86 \\
& FY 84 & FY 87 \\
& FY 85 & FY B8 \\
\hline
\end{tabular}

Classification

Type Research - Basic

Type Motion - Reciprocating

Variables

Process

- Friction

Y 8 G

FY 88

Materials - Metals Coatings

Subject

Objective

Energy Relevance

2

2

Application

\section{Objective}

To understand the relationship between hardness and deformational frictional behavior.

Description

l'etal and nonmetal coatings are applied to pure well characterized metal surfaces. Friction and wear is measured and correlated with quasi states and scratch hardness values. 


\section{Title}

$\mathrm{Bi}-$ Directional Effects in the "Run-in Process"

\begin{tabular}{|l|ll|}
\hline $\begin{array}{l}\text { Investigators } \\
\text { P. Blau }\end{array}$ & $\begin{array}{c}\text { Organization } \\
\end{array}$ & NiES \\
\hline Sponsor & Schedule and Funding \\
ONR & FY 83 & FY 86 \\
& FY B4 & FY 87 \\
& FY 85 & FY 88 \\
\hline
\end{tabular}

Classification

Type Research -Basic

Type llotion - Reciprocating Sliding

Subject

Objective

2

Variables -

Process - Friction

Energy Relevance

Materials - Metals

Application

Objective

To gain an understanding of run-in processes and factors which affect it.

\section{Description}

Point by point friction measurements are made in a reciprocating pin on disk machine from the initiation of sliding until the friction coefficient stabilizes. Friction coefficients at identical points in successive traverses (botr reversing and continuous) are compared using copper and iron base alloys. Changes in friction are correlated with structural changes taking place in the alloy and comparisons made between the two sliding motions.

In a second project the effect of surface contamination is being studied. Controlled atmospheres are being used to change the nature of the surface contémination. 


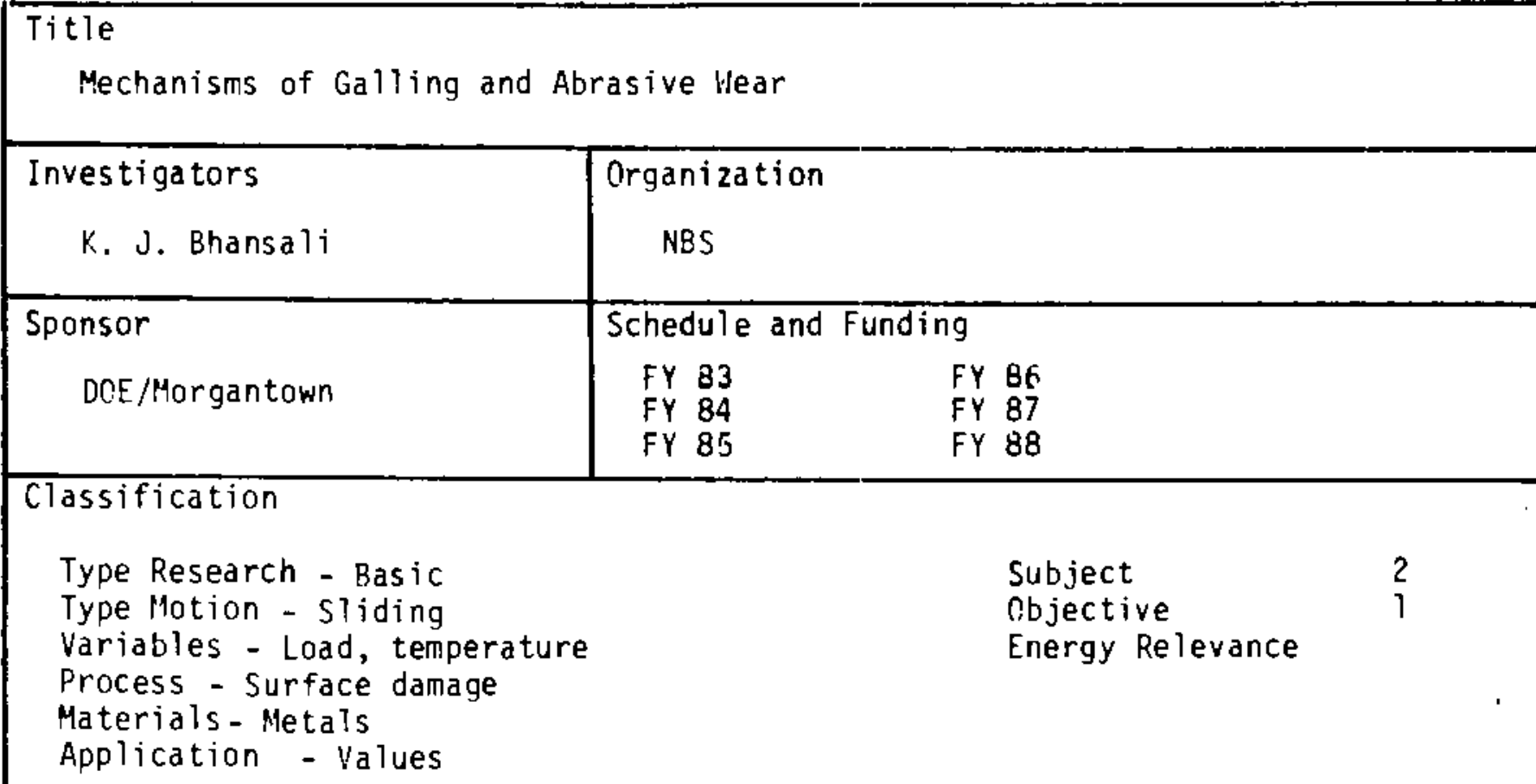

Objective

To obtain a better understanding of the affect of material properties on galling severity.

Description

A study is being conducted to gain a better understanding of galling processes in metals. As a first step in the study, it was necessary to determine a method of measuring the severity of galling.. A variety of techniques were investigated. It was found that changes in galling surface damage could be measured by changes in surface topography. The best measures were maximum peak to valley roughness and displaced volume. An instrument is presently being constructed to measure these quantities for test specimens.

The maximum peak to valley roughness ( $\left.P_{t}\right)$ is used to investigate the effects of a number of material, design and operating variables on galling. Variables studies are load, finish, alignment, area, shape, and a variety of material properties such as stacking fault energy, microstructure, hardness, elongation, work hardening index and oxide films. 


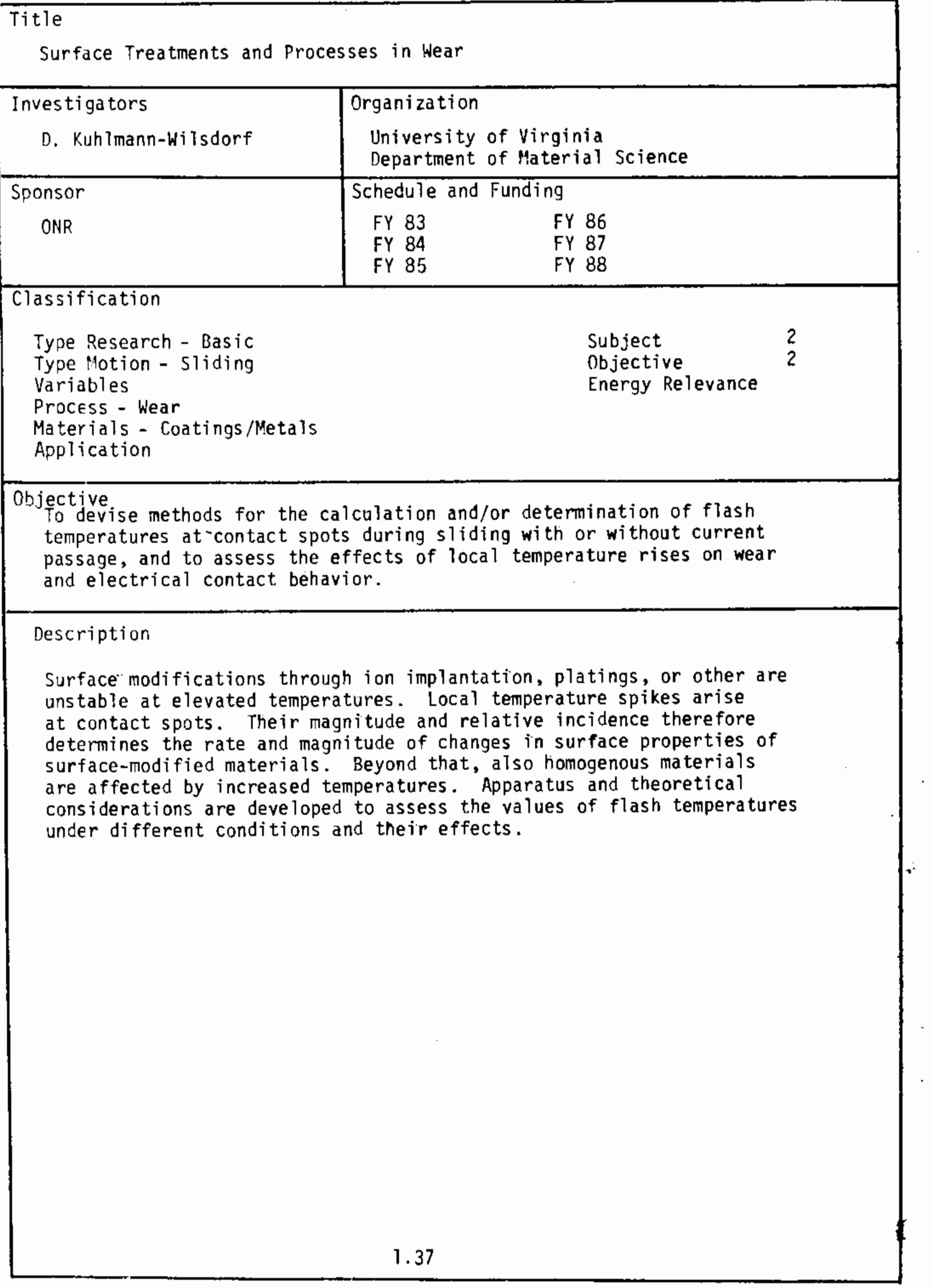




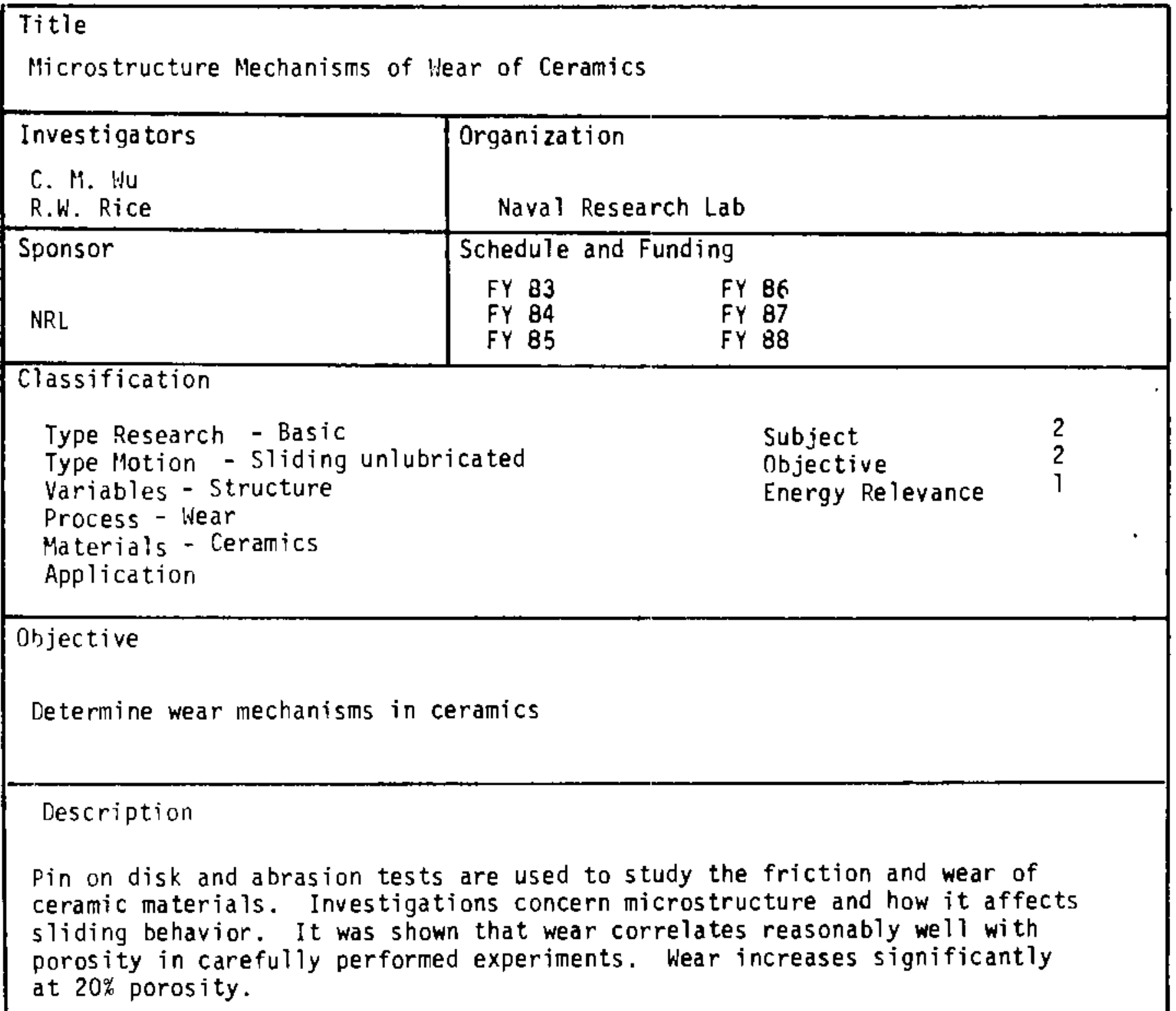


Title
Friction and Wear Study of Composites: Microstructura] Effects

\begin{tabular}{|l|ll|}
\hline Investigators & Organization \\
N.P Suh et a1 & MIT \\
\hline Sponsor & Schedule and Funding \\
ONR & FY 83 & FY 86 \\
& FY 84 & FY 87 \\
& FY 85 & FY 88 \\
\hline
\end{tabular}

Classification

Type Research - Basic

Type llotion - Sliding Dry

Variables -

Process - Friction, wear

Materials - Polymer composites

Application
Subject

Objective

Energy Relevance

object've

To understand wear mechanisms in composites.

Description

According to the Delamination Theory of Wear, Microstructures have significant

effects on friction and wear behavior of materials. It is shown that fibers oriented perpendicular to the surface wear the least, and that matrix material and structure affects both friction and wear behavior. In this talk, the tribological behavior of graphite fiber/polyurethane composites and perlitic steels will be presented including mechanisms of wear and friciion of these materials. Then, an analytical solution for wear of graphite reinforced polyurethane will also be described which predicts the experimentally determined wear rates quite well.

An analytical solution was not presented. 


\section{Title \\ Quantitative Correlations Petween Microstructural Parameters and \\ Tribological Behavior in Several Alloy Systems}

\begin{tabular}{l|ll}
$\begin{array}{l}\text { Investigators } \\
\text { P. J. Blau }\end{array}$ & Organization \\
A. W. Ruff & National Bureau of Standards \\
\hline Sponsor & Schedule and Funding \\
& FY 83 & FY 86 \\
ONR & FY 84 & FY 87 \\
& FY 85 & FY 88
\end{tabular}

\section{Classification}

Type Research - Basic

Type llotion - Sliding dry

Variables - Structure, Physical properties

Process - Wear

Materials - Metals

Application -
Subject

Objective

Energy Relevance
2

2

Objective

To correlate wear with the metalurgical properties of materials.

Description

Wear and friction studies are carried out with several alloy systems.

Correlations are attempted with such parameters as microstructure, hardnessdepth spectrum, grain size and others. 


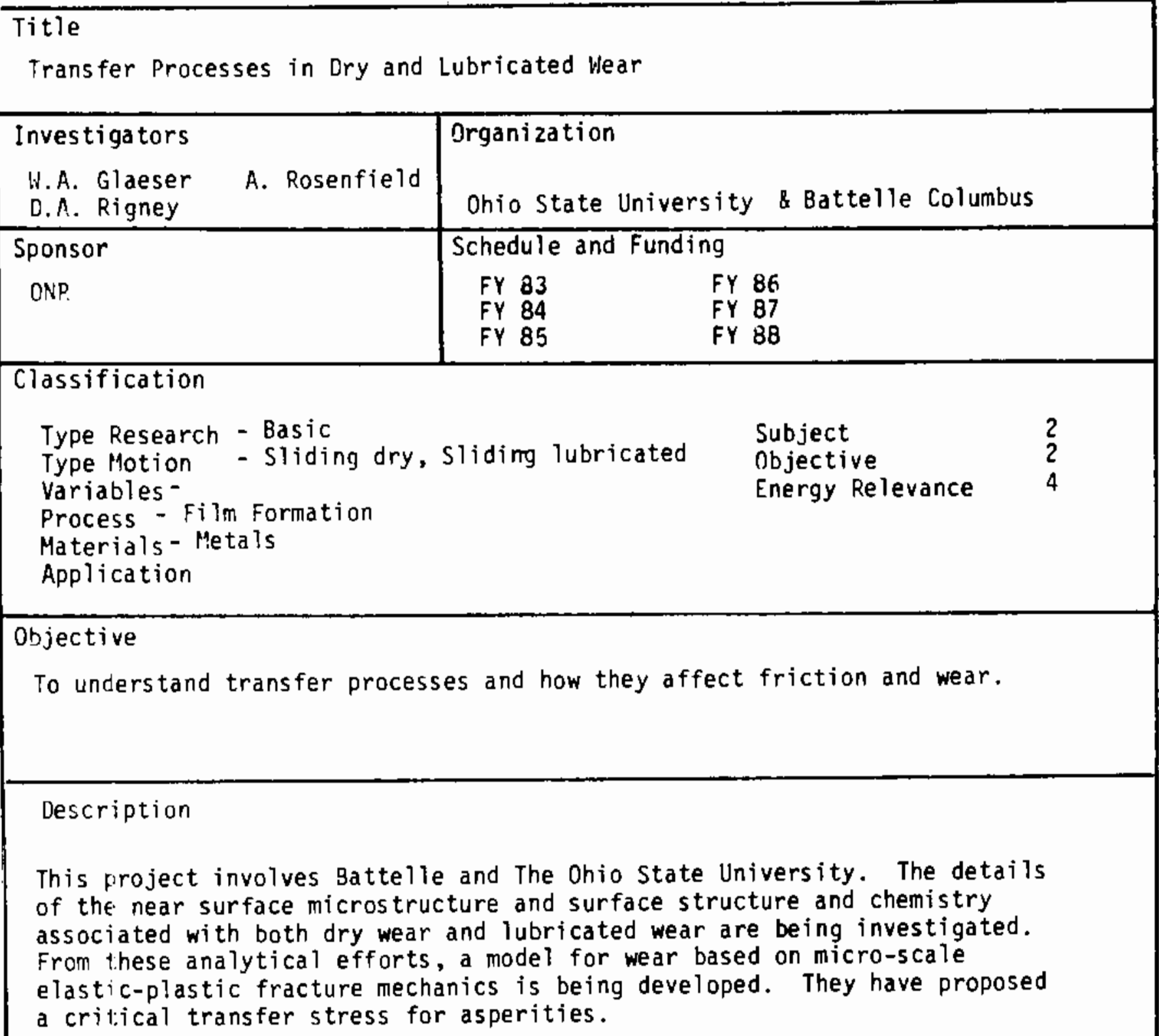




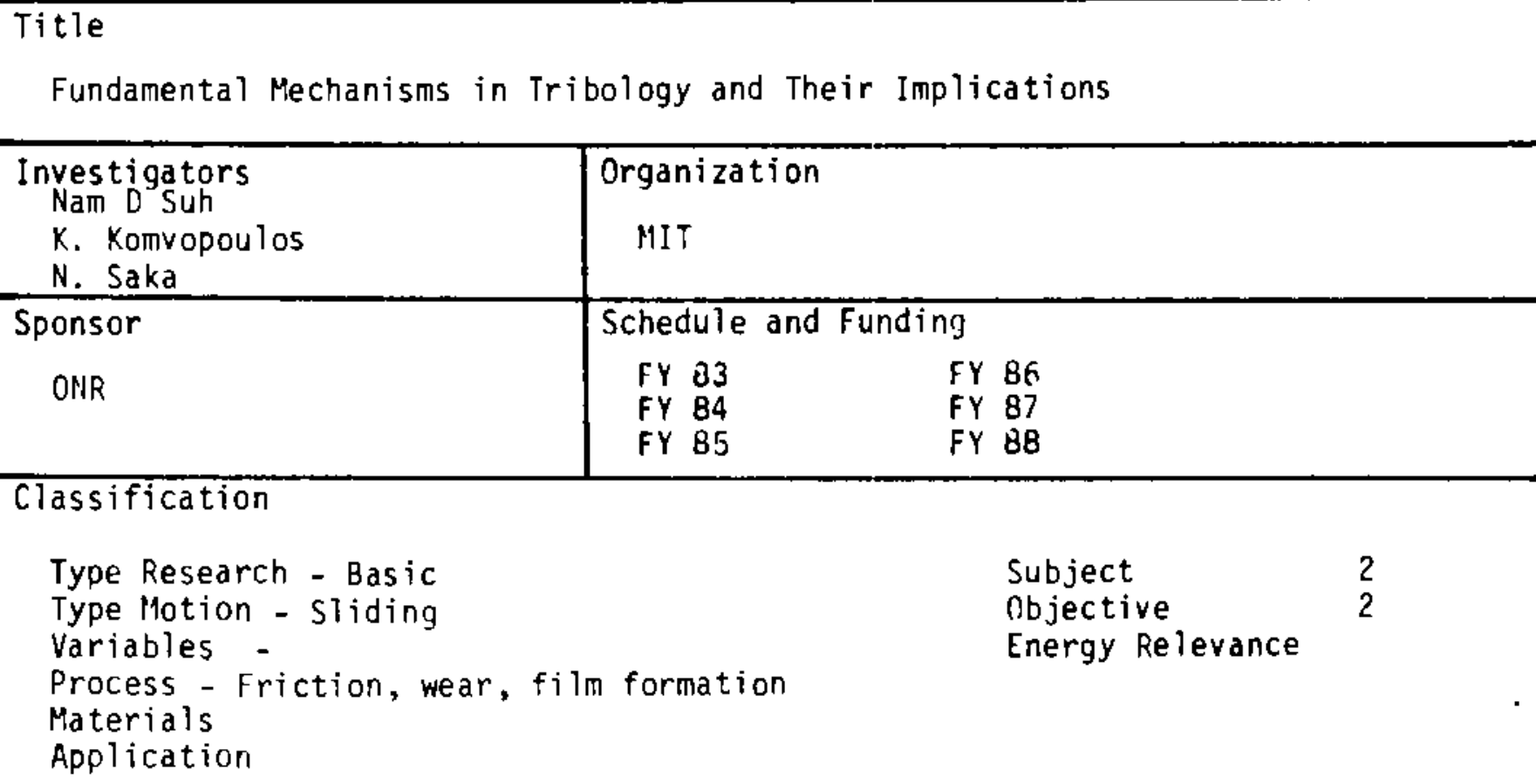

objective

To elucidate the basic mechanisms of friction and wear and to use this information to solve field problems.

Description

This research work is done to elucidate the basic mechanisms of friction and wear between sliding surfaces. The mechanism of subsurface crack propagation will be studies as a means of clarifying the relationship between friction and wear.

The authors see wear and surface damage as a material response to frictional behavior at the surface.

The latest work studies the role of oxide film. They are proposing to find a lubricant additive which forms hard wear resistant films - rather than soft films. 


\begin{tabular}{|c|c|}
\hline Title & \\
\hline Fretting Sur & Amplitude Slip \\
\hline Investigators & Organization \\
\hline Paul Kennedy & Naval Air Development Center \\
\hline Sponsor & Schedule and Funding \\
\hline NADC & $\begin{array}{l}\text { FY } 83 \\
\text { FY } 84 \\
\text { FY } 85\end{array}$ \\
\hline
\end{tabular}

Classification

Type Research - Basic

Type llotion - Reciprocating

Variables - Distance

Process - Surfaced damage, fretting

Subject

Objective

Energy Relevance

Materials - Metals

Application -

Objective

To determine the effect of slip amplitude on fretting damage.

Description

Fretting tests are run at a variety of slip amplitudes with different materials. Damage and chemical changes are noted as a function of ampli tude. 


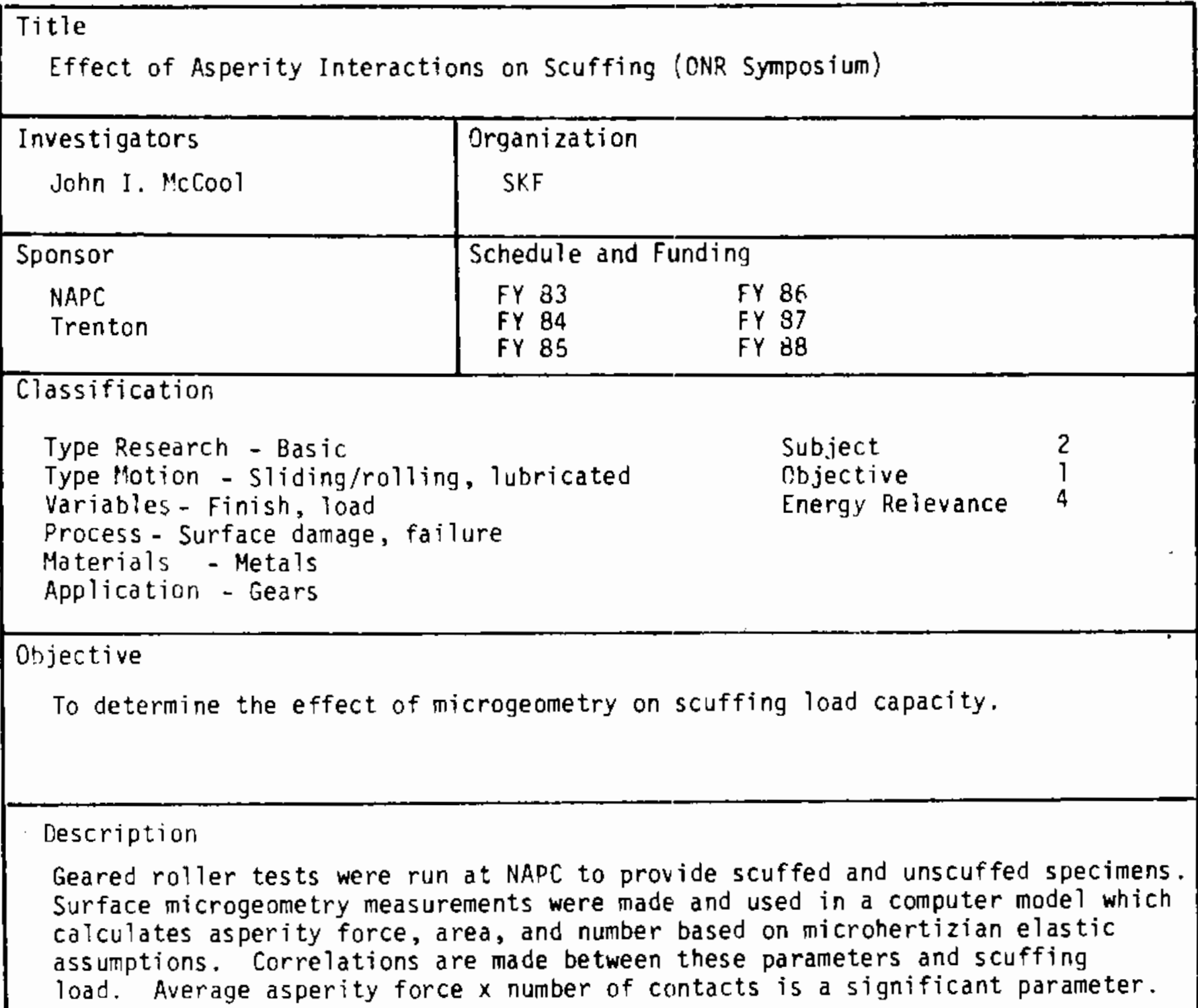




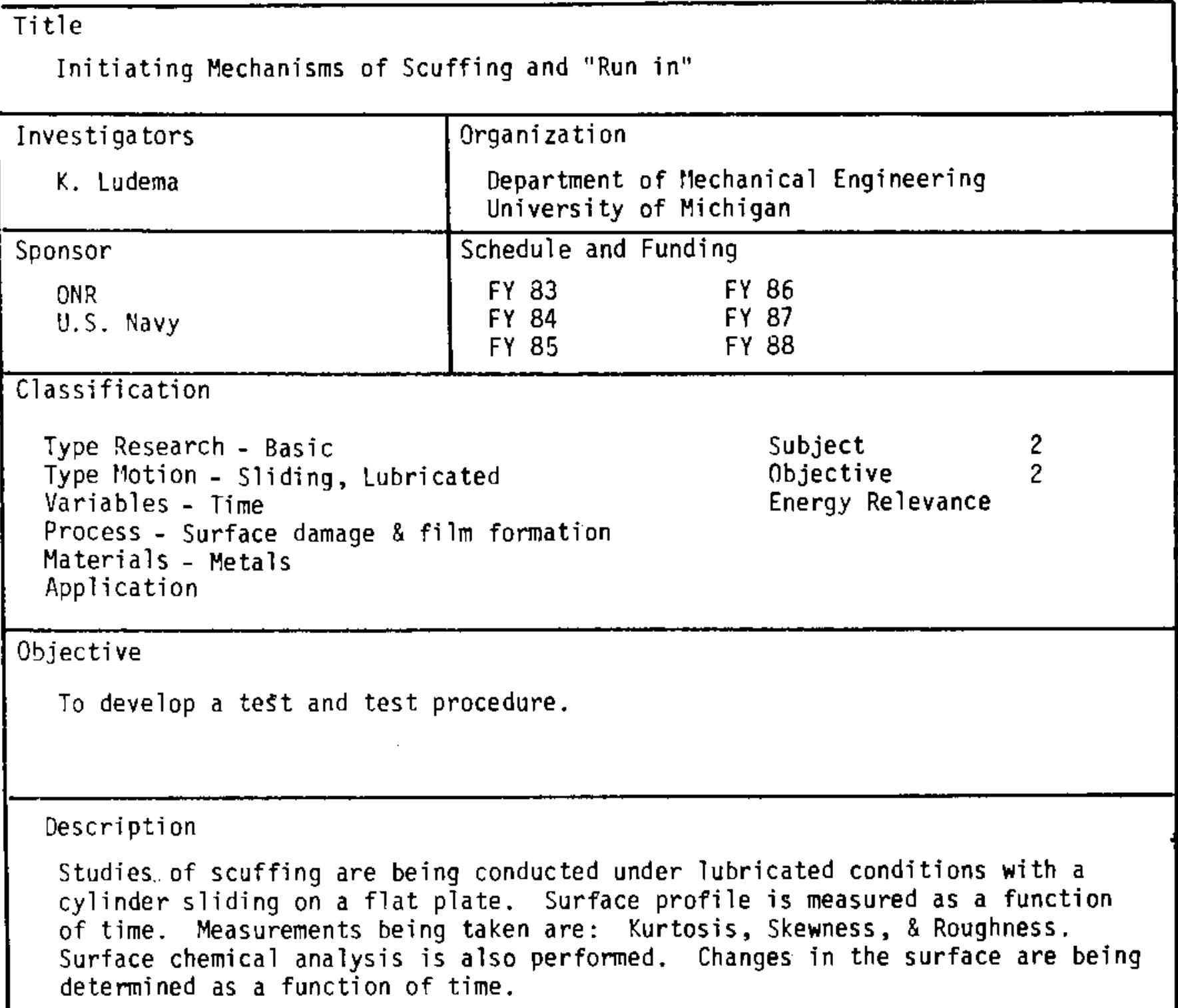


Title

Therma? Phenomena in Tribology

\begin{tabular}{l|ll}
\hline Investigators & $\begin{array}{l}\text { Organization } \\
\text { Ward 0. Winer }\end{array}$ & $\begin{array}{l}\text { School of Mechanical Engineering } \\
\text { Georgia Institute of Technology }\end{array}$ \\
\hline Sponsor & Schedule and Funjing \\
National Science Foundation & FY 83 & FY 86 \\
& FY 84 & FY 87 \\
& FY 85 & FY 88
\end{tabular}

Classification

Type Research - B Basic

Type llotion - Variable

Variables - Numerous

Process - Surface Temperature

Materials - Open

Application - Various
Subject -3

Objective - 2

Energy Relevance - 1

\section{Objective}

To develop a basic understanding of selected problems associated with themal phenomena in tribosystems.

Description

The objective of this program will be to develop a basic understanding of selected problems associated with the thermal phenomend in tribosystems, utilizing the capability developed in this laboratory. The focal point for the research will be the determination of the role of frictional hotspots in wear and load capacity limitations of tribocontacts. A longer term objective is the systematic understanding of thermal phenomena in tribosystems.

Hotspots have already been observed in this laboratory in several tribosystems. What is now required, and proposed, is to quantify the temperatures and determine the transient dynamics of the notspots. These measurements can be made with a tribosystem already available in this laboratory with the addition of the scanning infrared camera required in this proposal. A high speed data acquisition system and a microcomputer is available but will require additional mass storage which is also requested in this proposal.

The optics of the requested IR system can scan an area approximately four millimeters on a side with an areal resolution of approximately 30 micrometer diameter. The $30 \mathrm{micrometer}$ areal resolution was chosen because the hotspot photographs indicate that is the typical hotspot size. 
Title

Transport Processes in the Contact Line Region

\begin{tabular}{|c|cc|}
\hline $\begin{array}{c}\text { Investigators } \\
\text { P.C. Wayner, Jr. }\end{array}$ & \multicolumn{2}{|c|}{ Organization } \\
& \multicolumn{2}{|c|}{ RPI-Chemical Engineering } \\
\hline Sponsor & Schedule and Funding \\
ARO-Mechanics & FY 83 & FY 86 \\
& FY 84 & FY 87 \\
& FY 85 & FY 88
\end{tabular}

Classification

Type Research - Basic

Type Motion - Lubricated sliding

Variables - Physical properties, chemical

Process - Lubrication

Materials - Fluid lubricants

Application properties

Subject

Objective

Energy Relevance
3

2

3

Objective

To study the physiochemical processes of wetting, and heat, mass, and momentum transport in ultra thin films.

Description

The physiochemical processes of wetting and heat, mass, and momentum transport in ultra-thin films which have a thickness $\delta<10-5$

(including the contact line region, $\delta \rightarrow 0$ ) are being studied. These processes are controlled by a gradient in the chemical potential which is a function of temperature, composition, and film thickness. In these thin film systems, experimental results have demonstrated that interfacial effects are magnified and that a small amount of a second component can cause dramatic changes in wetting and fluid flow. Therefore, a systematic study of the effect of changes in the bulk composition on wetting and transport processes in non-isothermal ultra-thin films is being performed. Since lubrication is a non-isothermal process, controlled heat transfer experiments are used so that the effects of temperature gradients are present.

Cur initial models emphasized the effect of the shape of the thin film on fluid flow and heat transfer. New models that include the combined effects of shape, composition and temperature gradients on fluid flow and mass transfer will be developed to describe these experimental results. Moreover, the effect of concentration on the shape of an equilibrium film needs to be modeled for reference. As soon as possible more sophisticated optical techniques based on polarized light should be used to measure the film profile and concentration gradient near the contact line where the thickness approaches a monolayer. For this purpose, an ellipsometer capable of viewing a small area is needed. 
Title

Elastostatic Charging of Plastics Sliding on Metals

\begin{tabular}{|c|c|}
\hline $\begin{array}{l}\text { Investigators } \\
\text { S.F. Murray } \\
\text { W. Holzhaver }\end{array}$ & $\begin{array}{l}\text { Organization } \\
\qquad \text { RPI-Mechanical Engineering }\end{array}$ \\
\hline Sponsor & Schedule and Funding \\
\hline ARo - Mechanics & $\begin{array}{l}\text { FY } 83 \\
\text { FY } 84 \\
\text { FY } 85\end{array}$ \\
\hline
\end{tabular}

Classification

Type Research - Basic

Type lotion - Unlubricated sliding

Variables

Process

Materials - Polymers

Application
Subject 3

objective 2

Energy Relevance

objective

To study the formation of transfer films and their effect on subsequent sliding behavior.

Description

The development of static charges on dielectric surfaces--as a result of contact or sliding motion--is a phenomenon which has been known since ancient times. Yet, even today our knowledge of the cause and significance of this effect is far from complete. The current trend toward the use of plastics and ceramics for both structural elements and tribological devices makes this subject very pertinent at the present time.

The work in progress in this laboratory deals with one very specific aspect of the problem; nemely, the formation of adherent transfer films and the effect of these films on subsequent sliding behavior and wear of the plastic. It has been well established that many plastics deposit a transfer film on metal surfaces during the initial stages of sliding the plastic against a metal. Sliding then becomes the case of bulk plastic sliding against a thin, transferred film of plastic on a metal substrate. Many investigators believe that the formation and durability of these transferred films is the key to effective sliding, particularly with certain plastics such as Teflon. While electrostatic charging may not have a significant effect on the adhesion of bulk solids, it could certainly play a major role in the formation and effective life of thin transfer films. 
Title

Three D Effects in Fluid Film Lubrication

\begin{tabular}{|c|cc|}
\hline $\begin{array}{c}\text { Investigators } \\
\text { C. Ettles }\end{array}$ & Organization \\
& \multicolumn{2}{|c|}{ Rensselaer Polytechnic Inst. } \\
\hline Sponsor & Schedule and Funding \\
NSF-Mechanical Systems & FY 83 & FY 86 \\
& FY 84 & FY 87 \\
& FY 85 & FY 88 \\
\hline
\end{tabular}

Classification

Type Research - Basic

Type Motion-Lubricated sliding

Variables

Process -

Materials - Fluid Lubricants

Application

Objective

To include in fluid film bearing theory the differential temperature distributions in the $f i l m$.

Description

As a result of different shear rates across the fluid, film temperatures vary and heat disapation is different at opposing surfaces. An analytical program is under way to determine how this affects bearing temperatures ard performance. Results are compared with literature data on bearing temperature distributions. 


\section{Title}

Asperity Interaction in Mixed Lubrication

\begin{tabular}{l|ll} 
Investigators & Organization \\
C. Pan & & \\
\hline Sponsor & Schedule and Funding \\
NSRDC-Annapolis & FY 83 & FY 86 \\
& FY 84 & FY 87 \\
& FY 85 & FY 88
\end{tabular}

Classification

Type Research - Basic

Type Motion - Lubricated sliding

Variables - Finish, geometry

Process - Lubrication

Subject

Objective

Energy Relevance

3

Materials- Metals

Application - Fluid film bearings

\section{Objective}

To assist with analysis of asperity interaction model development of sliding surface bearings operating in mixed lubrication.

\section{Description}

The study shall (A) provide procedure to incorporate moment balance, cavitation conditions, and stochastic asperity interactions into two dimensional model of thrust bearing with longitudinal roughness, (B) develope procedures to include end leakage into three dimensional model, (C) introduce skewness in roughness features, and (D) develop physical means to measure and characterize realistic interactive surfaces as they relate to developed models. 
Title

Thermomechanical Effects in High Speed Seal Rubs

\begin{tabular}{|c|cc}
\hline $\begin{array}{c}\text { Investigators } \\
\text { F.E. Kennedy }\end{array}$ & $\begin{array}{c}\text { Organization } \\
\text { Dartmouth College }\end{array}$ \\
\hline Sponsor & & \\
NASA & Schedule and Funding \\
& FY 83 & FY 86 \\
& FY 84 & FY 87 \\
FY 85 & FY 88
\end{tabular}

Classification

Type Research -Applied

Type Motion - Unlubricated Sliding

Variables - Velocity

Subject

Objective

Process - Wear, Abrasion

Energy Relevance

Materials - Metals

Application - Seals (gas path)

Objective

To gain a better understanding of thermal and mechanical phonomena associated with high speed rubs.

Description

Recent attempts to improve the efficiency of aircraft gas turbine engines have led to the reduction of clearances in the many gas path seals used in modern engines. Reductions in seal clearances increase the likelihood that rubbing will occur between stationary seal components and high speed rotating components. This project aims at a better understanding of the themal and mechanical phenomena associated with high speed seal rubs and the material and design parameters which influence these phenomena. The experimental phase of the project employs a unique singlepass rub test device build specifically for this purpose. The analytical phase of the project relies on the use of finite element programs suitable for nodelling the temperatures and deformations in high speed rubbing contiacts. 


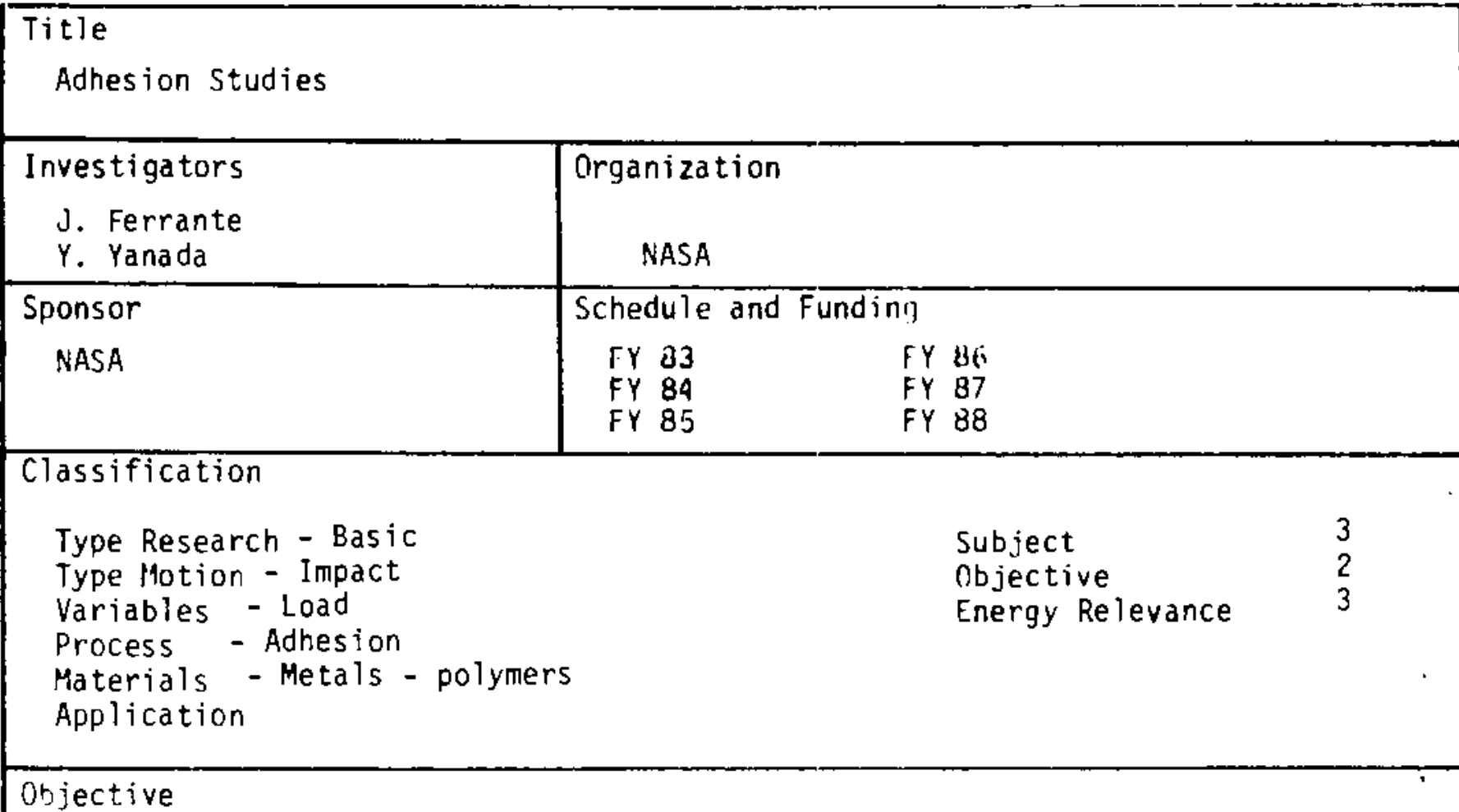

To understand metal/metal and metal/polymer adhesion

Description

Although metallic adhesion has played a central part in much tribological speculation, few quantitative theoretical calculations are available. This is in part due to the difficulties involved in such calculations and in part due to the fact that the theoretical physics community is not particularly involved with tribology. The calculations currentiy involved in metallic adhesion show that this can be generalized into a scaled universal relationship. It is also shown that relationships exist to other types of covalent bonding such as cohesive, chemisorptive, and molecular bonding. A simple relationship between surface energy and cohesive energy is offered. This relationship can be used to predict metal/metal and metal/polymer adhesion. A microtensile test has been set up to correlate theoretical with experimental metal polymer adhesion. 
Title

Traction Model Development

\begin{tabular}{|c|c|}
\hline $\begin{array}{c}\text { Investigators } \\
\text { J. } \mathrm{McCOOl}\end{array}$ & $\begin{array}{l}\text { Organization } \\
\text { SKF }\end{array}$ \\
\hline Sponsor & Schedule and Funding \\
\hline WPAFB-ML & $\begin{array}{ll}\text { FY } & 83 \\
\text { FY } & 84 \\
\text { FY } & 85\end{array}$ \\
\hline
\end{tabular}

Classification

Type Research - Applied

Type Motion - Lube Slide/Roll

Variables

Process - Lubrication

Subject

Objective

Energy Relevance 4,6

Materials - Fluid Lubes

Application

Objective

Develop improved-traction models as subroutines for advanced dynamic computer models.

Description

Currently available traction models are being assessed for their deficiencies in providing accurate reliable traction values for advanced aerospace

lubricants. Improved traction models will be developed which handle the varied properties of advanced synthetic hydrocarbon and fluorinated base stocks. The goal is to develop traction models for simulating the operation/performance of lubricated components. 
Title

Thermomechanical Effects in Sliding !ear

\begin{tabular}{|c|c|}
\hline $\begin{array}{l}\text { Investigators } \\
\qquad \text { F.E. Kennedy }\end{array}$ & $\begin{array}{l}\text { Organization } \\
\text { Dartmouth College }\end{array}$ \\
\hline Sponsor & Schedule and Funding \\
\hline ONR & $\begin{array}{ll}\text { FY } & 83 \\
\text { FY } & 84 \\
\text { FY } & 85\end{array}$ \\
\hline
\end{tabular}

Classification

Type Research - Basic

Type Motion - unlubricated sliding

Subject

Objective

3

Variables-Load, velocity, temp., phy properties,

Energy Relevance 4

Process - Failure composition.

Materials - Metals

Application - Seals

\section{Objective}

To determine the contact conditions in mechanical face seals and the influence of those conditions on seal failure.

\section{Description}

The purpose of this project it to get a better understanding of the modes of failure of mechanical face seals and of the design parameters which affect them. An experimental effort is aimed at determining the contact conditions (size and number of contact spots, contact pressure, and temperature) which occur in actual face seals. A unique contact probe has been designed and used for this purpose. The influence of seal surface waviness and roughness on contact conditions is also being studied. A concurrent analytical effort, using finite element technique, is studying the temperature and stress distribution near the contact patches on the seal surface. 


\section{Title}

Three-Dimensional Model of a Moving Asperity for Thermal Cracking

\begin{tabular}{|l|ll|}
\hline $\begin{array}{l}\text { Investigators } \\
\text { F. Ju }\end{array}$ & $\begin{array}{l}\text { Organization } \\
\text { University of New Mexico }\end{array}$ \\
\hline $\begin{array}{l}\text { Sponsor } \\
\text { ONR }\end{array}$ & $\begin{array}{c}\text { Schedule and Funding } \\
\text { FY } 83\end{array}$ & FY 86 \\
& FY 84 & FY 87 \\
FY 85 & FY 88 \\
\hline Classification & & \\
Type Research - Basic & & Subject \\
Type Motion - Sliding & & Objective \\
Variables - Time, load & & \\
Process - Stress, temperature, Surface damage & \\
Materials - Metals & & \\
Application- Seals & &
\end{tabular}

\section{Objective}

To study failure resulting from excessive frictional heating in sliding.

\section{Description}

Analytical model predicts mechanical and thermal stresses of a moving asperity. Results show that the maximum stress occurs at a depth .1 the asperity size. Fracture occurs there, near the trailing edge of the asperity. 


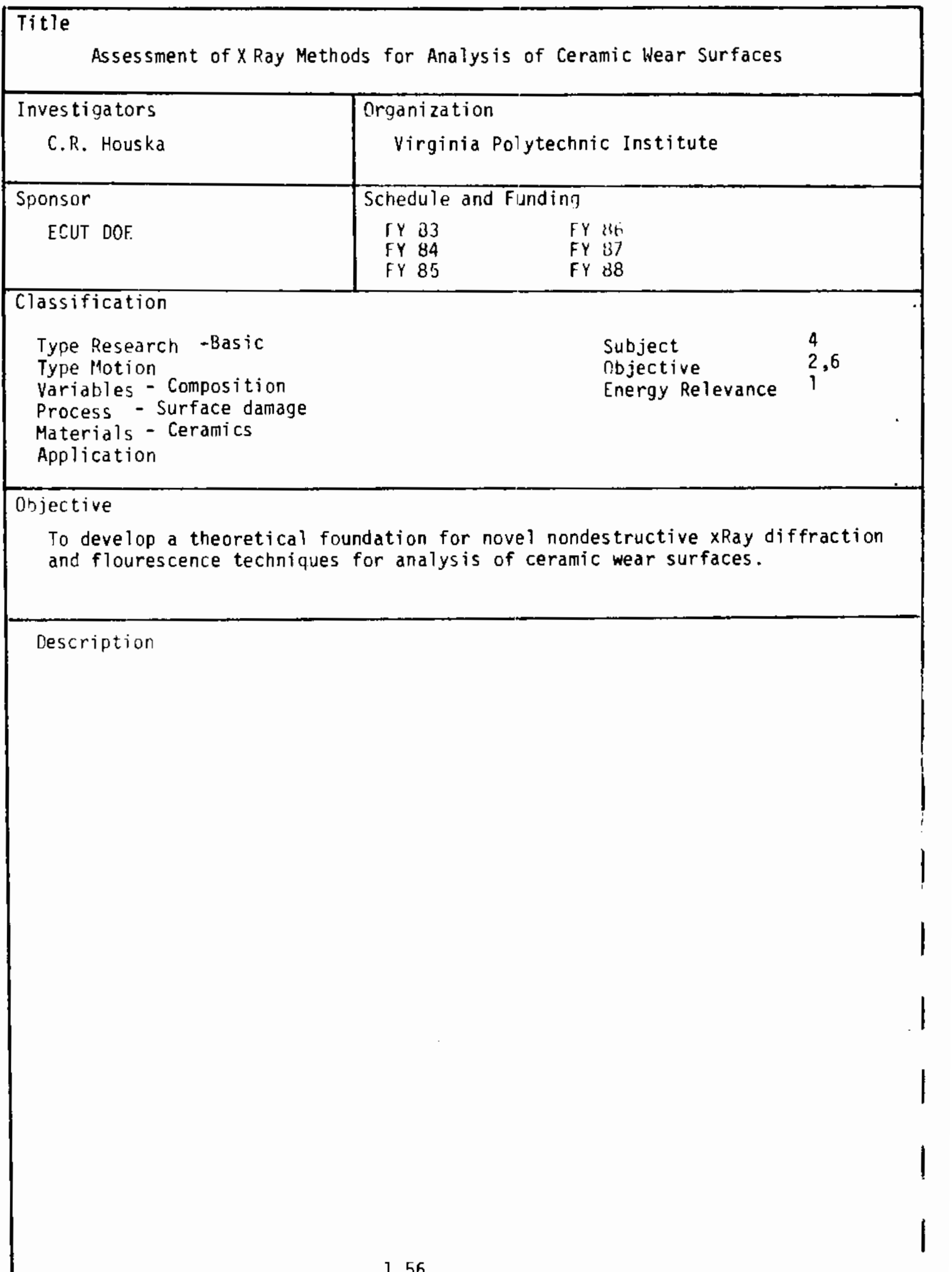




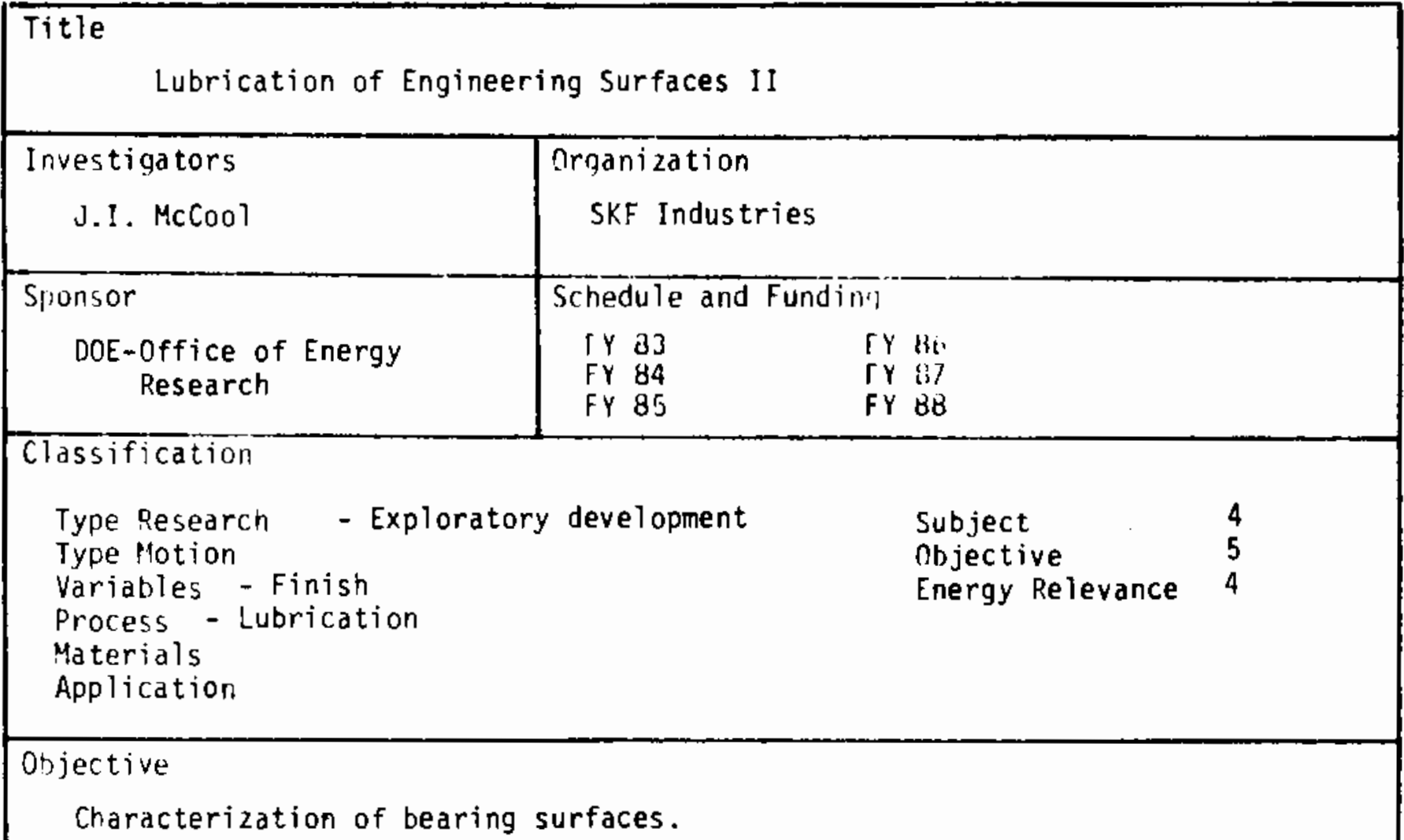

\section{Description}

The objective is to study on the characterization of bearing surfaces for applications in the design of high performance traction drives, gears, bearings, etc.. Software developed in a previous project uses a simulation mode 1 to determine the real contact area, load, and asperity pressure when two inicroscopically rough surfaces are brought into contact. These values measure the severity of the contact and hence the propensity for wear and surface fatigue. The model is driven by nine parameters (bispectral moments) which describe the statistical microgeometry of a general anisotropic surface. The model assumes that the surface heights, shapes, and curvatures follow a multidimensions 1 gaussian distribution and that the surface asperities are mechanically and statistically independent. In the current project the effort has been devoted to: 1) quantification of the random and systematic errors incurred in processing stylus profile data to obtain the nine surface parameters as functions of the processing parameters, e.g., sampling frequency and sample length; 2) assessing the effect of the multidimensiona gaussian assumption on predictions of the contact conditions; 3) assessing the effect of the assumption of mechanical and statistical independence of asperities; and 4) developing rules for setting a filter pass band for surface profile processing to yield values of the roughness parameters appropriate for specific applications. 


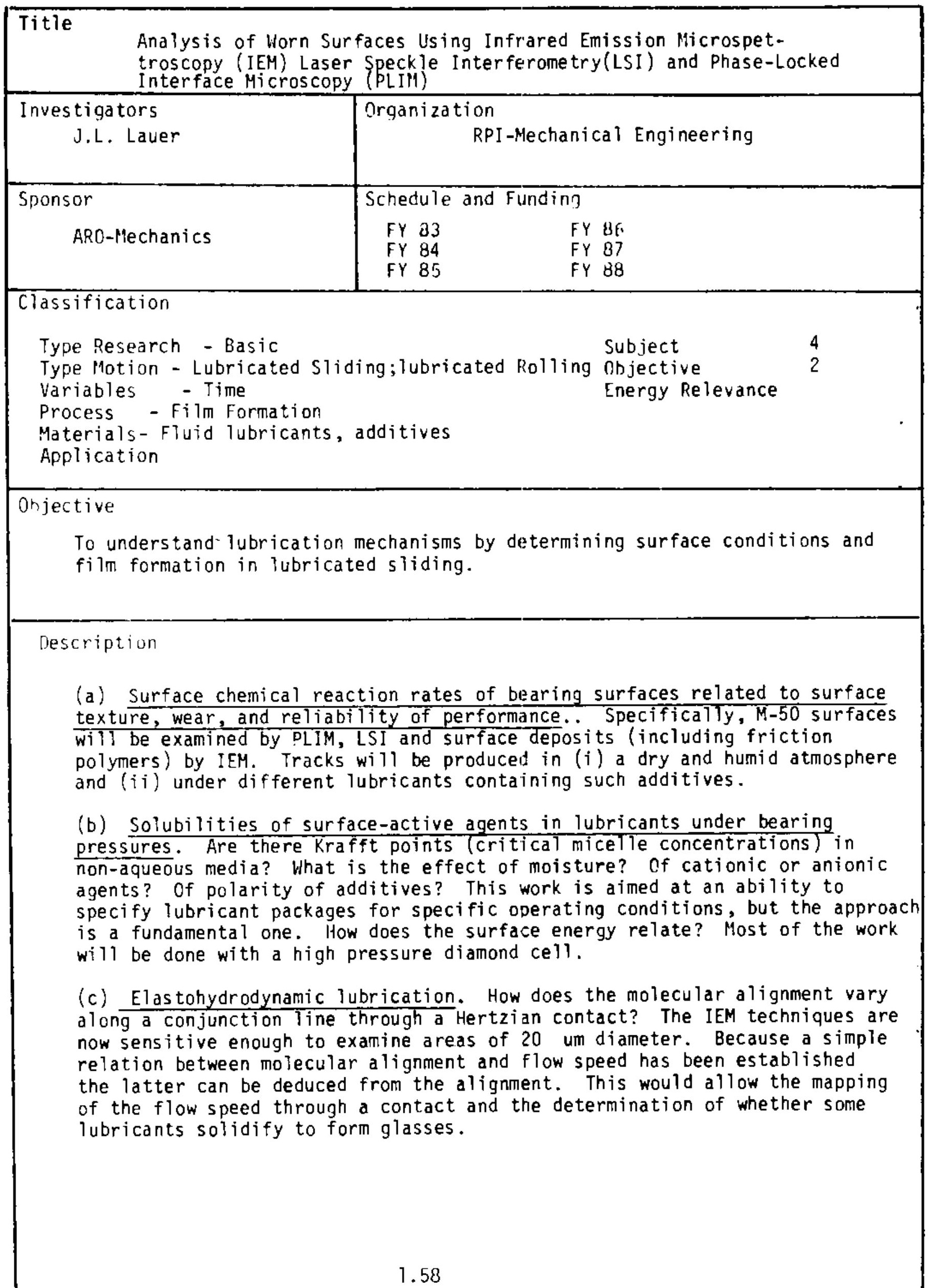




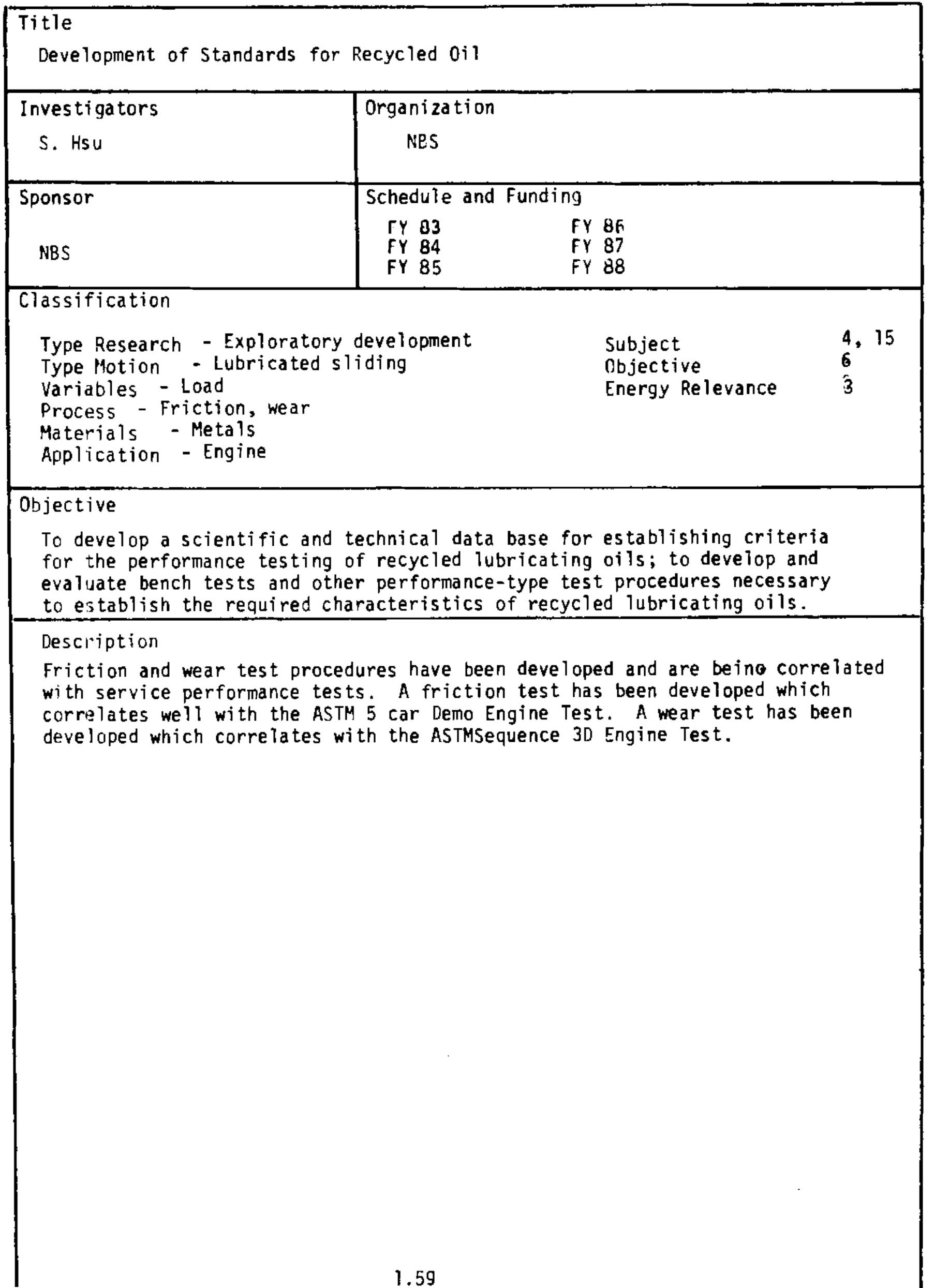


Title

Measurement of Dynamic Hardness

\begin{tabular}{|c|c|}
\hline $\begin{array}{l}\text { Investigators } \\
\text { R. Polvani }\end{array}$ & $\begin{array}{c}\text { Organization } \\
\text { NBS }\end{array}$ \\
\hline Sponsor & Schedule and Funding \\
\hline NBS & 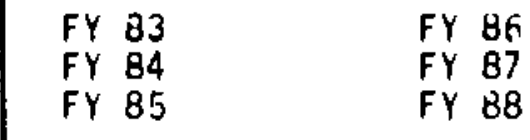 \\
\hline
\end{tabular}

Classification

Type Research - Explordtory Developmient

Subject

Objective

4

Type llotion - Impact

Energy Relevance

Variables

Process - Surface Stresses

Materials - Metals

Application

Objective

Deveiop and construct a machine to measure dynamic hardness.

Description

An electro-magnetic device has been set up to measure dynamic hardness. Contact times can be varied from $10^{-4} \mathrm{sec}$ to hours. A given force/time wave/ovm is applied and the penetration displacement is observed. Results are now being assembled on different materials. 


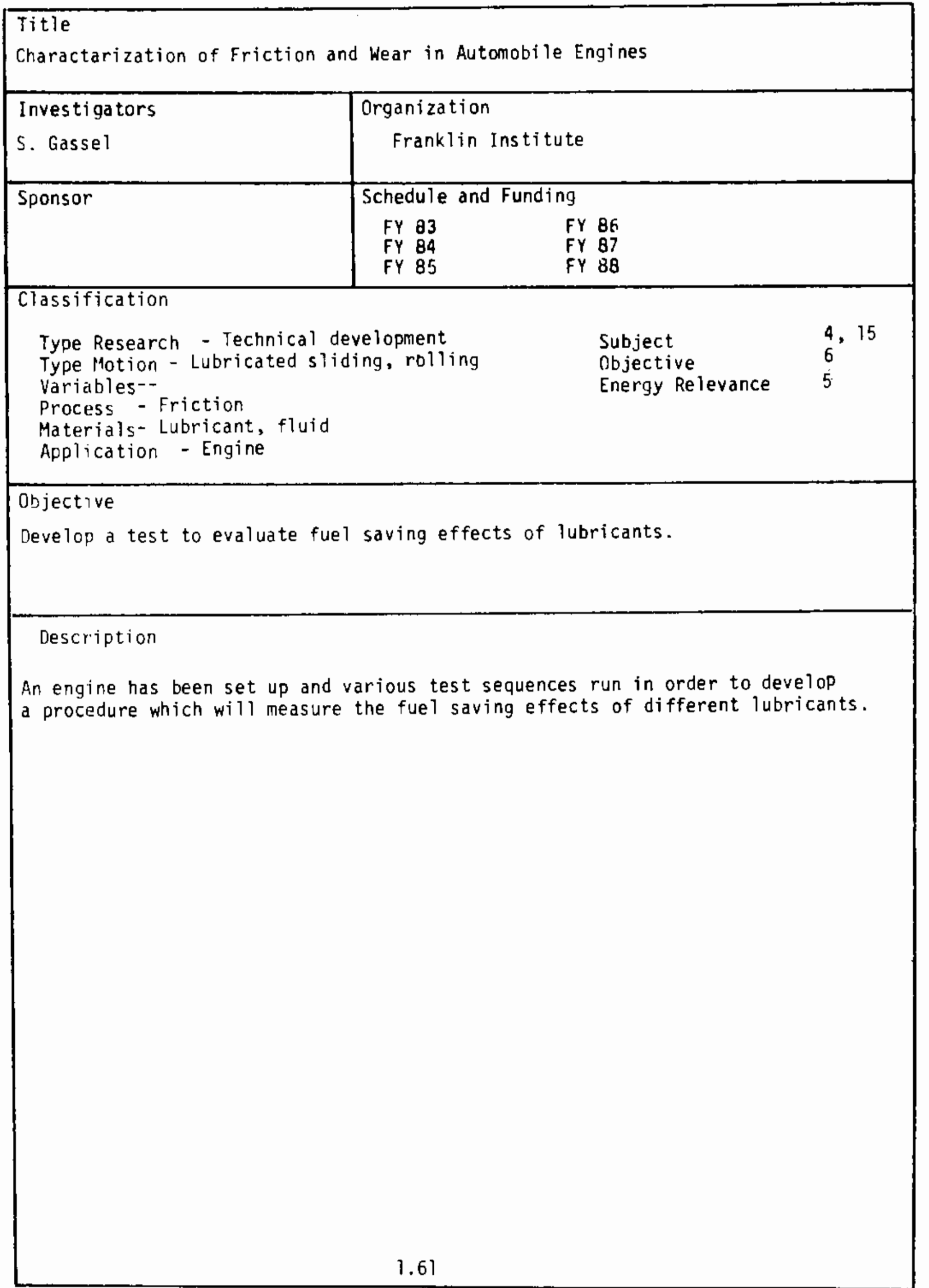


Title

An Automated System for Surface Topography Measurements Using SEM Stereo

Micrographs

\begin{tabular}{|l|ll}
\hline Investigators & Organization \\
B.B. Aggarwal & SKF \\
\hline Sponsor & & \\
& Schedule and Funding \\
& FY 83 & FY 86 \\
& FY 84 & FY 87 \\
& FY 85 & FY B8
\end{tabular}

Classification

Type Research - Exploratory Research

Type Hotion -

Variables - Finish

Process - Surface damage

Materials

Application

Objective

To develop a non contact surface profile measurement system.

Description

A non contacting optical instrument was devised to measure surface profile 


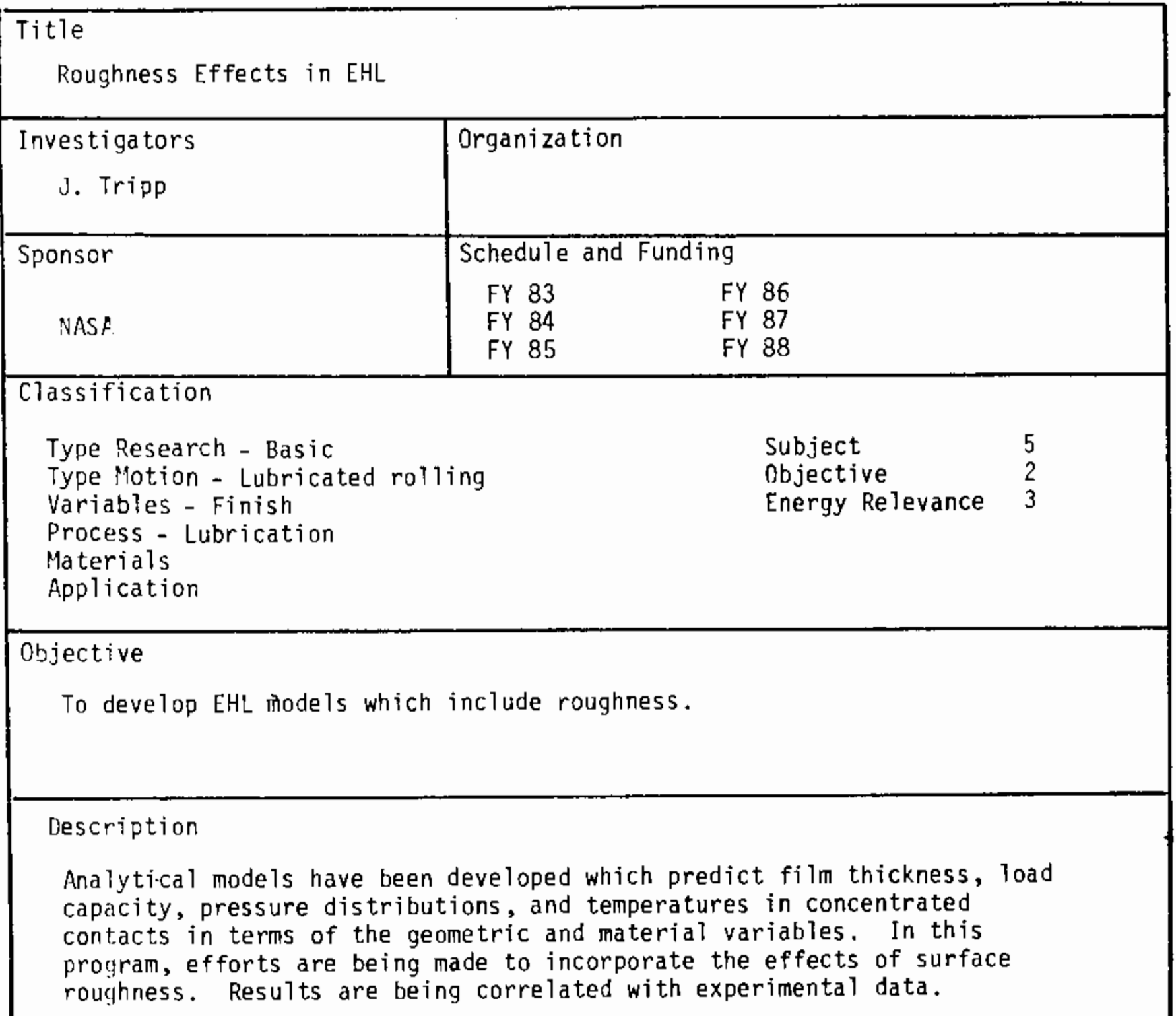




\section{Title}

Transient EHL Effects in Starved Ball Bearings

\begin{tabular}{|c|c|c|}
\hline $\begin{array}{l}\text { Investigators } \\
\qquad E . P . \text { Kingsbury }\end{array}$ & \multicolumn{2}{|c|}{$\begin{array}{c}\text { Organization } \\
\text { NASA }\end{array}$} \\
\hline Sponsor & \multicolumn{2}{|c|}{ Schedule and Funding } \\
\hline NASA & $\begin{array}{ll}\text { FY } & 83 \\
\text { FY } & 84 \\
\text { FY } & 85\end{array}$ & $\begin{array}{l}\text { FY } 86 \\
\text { FY } 87 \\
\text { FY } 88\end{array}$ \\
\hline
\end{tabular}

Classification

Type Research - Applied

Type Motion - Lubricated rolling

Variables- Time, chemical properties

Subject

Cbjective

Process - Film formation, lubrication

Energy Relevance

5

2

Materials - Fluid lubricants

Application - Roliing contact bearings

Objective

To study transient effects in film thickness which influence EHL calculations.

\section{Description}

The independent variabies used in most calculations for EHL film thickness

in ball bearings involve lubricant properties, contact elasticity, load and bearing kinematics. The calculations are for steady state, and give a time-constant fi?m thickness. Experiments have shown four distinct processes in starved ball bearings which are explainiable assuming a time-varying film thickness. This contribution describes these four processes, as well as another transient EHL effect which does not involve the thickness of the film. A simple model, based on experimental considerations, allows direct calculation of several of the thickness transients. 


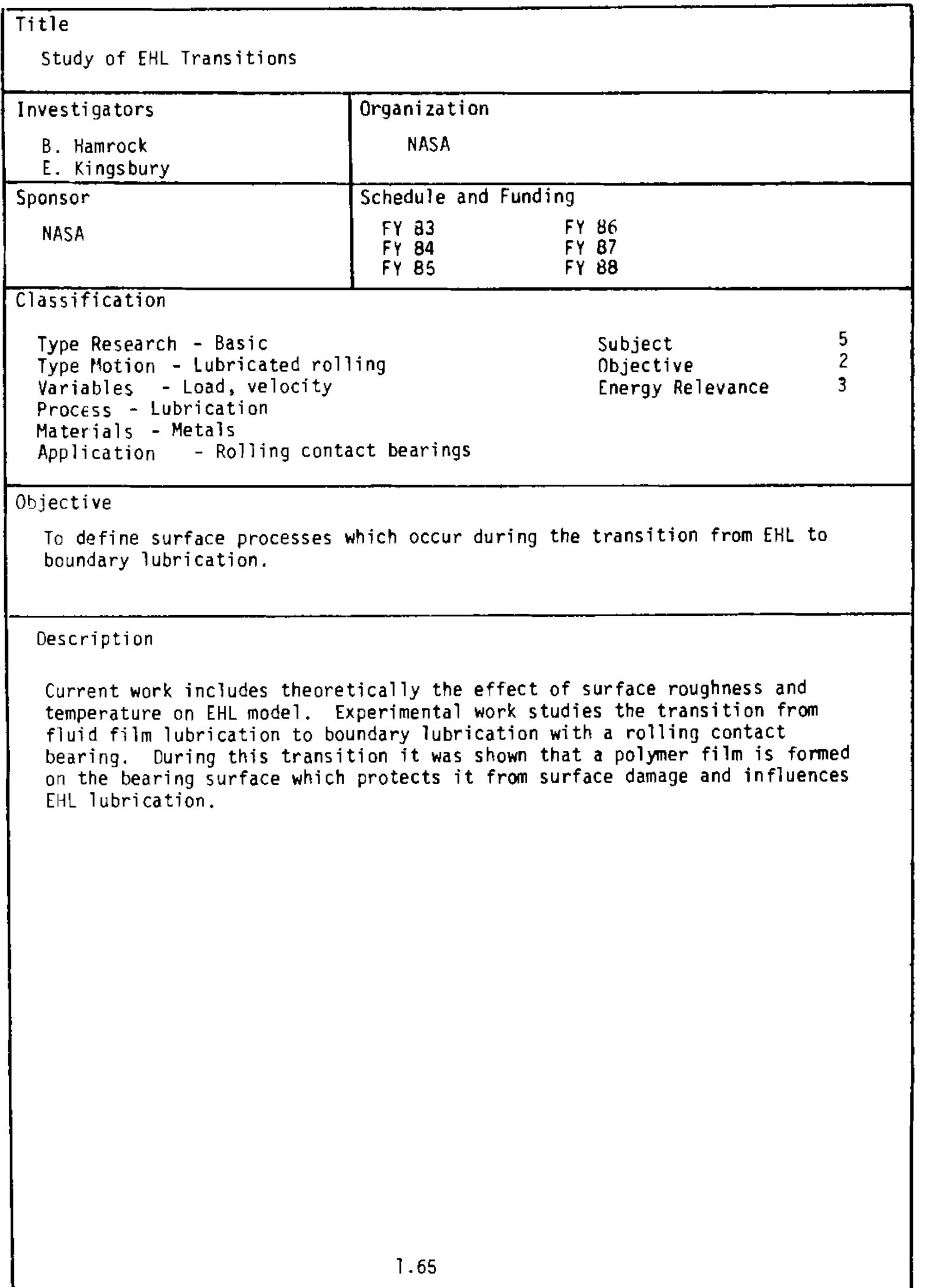




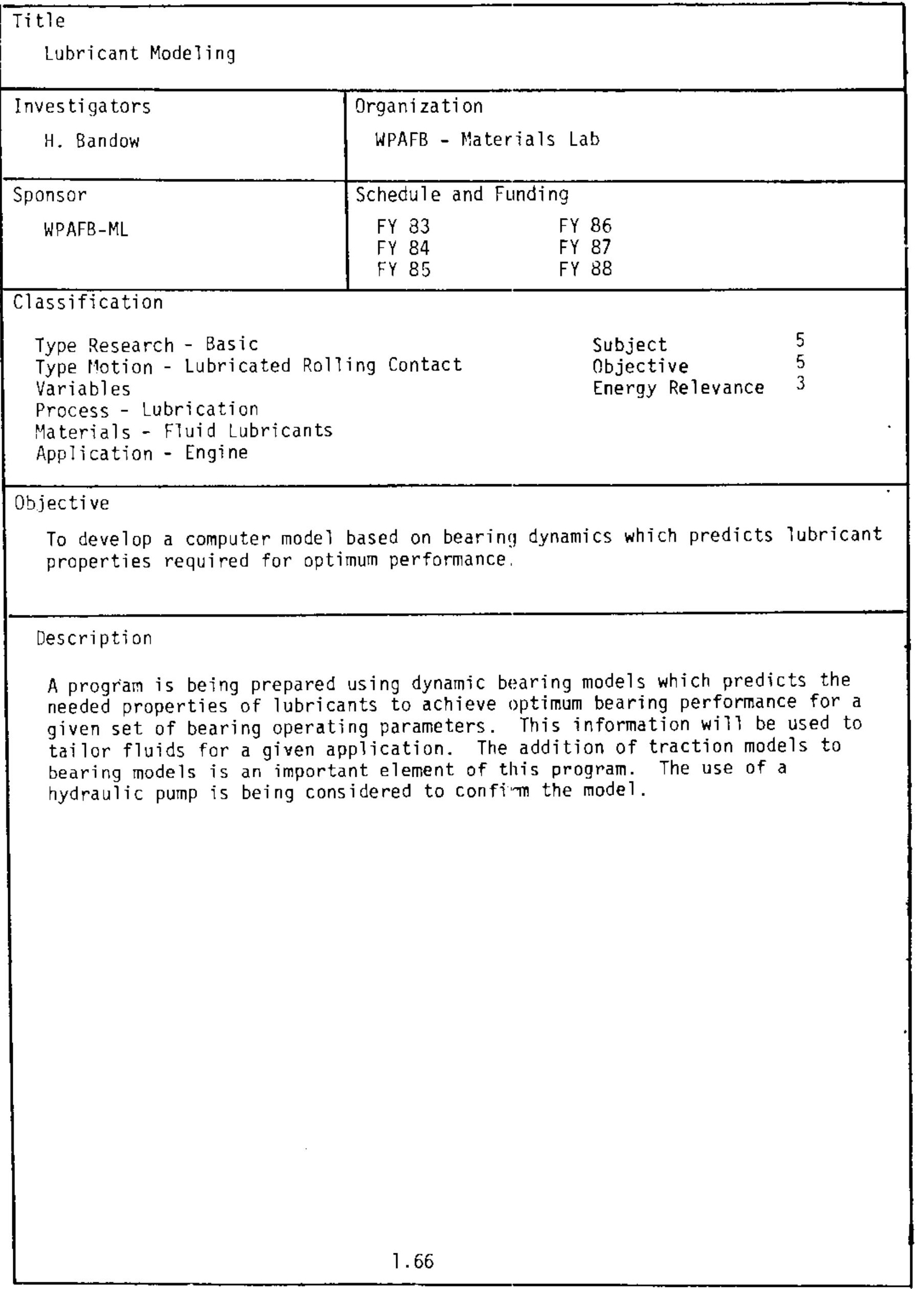




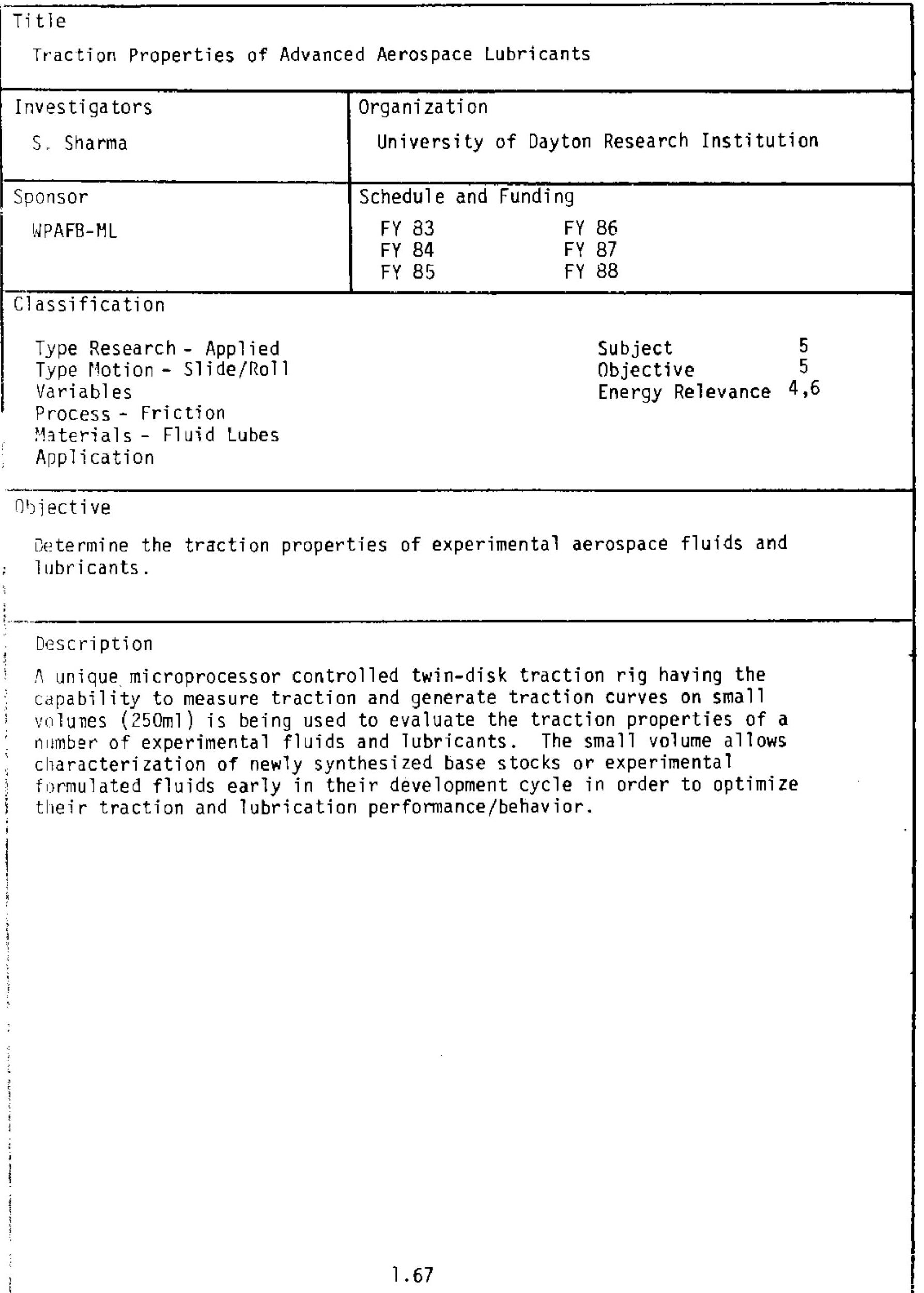


Title

Corrosion Protection from Propellant By-products by MIL-L-63460 (CLP) Lubricants

\begin{tabular}{|c|c|c|}
\hline $\begin{array}{l}\text { Investigators } \\
\text { S.M. Whalen }\end{array}$ & \multicolumn{2}{|c|}{$\begin{array}{l}\text { ARDC } \\
\text { Picatinny Arsena? }\end{array}$} \\
\hline Sponsor & \multicolumn{2}{|c|}{ Schedule and Funding } \\
\hline ARDC - Picatinny & $\begin{array}{llc}\text { FY } & 83 & 45 K \\
\text { FY } & 84 & 0 \\
\text { FY } & 85 & 50 K\end{array}$ & $\begin{array}{lll}\text { FY } & 86 & 50 K \\
\text { FY } & 87 & \\
\text { FY } & 88 & \end{array}$ \\
\hline
\end{tabular}

Classification

Type Research - Applied

Type Motion - Lubricated Slide/Roll

Variables - Environment

Subject

Objective

6

Process - Film Formation

Energy Relevance 3

Materials - Fluid Lubricants

Application - Various

Objective

Develop laboratory test to screen out ineffective corrosion preventive CLP lubricants prior to their testing on M-60 machine guns.

Description

Compare corrosion protection of proven adequate and inferior CLP lubricants on steel panels exposed to the heat and corrosive energetic gases experienced by the $M-60$ machine gun . 


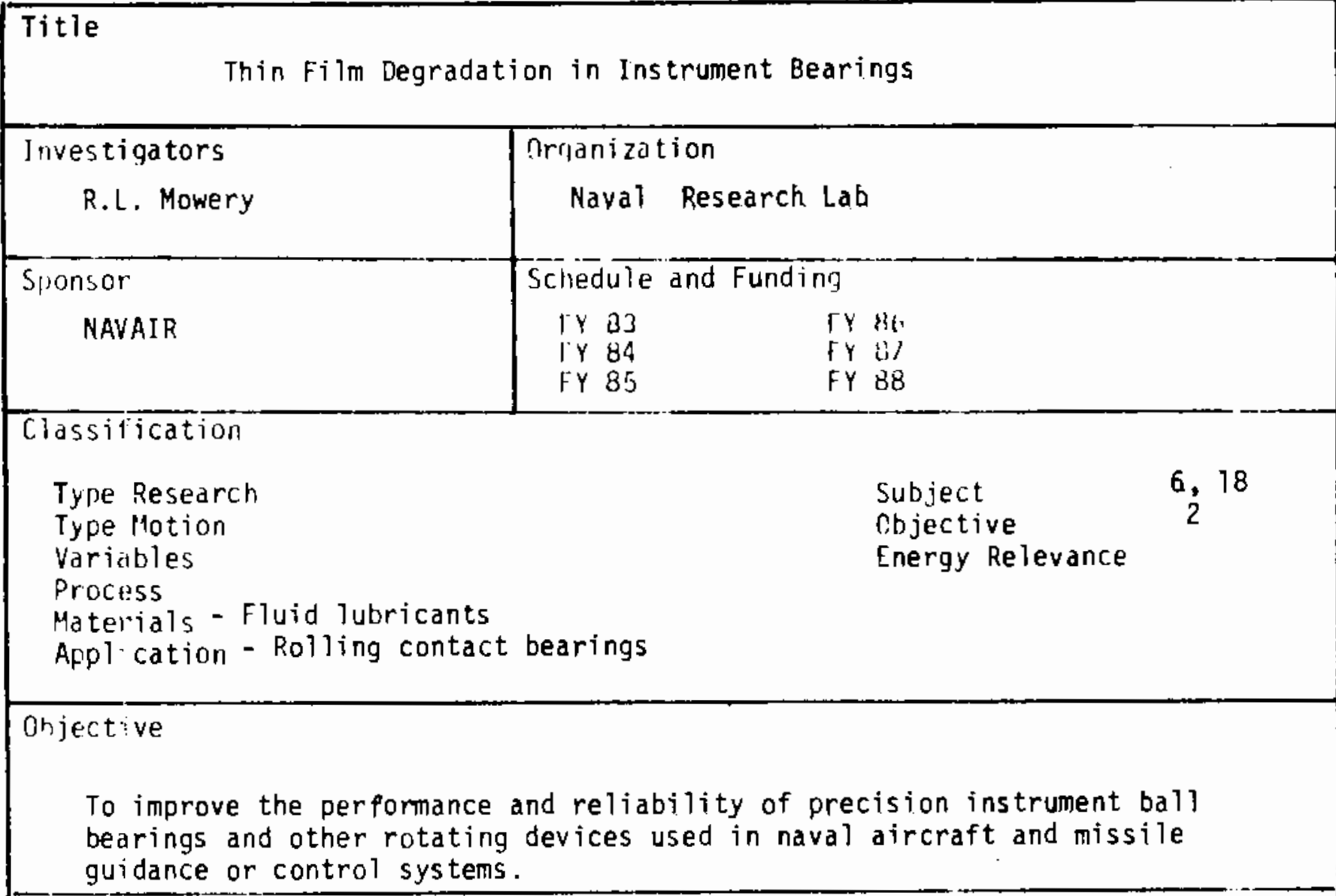

Description

Films of instrument lubricant will be laid down on appropriate bearing metal surfaces and subjected to various environmental stresses (heat, wear, etc.). Changes in lubricant additive/surface chemistry will be monitored. Results will be employed to improve lubricant. Additive or metal properties in order to increase lubricant/bearing reliability. Electroactive polymens (EAPS), E.G. Polyacetylene, will be modified by ion implantation and other appropriate means to determine their applicability as antistatic parkaging material for precision bearings. 


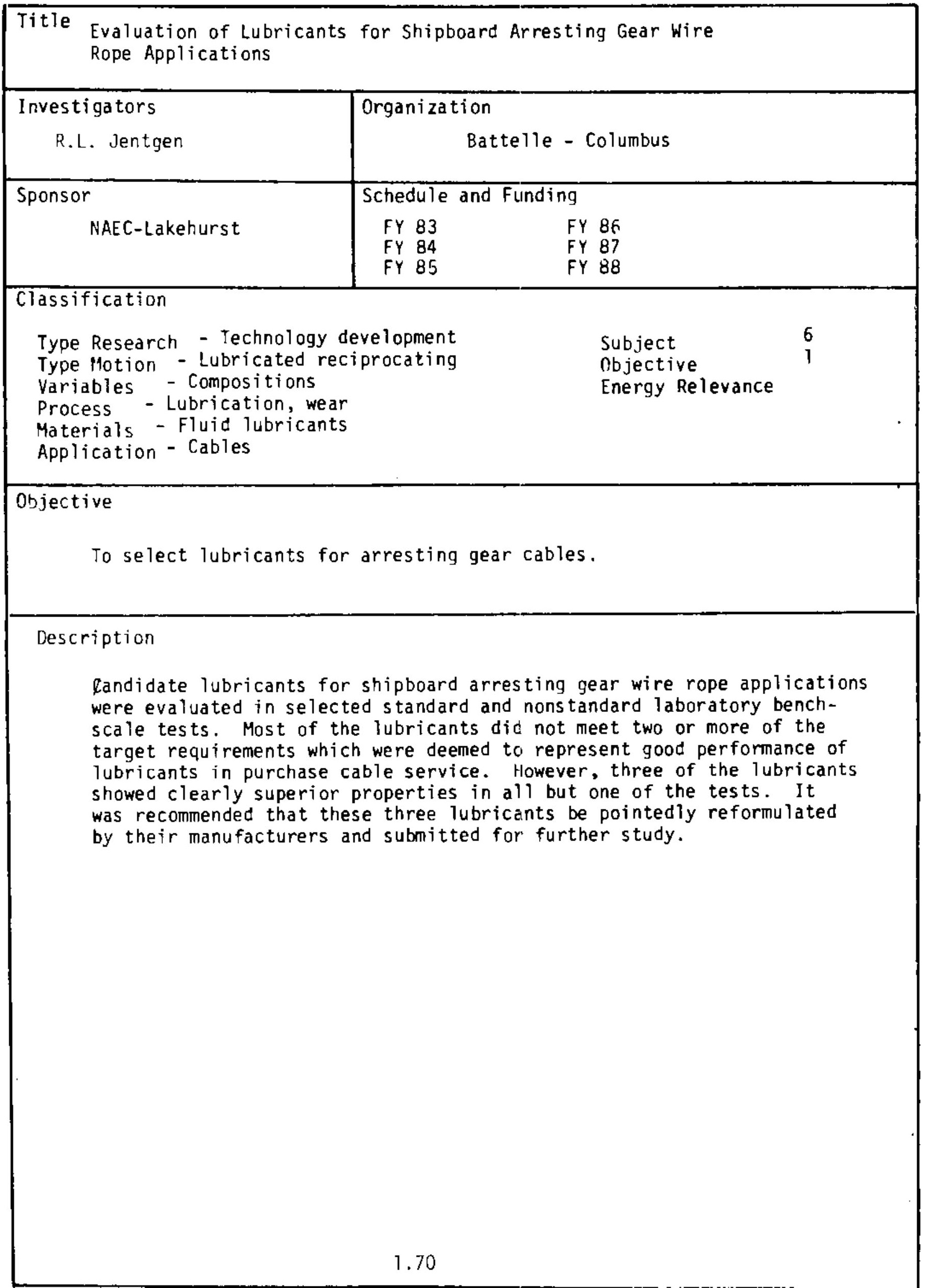




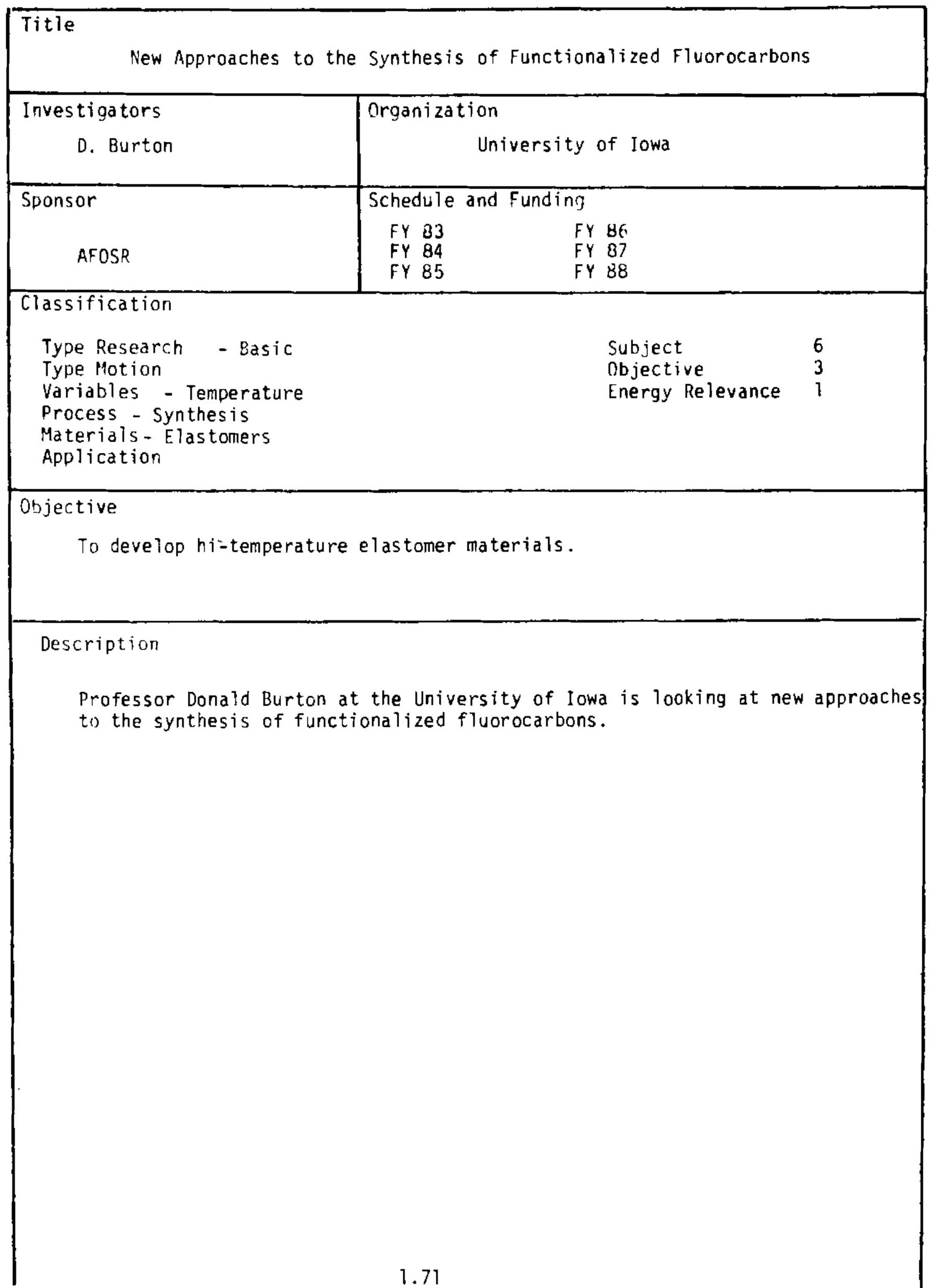




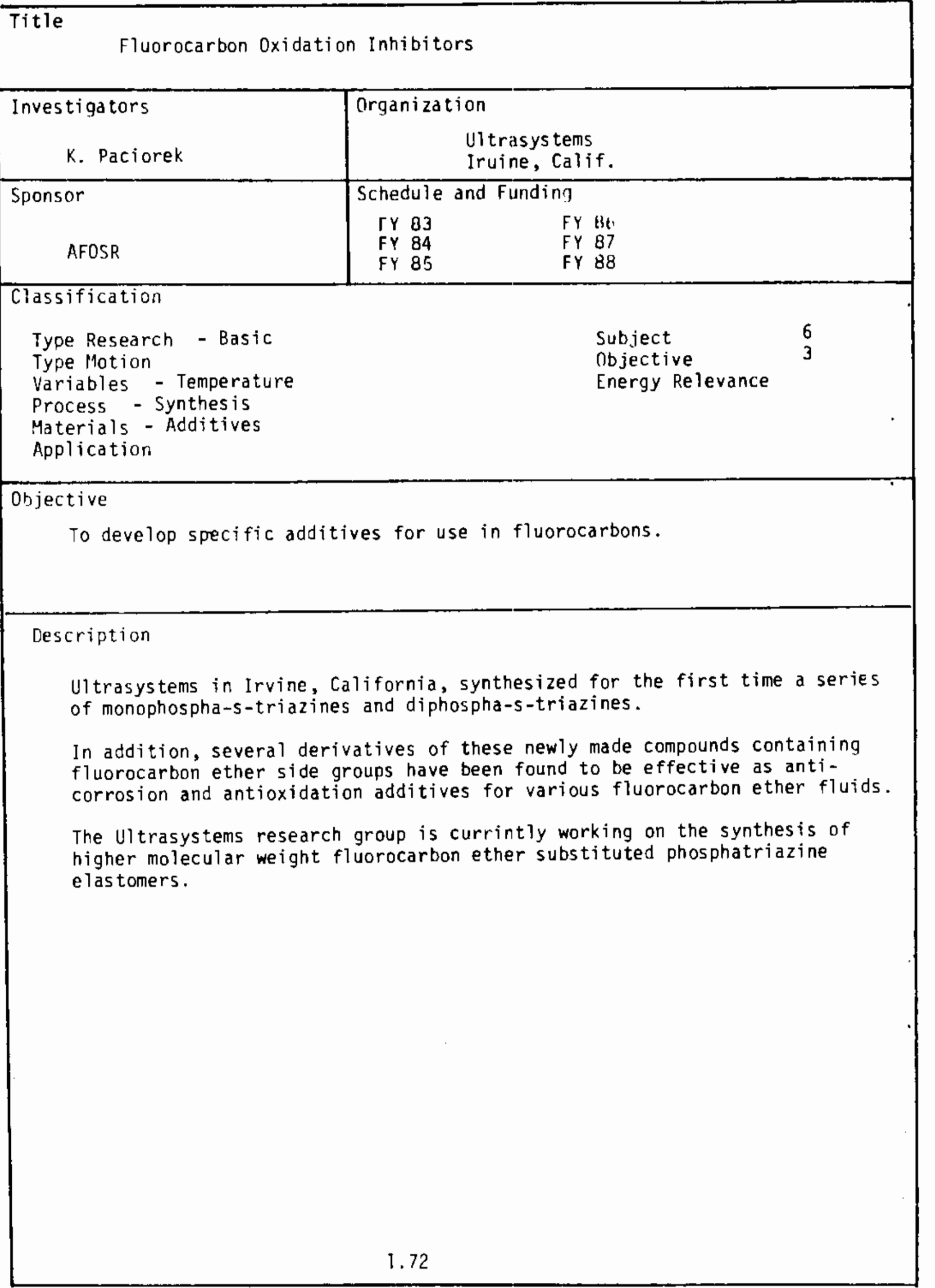




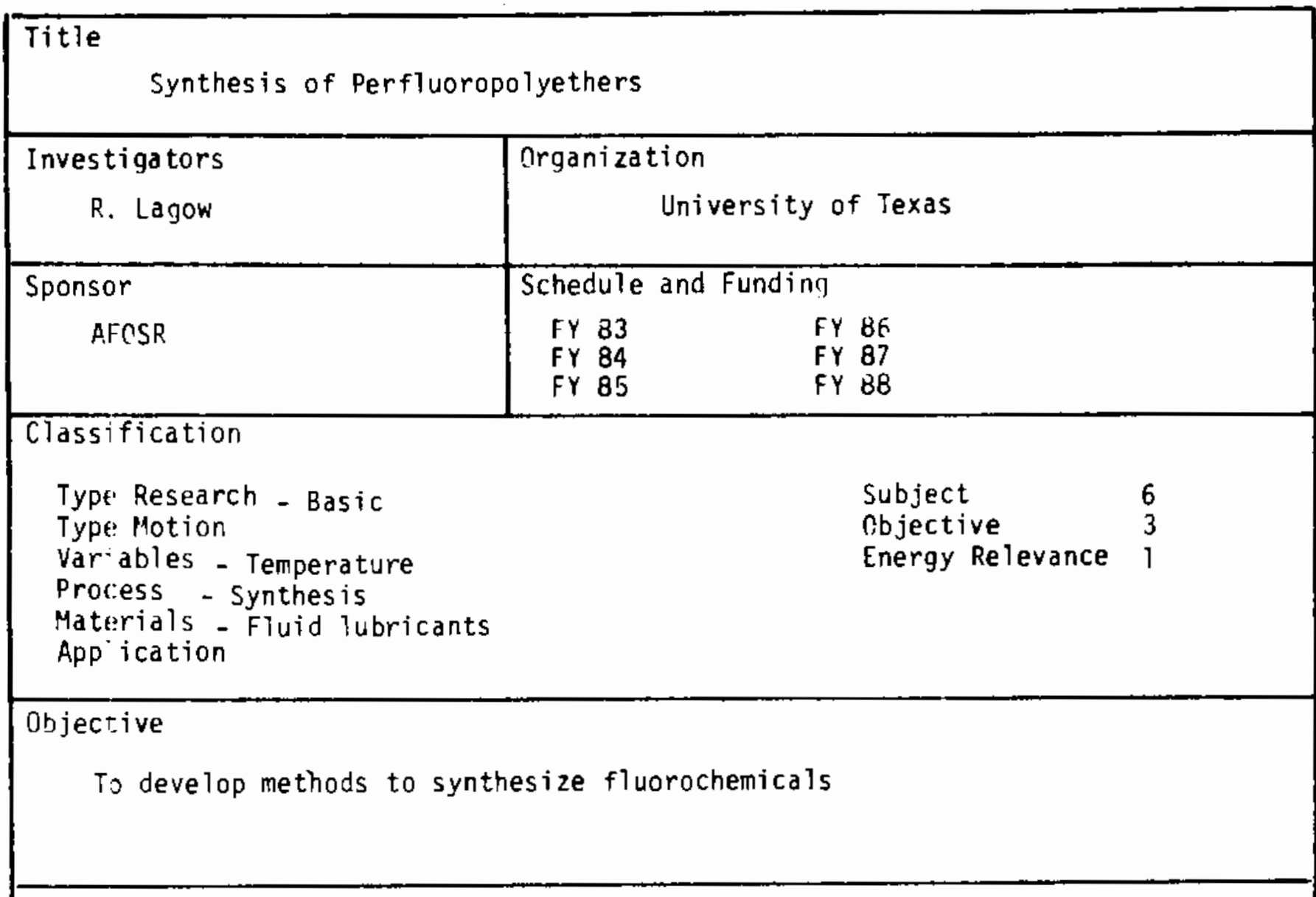

Description

Recently, a new general synthes is for perfluoropolyethers was developed in Lagow's laboratory. The unique advantage of this new synthetic technique is that it makes possible the synthes is of very highly branched polyethers which is not possible using the conventional polymerization technology. 


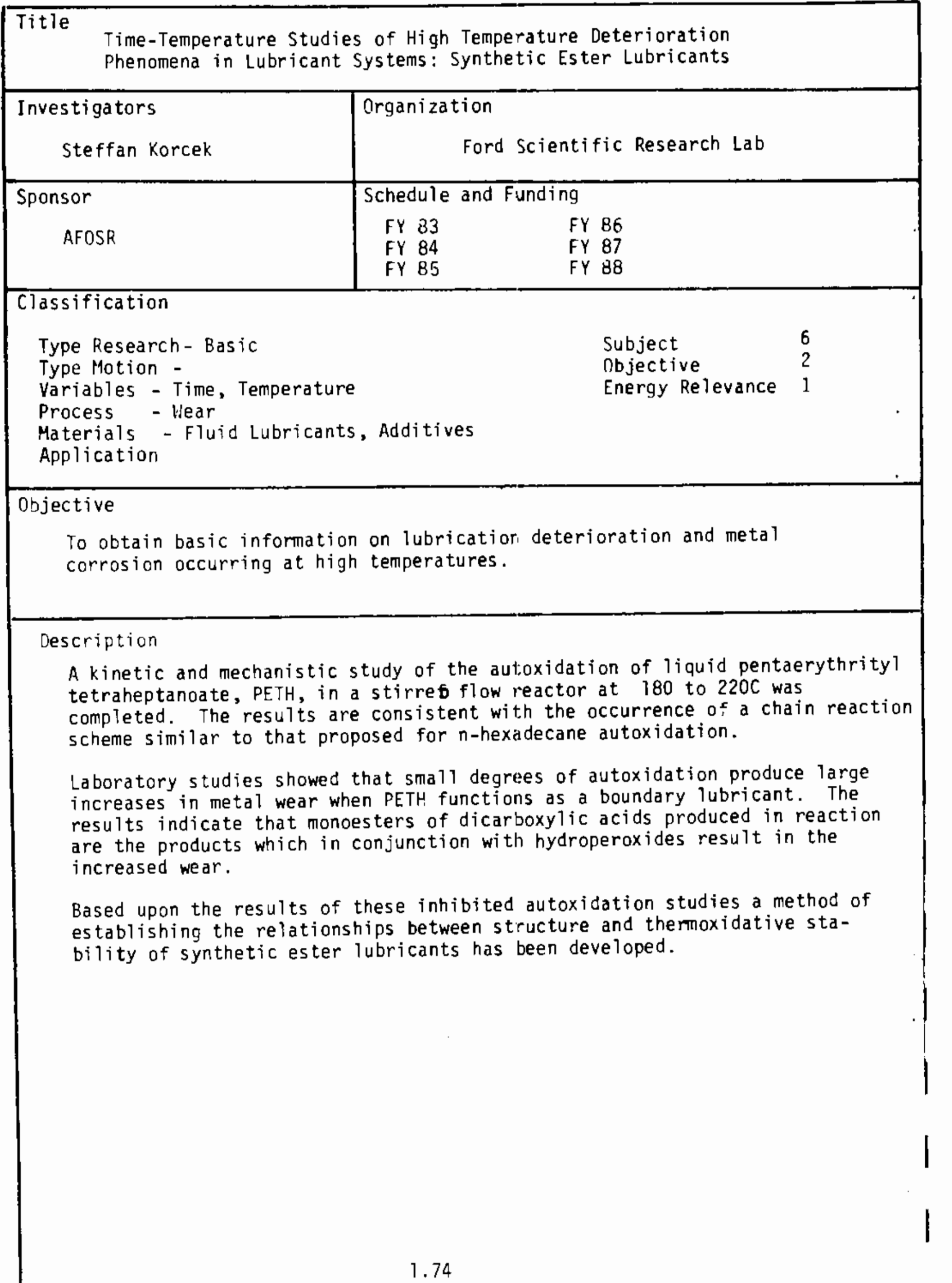




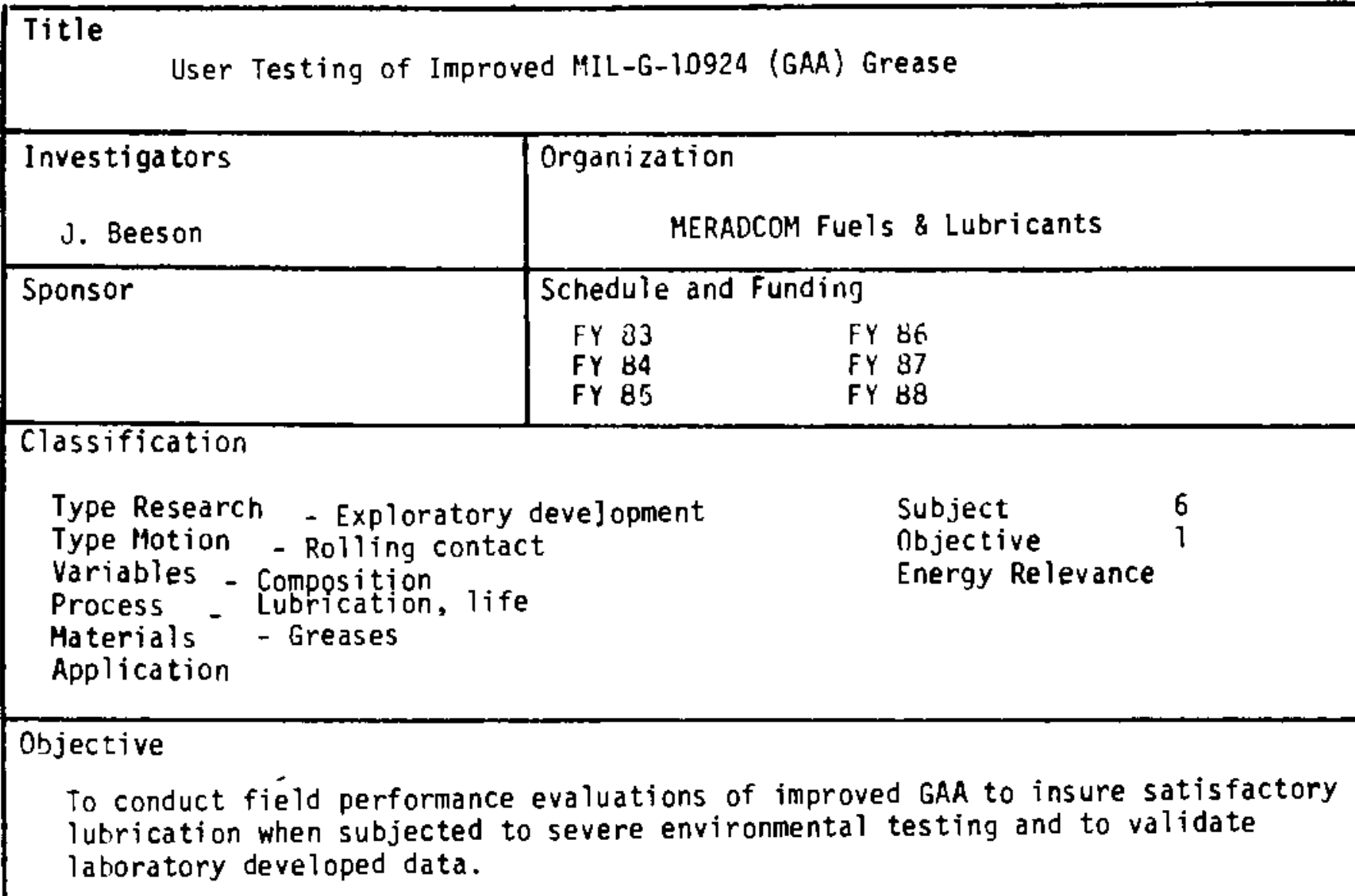

Description

Identify specific applications and environements warranting inclusion in field tests. Solicit cooperation from DOD activities to secure representative vehicle and equipment test beds and conduct controlled field testing. 


\section{Title}

DoD Long Life Grease

\begin{tabular}{|c|c|}
\hline $\begin{array}{l}\text { Investigators } \\
\text { J. Beeson }\end{array}$ & $\begin{array}{l}\text { Organization } \\
\qquad \text { MERADCOM - Fuels \& Lubricants }\end{array}$ \\
\hline Sponsor & $\begin{array}{l}\text { Schedule and Funding } \\
\text { FY } 33 \\
\text { FY } 84 \\
\text { FY } 85\end{array}$ \\
\hline
\end{tabular}

\section{Classification}

Type Research - Applied

Type Motion

Variables - Composition, environment

Process - Lubrication, life

Materials - Greases

Application

Objective

Subject

Objective

Energy Relevance
6 1

To develop a high performance grease that prevents corrosion and satisfactorily performs under all geographic and environmental conditions with extended service capabilities.

Description

Identify specific applications for this grease and develop target requirements. Select candidate products for laboratory screening and field testing. Identify other areas of consolidation with military specification greases and proprietary products. 


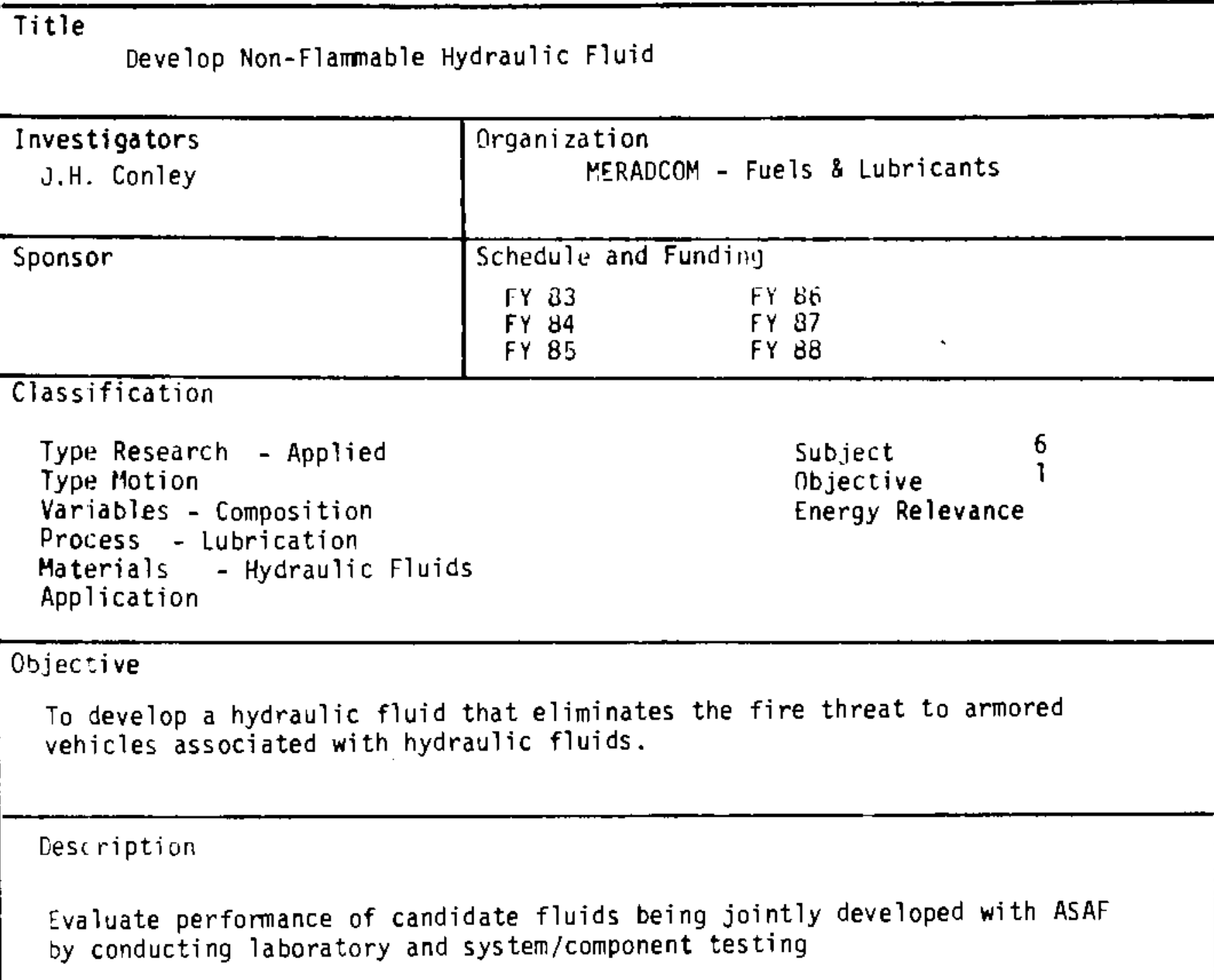


\begin{tabular}{ll}
\hline Title & $\begin{array}{l}\text { Improved Fluids for Existing and Advanced Design } \\
\text { Helicopter Transmissions }\end{array}$
\end{tabular}

\begin{tabular}{|c|c|}
\hline Investigators & $\begin{array}{l}\text { Organization } \\
\qquad \text { MERADCOM Fuels \& Lubricants }\end{array}$ \\
\hline Sponsor & $\begin{array}{l}\text { Schedule and Funding } \\
\text { FY } 83 \\
\text { FY } 84 \\
\text { FY } 85\end{array}$ \\
\hline
\end{tabular}

Classification

Type Research - Applied

Type Motion

Variables - Temperatures, Loads, Compositions

Process - Lubrication

Materials - Fluid lubricants

Application - Transmissions

Objective

To develop a helicopter transmission fluid/gear combination for advanced designed helicopter transmission systems suitable for operation at high temperature and loads. To formulate short-term solutions to current field problems.

Description

Develope a cooperative test plan with US Army, US Navy, and Air Force. Select candidate fluids/material. Conduct laboratory evaluations and component testing. Identify potential problems prior to rig testing. Conduct full scale testing. 


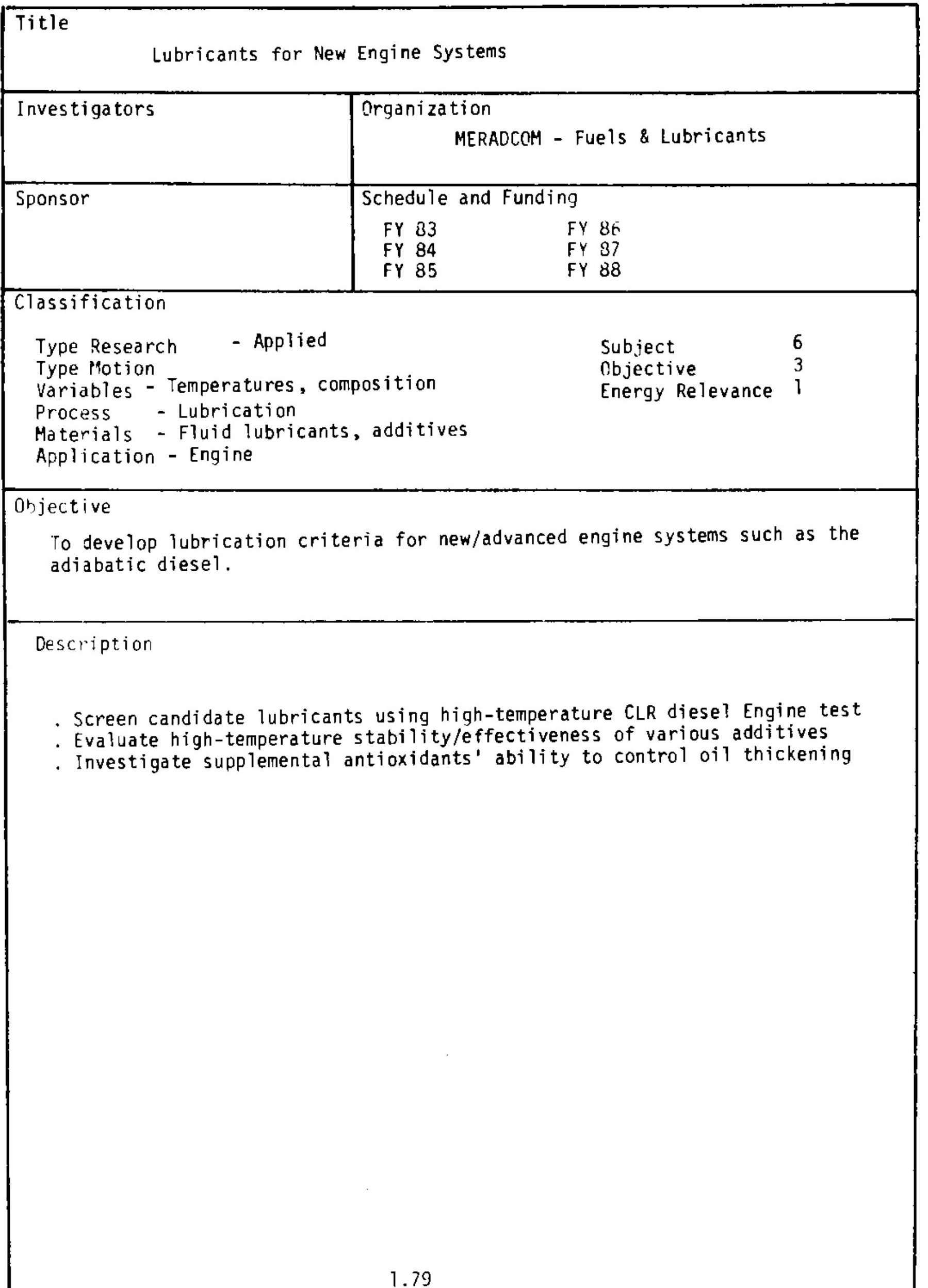




\begin{tabular}{|c|c|}
\hline Universal Engine Lubrica & cants \\
\hline Investigators & $\begin{array}{l}\text { Organization } \\
\text { MERADCOM Fuels and Lubricants }\end{array}$ \\
\hline Sponsor & \begin{tabular}{|c|} 
Schedule and Funding \\
FY 83 \\
FY 84
\end{tabular} \\
\hline $\begin{array}{l}\text { Classification } \\
\text { Type Research - Applied } \\
\text { Type Motion - Composition } \\
\text { Variables - Life } \\
\text { Process - M - Fluid lubricants } \\
\text { Materials } \\
\text { Application - Engines }\end{array}$ & $\begin{array}{lll} & & \\
\text { Subject } & 6 \\
\text { Objective } & 7 \\
\text { Energy Relevance }\end{array}$ \\
\hline $\begin{array}{l}\text { Objective } \\
\text { To develop multiviscosity/ext } \\
\text { ground equipment. }\end{array}$ & xtended drain oils for combat and tactical \\
\hline $\begin{array}{l}\text { Description } \\
\text { - Screen candidate multivisc } \\
\text { ability for expanded seaso } \\
-2 \text { and } 4 \text { cycle diese } \\
- \text { Power transmission } \\
\text { Define low-temperature use } \\
\text { bility and flow properties }\end{array}$ & $\begin{array}{l}\text { scosity engine oil technologies to verify suit- } \\
\text { sonal operation } \\
\text { el engines } \\
\text { systems } \\
\text { se parameters for diesel engines (e.g., pumpa- } \\
\text { es) }\end{array}$ \\
\hline
\end{tabular}




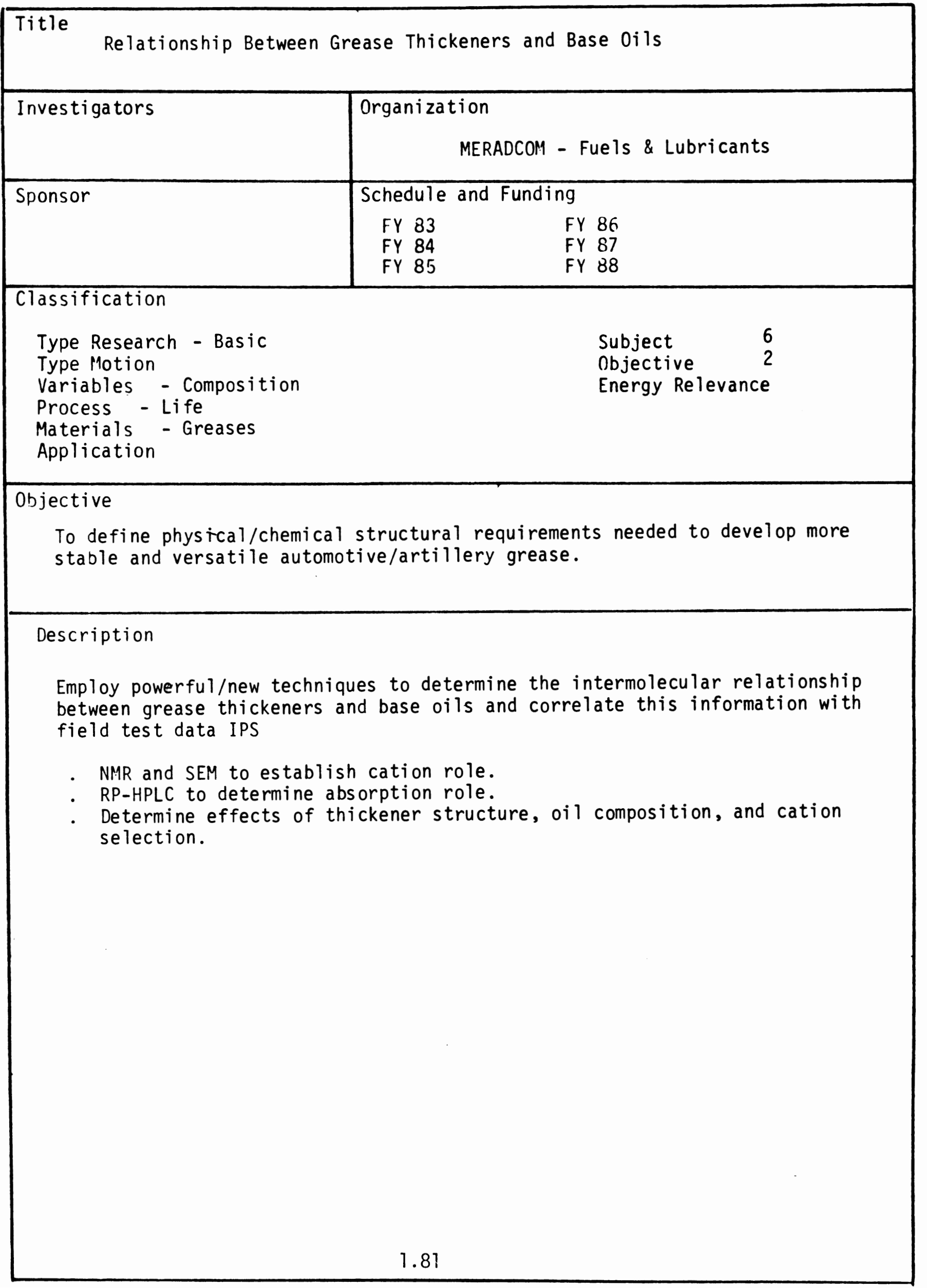




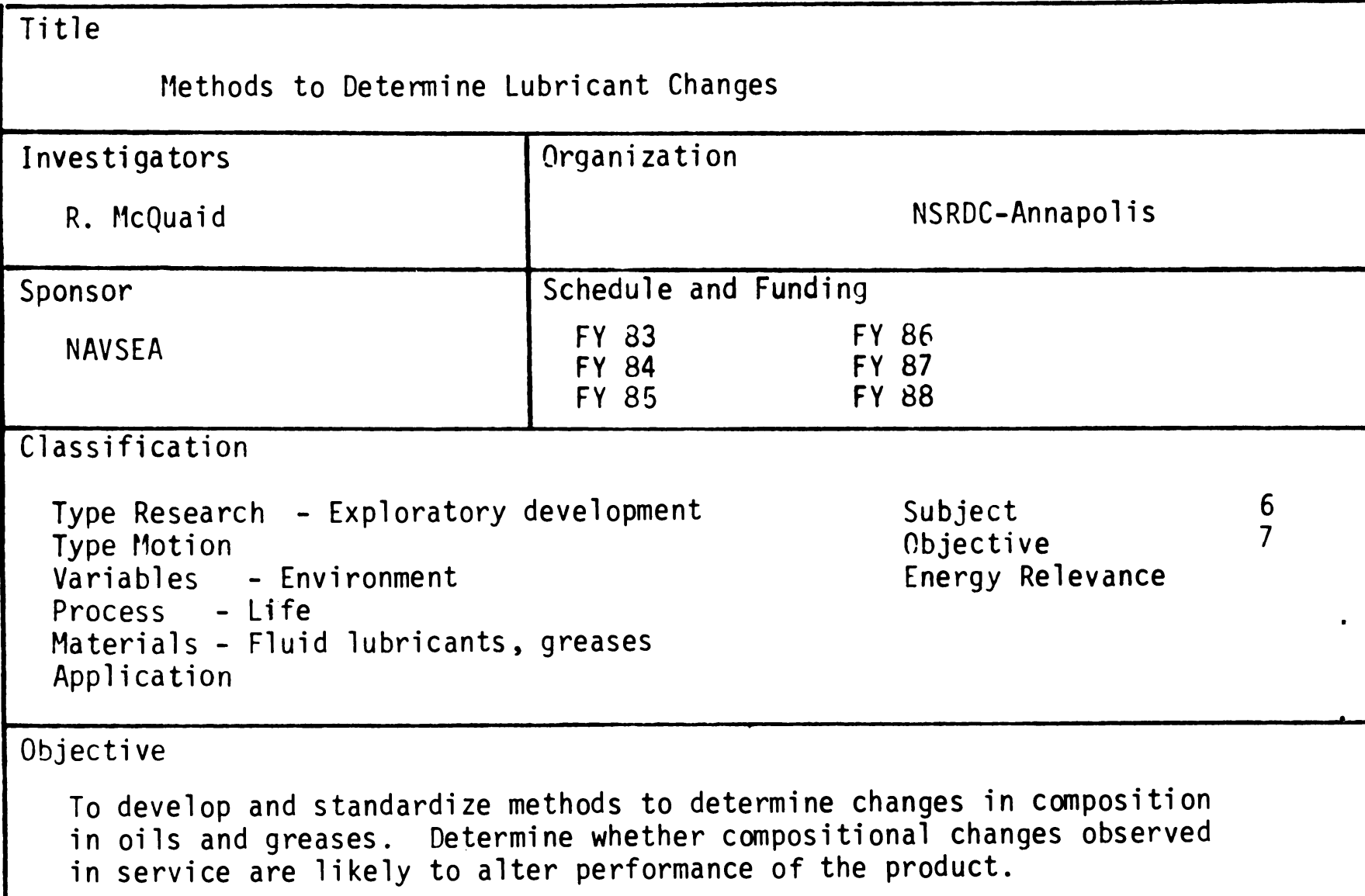

Description

Determine infrared (IR) spectra, high pressure liquid chromatograph (HPLC) and gas chromatograph/mass spectra (GC) properties or other appropriate property measurements of qualified products as received from manufacturer, determine $i R, H P L C$, and GC after varying lengths of time in service to determine compositional changes during use. Identify changes and estimate effect of changes on lubricating and other performance properties of lubricant or hydraulic fluid. Attempt to simulate compositional changes by thermal and oxidative means. Determine whether differential thermal analysis or scanning calorimetry provides a means for predicting compositional changes or measuring compositional changes after they have occured.

(U) (8302-8310) work complete in FY83 gas chromatographic determinations, infrared spectra and high performance liquid chromatographic determinations are required to fully characterize any oil product, infrared spectra is the only determination applicable to greases. 


\begin{tabular}{|c|c|c|c|}
\hline \multicolumn{4}{|l|}{ Title } \\
\hline \multicolumn{4}{|c|}{ Ship Lubricant Reduction Program } \\
\hline Investigators & Organizatic & \multirow{2}{*}{\multicolumn{2}{|c|}{ NSRDC-Annapolis }} \\
\hline J. Taylor & & & \\
\hline Sponsor & \multicolumn{2}{|c|}{ Schedule and Funding } & \\
\hline NAVSEA & $\begin{array}{l}\text { FY } \\
\text { FY } 83 \\
\text { FY } 85\end{array}$ & $\begin{array}{l}\text { FY } 86 \\
\text { FY } 87 \\
\text { FY } 88\end{array}$ & \\
\hline \multicolumn{4}{|l|}{ Classification } \\
\hline \multicolumn{2}{|c|}{$\begin{array}{l}\text { Type Research - Technology development } \\
\text { Type Motion } \\
\text { Variables } \\
\text { Process - Lubrication } \\
\text { Materials - Fluid lubricants, greases } \\
\text { Application }\end{array}$} & $\begin{array}{l}\text { Subject } \\
\text { Objective } \\
\text { Energy Relevance }\end{array}$ & $\begin{array}{l}6 \\
7\end{array}$ \\
\hline \multicolumn{4}{|l|}{ Objective } \\
\hline \multicolumn{4}{|c|}{$\begin{array}{l}\text { To revise and update weapons lubricant list of tech manual CD } 3000 \text { to } \\
\text { el iminate maximum number of MIL-SPeC and proprietary lubricants. }\end{array}$} \\
\hline
\end{tabular}

\section{Description}

There is a Navy wide program to reduce the required number of lubricants used aboard ships. This is to be done by reducing the number of military specification lubricants and replacing a proprietary produce whenever possible with a military specification. The result will be a reduction in lubricant inventory and an overall reduction in lubricant cost. Lubricants for new construction ships are being reviewed and recommendations will be reported. 
Title

Synthetic Hydrocarbon Hydraulic Fluids

\begin{tabular}{|l|ll}
\hline $\begin{array}{l}\text { Investigators } \\
\text { M. Bieberich }\end{array}$ & Organization \\
& & \multicolumn{2}{c}{ NSRDC-Annapolis } \\
\hline Sponsor & Schedule and Funding \\
& FY 83 & FY 86 \\
& FY 84 & FY 87 \\
& FY 85 & FY 88 \\
\hline
\end{tabular}

Classification

Type Research - Technology Development

Type Motion

Subject

Objective

Variables

Energy Relevance

Process

Materials - Hydraulic fluids

Application

Objective

To determine the feasibility of replacing MIL-F-17111A hydraulic fluids (petroleum) with synthetic hydrocarbon base fluids having improved fire resistance.

Description

MIL-F-17111A fluids derived from petroleum oil are used to operate Navy ordnance systems such as gun mounts and guided missile launching systems. The "IL-F-17111A fluids are relatively flammable and a more fire resistant replacement fluid is needed. Polyalphaolefin synthetic hydrocarbon fluids have significantly higher flash and fire points. They also have outstanding low temperature fluidity properties which are required for fluids operating ordnance systems. Modifications to existing MIL-F-17111A type polyalphaolefin fluids will be made to improve certain performance properties, and the most promising formulation will be evaluated in a hydraulic loop. 


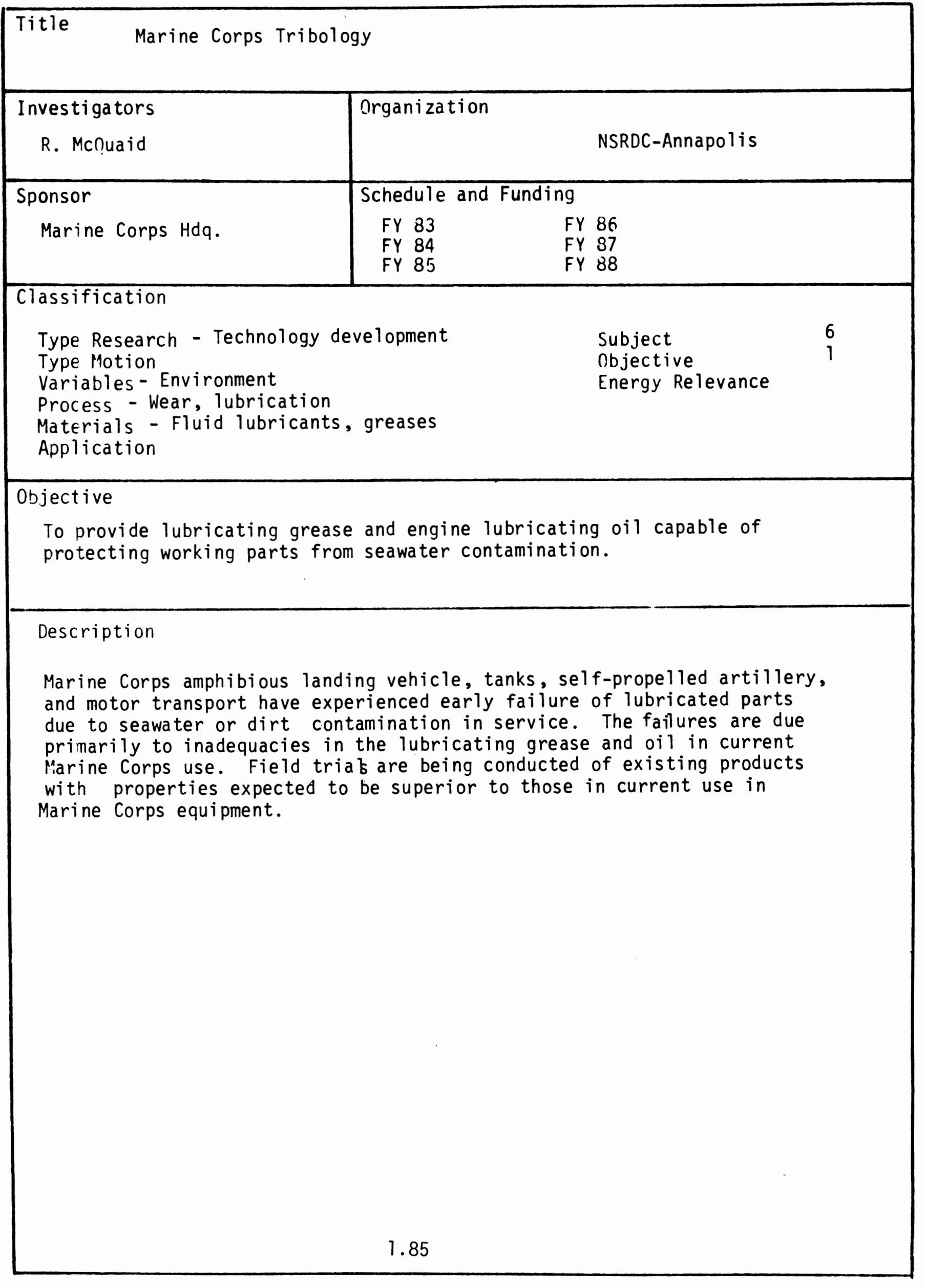


Title

Grease Lubricated Helo Transmissions

\begin{tabular}{|l|ll|}
\hline $\begin{array}{l}\text { Investigators } \\
\text { L. Stallings }\end{array}$ & $\begin{array}{l}\text { Organization } \\
\text { NADC }\end{array}$ \\
\hline Sponsor & Schedule and Funding \\
NADC & FY 83 & FY 86 \\
& FY 84 & FY 87 \\
FY 85 & FY 88 \\
\hline Classification & & \\
Type Research - Applied research & Subject \\
Type Motion & & Cbjective \\
Variables - Compositions & & \\
Process - Lubrication & & \\
Materials - Greases & & \\
Application - Transmissions & & \\
\hline
\end{tabular}

Objective

To determine requirements and specifications for greases for helicopter transmissions.

Description

Helicopter transmissions are normally oil lubricated. Although these are effective both from a lubrication and a cooling standpoint, leakage is always a problem and is the most frequent cause of service removal. Greases are a possible alternative and in fact some transmissions are now grease lubricated. For military service it is necessary to prepare specifications for such greases and to define their requirements. This is the purpose of this program. 


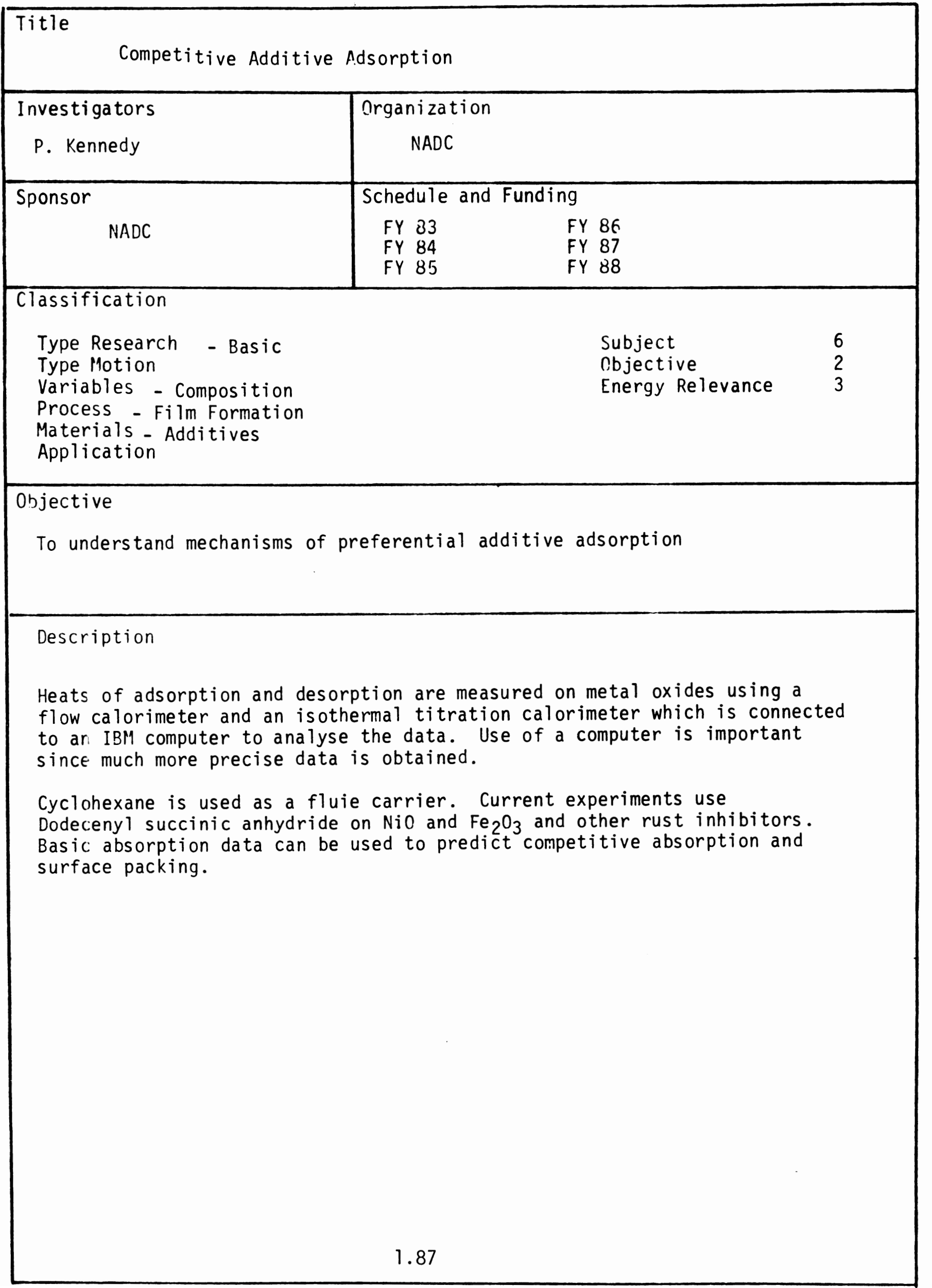


Title

Spline Wear

\begin{tabular}{|l|ll}
\hline $\begin{array}{l}\text { Investigators } \\
\text { E. Jewe1 }\end{array}$ & Organization \\
& NADC \\
\hline Sponsor & Schedule and Funding \\
NA.DC & FY 83 & FY 86 \\
& FY 84 & FY 87 \\
& FY 85 & FY 88
\end{tabular}

\section{Classification}

Type Research - Exploratory development

Type llotion - Reciprocating

Variables - Composition

Subject

Objective

Energy Relevance

Process - Wear

Materials - Additives

Application - Splines

Objective

To develop a grease which will reduce wear of splines.

Description

Splines are subject to rapid wear due to fretting. Lubrication is difficult due to the small amplitude; oil is prevented from flowing into the contact area. As a result greases have a limited life where they are effective in a spline. Different greases do, however, have different lives. The reason for this has not beed adequately defined. The purpose of this research is to define those life extending properties by using a spline test with different greases and to develop a grease which minimizes wear. The approach used is to select a synthetic hydrocarbon grease and evaluate the effects of different additives. 


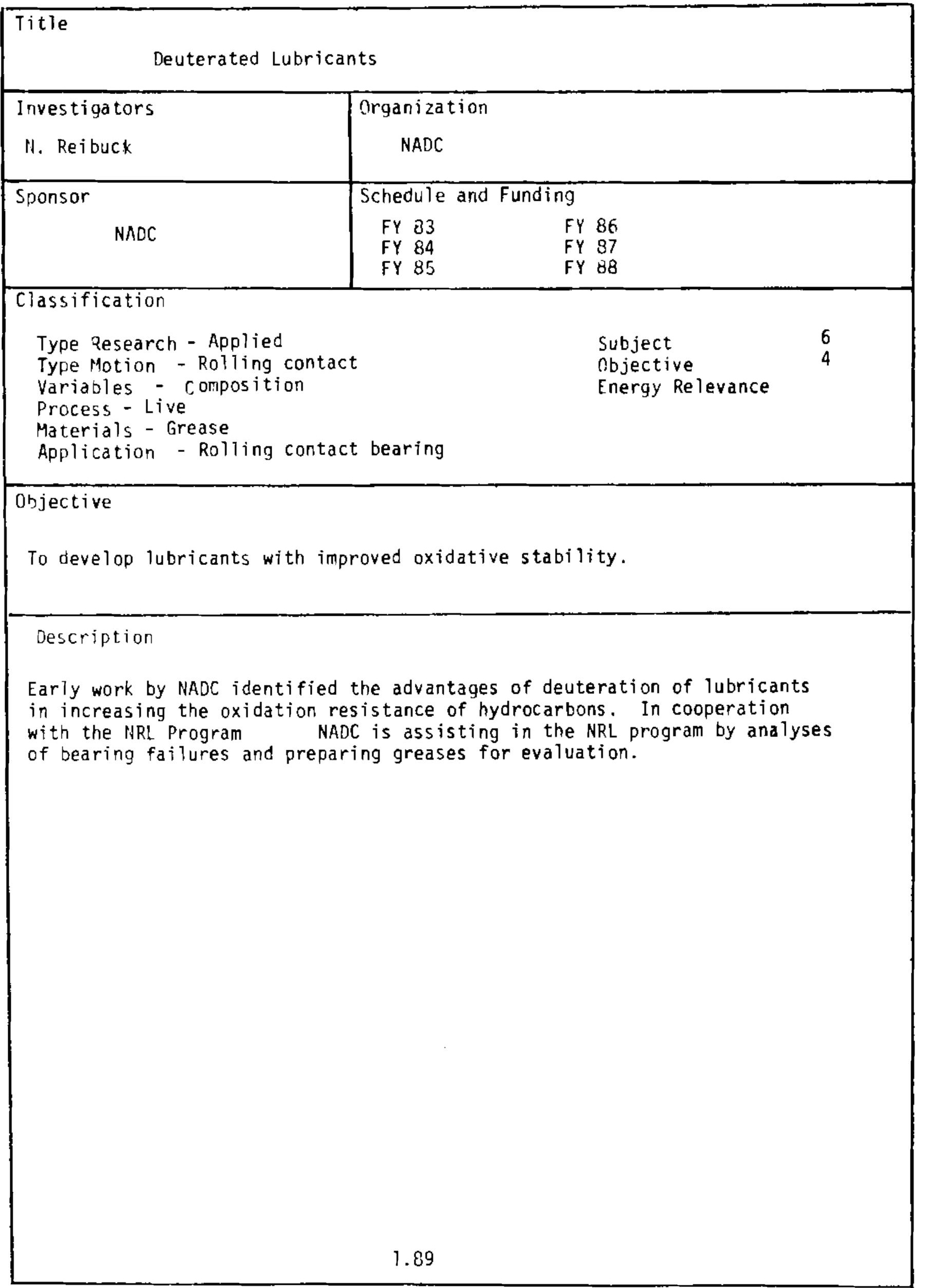




\begin{tabular}{|c|c|}
\hline \multicolumn{2}{|c|}{$\begin{array}{l}\text { Title Evaluation of the Oxidative Stabilities of a Deuterated } \\
\text { and Non Deuterated Neopentyl polyester. }\end{array}$} \\
\hline \multirow{2}{*}{$\begin{array}{l}\text { Investigators } \\
\text { S.G. Pande } \\
\text { R.N. Bolster } \\
\end{array}$} & \multirow{2}{*}{$\begin{array}{l}\text { Organization } \\
\text { Geo-Centers Inc. }\end{array}$} \\
\hline & \\
\hline Sponsor & Schedule and Funding \\
\hline $\begin{array}{l}\text { NAVAL Research Lab } \\
\text { NAVSEA. }\end{array}$ & $\begin{array}{ll}\text { FY } & 86 \\
\text { FY } & 87 \\
\text { FY } 88\end{array}$ \\
\hline \multicolumn{2}{|l|}{ Classification } \\
\hline $\begin{array}{l}\text { Type Research - Applied } \\
\text { Type Motion - Temp } \\
\text { Variables - Lubrication } \\
\text { Process - Greases } \\
\text { Materials - Gpplication } \\
\text { Aplo }\end{array}$ & $\begin{array}{l}\text { Subject } \\
\text { Objective } \\
\text { Energy Relevance }\end{array}$ \\
\hline \multicolumn{2}{|c|}{$\begin{array}{l}\text { Objective } \\
\text { To extend motor bearing } 1 \text { ife with deuterated fluids as grease base stocks. }\end{array}$} \\
\hline \multicolumn{2}{|c|}{$\begin{array}{l}\text { Description } \\
\text { Several deuterated and nondeuterated neopentyl polyol ester basestocks } \\
\text { have been evaluated for oxidative stability at } 220^{\circ} \mathrm{C} \text { using systematic } \\
\text { screening and characterization tests. Also, experimental lubricating } \\
\text { greases have been prepared from selected basestocks for motor bearing life } \\
\text { tests. }\end{array}$} \\
\hline \multicolumn{2}{|c|}{$\begin{array}{l}\text { Assuming bearing life to be solely dependent on lubricant oxidative } \\
\text { stability, the deuterated grease prepared from a pentaerythritol perdeutero } \\
\text { tetrahexanoate ( } 98.6 \text { atom) ester with low alkali metal content, is expected } \\
\text { to exhibit a fivefold longer life than its nondeuterated analog, also with } \\
\text { low alkali metal content. Nondeuterated lithium stearate was used as the } \\
\text { grease thickener. A significant enhancement in oxidative stability occurs } \\
\text { on combination of the dual effects of deuteration and alkali metal con- } \\
\text { centration in the presence of an amine-type antioxidant. The test data } \\
\text { indicate that lubricants formulated in this manner have potential operating } \\
\text { temperatures as high as } 230^{\circ} \mathrm{C} \text {. }\end{array}$} \\
\hline \multicolumn{2}{|r|}{1.90} \\
\hline
\end{tabular}




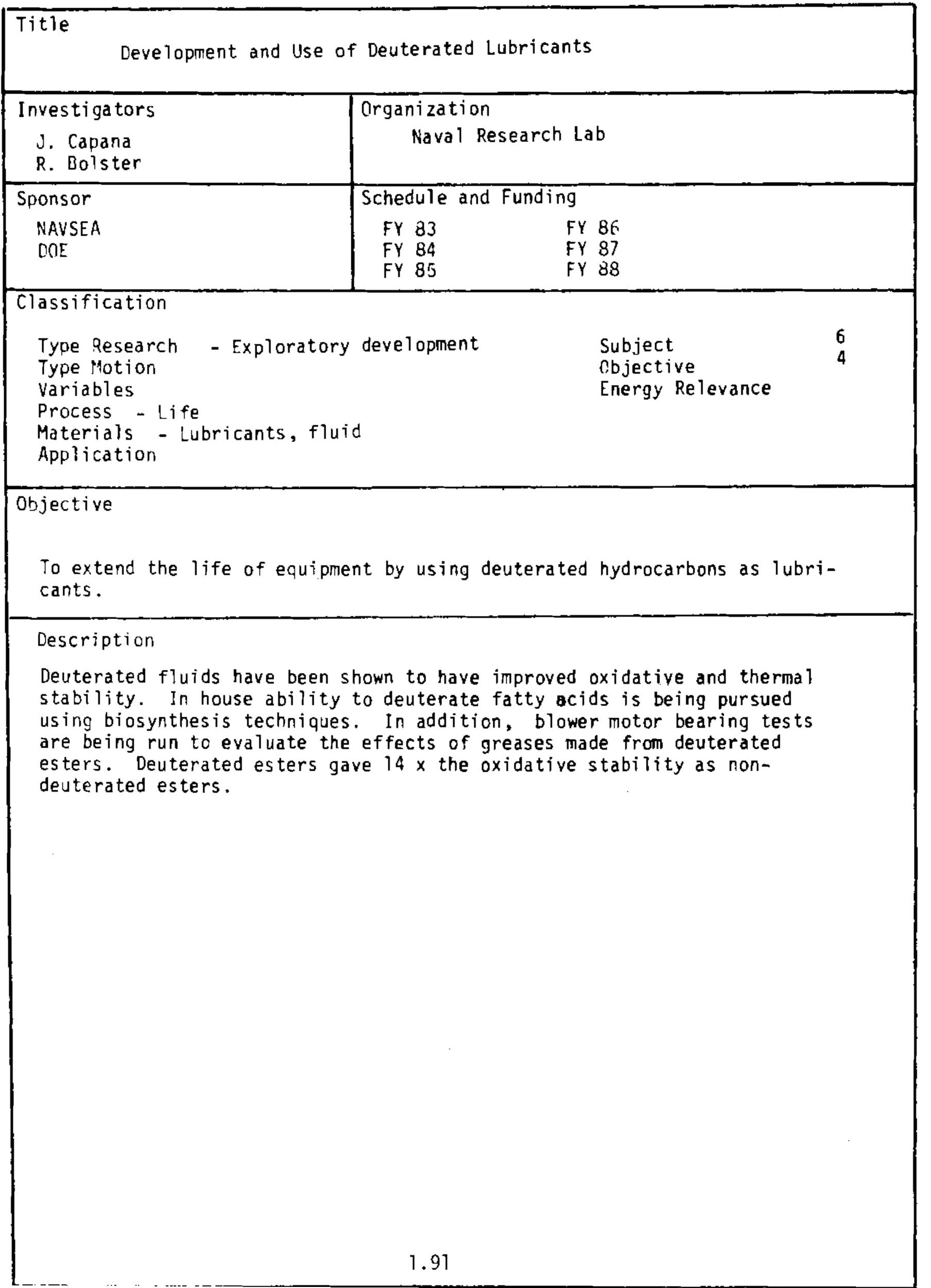


Title

Turbine Engine Lubricant Development

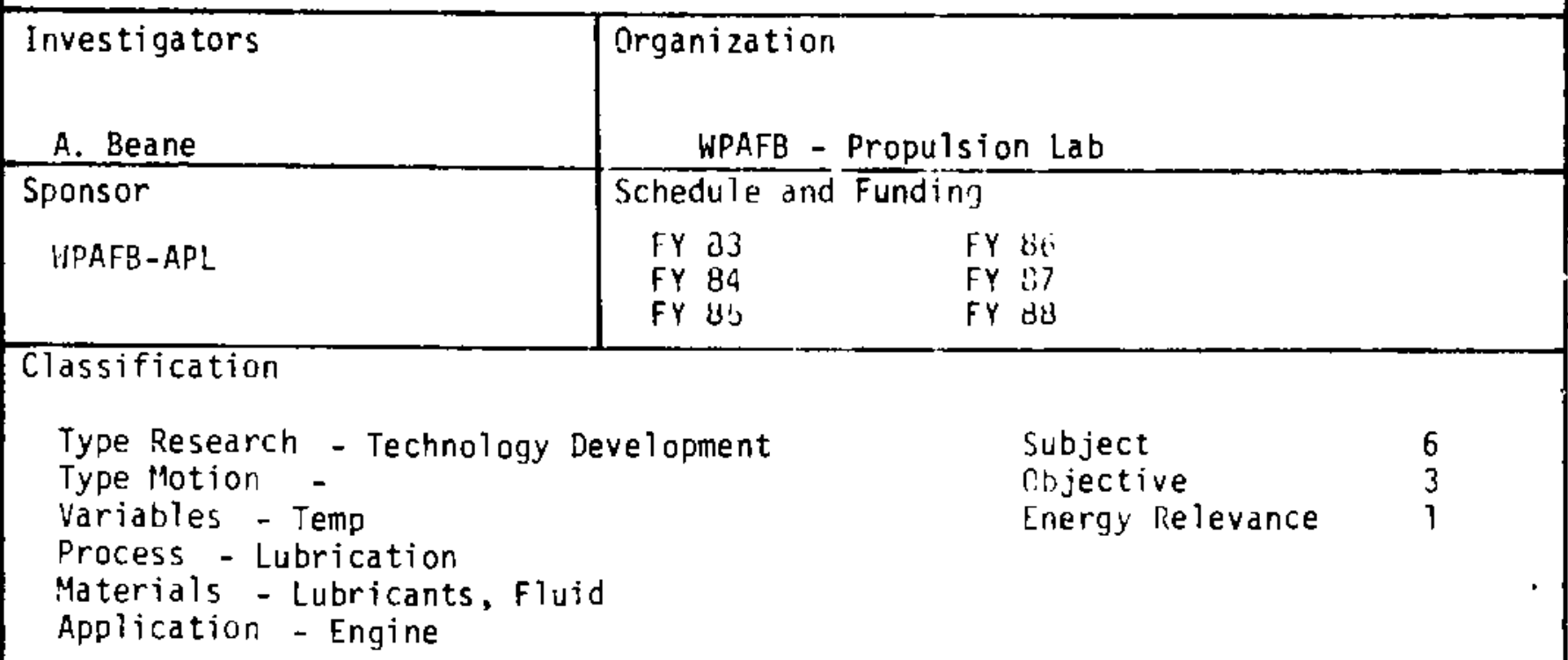

Objective

To develop new Tubricants and define requirements for advanced engines.

Description

Develop new lubricants and define requirements for current and proposed turbine engine and power generation systems.

Provide engine lubricant requirements to industry in terms of physical properties and performance criteria. Conduct oil testing laboratory and full scale engine to ensure oils meet these requirements, and to study advanced lubricant capabilities. Evaluate the toxicological characteristics of lubricant formulations and additives considered suspect. 


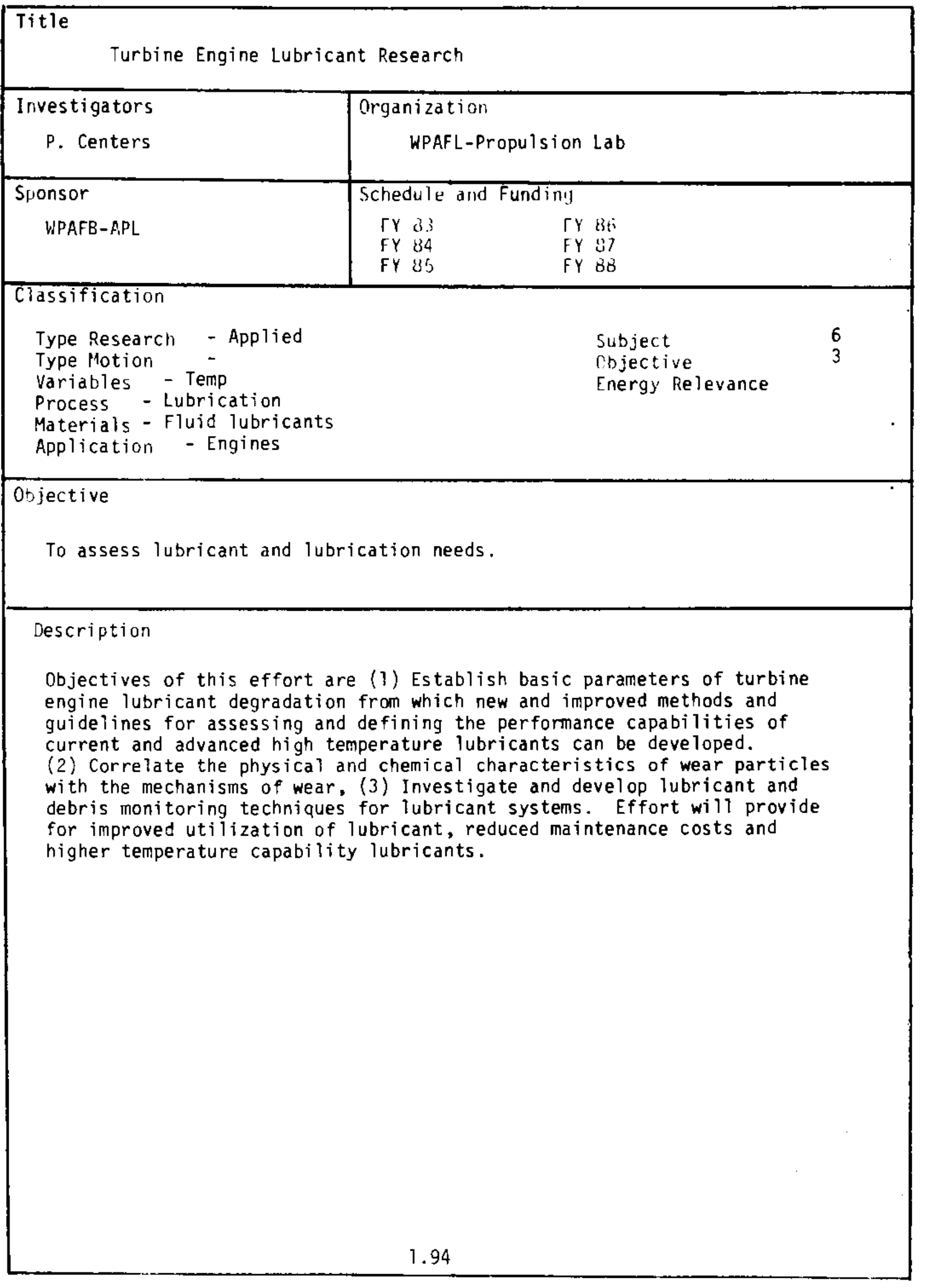




\begin{tabular}{|c|c|c|c|}
\hline \multicolumn{4}{|l|}{ Title } \\
\hline \multicolumn{4}{|c|}{ Study of Additive Action Mechanisms in ZDP/TCP } \\
\hline Investigators & \multirow{2}{*}{\multicolumn{3}{|c|}{$\begin{array}{c}\text { Organization } \\
\text { NASA }\end{array}$}} \\
\hline D. Wheeler & & & \\
\hline Sponsor & \multicolumn{3}{|c|}{ Schedule and Funding } \\
\hline NASA & $\begin{array}{l}\text { FY } 83 \\
\text { FY } 84 \\
\text { FY } 85\end{array}$ & $\begin{array}{l}\text { FY } 86 \\
\text { FY } 87 \\
\text { FY } 88\end{array}$ & \\
\hline \multicolumn{4}{|l|}{ Classification } \\
\hline $\begin{array}{l}\text { Type Research - Applied } \\
\text { Type llotion - Sliding } \\
\text { Variables } \\
\text { Process - Film formation } \\
\text { Materials - Additives } \\
\text { Application }\end{array}$ & rch & $\begin{array}{l}\text { Subject } \\
\text { Cbjective } \\
\text { Energy Relevance }\end{array}$ & $\begin{array}{l}6 \\
2 \\
3\end{array}$ \\
\hline
\end{tabular}

Objective

To understand anti-wear and antiseize mechanisms in ZDP and TCP.

Description

Friction and wear studies are being conducted along with surface analysis techriques to understand the antiwear and antiseizure mechanisms of two well knowr: additives. It has been shown that a phosphide is formed in an 02 defficient atmosphere and a phosphate in an $\mathrm{O}_{2}$ rich atmosphere; these act as low shear strength films. 


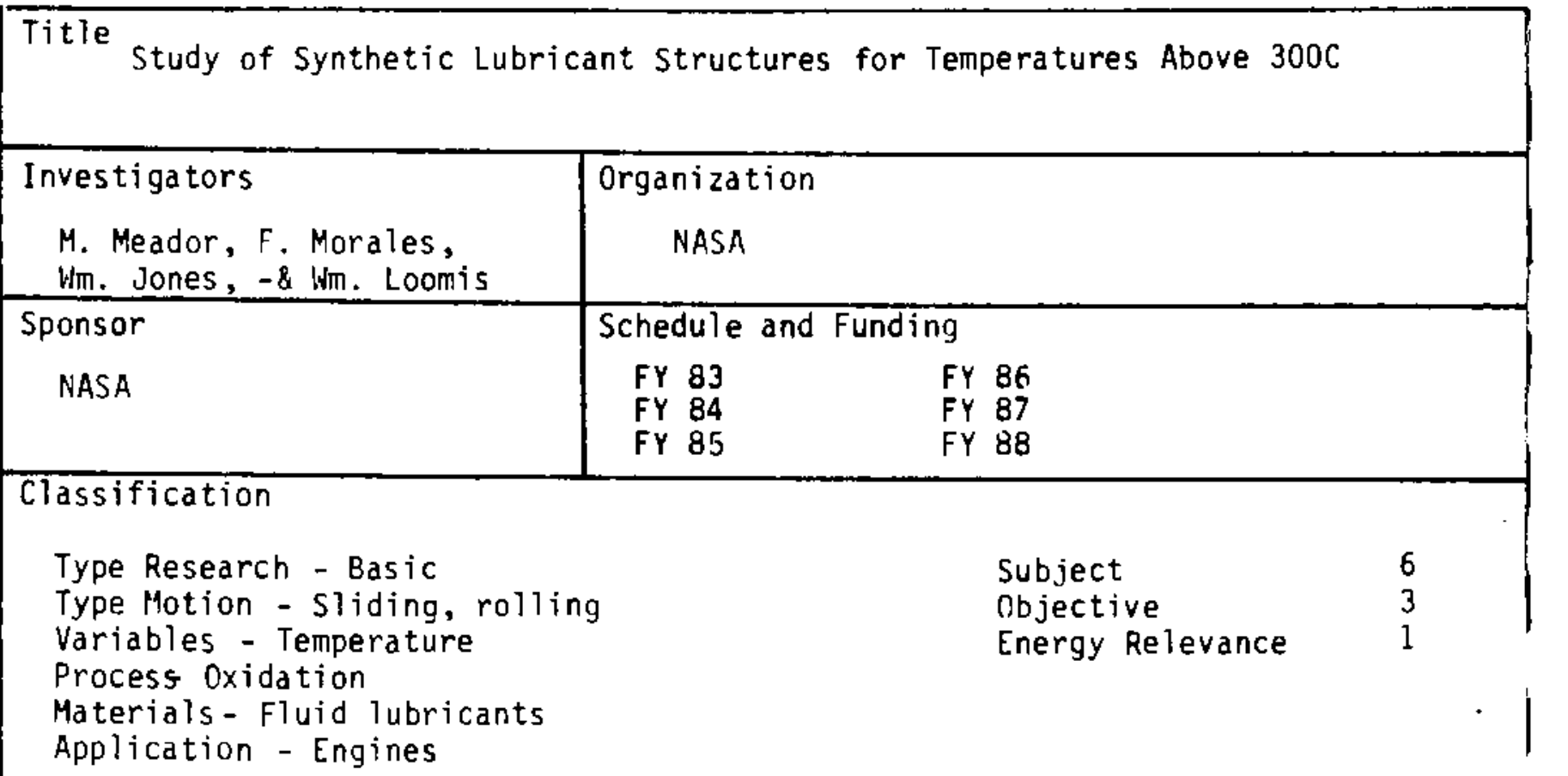

\section{Objective}

To isolate molecular structures which can be used as engine lubricants to $300 \mathrm{C}$

\section{Description}

The fundamental processes occurring during the thermal and oxidative degradation of hydrocarbons is studies. Particular emphas is is given to various classes of liquid lubricants such as mineral oils, esters, polyphenyl ethers, C-ethers and fluorinated polyethers. Experimental techniques for determining thermal and oxidative stabilities of lubricants are considered. The role of inhibitors and catalysis is also covered.

Currently studies are being carried out with perfioroalkylethers. Several different investigators are studying oxidation, thermal stability, lubricity, and metal catalyzation reactions 


\begin{tabular}{|c|c|}
\hline \multicolumn{2}{|l|}{ Title } \\
\hline Advanced Hydr & erials \\
\hline Investigators & Organization \\
\hline L. Gschwender & WPAFB - Materials Laboratory \\
\hline Sponsor & Schedule and Funding \\
\hline WPAFB-ML & $\begin{array}{l}\text { FY } 83 \\
\text { FY } 84 \\
\text { FY } 85\end{array}$ \\
\hline
\end{tabular}

Classification

Type Research - Applied

Type Motion

Variables - Structure, Properties

Process - Lubrication

Materials - Hydraulic Fluids

Application - Actuators, Pumps

\section{Objective}

To develop low temperature MIL-H-83282 hydraulic fluid for current alert aircraft. Develop advanced high temperature fluids for future aircraft sys tems.

Description

Formulations with Pho base stocks having $-65^{\circ} \mathrm{F}$ viscosity properties without sacrificing fire resistance are sought. Viscosity index improvers may be used to improve viscosity properties over operational temperature range. Advariced base stocks based on silahydrocarbon materials are synthesized and their structure-property relationships established. Economical synthes is routes for silahydrocarbons are sought. 


\begin{tabular}{|c|c|}
\hline $\begin{array}{l}\text { Title } \\
\text { Nonf Tammable }\end{array}$ & /Seals \\
\hline $\begin{array}{l}\text { Investigators } \\
\text { C. Snyder }\end{array}$ & $\begin{array}{l}\text { Organization } \\
\text { WPAFB - Materials Laboratory }\end{array}$ \\
\hline Sponsor & Schedule and Funding \\
\hline WPAFB-ML & $\begin{array}{l}\text { FY } 83 \\
\text { FY } 84 \\
\text { FY } 85\end{array}$ \\
\hline
\end{tabular}

\section{Classification}

Type Research - Applied

Type Motion

Variables - Structure, Properties

Subject

Objective

6

Energy Relevance

Process - Lubrication

Materials - Hydraulic Fluids

Application - Actuators, Pumps

\section{Objective}

To develop hydraulic fluids/seals for nonflamable hydraulic systems for future aircraft.

Description

Candidate nonflammable hydraulic fluid is chlorotrifluoroethylene (CTFE).

Model compounds are synthesized for study as base stocks. Additives are selected/formulated for effective response as antiwear and anitcorrosion inhibitors. Elastomeric seal materials with compatibility performance in CTFE are synthesized/formulated/evaluated. Candidate formulations are evaluated in pump test stands and actuator rigs for performance. 


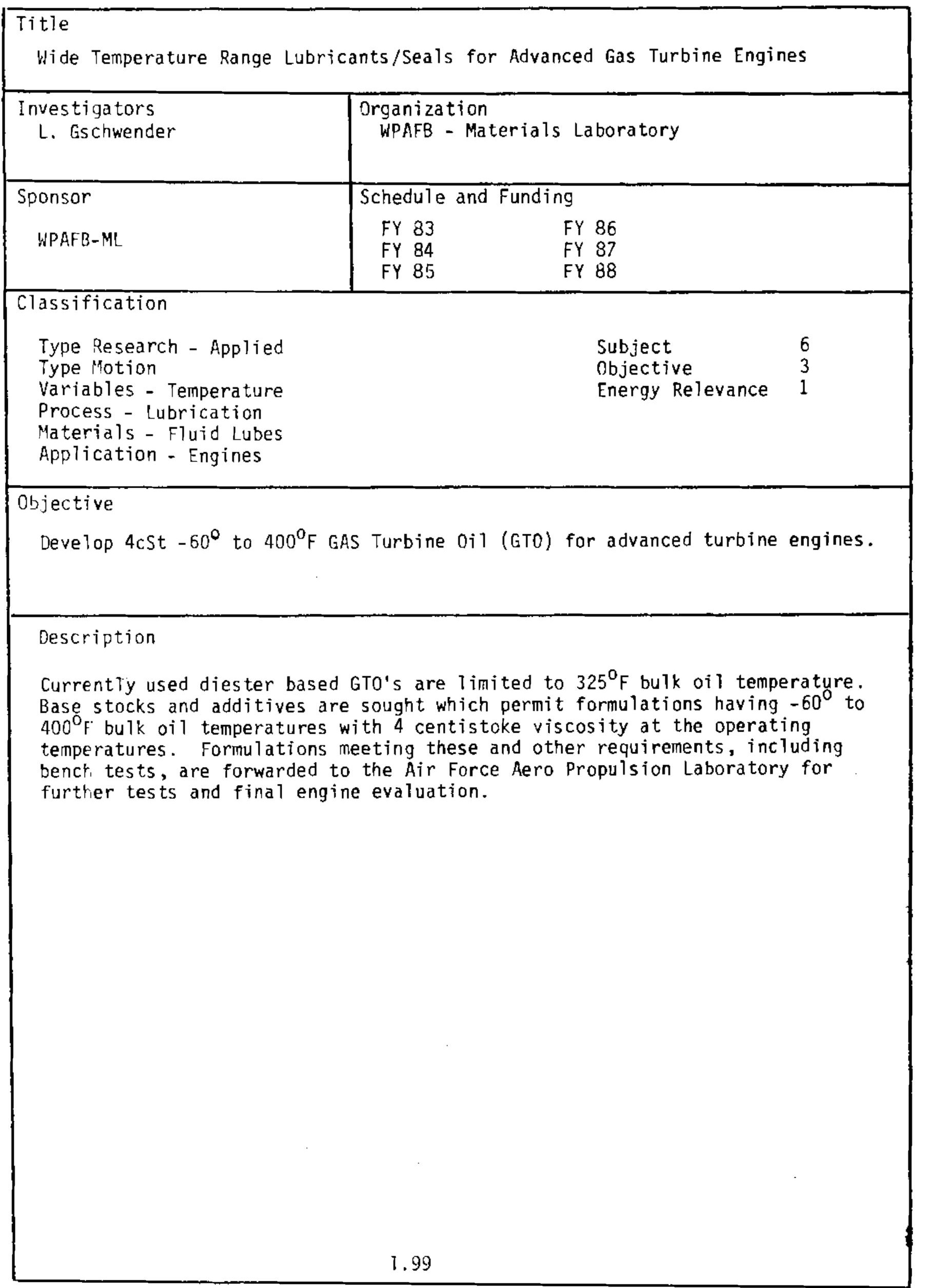






Classification

Type Research - Applied

Type Motion

Variables - Temperature

Process - Lubrication

Materials - Fluid Lubes

Subject $\quad 6$

$\begin{array}{ll}\text { Objective } & 3 \\ \text { Energy Relevance } & 1\end{array}$

Application - Engines

Objective

Develop high temperature thermally, oxidatively stable GTO candidate materials for use at $600^{\circ}-700^{\circ} \mathrm{F}$.

Description

Initial efforts will establish fundamental understanding and sound technology base in the highly fluorinated fluids and additives. Perfluoroalkylether (PFAE) base fluids will be synthesized and characterized for structureproperty relationship. Fluorinated additives which exhibit response in these fluids are sought and their interaction with base fluids and surfaces will be investigated and characterized. 


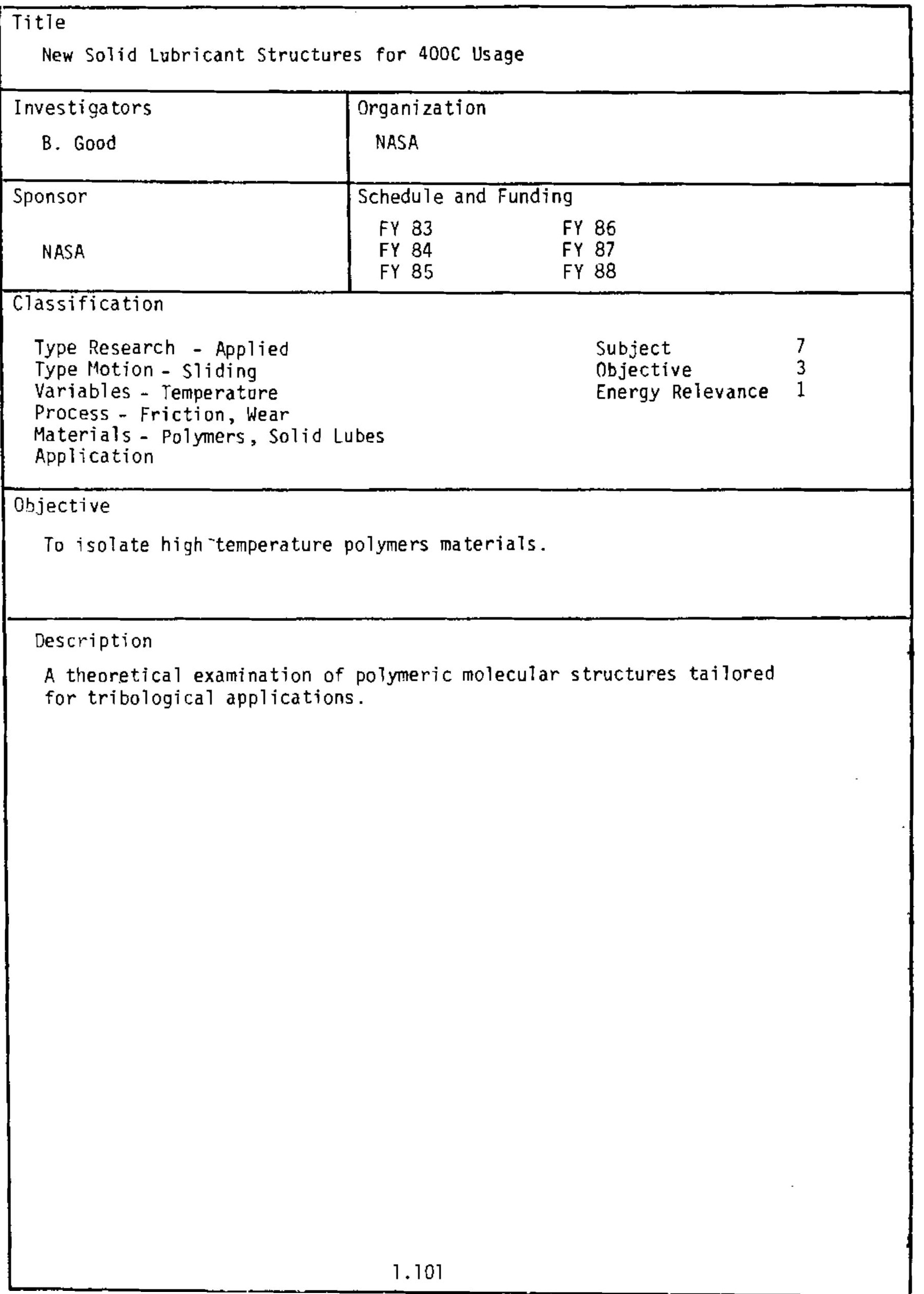




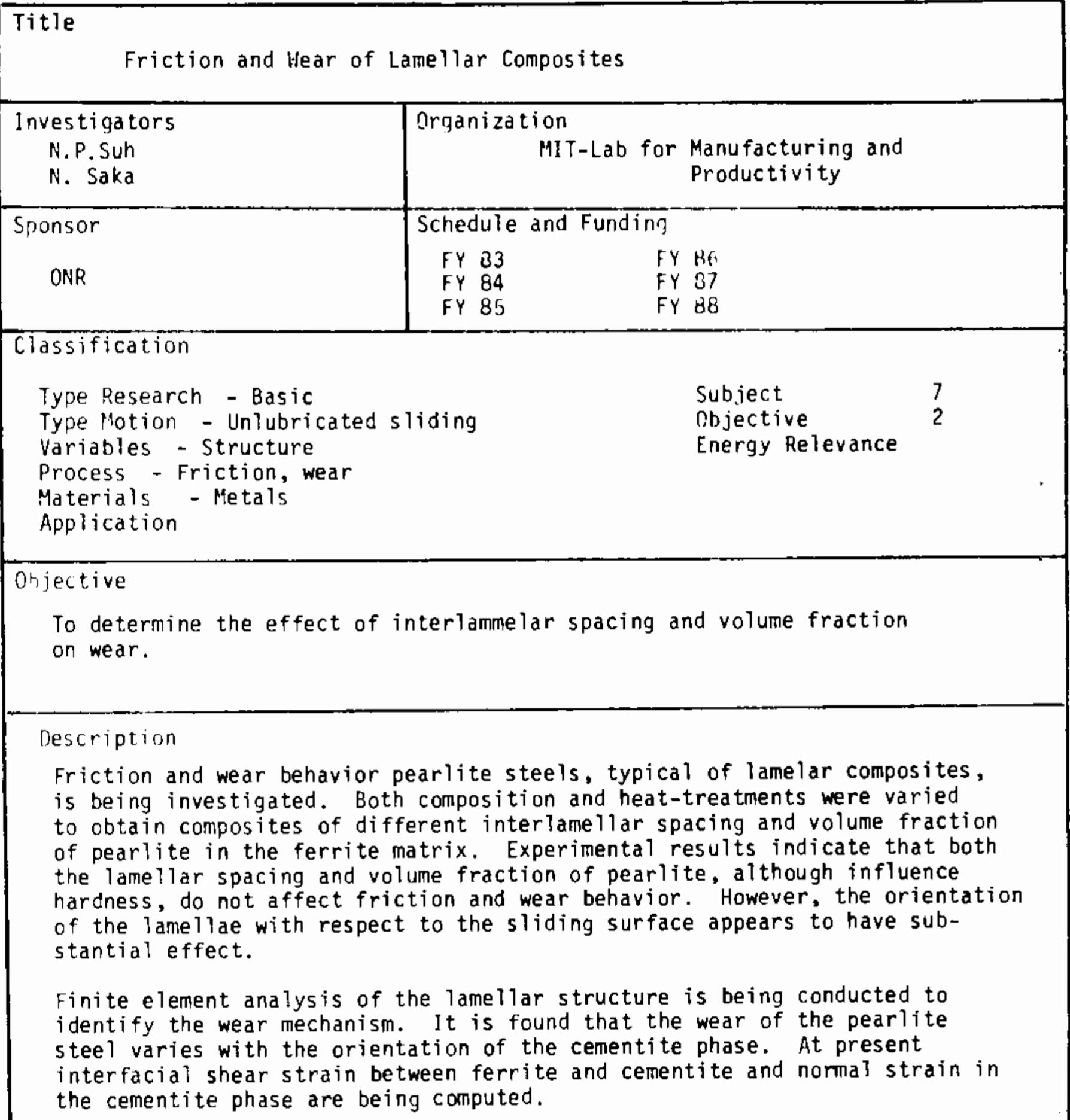


Title

Solid Film Rolling Element Bearings

\begin{tabular}{|c|c|}
\hline $\begin{array}{l}\text { Investigators } \\
\text { S.A. Barber } \\
\text { J.W. Kannel }\end{array}$ & $\begin{array}{l}\text { Organization } \\
\text { Battelle-Columbus }\end{array}$ \\
\hline Sponsor & Schedule and Funding \\
\hline AFWAL/DARPA & $\begin{array}{lll}\text { FY } & 83 & \text { FY } 86 \\
\text { FY } & 84 & \text { FY } 87 \\
\text { FY } & 85 & \text { FY } 88\end{array}$ \\
\hline
\end{tabular}

Classification

Type Research - Exploratory Development

Subject

7,18

Type Motion - Lubricated Rolling

Variables - Temperature, Stress

Objective

3

Process - Life

Materials - Solid Lubricants

Application - Rolling Contact Bearings

Objective

To determine feasibility of lubricating rolling element bearings with solid lubricants.

Description

A substantial weight reduction in limited-life turbine engines could be rea? ized by replacing liquid lubricated main engine bearings with bearings lubricated by a replenishable solid film lubricant. The feasibility of this approach was evaluated by examinijng:(1) The effect of solid film on contact stresses within the bearing, (2) The effect of alternate cage intervals on bearing stability at high speeds and temperatures, and (3) The use of the retainer material as a possible sol-d lubricant source. Experimental investigations of solid film transfer mechanisms were conducted, as well an analytical investigations of stresses and bearing stability. 


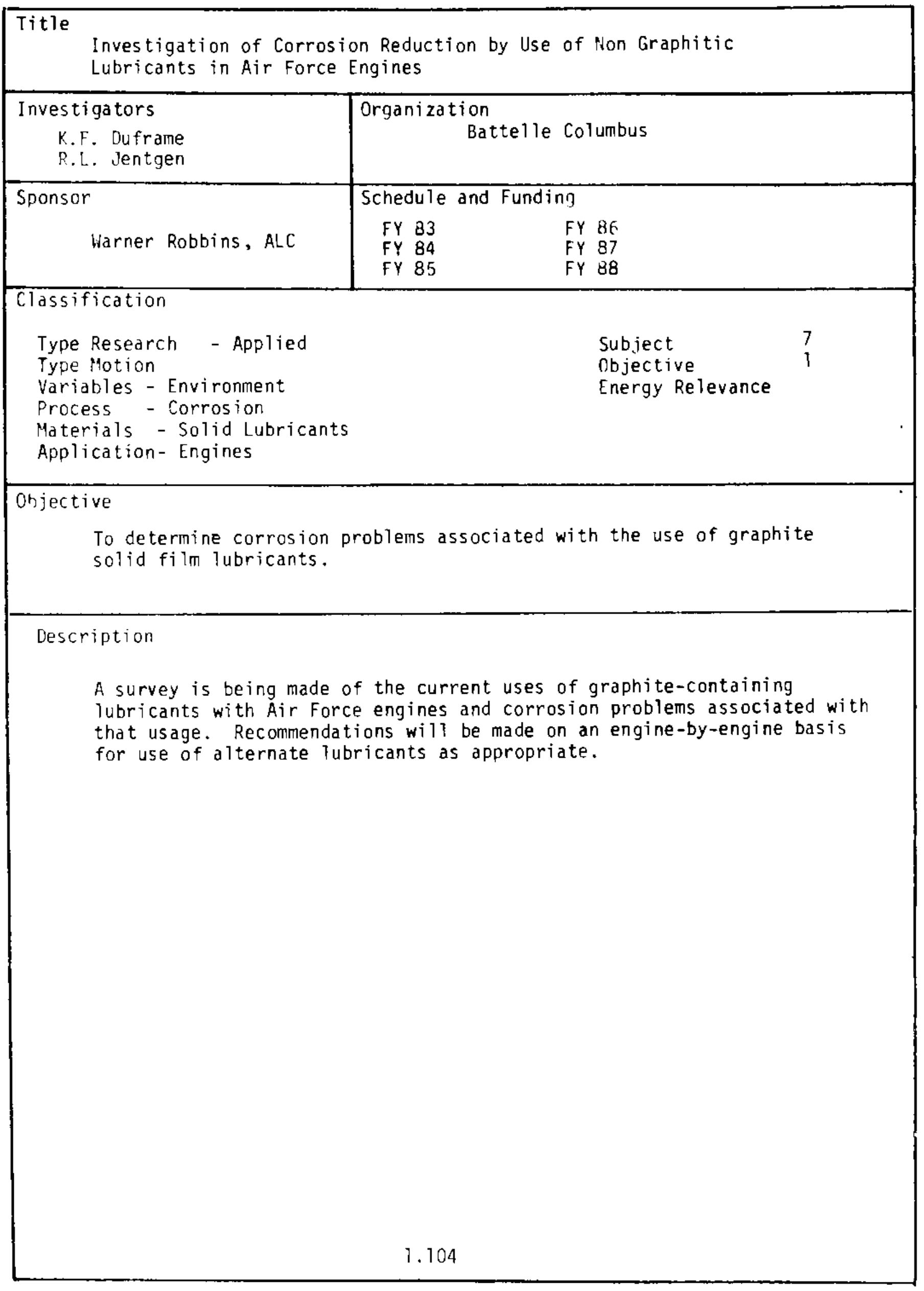




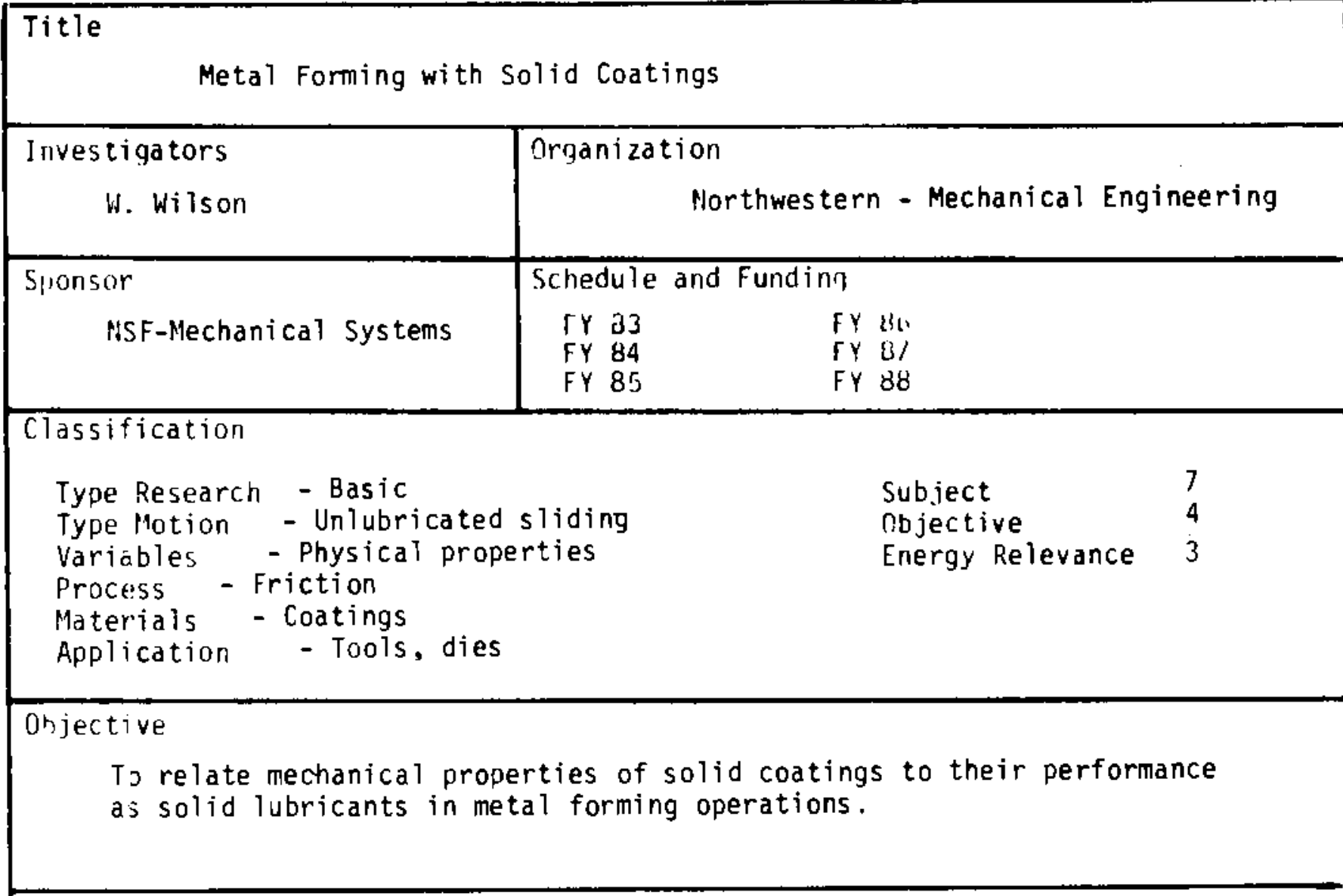

Description

A study is being made to determine mechanisms of lubrication using solid films in a variety of metal forming processes. Soft coatings (polymers, waxes, etc.) are applied to various work piece materials. The effect of material properties on film thickness, friction, break down stress, and plastic flow are being investigated. 
Title

Water Based Solid Film Lubricants

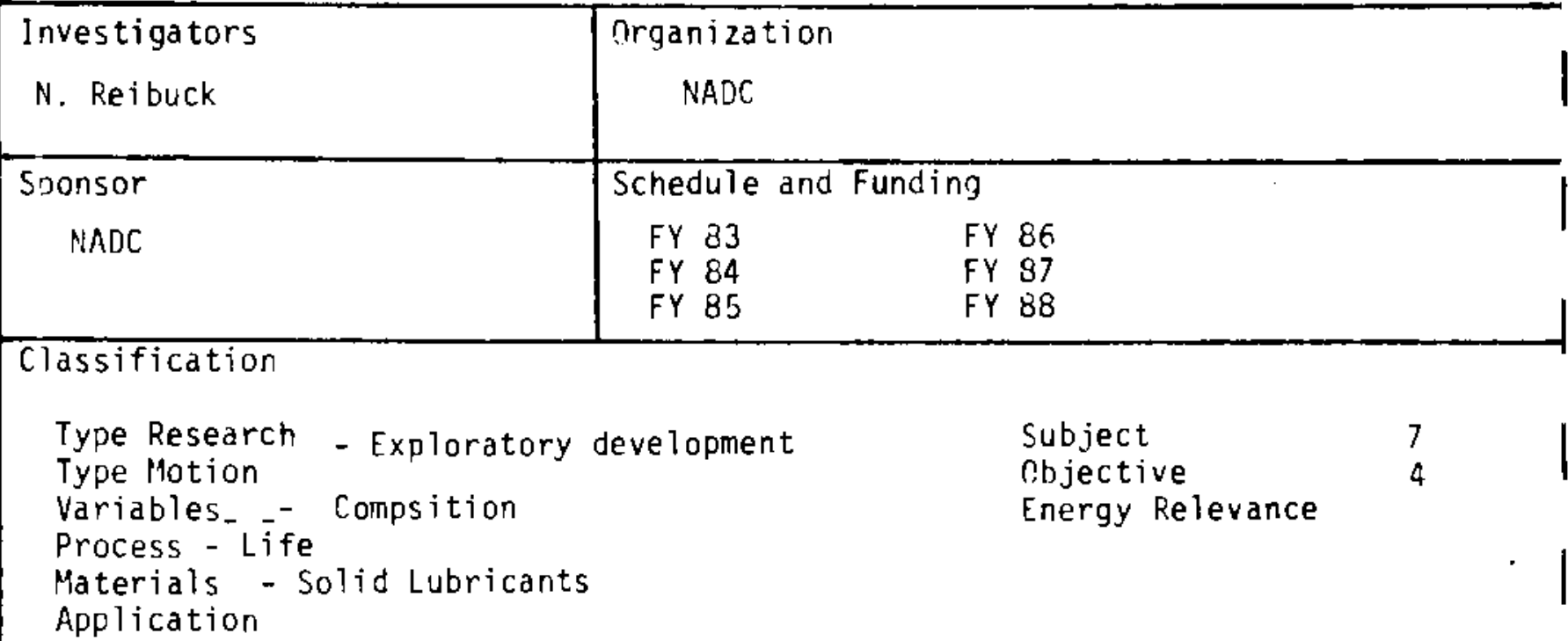

Objective

To evaluate lithium silicate as a substitute for sodium silicate in ML-1-813229 bonded solid film lubricant.

\section{Description}

A need exists for a water resistant high temperature solid film lubricant which provides corrosion protection. Specification MIL-L-81329 covers a water based solid film lubricant which contains milybdenum disulfide and graphite and uses sodium silicate as a binder. This material has excellent high temperature capabilities $400^{\circ} \mathrm{C}$ (7520 F), but is seriously deficient in water resistance and corrosion preventive capabilities.

The dual objectives of this program are to develop a high temperature water based solid film lubricant with good water resistance and corrosion protection properties superior to specification MIL-L-81329 and to develop a water based version of specification MIL-L-8937 material to eliminate the use of organic solvents.

Solid film lubricants using water soluble organic resins as binders were studied as possible replacements for MIL-L-8837 solvent based materials. The best material studied of this type showed only half the endurance life required for specification MIL-L-8937 materials. 


$$
\text { Title Intercalated Solid Lubricants }
$$

\begin{tabular}{|c|c|}
\hline $\begin{array}{c}\text { Investigators } \\
\text { A. Conte }\end{array}$ & $\begin{array}{c}\text { Organization } \\
\text { NADC }\end{array}$ \\
\hline Sponsor & Schedule and Funding \\
\hline NADC & $\begin{array}{l}\text { FY } 83 \\
\text { FY } 84 \\
\text { FY } 85\end{array}$ \\
\hline
\end{tabular}

Classification

Type Research - Basic

Type Motion - Lubricated sliding

Variables - Compositions

Subject

Objective

Process - Friction, Life

Energy Relevance 3

Materials - Solid Lubricants

Application

Objective

To develop improved solid lubricants by intercalation with other compounds.

Description

Using graphite as a model host compound the process of intercalation, i.e. the insertion of foreign atoms or molecules between molecular plance of layer lattice solids has been shown to provide new materials with intrinsic lubricating properties. A. three year research program has been carried out to establish basic scientific guidelines for the use of intercalated graphite compounds as improved solid lubricants. The falex test apparatus was used to determine the endurance life and load capacity of such compounds. Results were compared with MiS 2 and graphite. Transition metal chlorides of $\mathrm{Co}, \mathrm{Fe}, \mathrm{Cu}$, and $\mathrm{Ni}$ when intercalated into the graphite structure increased the endurance life of the solid film lubricants by a factcr of 2.4 and the load carrying ability by a factor of 2.2. Transition metals $C_{0}$ and $\mathrm{Fe}$ increased endurance $1 \mathrm{ife}$ up to 4.5 times. A mechanism has been proposed based upon thermal analys is and kinetic rate observations to explain this lubricating action. Using this approach an alternative to $\mathrm{MlOS}_{2}$ can be made available. 


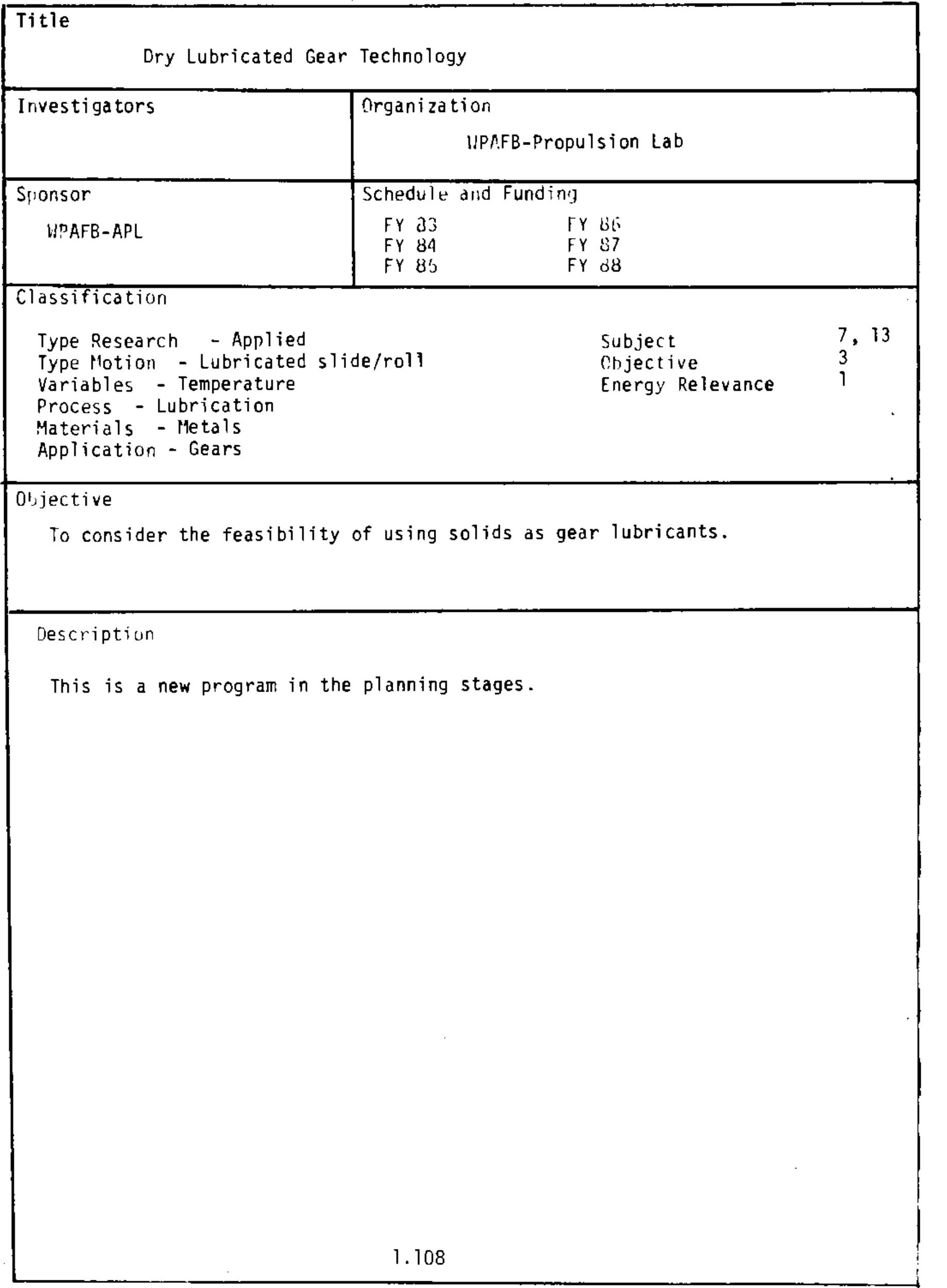




\section{Title}

Solid Lubricant Design Methodology

\begin{tabular}{|c|c|}
\hline $\begin{array}{l}\text { Investigators } \\
\text { B.B. Aggarwal } \\
\text { R.L. Bovenkerk }\end{array}$ & $\begin{array}{l}\text { Orqanization } \\
\text { SKF Technology Services }\end{array}$ \\
\hline Spronsor & Schedule and Fundim \\
\hline NASA-Lewis & $\begin{array}{ll}\text { FY } & 3.3 \\
\text { FY } & 84 \\
\text { FY } & 85\end{array}$ \\
\hline
\end{tabular}

Classification

Type Research - Applied

Type Potion - Lubricated slide/roll

Variables - Load, velocity, temperature

Process - Lubrication

Materials - Solid lubricants

Application - Rolling contact bearings

\section{Ohjective}

To define effective operating ranges for solid lubrication and to develop

a design methodology.

Description

Solid lubrication design methodology is being developed which is analogous to the elastohydrodynamic theory for liquid lubricated rolling element bearings. The proposed approach consists of experimental tasks in which various solid lubricants will be studied in rolling/sliding contact. The test conditions selected for these tasks encompass the range of bearing temperatures, contact stresses, and sliding speeds projected during the operation of turbocharged adiabatic diesel engines. Concurrent analytical tasks are aimed at developing models for the solid lubricant systems. The outcome of this program will include experimental data on the solid lubrication of advanced materials and analytical guidelines necessary for the design of solid lubricated rolling element bearings, and other solid lubricated components. 


\section{Title}

Hi Temp Lubricating Materials

\begin{tabular}{|l|ll|}
\hline Investigators & Organization & \\
H. Siney & & \\
\hline Sponsor & Schedule and Funding \\
& FY 83 & FY 86 \\
& FY 84 & FY 87 \\
& FY 85 & FY 88 \\
\hline Classification & & \\
Type Research - Applied & & Subject \\
Type Mlotion - Lubricated sliding & Objective \\
Variables - Temperatures & Energy Relevance \\
Process - Friction, wear & 1 \\
Materials - Coatings, solid lubes & \\
Application &
\end{tabular}

Objective

To develop high temperature lubricating coatings.

Description

Advanced technology engines such as the adiabatic diesel and the small, efficient gas turbine have severe lubrication and wear problems at the temperatures beyond the capabilities of any of these lubricants. Here, self-lubricating ceramics and inorganic composites for use at $1000^{\circ} \mathrm{C}$ or higher are of interest.

To meet this need a program is under way to develop $1500 \mathrm{C}$ ceramic lubricating coatings and infiltrated NiCr alloys. 


\section{Titie}

Solid Lubricant Powder Materials/Technology for Application in Turbine

Engine Rolling Element Bearings

\begin{tabular}{|l|ll}
\hline $\begin{array}{l}\text { Investigators } \\
\text { K. Mecklenburg }\end{array}$ & $\begin{array}{l}\text { Organization } \\
\text { WPAFB - Materials Laborat }\end{array}$ \\
\hline Sponsor & Schedule and Funding \\
WPAFB-ML & FY 83 & FY 86 \\
& FY 84 & FY 87 \\
& FY 85 & FY 88
\end{tabular}

Classification

Type Research - Development

Subject

Objective

Energy Relevance 3

Variables - Properties

Process - Lubrication

Materials - Solid Lubricants

Application - Rolling Bearings

Objective

Develop solid lubricant powder materials for use as dry lubrication techniques for rolling element bearings.

\section{Description}

This effort will augment Aeropropulsion Laboratory program to design/develop a powder lubrication system for turbine engine bearings. Emphasis will be on selection/characterization of solid lubricant materials which are effective Tubricants in free-flowing powder form. The effort will provide a concentrated study of the powder materials and their properties leading to selection of candidates for evaluation as powder lubricants carried in an air/gas stream through rolling element bearings. 


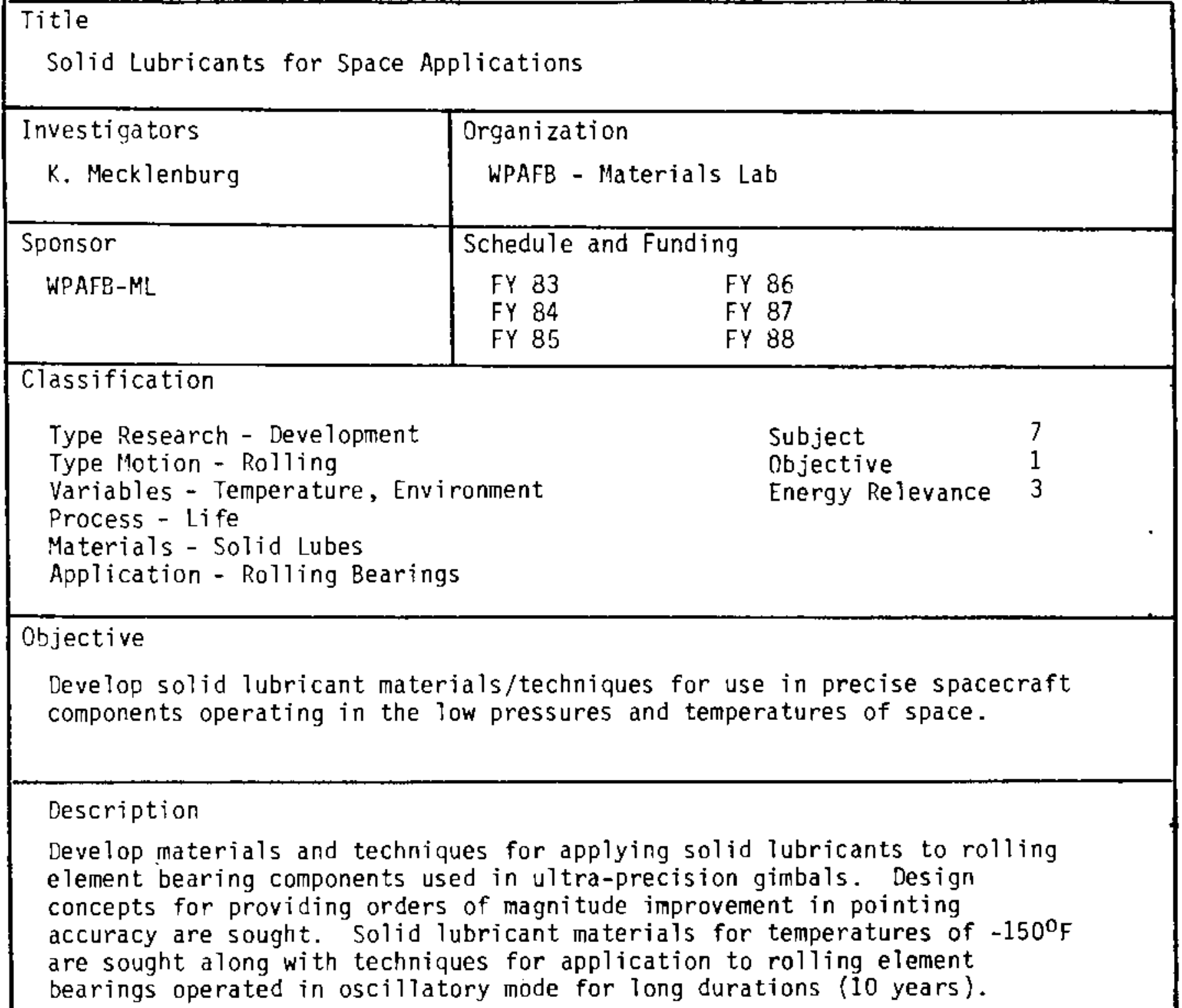

\begin{tabular}{|l|ll|}
\hline $\begin{array}{l}\text { Investigators } \\
\text { K. Mecklenburg }\end{array}$ & $\begin{array}{l}\text { Organization } \\
\text { WPAFB - Materials Lab }\end{array}$ \\
\hline Sponsor & Schedule and Funding \\
WPAFB-ML & FY 83 & FY 86 \\
& FY 84 & FY 87 \\
& FY 85 & FY 88 \\
\hline
\end{tabular}

Classification

Type Research - Development

Type Motion - Rolling

Variables - Temperature, Environment

Process - Life

Materials - Solid Lubes

Application - Rolling Bearings

Objective

Develop solid lubricant materials/techniques for use in precise spacecraft components operating in the low pressures and temperatures of space.

Description

Develop materials and techniques for applying solid lubricants to rolling element bearing components used in ultra-precision gimbals. Design concepts for providing orders of magnitude improvement in pointing accuracy are sought. Solid lubricant materials for temperatures of $-150^{\circ} \mathrm{F}$ are sought along with techniques for application to rolling element bearings operated in oscillatory mode for long durations (10 years). 


\section{Title}

Fundamentals of Solid Lubricated Ceramics

\begin{tabular}{|c|ll}
\hline $\begin{array}{l}\text { Investigators } \\
\text { M. Gardos }\end{array}$ & $\begin{array}{l}\text { Organization } \\
\text { Hughes Aircraft Co. }\end{array}$ \\
\hline Sponsor & & \\
DARPA/ML & Schedule and Funding \\
& FY 83 & FY 86 \\
& FY 84 & FY 87 \\
& FY 85 & FY 88 \\
\hline
\end{tabular}

Classification

Type Research - Fundamental

Type Motion

Variables - Chemical Properties

Process - Adhesion, Friction, Lubrication

Subject

objective

7,8

Energy Relevance 1

Materials - Solid Lube, Ceramic

Application

Objective

To develop the fundamental understanding of solid lubricant/ceramic materials interactions leading to a sound technology base for application in weapon systems.

Description

A highly interdisciplinary program using subcontracted expertise has been planned to delve into the basic intrinsic properties of solid lubricant materials and ceramic substrates to develop the necessary understanding of the fundamental surface properties/interactions to allow development of high temperature solid lubricated ceramic systems. 
Title

Antimony Thioantimonate: Lubricating Properties and Mechanisms

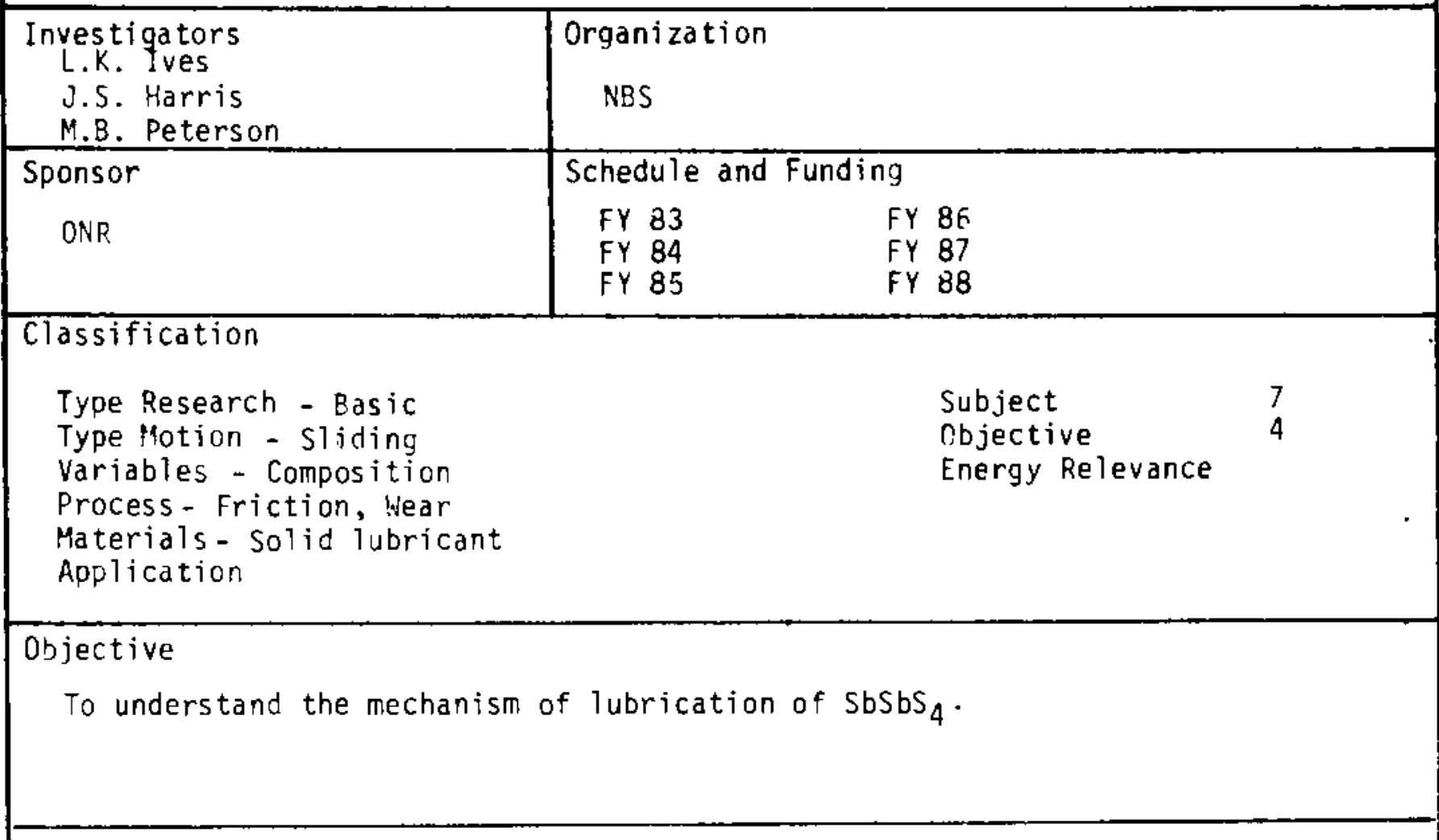

Description

A variety of tests are being run to evaluate the benefits of $\mathrm{SbSbS}_{4}$ as a grease additive. A new abrasion test device has been developed to measure lubricant abrasion and abrasion resistance. 
Title

Tribological Systems Operating in Extreme Conditions: Novel Surface

Modification Processes

\begin{tabular}{|l|ll}
\hline $\begin{array}{l}\text { Investigators } \\
\text { M. Kaminsky }\end{array}$ & Organization \\
& Argonne National Lab \\
\hline Sponsor & Schedule and Funding \\
& FY 83 & FY $86 x$ \\
DOE ECUT & FY $84 X$ & FY $87 x$ \\
& FY $85 X$ & FY $88 X$
\end{tabular}

Crassification

Type Research - Applied

Subject

Objective

Variables - Properties

Energy Relevance 2

Process - Friction, Wear

Materials - Coatings

Application

Objective

Develop surfaces 'with improved friction, wear, corrosion or erosion behavior for tribological applications.

Description

Theortical and experimental studies are being conducted to develop novel materials/surfaces for tribologicals. Modeling studies of recoil and firect implantation of single and multiple species into binary and tertiary compounds. The experimental effort will include recoil and direct implantation into alloys and the characterization and the testing of the implanted material for tribological applications. 


\section{Title}

Development of Hard Coatings for Tribological Coatings.

\begin{tabular}{|c|c|c|c|}
\hline $\begin{array}{l}\text { Investigators } \\
\text { M. Kaminsky }\end{array}$ & \multicolumn{3}{|c|}{$\begin{array}{l}\text { Organization } \\
\text { Argonne National Laboratory }\end{array}$} \\
\hline $\begin{array}{l}\text { Sponsor } \\
\text { ECUT/DOE }\end{array}$ & $\begin{array}{c}\text { Schedule } \\
\text { FY } 83 \\
\text { Fy } 84 \\
\text { Fy } 85\end{array}$ & $\begin{array}{l}n g \\
\text { Fy } 86 \\
\text { FY } 87 \\
\text { FY } 88\end{array}$ & \\
\hline $\begin{array}{l}\text { Classification } \\
\text { Type Research - Basic } \\
\text { Type Motion - Siliding } \\
\text { Variables } \\
\text { Process } \\
\text { Materials - Coatings } \\
\text { Application }\end{array}$ & 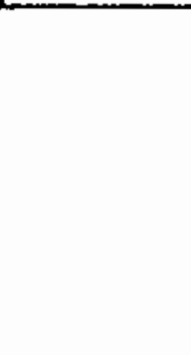 & $\begin{array}{l}\text { Subject } \\
\text { Objective } \\
\text { Energy Relevance }\end{array}$ & $\begin{array}{l}8 \\
2,6 \\
2\end{array}$ \\
\hline $\begin{array}{l}\text { Objective } \\
\text { To develop the base tech } \\
\text { tribological application }\end{array}$ & $\begin{array}{l}y \text { of coat } \\
\text { er extrem }\end{array}$ & $\begin{array}{l}\text { olid lubricants for } \\
\text { ons. }\end{array}$ & \\
\hline
\end{tabular}

Description

This program will establish and verify the correlation between the theoretical predictions on improvement in tool life based on a thermomechanical model of the tool wear process, and the performance of hard coated, high speed cutting tools. The program will help in providing the tools and knowledge necessary to design and produce novel coatings with greatly improved tribological properties. 
Title

Steady State Frictional Behavior of Thin Film Coatings

\begin{tabular}{|l|ll}
\hline $\begin{array}{l}\text { Investigators } \\
\text { Yutaka Shimazaki/ward Winer }\end{array}$ & $\begin{array}{l}\text { Organization } \\
\text { School of Mechanical Engineering } \\
\text { Georgia Institute of Technology }\end{array}$ \\
\hline Sponsor & Schedule and Funding \\
Georgia Institute of Technolog & FY 83 & FY 86 \\
& FY 84 & FY 87 \\
& FY 85 & FY 88
\end{tabular}

Classification

Type Research Basic

Type llotion Reciprocating

Variables Various

Process Film Formation

Materials Metals and Coatings

Application Various

Objective

To determine the time dependent friction and wear behavior of solid film lubricants.

Description

Steady state frictional behavior of thin film coatings are studied with the main emphasis on the effect of the applied coating thickness.

Four coating materials are studied, of wich three are solid lubricants $\left(\mathrm{MoS}_{2}, \mathrm{WSe}_{2}, \mathrm{WSe} \mathrm{H}_{2} / \mathrm{In} / \mathrm{Ga}\right)$ and one is wear resistance material (TiN). They are deposited by magnetron assisted sputtering on a steel substrate. Friction tests are performed with dry sliding under a normal atmosphere. The test configuration is a spherical slider sliding against a coated flat. The parameters studied include, film thickness, substrate roughness, applied load and substrate hardness. The effect of these parameters on the transition and steady state friction coefficients are evaluated.

The results show that the steady state friction coefficients of $\mathrm{MoS}_{2}$, $\mathrm{WSe}_{2}$, WSe ${ }_{2} / \mathrm{In} / \mathrm{Ga}$ coatings vary with the applied coating thicknesses. The minimumn and maximum friction coefficients obtained from each coating are $\mu_{\max }=0.66 / \mu_{\min }=0.07$ for $\operatorname{MoS}_{2}, \mu_{\max }=0.73 / \mu_{\text {min }}=0.05$ for WSe 2 ,

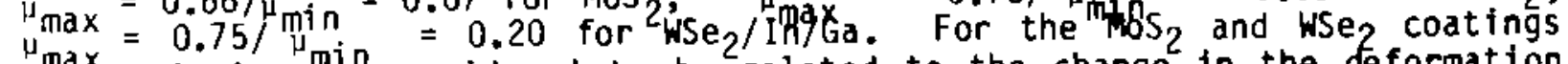
thplsx variation $95^{n}$ considered to be related to the change in the deformation mode of the coating. With the thicker coatings the wear track is fully covered with deformed coating material and the friction coefficients become higher. The steady state friction coefficient of WSe $/ \mathrm{In} / \mathrm{Ga}$ coatings are considered to be determined by the behavior of the debonded and resmeared coating material. The substrate hardness seems to play the most dominant role upon the behavior of the resmeared film.

A high value of the steady state friction coefficient is obtained with the TiN coatings $\left(\mu_{\text {max }}=0.90, \mu_{\text {min }}=0.57\right)$. During the steady state sliding is considered max be occurpling between the slider and transferred slider material. The effect of coating thickness in the Tin case is not significant. 
Tit Te
Studies of Dynamic Contact of Ceramics and Alloys for Advanced Heat Engines

\begin{tabular}{|c|c|}
\hline $\begin{array}{l}\text { Investigators } \\
\text { K.F. Dufrane } \\
\text { H.A. Glaeser }\end{array}$ & $\begin{array}{l}\text { Organization } \\
\text { Battelle - Columbus }\end{array}$ \\
\hline Sponsor & Schedule and Funding \\
\hline DOE / DRNL & $\begin{array}{l}\text { FY } 83 \\
\text { FY } 84 \\
\text { FY } 85\end{array}$ \\
\hline
\end{tabular}

Classification

Type Research - Basic

Subject 8

Type Motion - Reciprocating

Variables - Materials, Environment, Load, Speed

Objective

3

Process

Materials - Ceramics (monolithic and coatings) and metals

Application - Advanced heat engines

Objective

Develop generic understanding of friction and wear behavior of ceramic interfaces under conditions typical of advanced heat engines.

Description

An experimental study is being conducted with a laboratory apparatus to reproduce the important conditions of advanced heat engines. The primary focus is on the piston ring/cylinder interface. Materials are to be well-characterized before and after testing to provide basic data on the sliding process. Models are to be developed from the results of the tests to predict the friction and wear behavior of monolithic ceramics and ceramic coatings as functions of applied stress, oscillatory frequency and stroke, temperature, time, environment, and macroscopic material properties. 


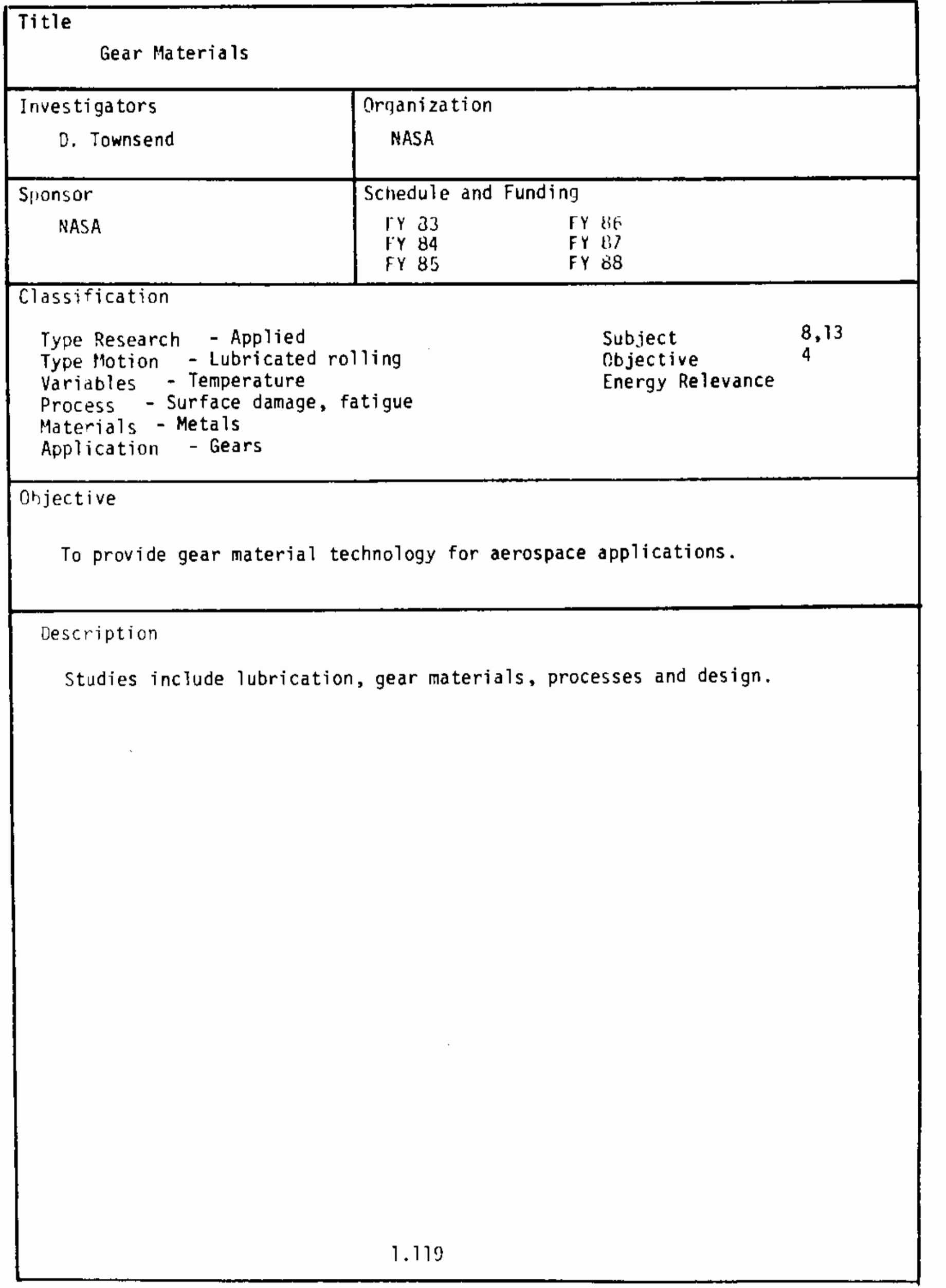




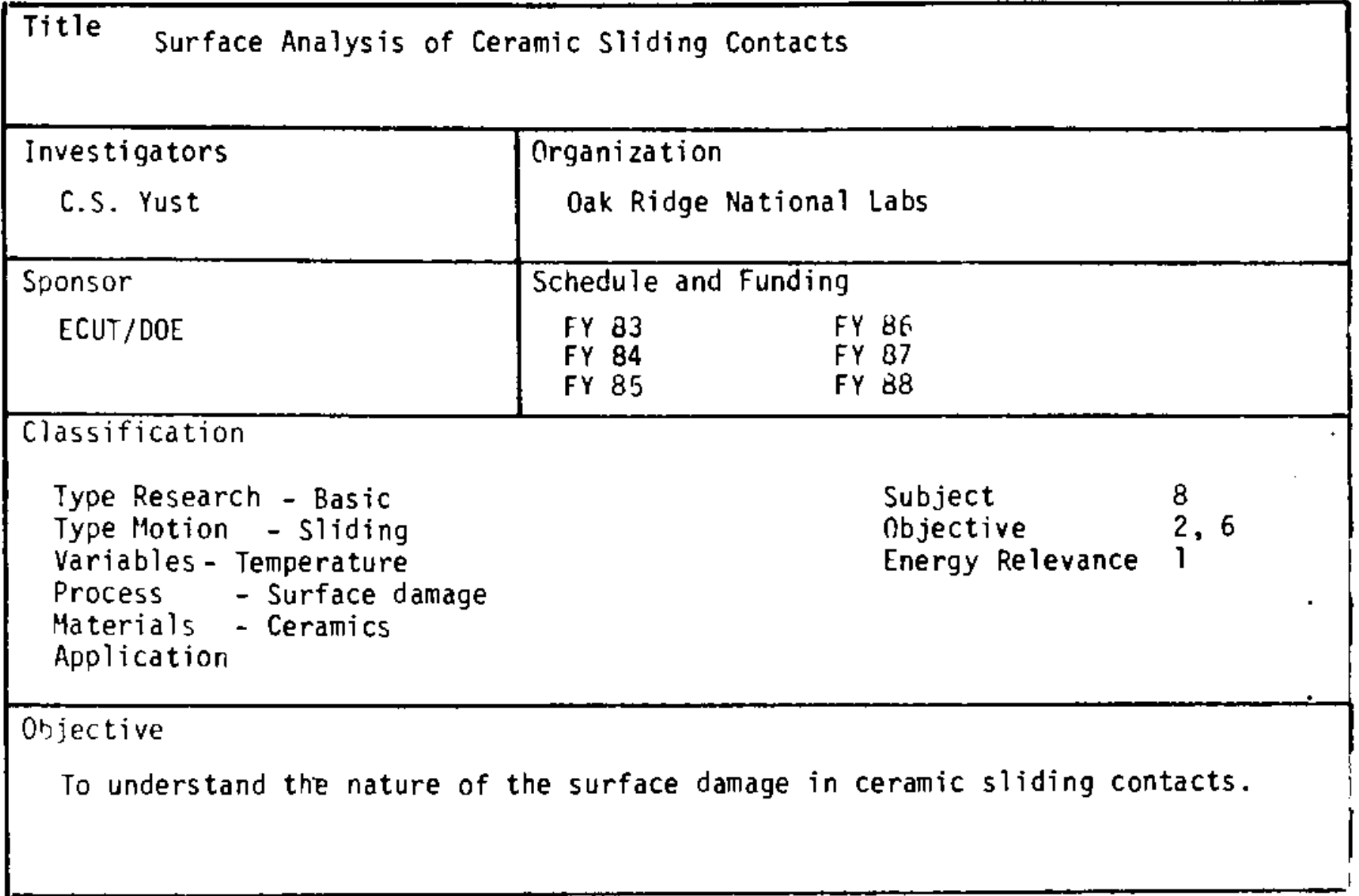

Description

A detailed surface examination is being made of ceramic wear test specimens. Observations are made of the wear tracks at various time increments to permit detection of early stages of sliding damage. Damage features are being correlated with wear mechanisms. 
Title

Friction and Hear of Dissimilar Ceramics at Elevated Temperatures

\begin{tabular}{|c|cc}
\hline $\begin{array}{c}\text { Investigators } \\
\text { F.J. Carignan }\end{array}$ & $\begin{array}{r}\text { Organization } \\
\text { Advanced Mechanical Technology Inc. }\end{array}$ \\
\hline Sponsor & Schedule and Funding \\
ECUT/DOE & FY 83 & FY 86 \\
& FY 84 & FY 87 \\
& FY 85 & FY 88 \\
\hline
\end{tabular}

Classification

Type Research - Applied

Type llotion - Uniubricated sliding

Variables - Temp

Process - Friction, wear

Subject

Objective

8

Materials - Ceramics

Energy Relevance 1

Application

Objective

To understand the tribological behavior of ceramic materials.

Description

Load/time matrix tests are being run on a pin on disk test apparatus at

high temperatures in order to determine the tribological characteristics

of ceramic combinations. 


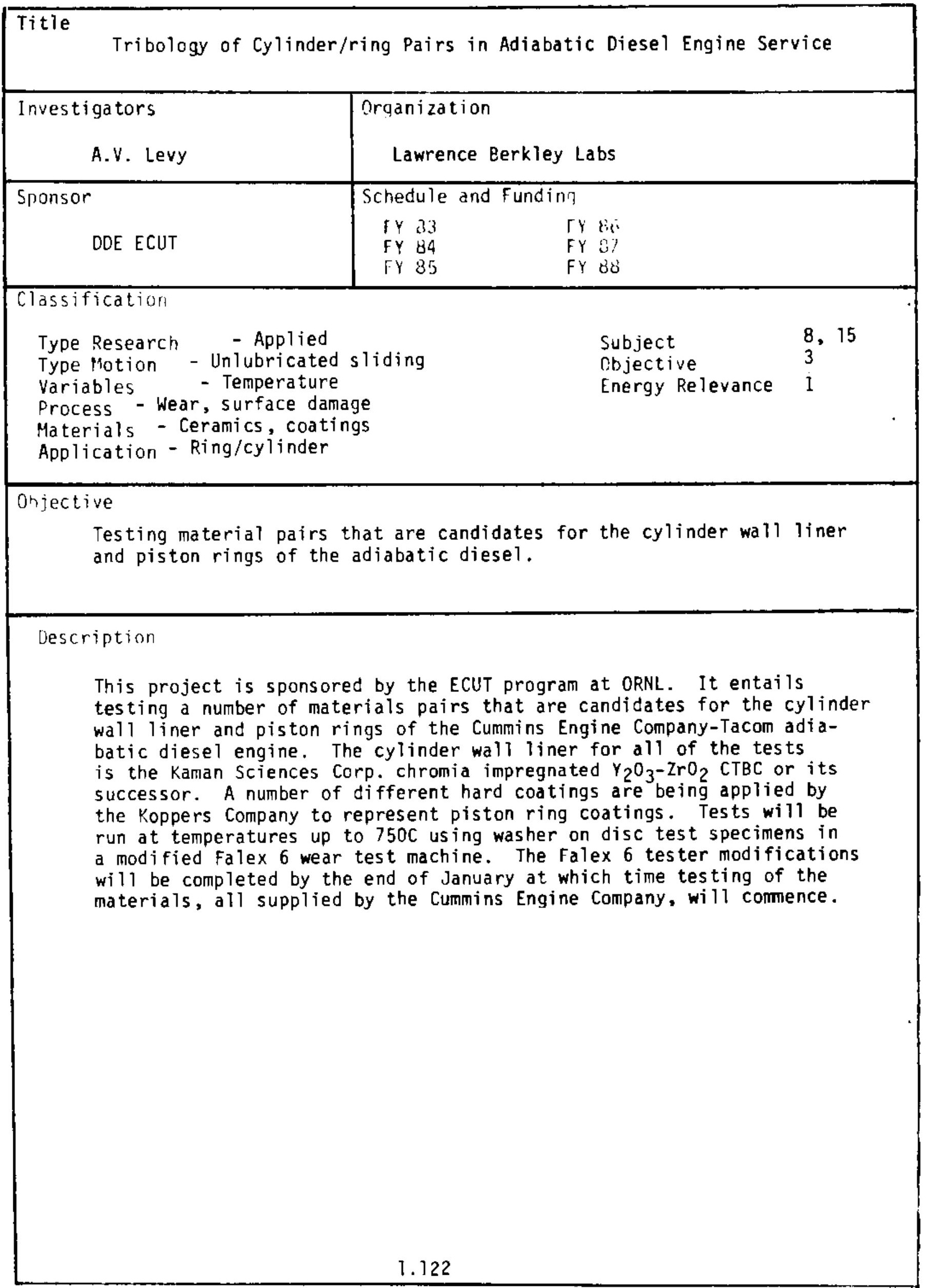




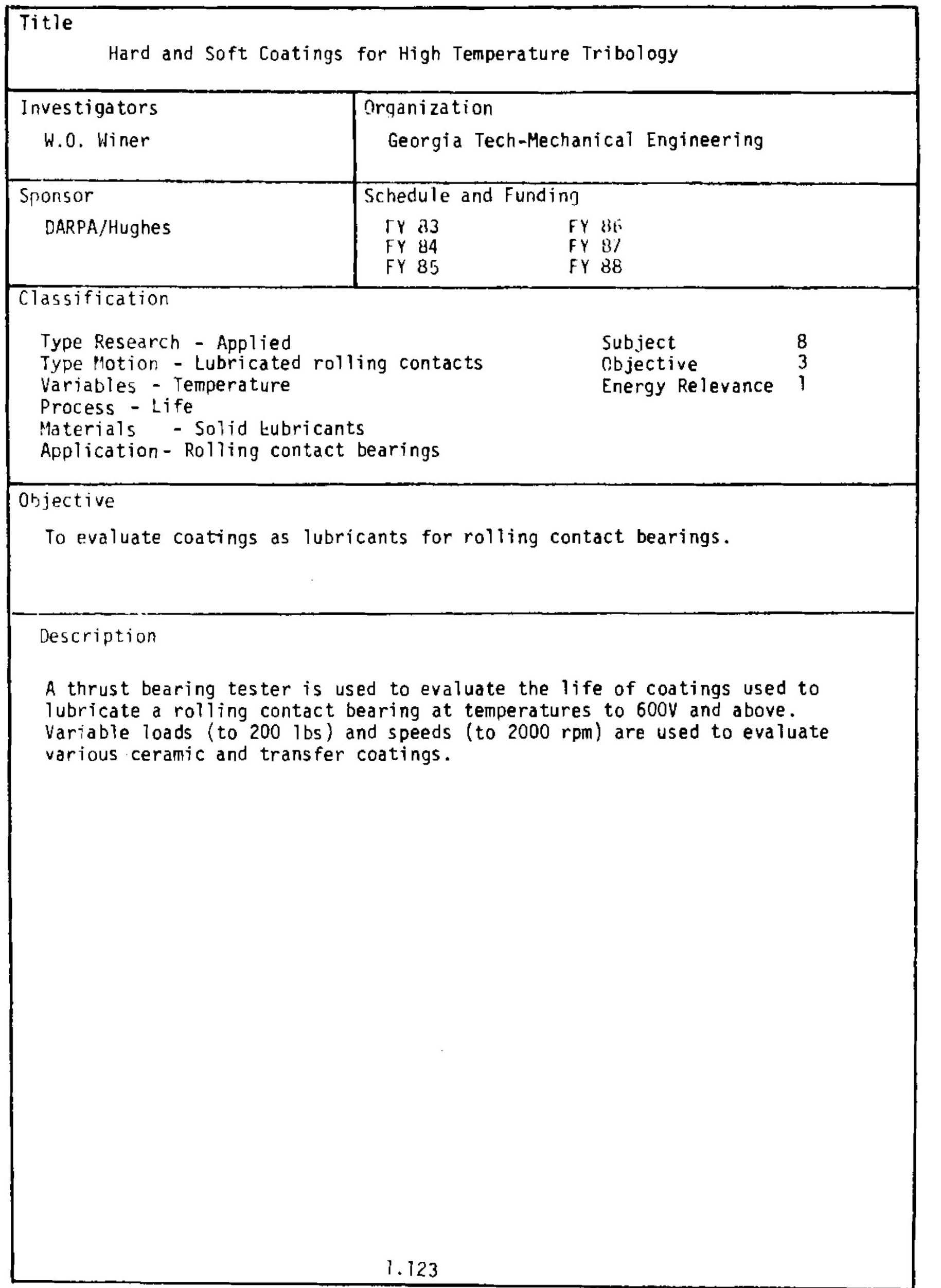


Title

Ceramic Frictional Studies

\begin{tabular}{|c|cc|}
\hline $\begin{array}{c}\text { Investigators } \\
\text { Paul Sutor }\end{array}$ & $\begin{array}{l}\text { Organization } \\
\text { Midwest Research Inst. }\end{array}$ \\
\hline Sponsor & Schetdule and Fundiny \\
DARPA/Air Force & TY 33 & FY \\
& FY 84 & Fy \\
& Fy 85 & FY 88
\end{tabular}

Classification

Type Research - Applied

Subject

8

Type Motion - sliding

Cbjective

3

Variables - Temperature

Energy Relevance $I$

Process - Friction, wear

Materials - Ceramics

Application

Orjective

To determine the friction and wear properties of ceramic-ceramic and ceramicmetal sliding pairs, and to demonstrate effective solid lubrication of ceramics and inetals.

liescription

Eighteen graphite fiber-reinforced, polyimide composites containing inorganic solid lubricants were extensively studies as high temperature lubricants for M-50 steel and hot-pressed silicon nitride. SEM/EDX was employed to study the sliding surfaces and mathematical models of the wear process were developed and evaluated. Unlubricated ceramic tribological studies were conducted at various loads, sliding velocities, and geometries of contact. Ceramics employed included silicon nitride, silicon carbide, and partially stabilized zirconia. Ceramic matrix composites, in which one phase was a high temperature lubricant, were evaluated for improved wear, friction, and transfer properties, sliding versus silicon nitride and steel. Auger spectroscopy and SEM/EDX was employed to characterize the sliding surfaces. The ceramic matrix composites included several silicon nitride-boron nitride compositions, silicon carbid-calcium fluoride/barium fluoride eutectic, and silicon carbide-graphite fluoride. 


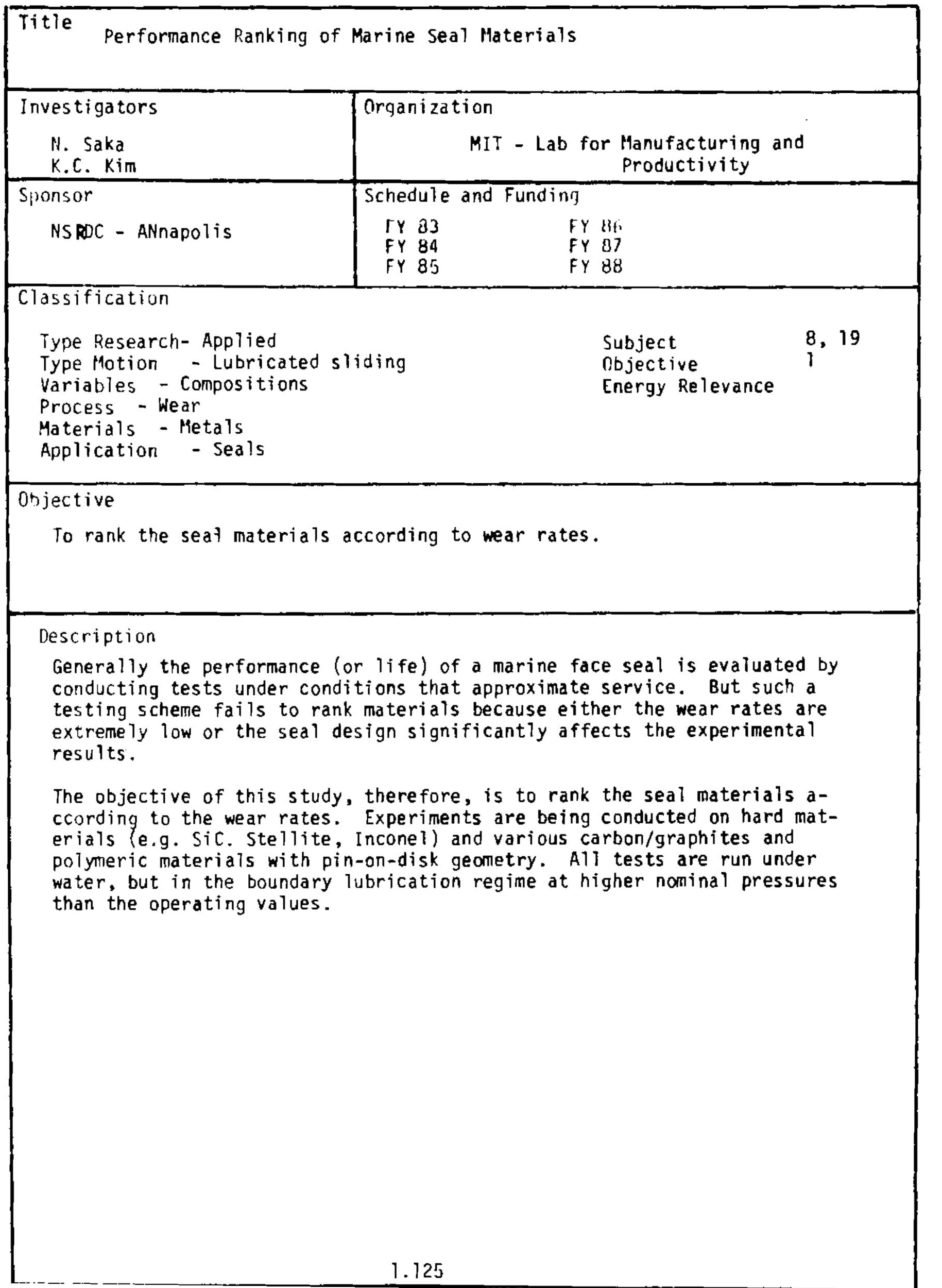


Title
Role of Chemical Affinity in the Frictional Behavior of Ceramics

\begin{tabular}{|c|c|c|}
\hline $\begin{array}{l}\text { Investigators } \\
\qquad \text { N.H. MacMilian }\end{array}$ & \multicolumn{2}{|c|}{$\begin{array}{l}\text { Orqanization } \\
\text { Materials Resea } \\
\text { Penn State Univ }\end{array}$} \\
\hline Sponsor & Schedule & and Funding \\
\hline NSF-Materials Science & $\begin{array}{ll}\text { FY } & 33 \\
\text { FY } & 84 \\
\text { FY } & 85\end{array}$ & $\begin{array}{l}\text { FY } 86 \\
\text { FY } 87 \\
\text { FY } 88\end{array}$ \\
\hline
\end{tabular}

Classification

Type Research - Basic

Type Motion - Unlubricated

Variables - structure, environment

Process - Friction, surface damage

Materials - Ceramics

Application

Onjective

To determine the effect of crystal structure, composition, and chemical affinity on frictional behavior.

Description

This project seeks to investigate the way in which the frictional force generated between, and the damage done to, ceramic surfaces in sliding contact depends on the chemical nature of those surfaces. It is proposed to measure the coefficient of friction, over a range of temperature in air, in argon and in vacuo, using like and unlike pairs of surfaces prepared in the test environment by fracture or abrasion.

The data obtained will be used to seek out and to test empirical relationships between frictional behavior and crysta? chemistry and those properties derived from it. 
Title

Friction and Wear of Ceramics at High Temperatures

\begin{tabular}{|c|c|}
\hline $\begin{array}{l}\text { Investigators } \\
\qquad \text { N. H. MacMilian }\end{array}$ & $\begin{array}{l}\text { Organization } \\
\text { Penn State University }\end{array}$ \\
\hline Sponsor & Schedule and Fundini \\
\hline US Army TACOM & $\begin{array}{ll}\text { FY } & 33 \\
\text { FY } & 84 \\
\text { FY } & 85\end{array}$ \\
\hline
\end{tabular}

Classification

Type Research - Applied

Type llotion - Unlubricated sliding

Variables - Environment, composition

Process - Friction, surface damage

Materials - Ceramics

Application - Ring/cylinder

Orjective

To evaluate materials for diesel ring/liner combinations.

Description

The objective of this work is to obtain friction and wear data needed in the development of the ceramic diesel engine. To this end it is proposed to study the sliding contact behavior under accurately simulated engine operating conditions $\{5-12 \mathrm{~cm}$ stroke, 0-300- rpm, 25-1200C, in air/hydrocarbon environments) of six friction couples, representing the six possible (1ike and unlike) combinations of piston and cylinder liner that can be made from the three candidate materials--sintered alpha silicon carbide, partially stabilized zirconia and a zirconia-coated metal. Note that accurate simulation fundamental understanding of friction and wear phenomena makes $i t$ dangerous to extrapolate data obtained from a test under one set of conditions to predict service life under different conditions. 
Title

Filled Porous Nickel Coatings for Wear Resistance

\begin{tabular}{|c|c|c|c|}
\hline $\begin{array}{l}\text { Investigators } \\
\qquad W . \text { Ebihara }\end{array}$ & \multicolumn{3}{|c|}{$\begin{array}{l}\text { Organization } \\
\text { AMRADCoM-Picatinny }\end{array}$} \\
\hline $\begin{array}{l}\text { Sponsor } \\
\text { A.ARADCOM-Picatinny }\end{array}$ & $\begin{array}{r}\text { Schedui } \\
\text { FY } 33 \\
\text { FY } 84 \\
\text { FY } 85\end{array}$ & $\begin{array}{ll} & \\
\text { ng } & \\
\text { FY } & 86 \\
\text { FY } & 87 \\
\text { FY } 88\end{array}$ & \\
\hline $\begin{array}{l}\text { Classification } \\
\text { Type Research - Applied } \\
\text { Type Motion - Uniubricated } \\
\text { Variables - Composition } \\
\text { Process - Vear } \\
\text { Materials - Coatings } \\
\text { Application - Gun tubes }\end{array}$ & iding & $\begin{array}{l}\text { Subject } \\
\text { Objective } \\
\text { Energy Relevance }\end{array}$ & $\begin{array}{l}8 \\
1 \\
2\end{array}$ \\
\hline $\begin{array}{l}\text { Objective } \\
\text { To develop wear resistanc }\end{array}$ & oatings & & \\
\hline
\end{tabular}

Description

Efforts are being made to deposit porous nickel coatings by electroplating. The pores are then filled with teflon or nylon to yield a low friction wear resistant coating. Ring and block tests are being run to evaluate the coatings. Applications include a variety of sliding mechanisms in guns. 


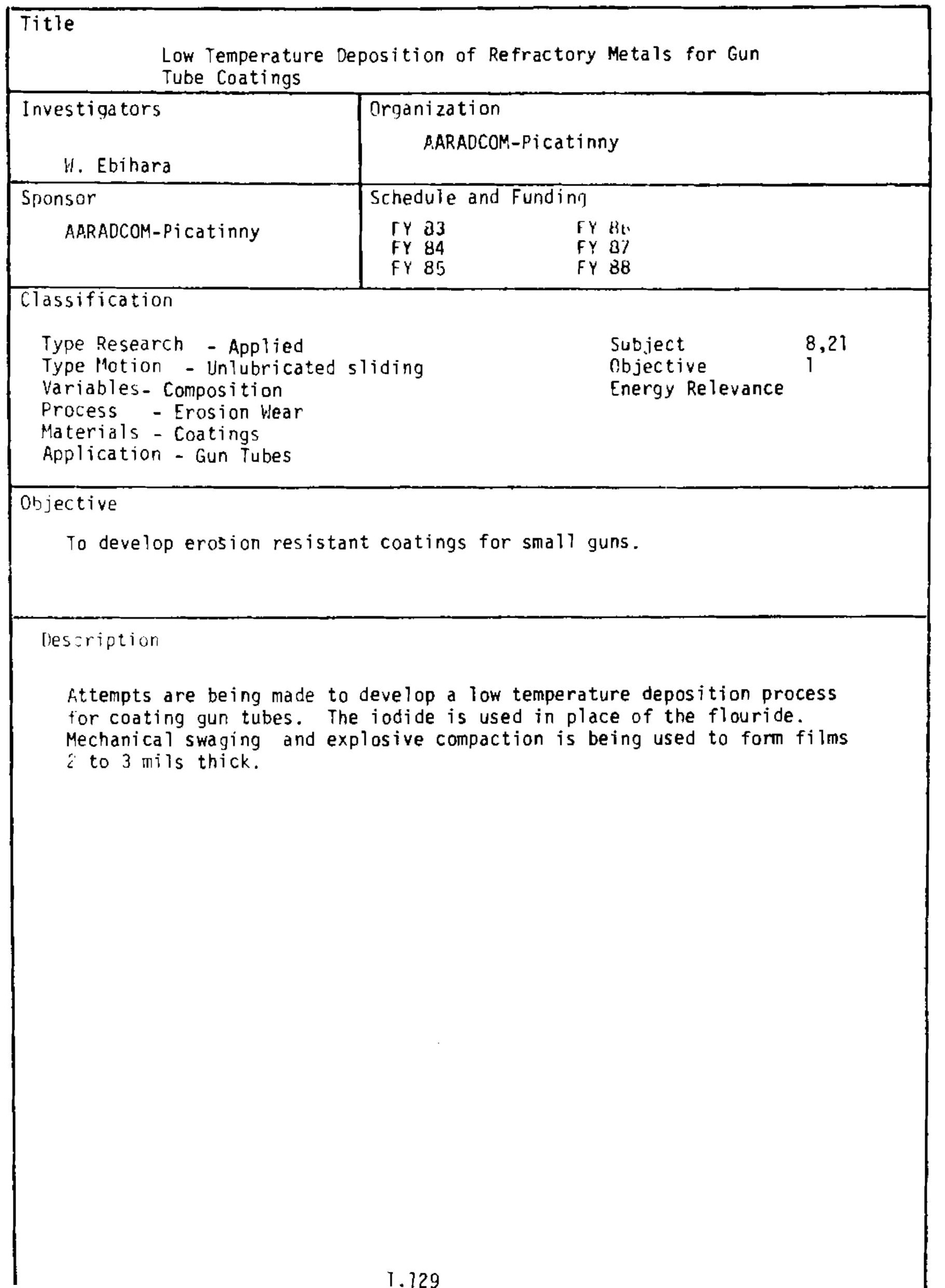




\section{Title}

Chromized Nickel Alloys as Gun Tube Materials

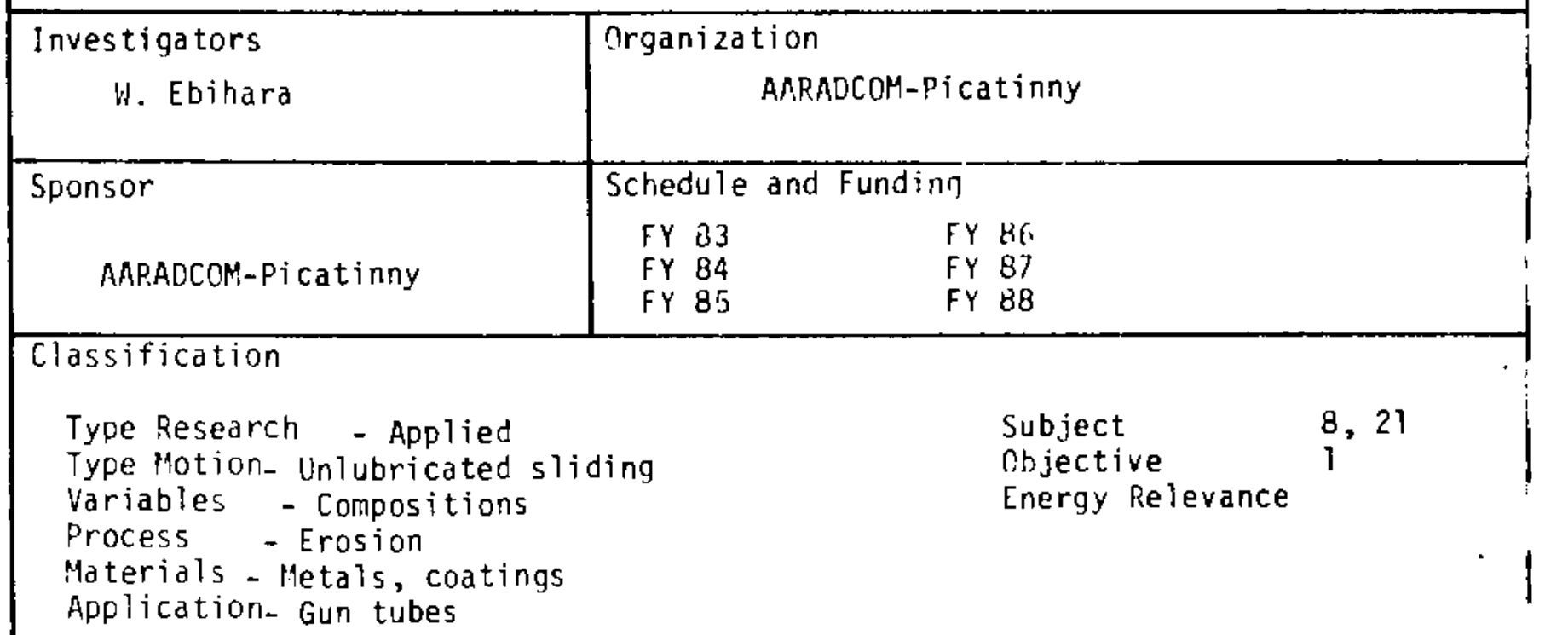

Ohjective

To improve erosion resistance in gun tubes.

Description

Chromized Incone? 718 is being evaluated as a replacement for cobalt-base liners currently used. Initially different coatings were evaluated with liner inserts. Current work includes complete liners made with the optimized coatings. 


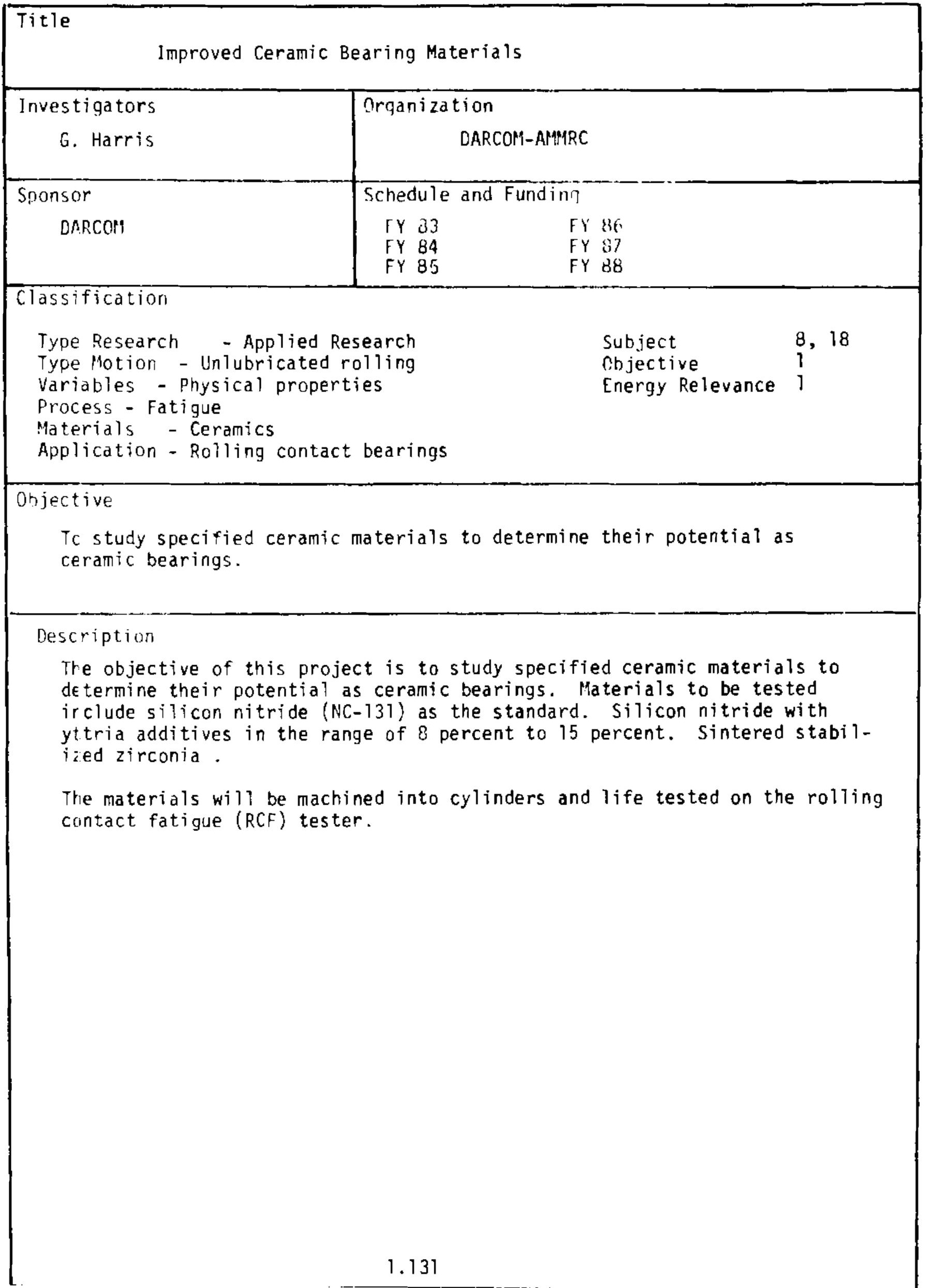




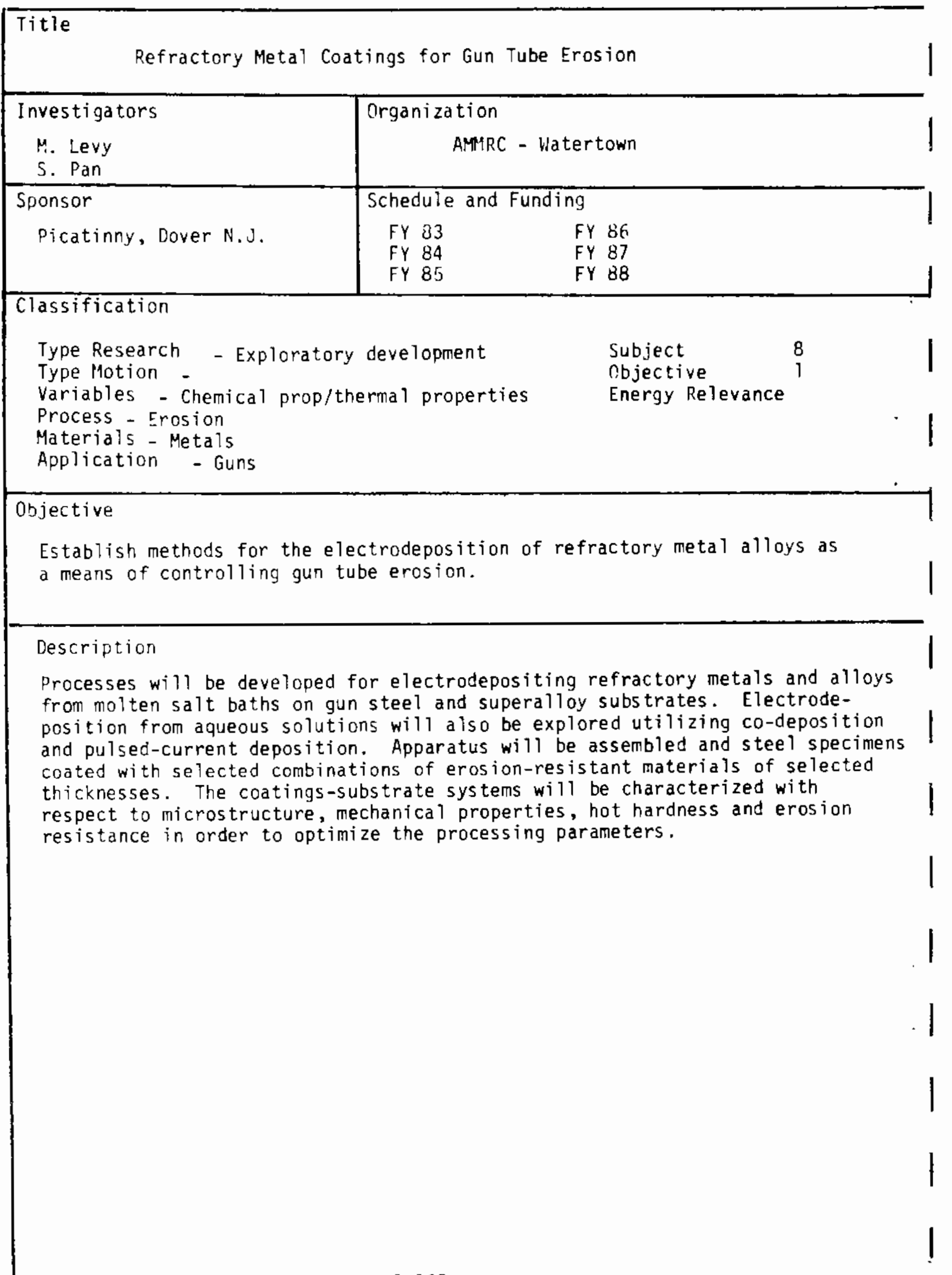




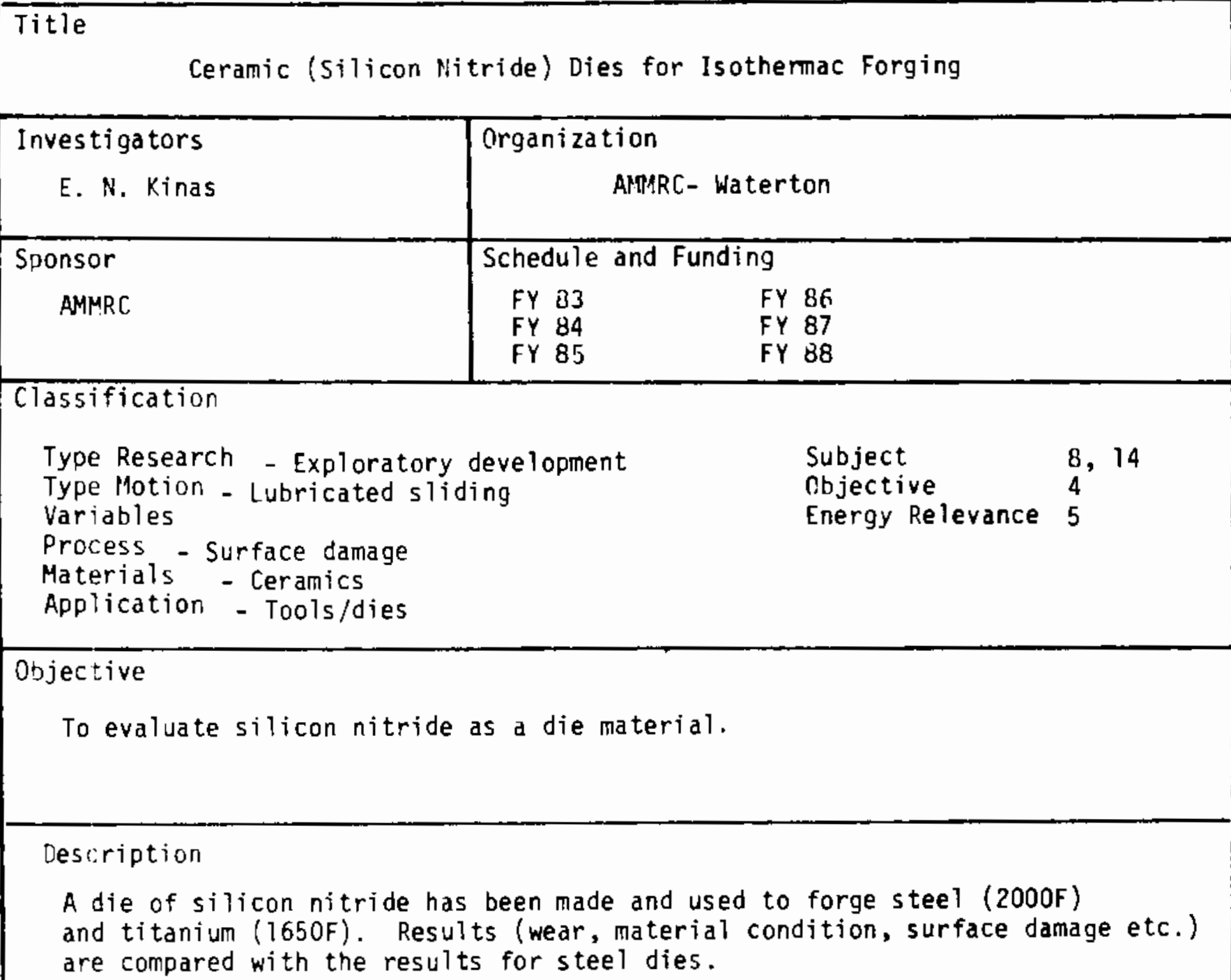


Title

Evaluation of Advanced Gear and Bearing Materials

\begin{tabular}{|c|cc}
\hline $\begin{array}{c}\text { Investigators } \\
\text { R. Middleton }\end{array}$ & $\begin{array}{c}\text { Organization } \\
\text { DARCOM M\&M Research Center } \\
\text { Watertown, MA }\end{array}$ \\
\hline Sponsor & Schedule and Funding \\
OARCOM AMMRC & FY 83 & FY 86 \\
& FY 84 & FY 87 \\
FY 85 & FY 88
\end{tabular}

Classification

Type Research - Applied

Type llotion - Lubricated sliding/roll

Variables - Composition load speed

Process - Wear

Materials - Metals

Application - Bearings, gears

Objective

To develop better materials for future high performance Army components of Army aircraft and ground vehicles.

Description

Current studies include the effects of carbides size, distribution, etc. in 52100 steel on wear rate. Efforts are being made to improve the wear rate by redistribution of carbides in the metal matrix. A pin/disk machine is being used to measure wear.

A disk/disk test is also being set up to evaluate gear materials at conditions beyond catalog loads and speeds. First work will consider carbides but other metallurgical properties will also be investigated. Eventually new materials will be introduced. 
Title

Lubricants and Materials for Advanced Propulsion Systems

\begin{tabular}{|l|ll}
\hline $\begin{array}{l}\text { Investigators } \\
\text { R. Valori }\end{array}$ & Organization \\
D. Popgoshev & & \\
\hline Sponsor & NAPTC - Trenton \\
& Schedule and Funding \\
NADC & FY 83 & FY 86 \\
& FY 84 & FY 87 \\
& FY 85 & FY 88 \\
\hline
\end{tabular}

Classification

Type Research - Exploratory development

Type Motion

Subject

Objective

8,6

variables

Energy Relevance

Process

Materials - Fluid lubricants, metals

Application - Engines

Objective

To assure the availability of lubricant/steel combinations for future propulsion systems which have optimum reliability with respect to bearing and gear performance.

Description

A continuous program is under way at NAPC to upgrade rolling contact bearing and gear materials. A rolling contact disk test is used. Materials evaluated include corrosion resistant steels ceramics, ion implanted metals and coatings. Several different projects are under way:

1. Effect of microtopography on scuffing resistance.

2. Effect of microtopography on life.

3. Effect of preconditioning on $l i$ fe and scuffing.

4. Screen Industry Materials \& Coatings. 


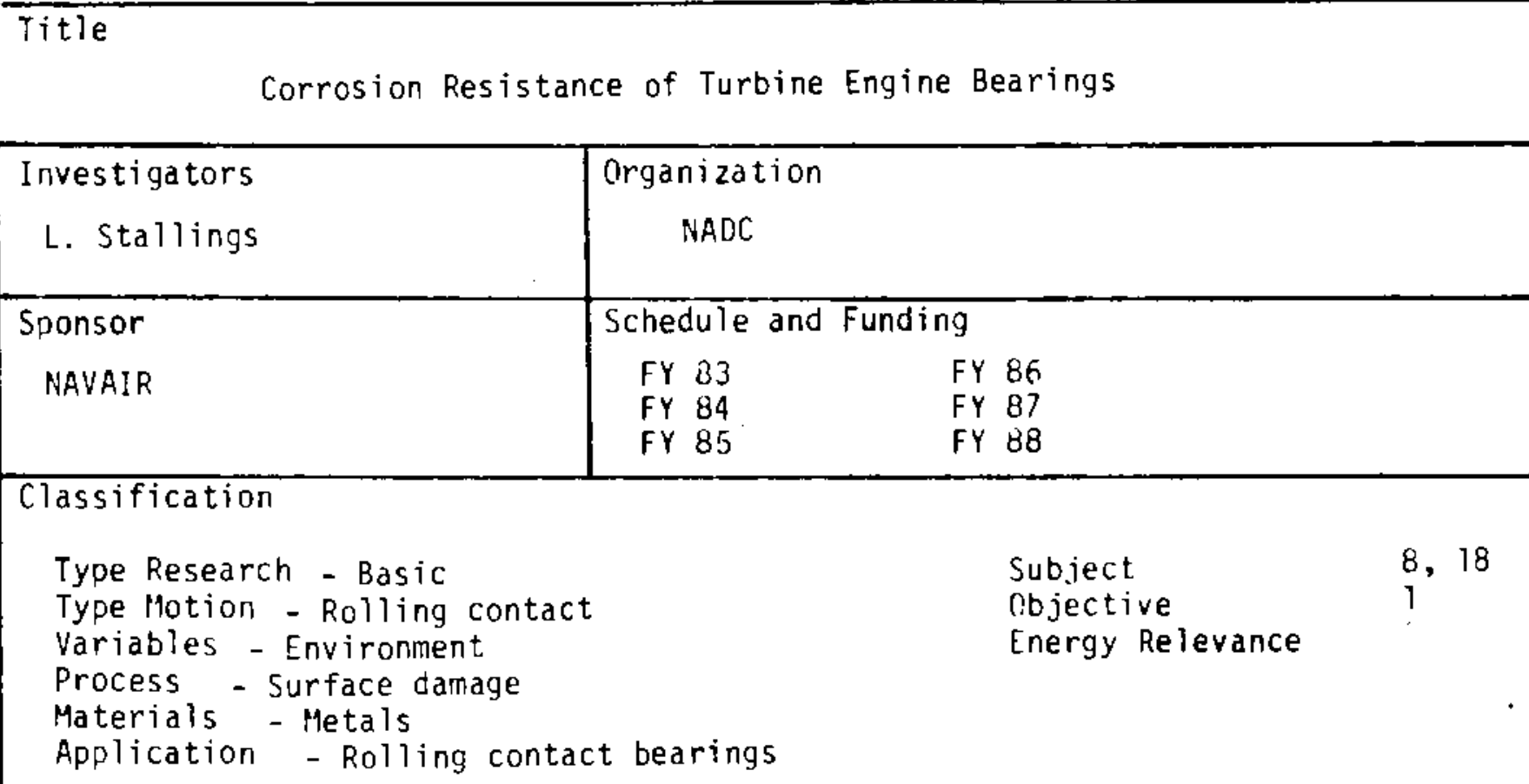

Objective

Determine mechanisms of corrosion of bearings in engine oils.

Description

Corrosion is one of the main reasons for removal of bearings from service over a broad range of applications. This has been shown to be true for jet engine bearings from military service. There is almost no data available to explain how such corrosion takes place. In this program a simulative test will be set up, and electrochemical techniques will be used to study corrosion mechanisms in new and contaminated oil. Static bearing tests will be used in initial experiments. 


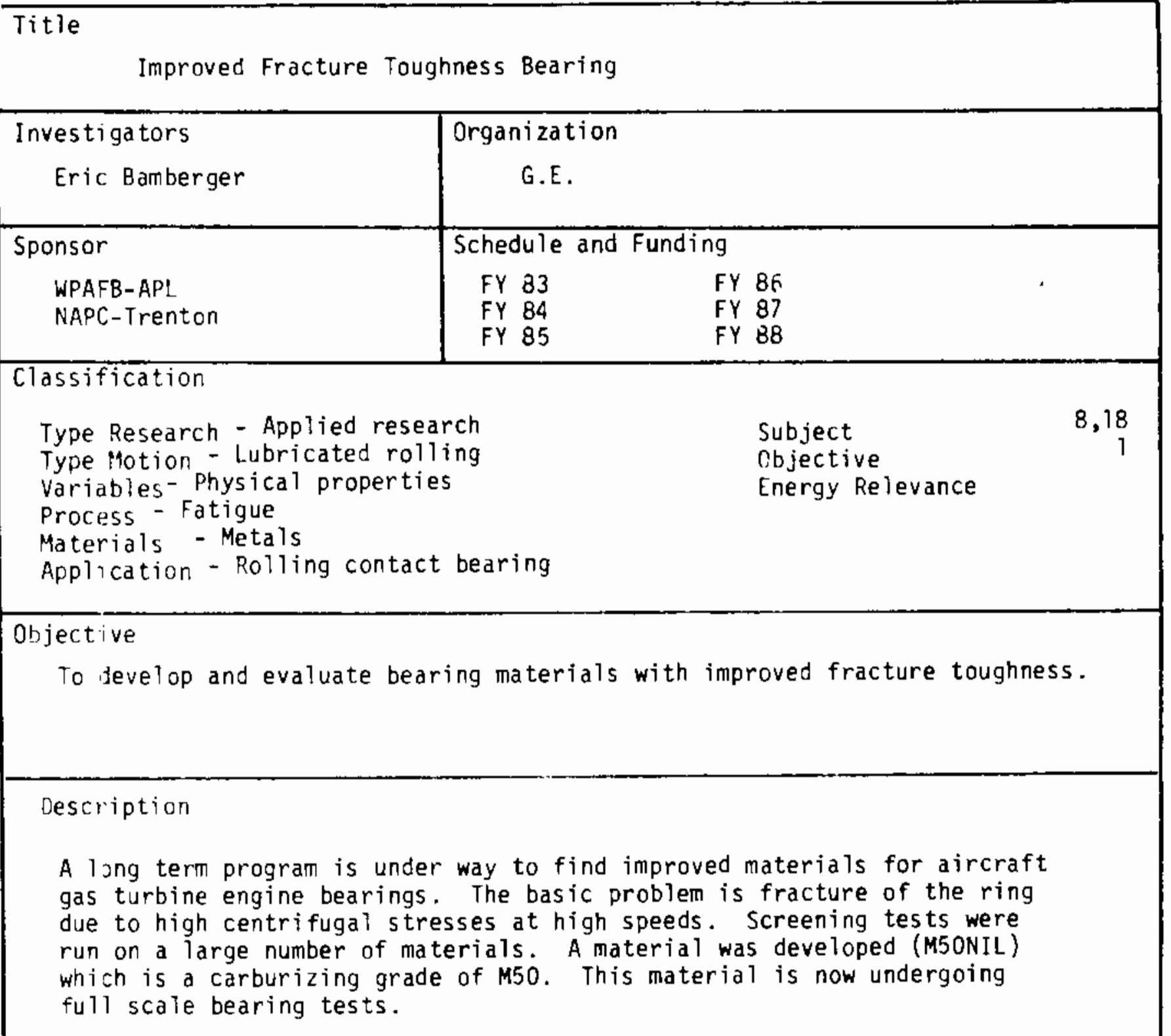




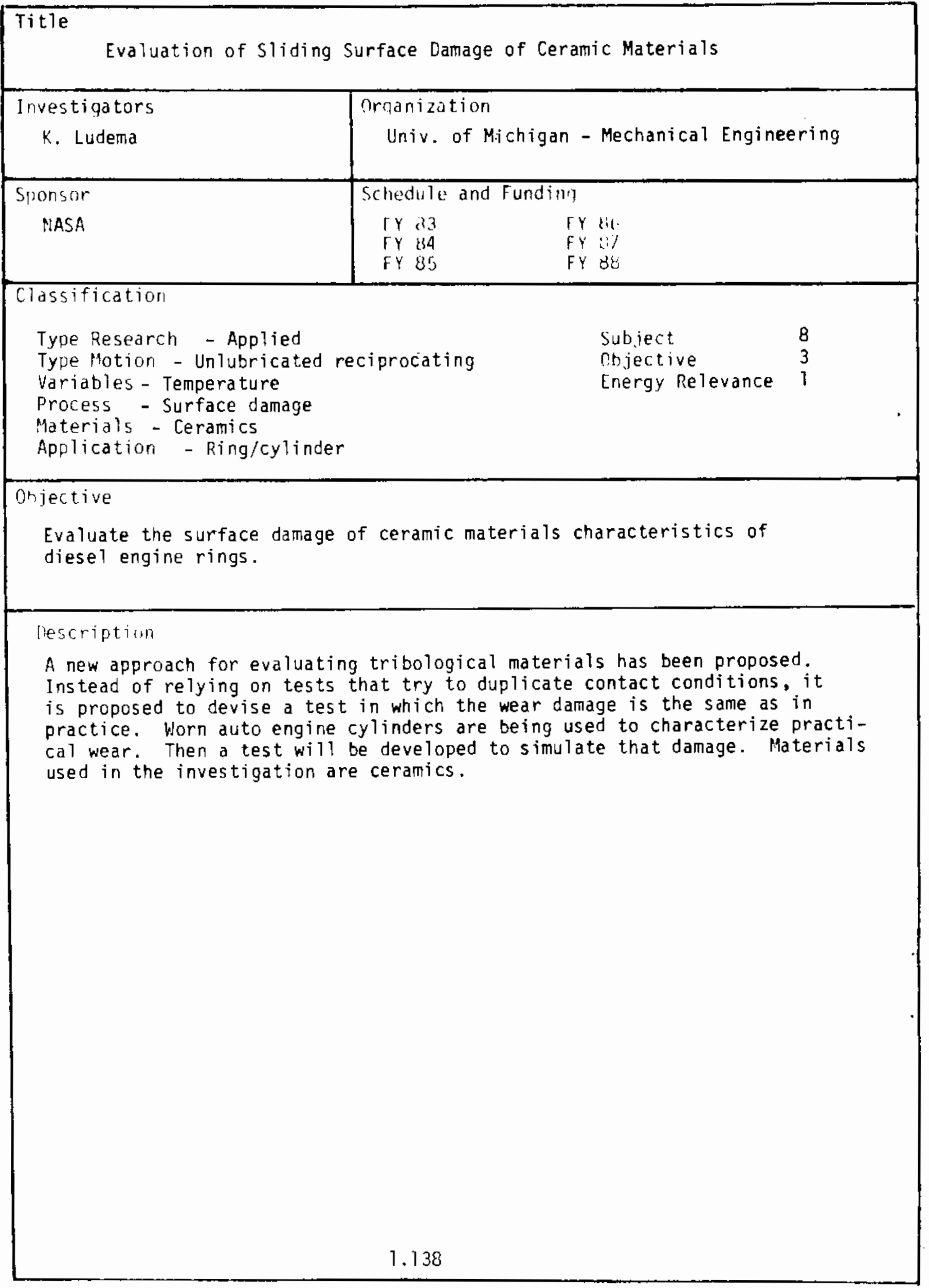




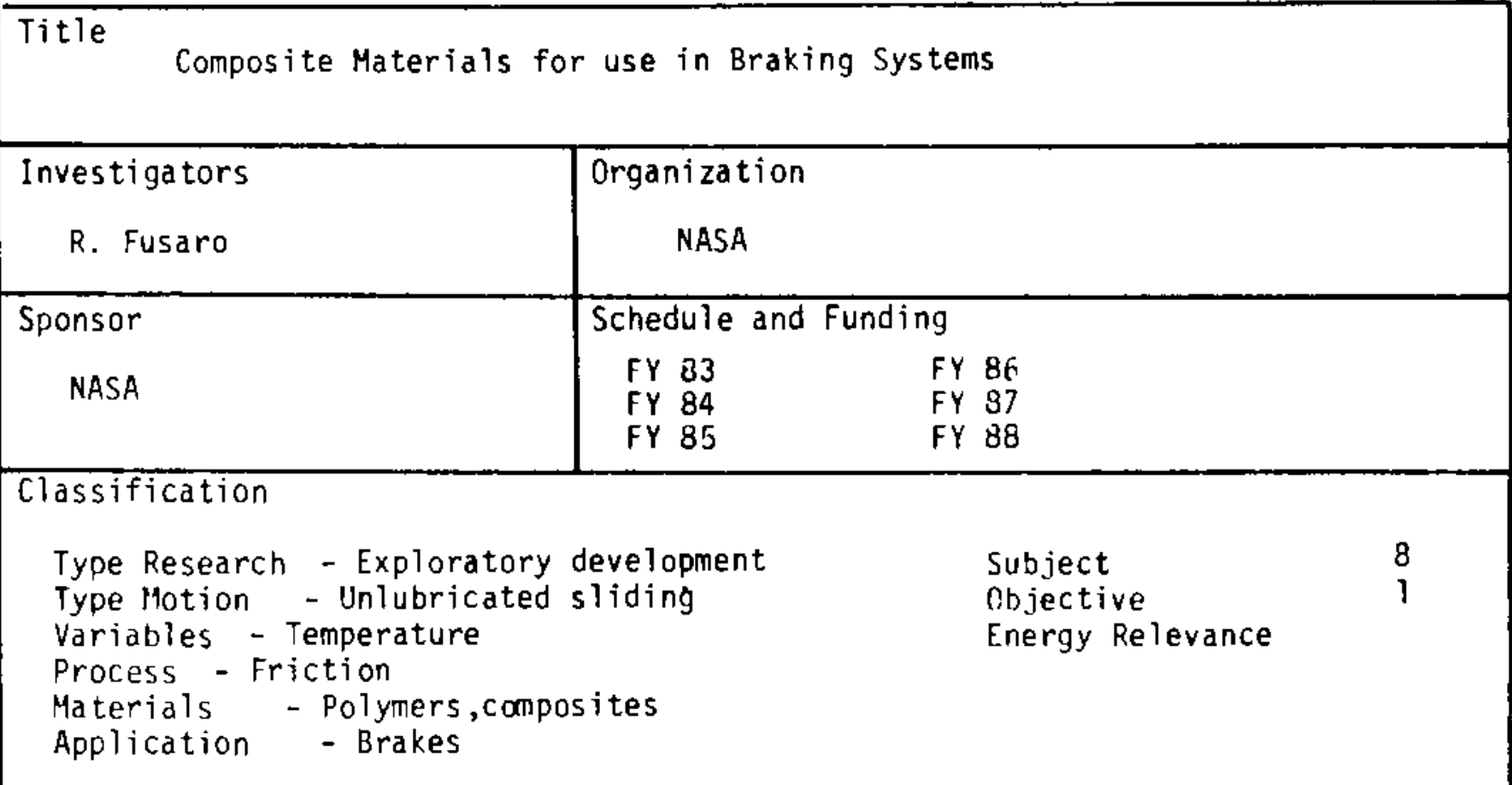

\section{Objective}

To develop high temperature brake materials.

Description

This program is a follow on to recent work on the development of filled polymers (especially polyimides) for $400 \mathrm{C}$ environments. Consideration is now being given to the use of these materials in brake systems where high friction is required. Further material modifications are being made and the resulting composites are being in pin/disk experiments. 


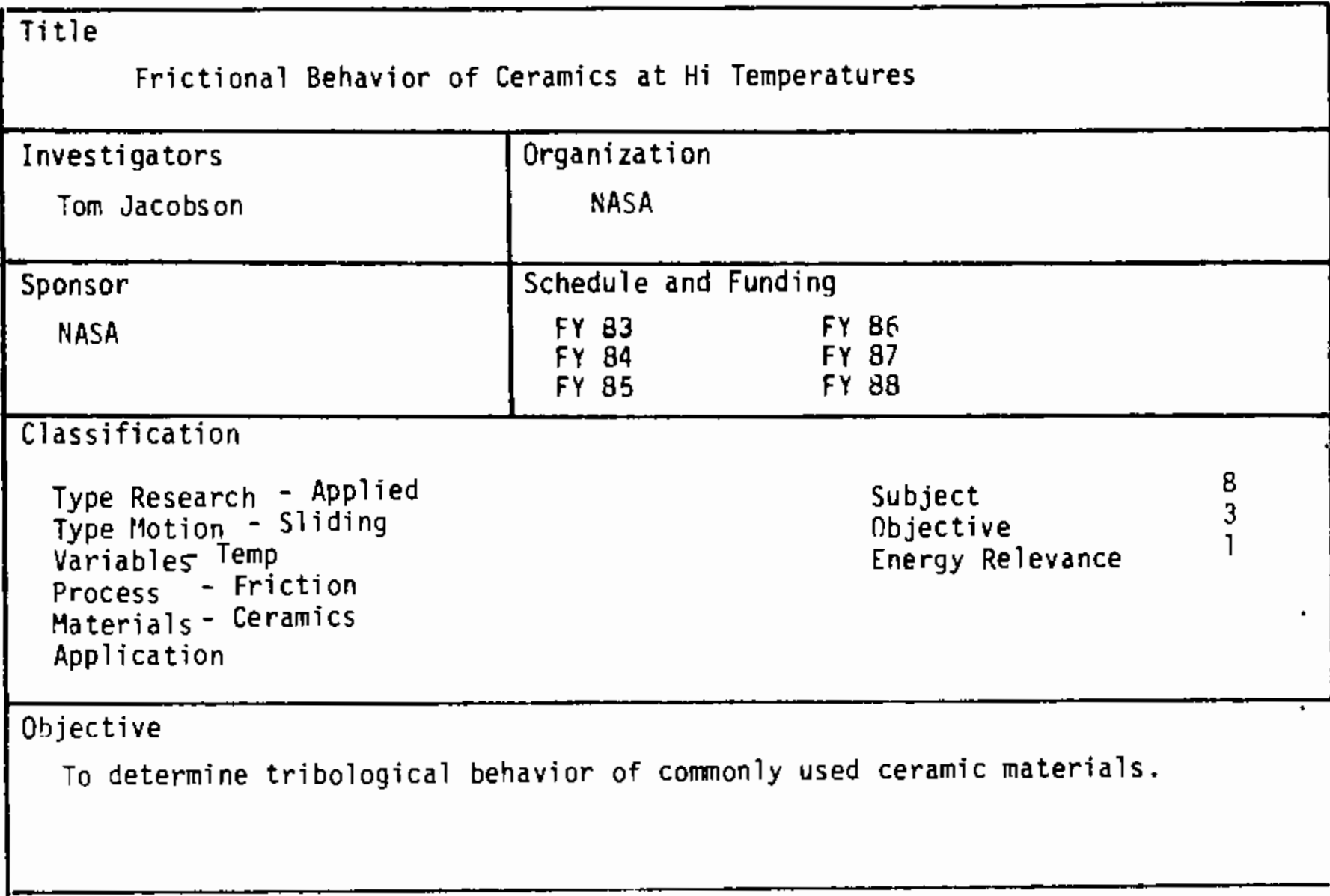

Description

Three different test devices are being used to study the frictional behavior of ceramic materials. A basic rig which operates at $1500 \mathrm{C}$ consists of a sphere on flat and allows surface analys is to be performed in situ. A pin on disk rig operates to $800 \mathrm{C}$ in air. A new rig is being constructed for the $1200 \mathrm{C}$ to $1500 \mathrm{C}$ temperature range which can accomodate different test geometries. Materials include both special ceramics prepared "in house" and comercial materials. 


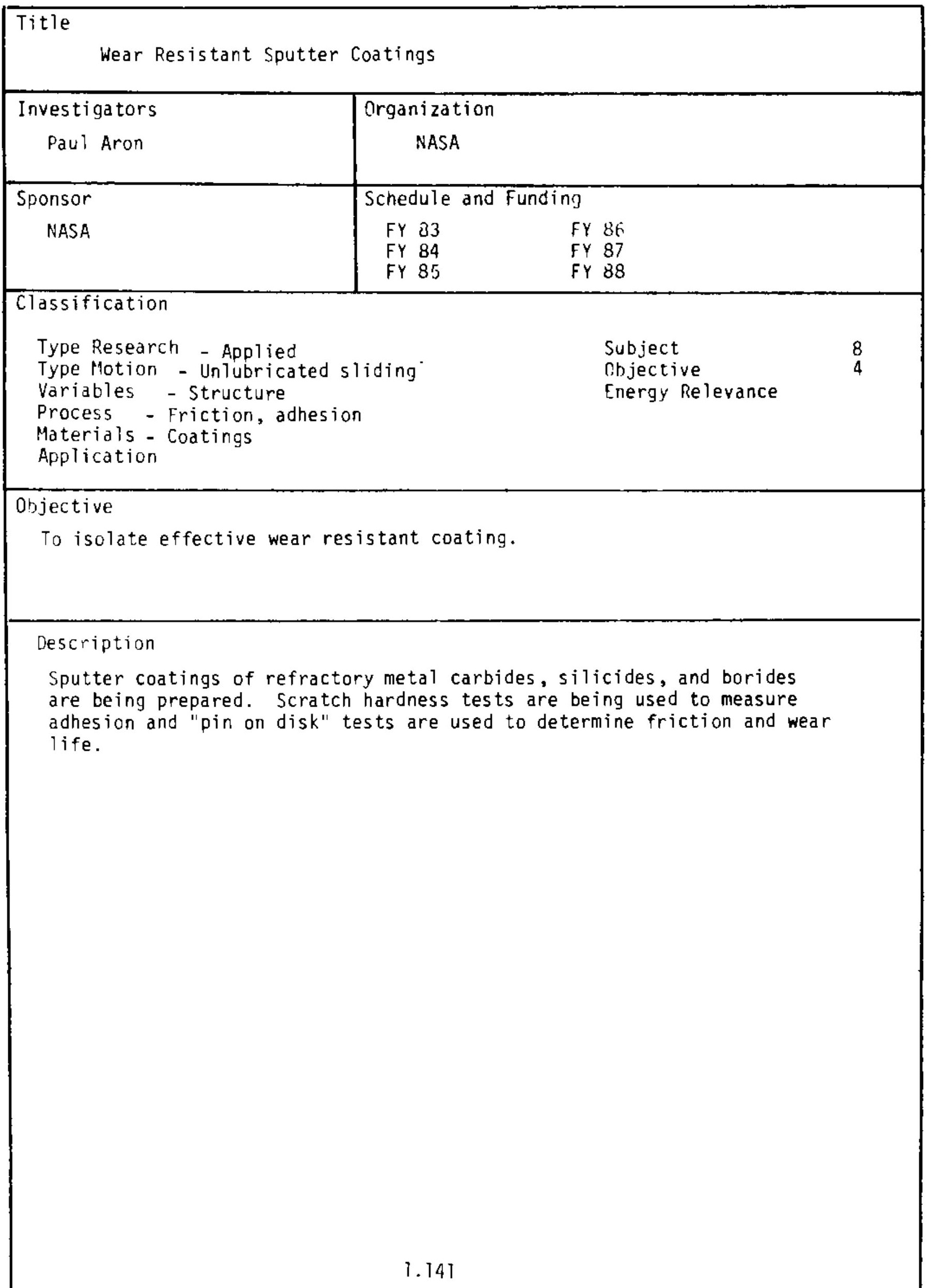




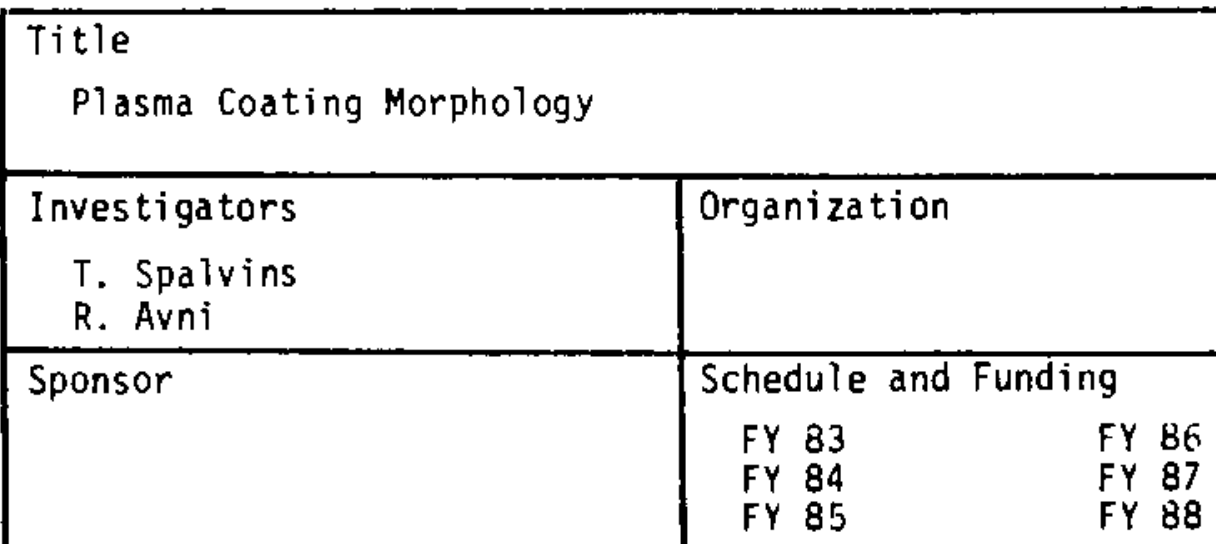

\section{Classification}

Type Research - Applied

Type Motion - Unlubricated sliding

Variables

Process - Friction, wear

Materials - Coatings

Application

Objective

To correlate the friction properties with coating morphology.

Description

Studies are being conducted with silicon nitride and silicon carbide films which have been deposited from gases by RF plasma deposition. This is only the most recent investigation in a series of investigations concerned with tribological coatings. Plasma deposited coatings have included a wide variety of materials including molybdenum disulfide, soft metals and layered coatings. In addition, more recent work studied ion nitriding processes. 


\section{Title}

Surface Modification of Meta?/Ceramic Substrates via Ion Implantation

\begin{tabular}{|c|c|c|}
\hline $\begin{array}{l}\text { Investigators } \\
\text { K. Meckienburg }\end{array}$ & \multicolumn{2}{|l|}{$\begin{array}{l}\text { Organization } \\
\quad \text { WPAFB - Materials Laboratory }\end{array}$} \\
\hline Sponsor & $\begin{array}{cc}\text { Schedule and Funding } \\
\text { FY } 83 & \text { FY } 86 \\
\text { FY } 84 & \text { FY } 87 \\
\text { FY } 85 & \text { FY } 88\end{array}$ & \\
\hline $\begin{array}{l}\text { Classification } \\
\text { Type Research- Development } \\
\text { Type Hotion } \\
\text { Variables - Properties } \\
\text { Process - Friction, Wear } \\
\text { Materials - Coatings } \\
\text { Application }\end{array}$ & $\begin{array}{l}\text { Subject } \\
\text { Objective } \\
\text { Energy Relevance }\end{array}$ & $\begin{array}{l}8 \\
4 \\
2\end{array}$ \\
\hline \multicolumn{3}{|c|}{$\begin{array}{l}\text { Objective } \\
\text { Enhance the tribological properties of bearing surfaces via altering } \\
\text { properties/composition with ion implanted species. }\end{array}$} \\
\hline \multicolumn{3}{|c|}{$\begin{array}{l}\text { Description } \\
\text { Ion implantation will be used to alter the surface/subsurface properties of } \\
\text { both steels and ceramics. Improved hardness, toughness and friction and wear } \\
\text { of these materials are sought. Species which react with the host material or } \\
\text { diffuse to the surface to react with the environment or other materials will } \\
\text { be investigated. characterization of the surfaces and/or altered materials } \\
\text { will be emphasized to establish a sound fundamental understanding of this } \\
\text { approach to achieving increased tribological performance. }\end{array}$} \\
\hline
\end{tabular}


Title

High Performance Elastomeric Seals

\begin{tabular}{l|l}
\hline $\begin{array}{l}\text { Investigators } \\
\text { W. Griffin } \\
\text { J. Sieron }\end{array}$ & Organization \\
WPAFB - Materials Lab
\end{tabular}

Classification

Type Research - Applied

Type Motion - Stiding

Variables - Structure, Temperature

Process

Materials - Elastomers

Application - Seals

Subject 8

Objective 3

Energy Relevance 1

\section{Objective}

To develop high temperature seals for gas turbine engine oils/fuels.

Description

Poiymers of fully fluorinated fluorocarbon ether nitrides will be synthesized for use as elastomeric materials leading to use as $0 i 1 /$ fuel seals at $700^{\circ}$ $800^{\circ} \mathrm{F}$ in advanced gas turbine engines. Advanced cross linking agents and reinforcement technology will be utilized to obtain optimum mechanical properties of these advanced seal materials. 


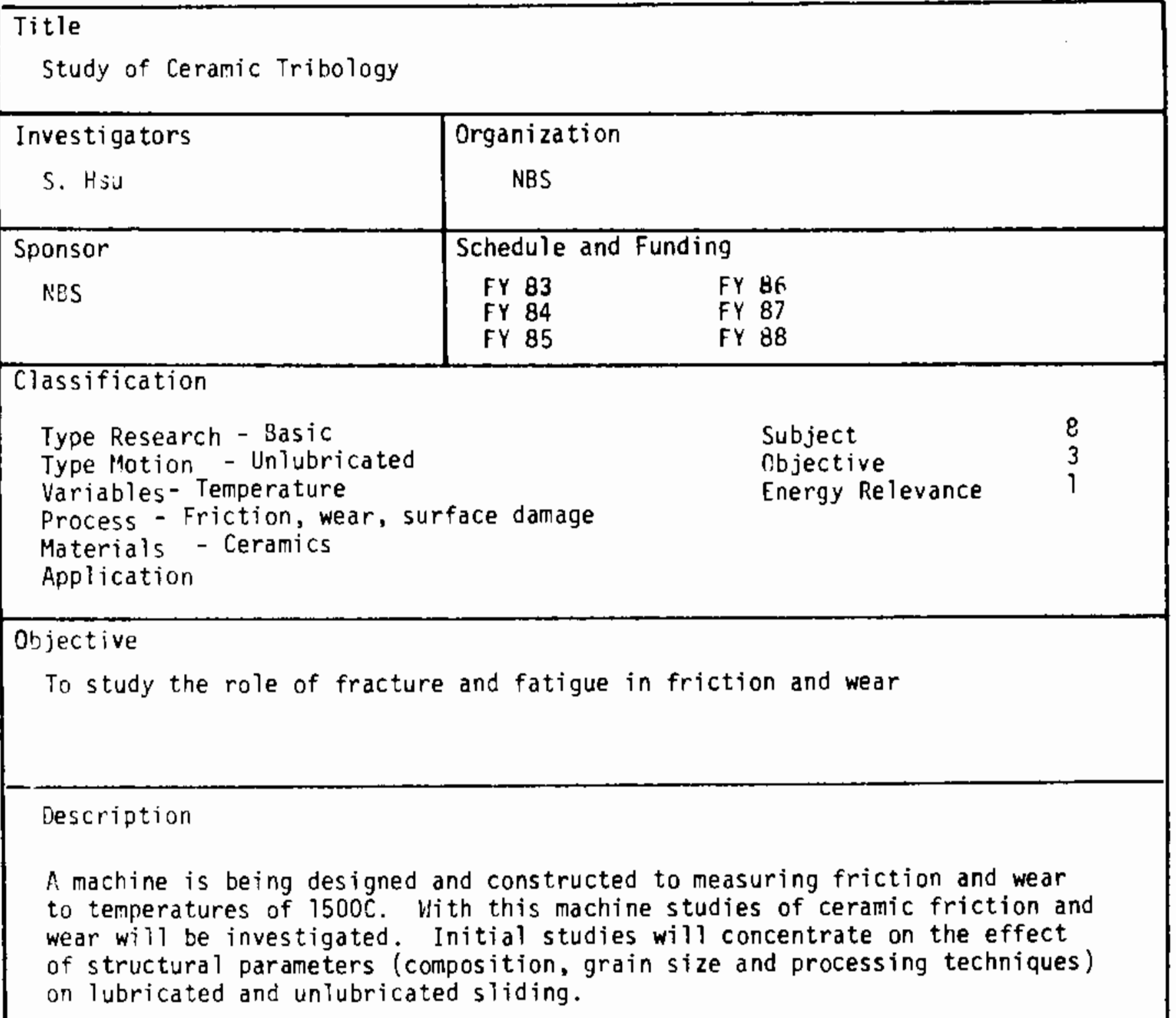




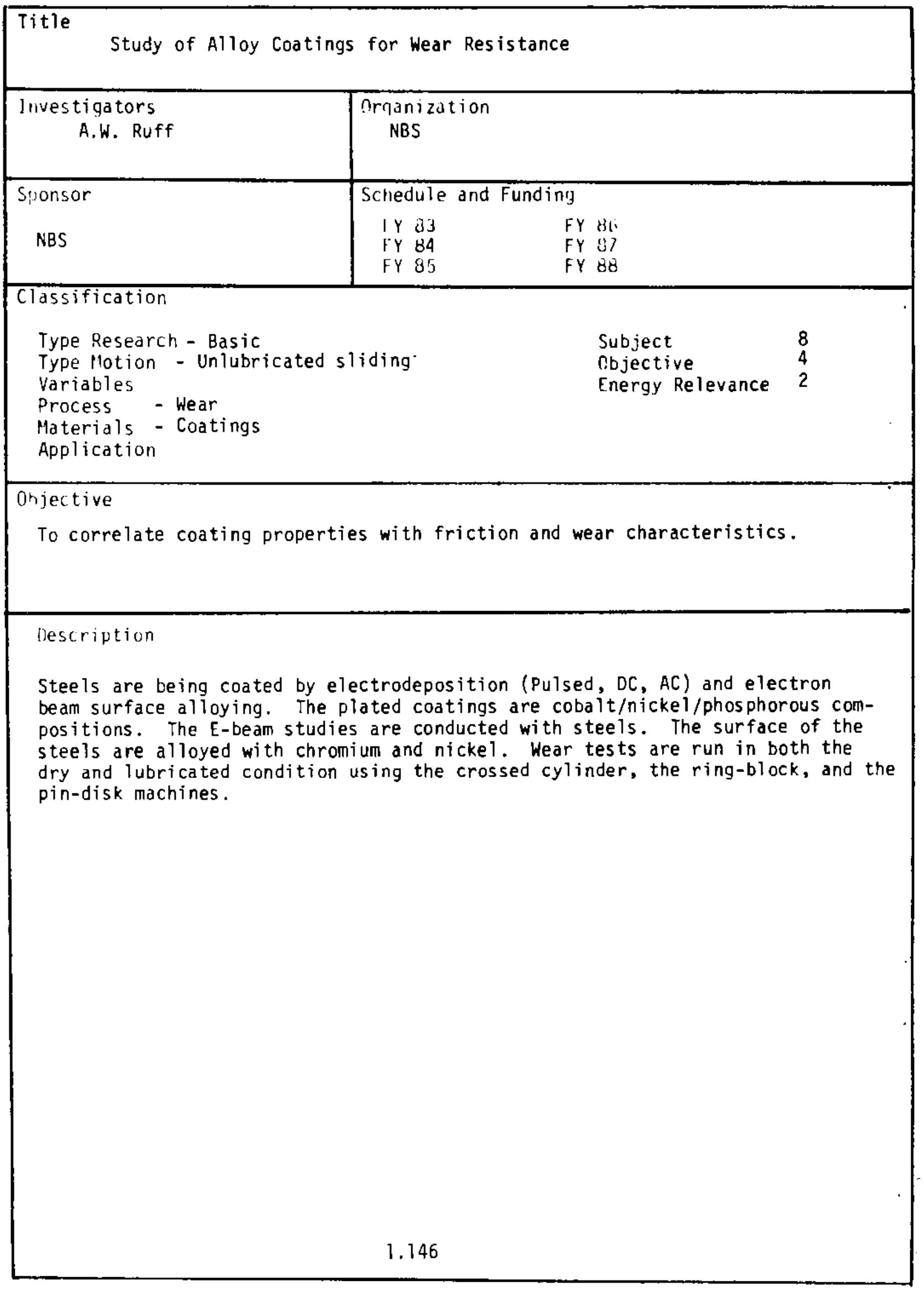


Title

Load-carrying Capacity of Advanced Material-Lubricant Combinations

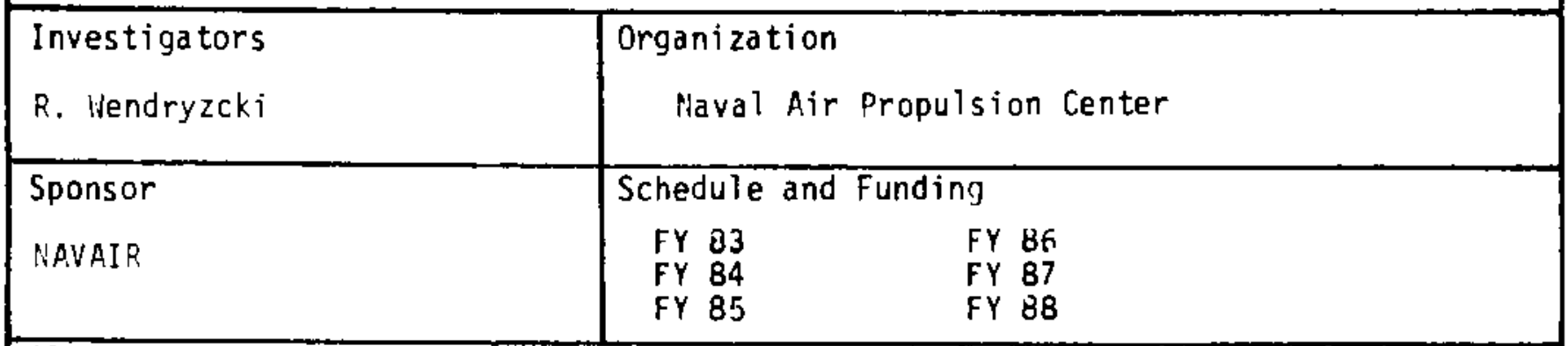

Classification

Type Research - Applied

Type Motion - Sliding/Rolling lubricated

Variables - Composition, Load

Subject

8,13

Process

- Load capacity

Objective

Materials - Metals

Energy Relevance

4

4

Application - Gear

Objective

To isolate gear materiais which will operate at higher temperatures, higher loads, and greater pitch line velocities.

Description

In th's program, advanced gear materials (VASCO X-2, CBS 600M, CES1000M, Cartech EX-00053 and EX-00014) in combination with non-additive synthetic bases zock, qualified MIL-L-23699, and advanced XAS-2354 type lubricants are evaluated on the Ryder Gear Machine (ASTM-D-1947). The evaluation is concerned with determining the load carrying capacity or scuffing/scoring resistance of each naterial and lubricant combination.

Future evaluations will be conducted on other advanced materials and lubricants as they become available. 


\section{Title \\ Tribological Properties of Ion Implanted Alloys}

\begin{tabular}{|l|ll}
\hline \begin{tabular}{l|l} 
Investigators \\
I. Singer
\end{tabular} & $\begin{array}{c}\text { Organization } \\
\text { Naval Research Lab }\end{array}$ \\
\hline Sponsor & & \\
& Schedule and Funding \\
NAVSEA & FY 83 & FY 86 \\
& FY 84 & FY 87 \\
FY 85 & FY 88
\end{tabular}

\section{Classification}

Type Research - Exploratory Development Type Motion - Sliding unlubricated

Variables - Composition, physical properties

Process - Friction, hear

Materials - Coating

Application

Objective

To determine implantation parameters which optimize tribological performance.

\section{Description}

The objective of this program is to determine ion implantation parameters (e.g., ion species, fluence, energy,...) which optimize tribological performance of components. This approach combines friction and wear studies, designed to examine the behavior of the very thin implanted layer, with surface chemical and microstructural analysis. 
bitleqopment of Wear Resistant Surfaces by Laser Surface Modification Techniques.

\begin{tabular}{l|ll}
\hline $\begin{array}{l}\text { Investigators } \\
\begin{array}{l}\text { U. Mazumber } \\
\text { C. Cusano }\end{array}\end{array}$ & $\begin{array}{c}\text { Organization } \\
\text { University of Illinois }\end{array}$ \\
\hline Sponsor & Schedule and Funding \\
& FY 83 & FY 86 \\
ONR & FY 84 & FY 87 \\
& FY 85 & FY 88
\end{tabular}

Classification

Type Research - Exploratory Development

Type Motion - sliding, unlubricated

Variables

Process - Friction wear

Subject

Objective

8

Energy Relevance

Materials - Coatings

Application

objective

Use of Laser to deveiop wear resistant surfaces.

Cescription

Laser surface alloying, laser cladding and laser chemical vapor deposition are keing investigated to develop wear resistant surfaces. Fe-Cr-Mn-C system is being studied for laser surface alloying and cladding whereas TiC is being studied for laser chemical vapor deposition. Some samples from Stellite 6 and $h E L C O$ (PA I5ED) have also been studied for cladding in order to generate baseline data. 


\section{Titie}

Advanced Lip Seals and Seal Materials for Stern Tube Applications

\begin{tabular}{|c|c|c|c|}
\hline $\begin{array}{l}\text { Investigators } \\
\text { L.W. Winn }\end{array}$ & \multicolumn{3}{|c|}{$\begin{array}{l}\text { Organization } \\
\text { Mechanica? Technology Inc. }\end{array}$} \\
\hline $\begin{array}{l}\text { Sponsor } \\
\text { MARAD }\end{array}$ & $\begin{array}{l}\text { Schedule ar } \\
\text { FY } 83 \\
\text { FY } 84 \\
\text { FY } 85\end{array}$ & $\begin{array}{ll}\text { FY } & \\
\text { FY } & 87 \\
\text { FY } & 88\end{array}$ & \\
\hline $\begin{array}{l}\text { Classification } \\
\text { Type Research - Exploratory } \\
\text { Type Motion - Sliding } \\
\text { Variables - Composition, geon } \\
\text { Process - Hear } \\
\text { Materials - Polymers } \\
\text { Application - Seals }\end{array}$ & Jevelopment & $\begin{array}{l}\text { Subject } \\
\text { Objective } \\
\text { Energy Relevance }\end{array}$ & $\begin{array}{l}8,19 \\
1 \\
5\end{array}$ \\
\hline
\end{tabular}

Objective

To improve performance of lip seals in ship stern tubes.

Description

Test equipment for sliding lip seal performance was built under the program. Wear testing of nitrile rubbers filled with dry lubricants was conducted.

A new lip seal design. potentially capable of meeting the low pressure sensitivity and shaft excursion requirements was conceived. An analysis of this configuration showed that these goals could be met. Following the analys is, manufacturing drawings were produced, and lip seals of the new design were fabricated for test. 


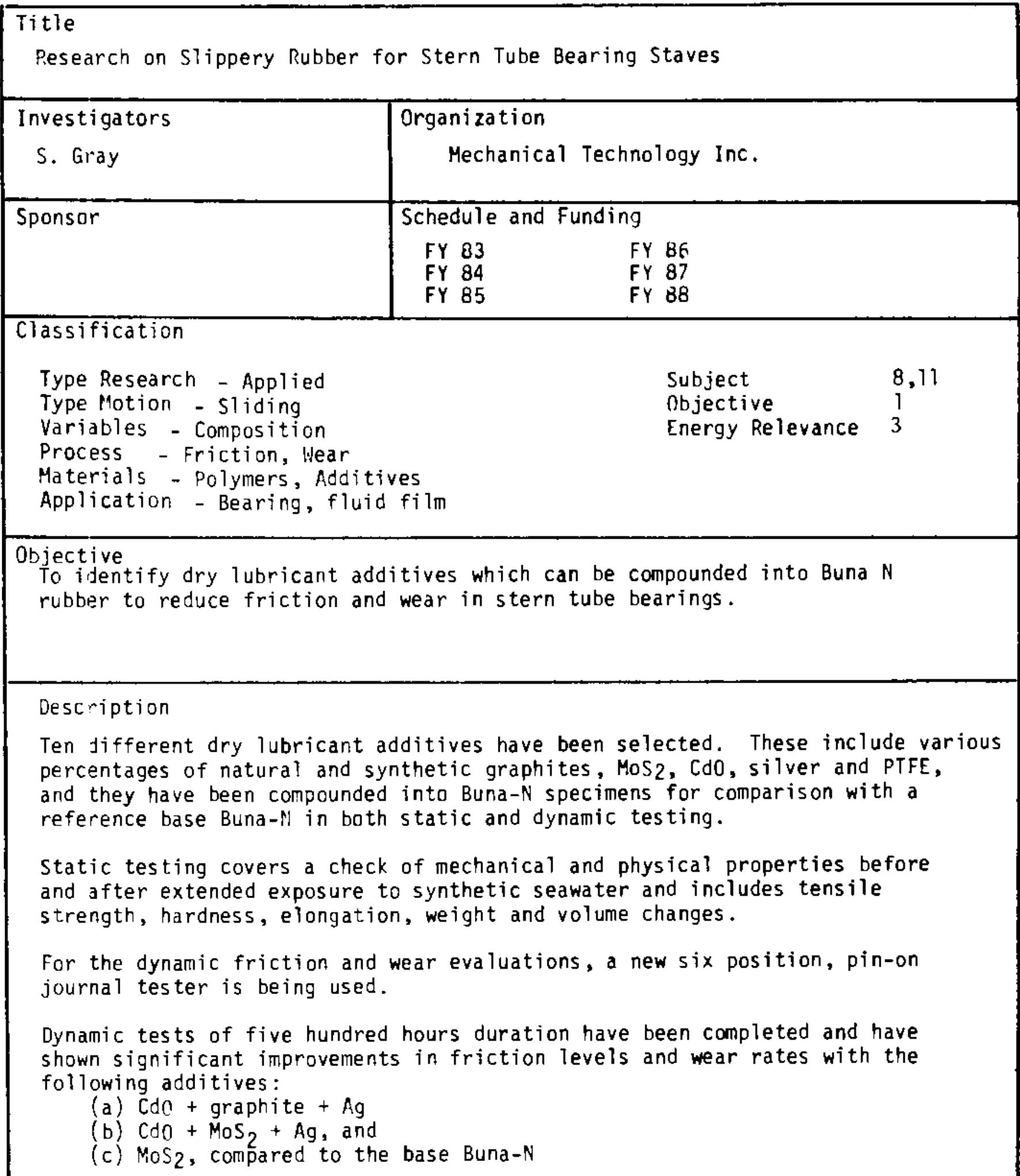




\section{Title}

Develop Engine $0 i 1$ Monitors

\begin{tabular}{|l|ll|}
\hline $\begin{array}{l}\text { Investigators } \\
\text { R.L. Mowery } \\
\text { R.N. Bolster }\end{array}$ & $\begin{array}{l}\text { Organization } \\
\text { Naval Research Laboratory }\end{array}$ \\
\hline Sponsor & & \\
& Schedule and Funding \\
& FY 83 & FY 86 \\
FY 84 & FY 87 \\
FY 85 & FY 88 \\
\hline Classification & & \\
Type Research - Technology Development & Subject \\
Type Plotion & & Objective \\
Variables & & 1 \\
Process - 0il Analysis & & \\
Materials - Fluid Lubricants & & \\
Application - Engines & & \\
\hline
\end{tabular}

To develop instramentation which will determine iubricant condition.

Description

1. A spectrograph is used to monitor anti-oxidant levels. Changes in line strength determine when the additive is depleted and the oil should be changed.

2. Sensors are being developed to measure fuel dilution and water content of engine oils. 


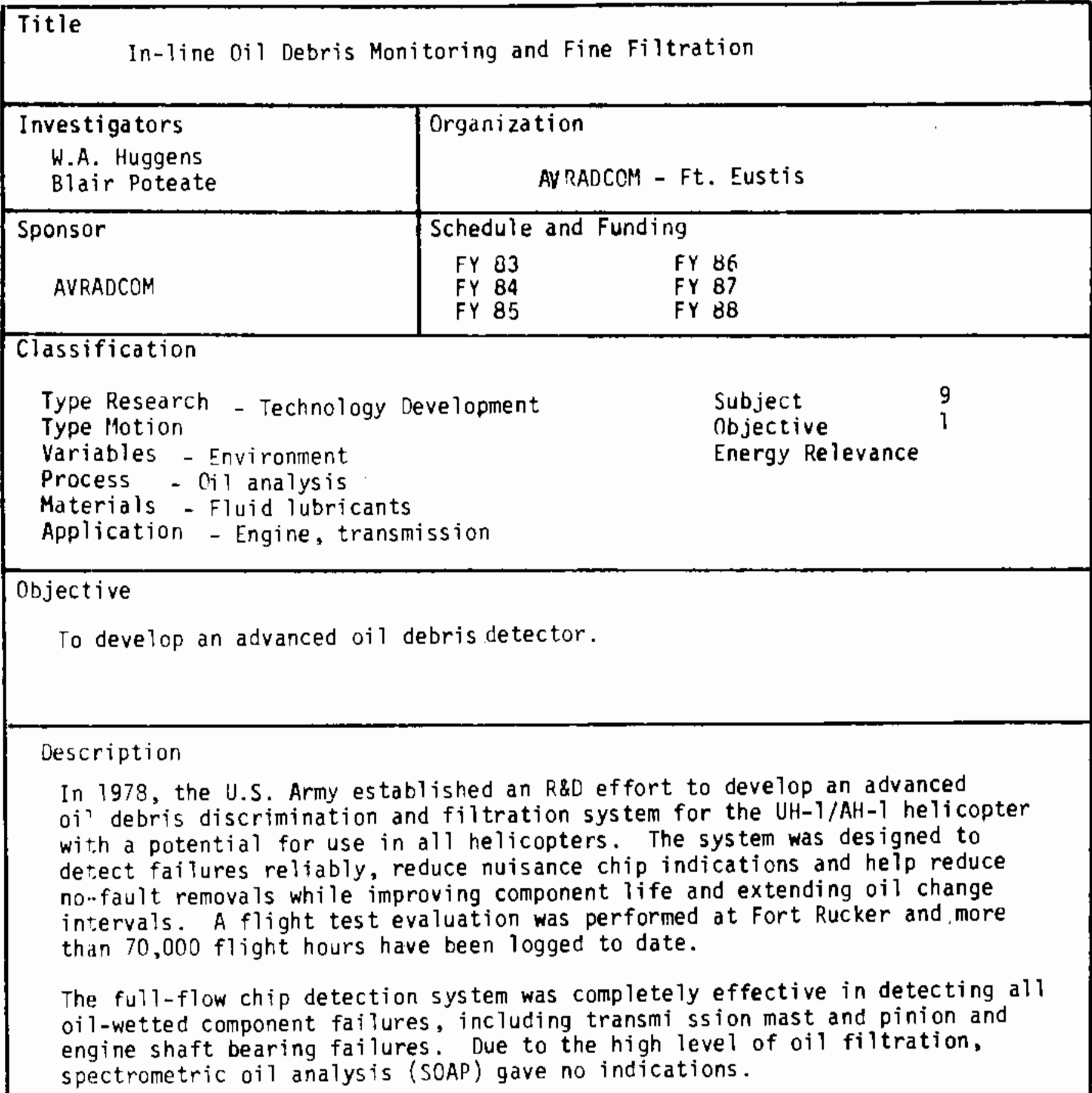




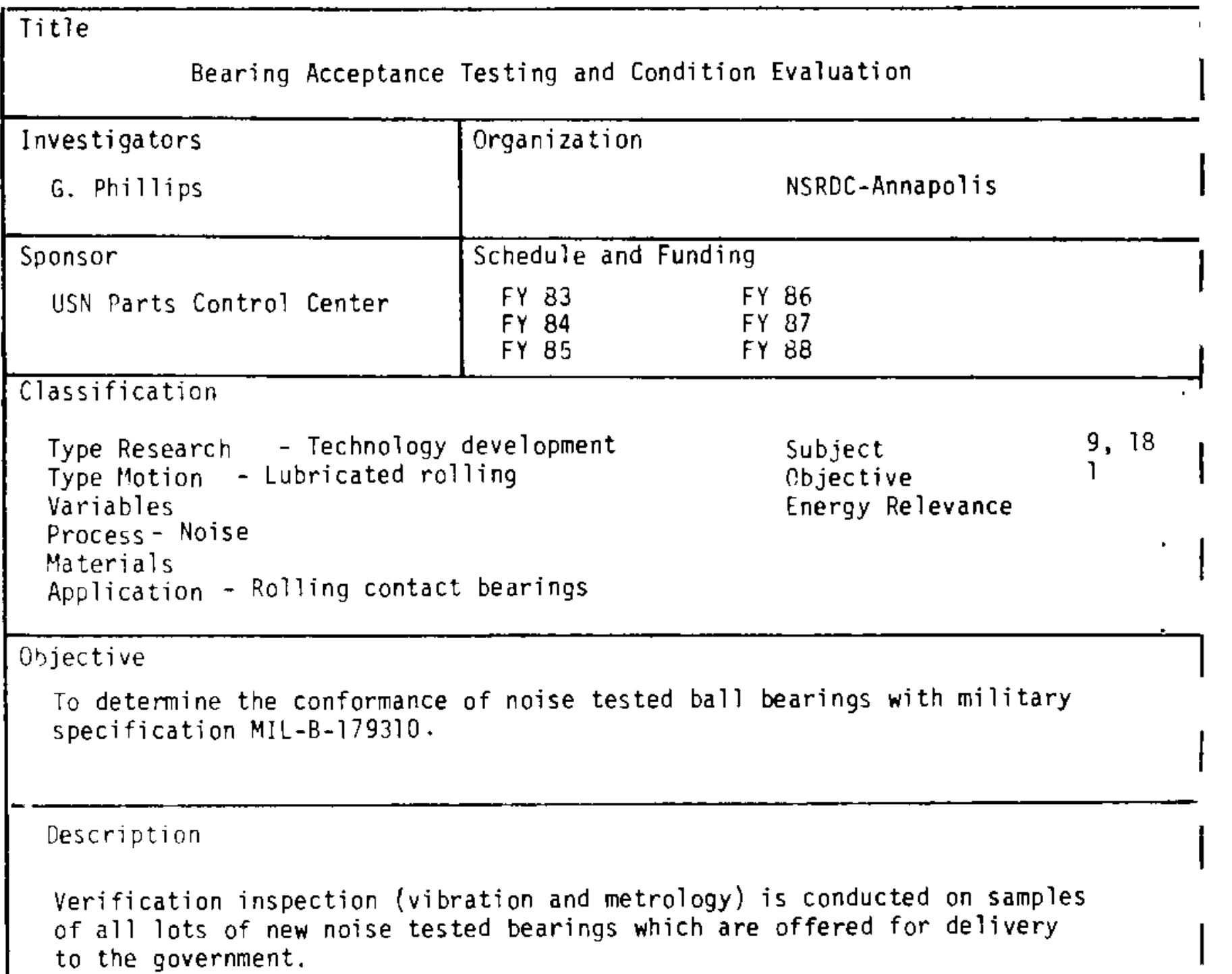




\begin{tabular}{|c|c|c|c|}
\hline \multicolumn{4}{|c|}{ Title Fiber Optics Bearing Performance Monitoring } \\
\hline $\begin{array}{l}\text { Investigators } \\
\text { G. Phillips }\end{array}$ & \multicolumn{3}{|c|}{$\begin{array}{l}\text { Organization } \\
\text { NSRDC - Annapol is }\end{array}$} \\
\hline $\begin{array}{r}\text { Sponsor } \\
\text { NAVSEA }\end{array}$ & $\begin{array}{c}\text { Schedule a } \\
\text { FY } 83 \\
\text { FY } 84 \\
\text { FY } 85\end{array}$ & $\begin{array}{ll}\mathrm{ng} & \\
\mathrm{FY} & 86 \\
\mathrm{FY} & 37 \\
\mathrm{FY} & 88\end{array}$ & \\
\hline \multicolumn{4}{|l|}{ Classification } \\
\hline $\begin{array}{l}\text { Type Research - Exploratory } \\
\text { Type Motion } \\
\text { Variables } \\
\text { Process - Failure } \\
\text { Materials } \\
\text { Application - Rolling eleme }\end{array}$ & $\begin{array}{l}\text { levelopment } \\
\text { t bearing }\end{array}$ & $\begin{array}{l}\text { Subject } \\
\text { C.bjective } \\
\text { Energy Relevance }\end{array}$ & i \\
\hline
\end{tabular}

Objective

To improve bearing reliability by condition monitoring.

Description

Reliable prediction of ball bearing failures and/or noise degradation as well as adequate post-assembly bearing installation checks are essential to prevent replacement simply on a time basis, to avoid"infant mortality" problems, and more importantly, to prevent a casualty to a critical machine during a mission. Recently, it has been shown that light reflected from the faces of rolling contact bearings can be conditioned to accurately describe bearing perfomance. Fiber optic probes are the transmitting media for the light source. A portable fiber optic bearing monitor was developed under the previous project. Developmental testing of the FOBM will continue with this current project. 


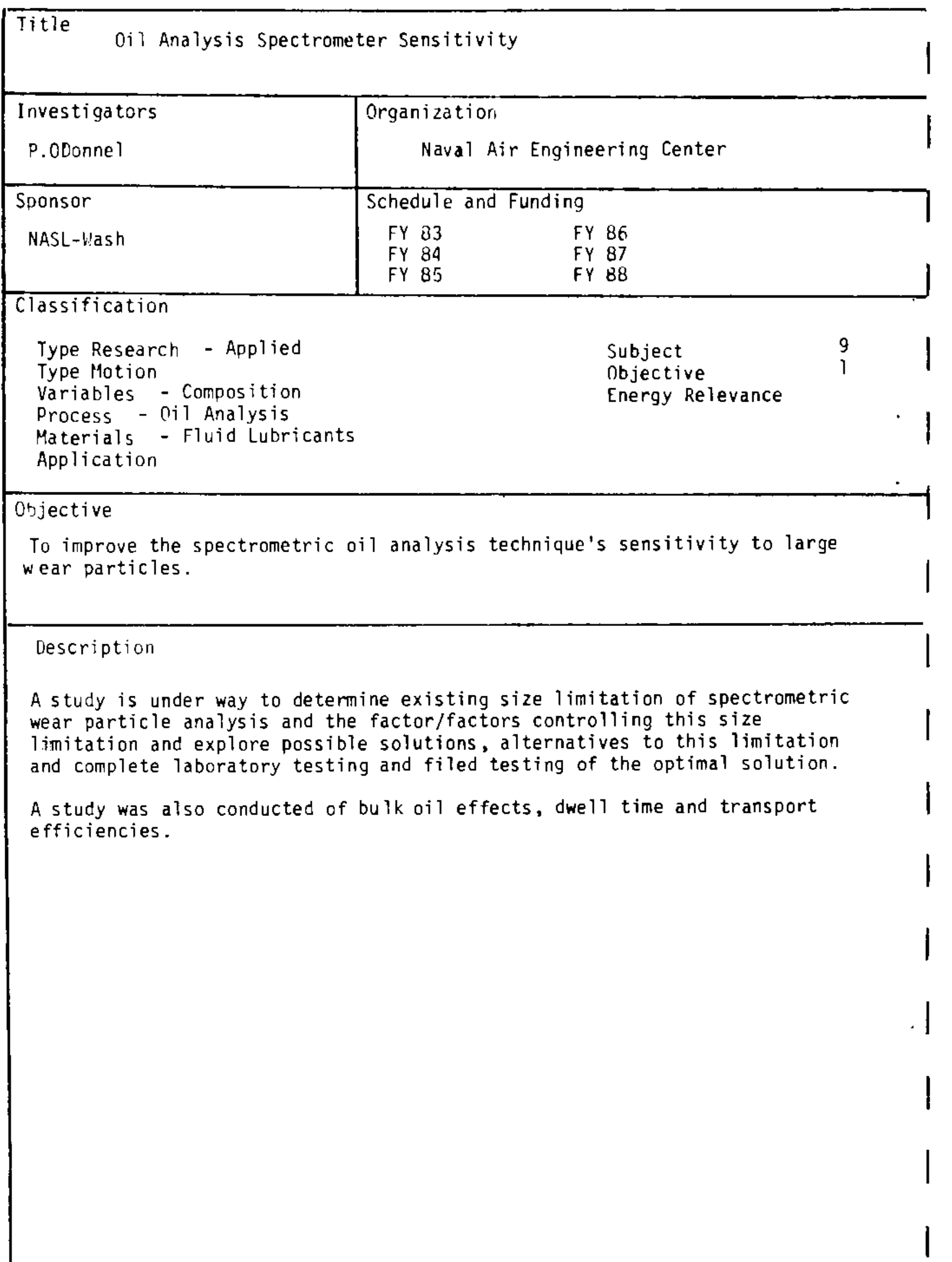




\begin{tabular}{|c|c|c|c|}
\hline \multicolumn{4}{|c|}{ Lubrication Analysis Techniques } \\
\hline Investigators & \multicolumn{3}{|c|}{$\begin{array}{l}\text { Organization } \\
\text { WPAFB-Propulsion Lab }\end{array}$} \\
\hline $\begin{array}{l}\text { Sponsor } \\
\text { WPAFB-PL }\end{array}$ & $\begin{array}{l}\text { Schedule and } \\
\text { FY } 33 \\
\text { FY } 84 \\
\text { FY } 85\end{array}$ & $\begin{array}{l}86 \\
87 \\
88\end{array}$ & \\
\hline $\begin{array}{l}\text { Classification } \\
\text { Type Research - Exploratory } \\
\text { Type Motion } \\
\text { Variables } \\
\text { Process - 0il analysis lubrica } \\
\text { Materials - Lubricants, fluid } \\
\text { Application - Engines }\end{array}$ & $\begin{array}{l}\text { deve lopment } \\
\text { ants }\end{array}$ & $\begin{array}{l}\text { Subject } \\
\text { Objective } \\
\text { Energy Relevance }\end{array}$ & $\begin{array}{l}9 \\
1\end{array}$ \\
\hline \multicolumn{4}{|c|}{$\begin{array}{l}\text { Objective } \\
\text { To develop new lubricant analys is techniques. }\end{array}$} \\
\hline \multicolumn{4}{|c|}{$\begin{array}{l}\text { Description } \\
\text { Preliminary in house research on new lubricant analysis techniques to } \\
\text { include: }\end{array}$} \\
\hline
\end{tabular}




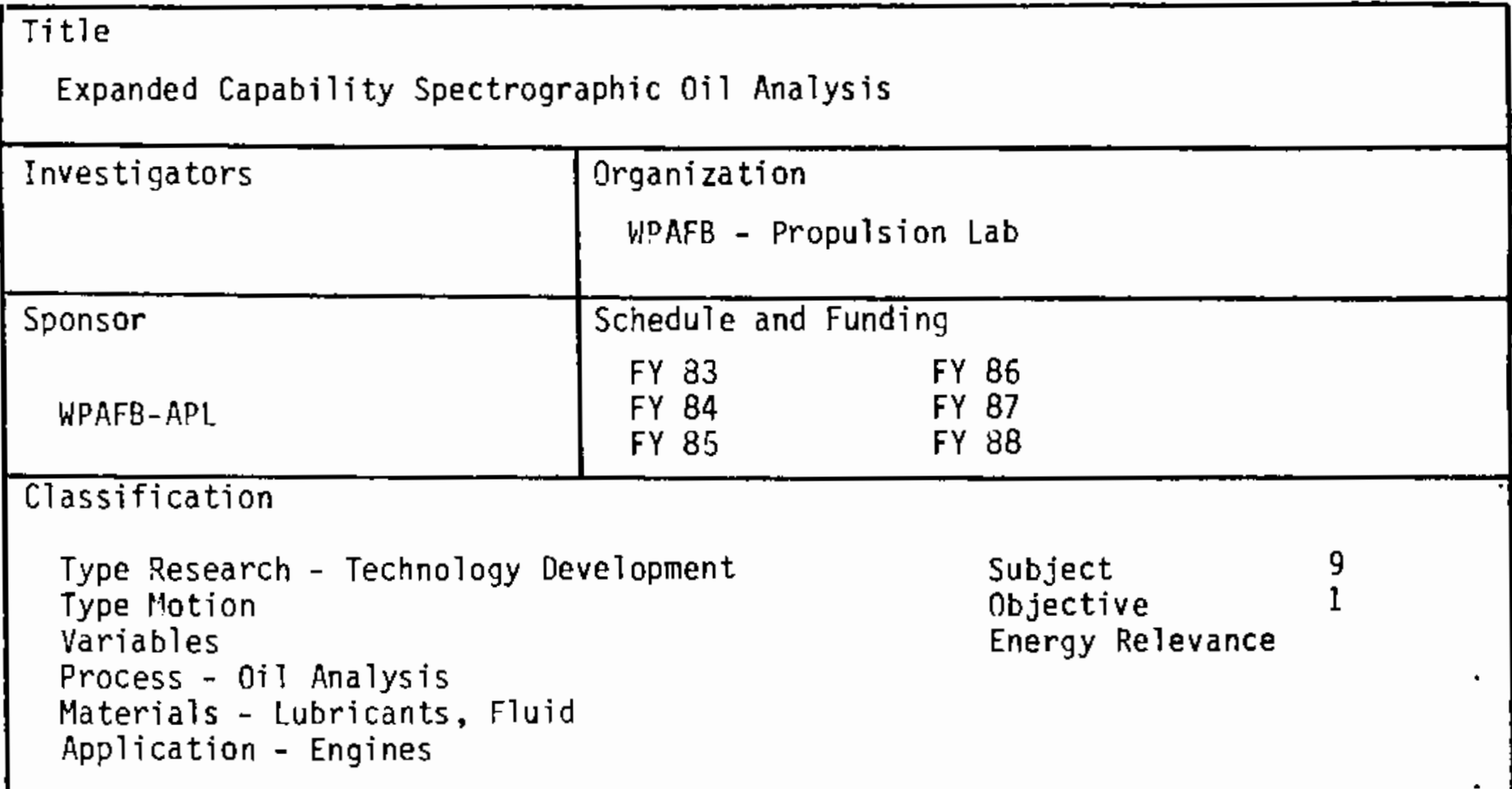

Objective

To install more accurate SOAP equipment.

Description

Examine feasibility of installing more accurate SOAP equipment at bases doing oil analysis. 


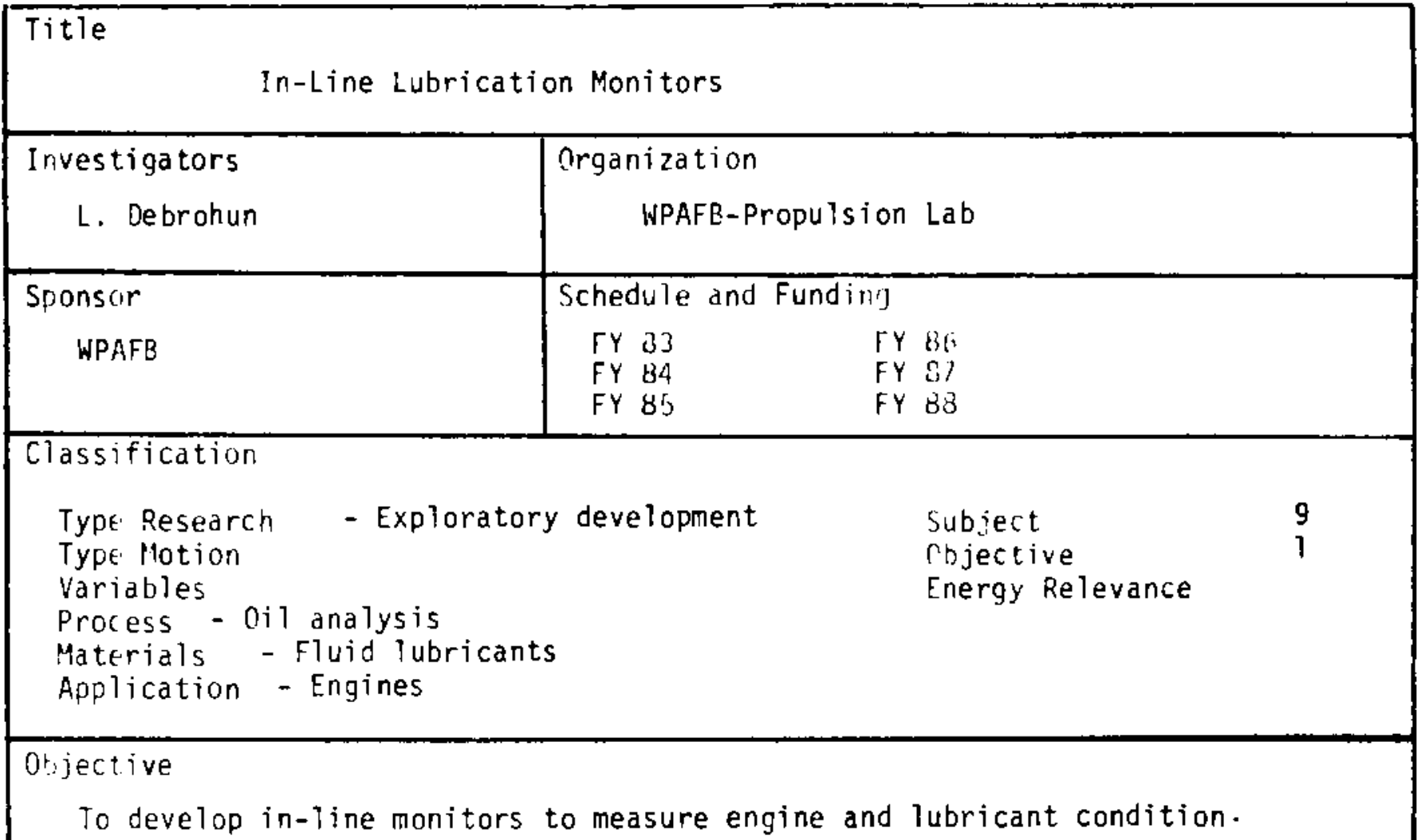

Description

A program is planned to develop and flight test in-line instruments which wi' 1 detect wear particles or lubricant oxidation which would indicate a variety of engine problems. One such instrument is an X-ray flouresence model. This device will be developed to detect 4 metals, evaluated, and then flight tested. 


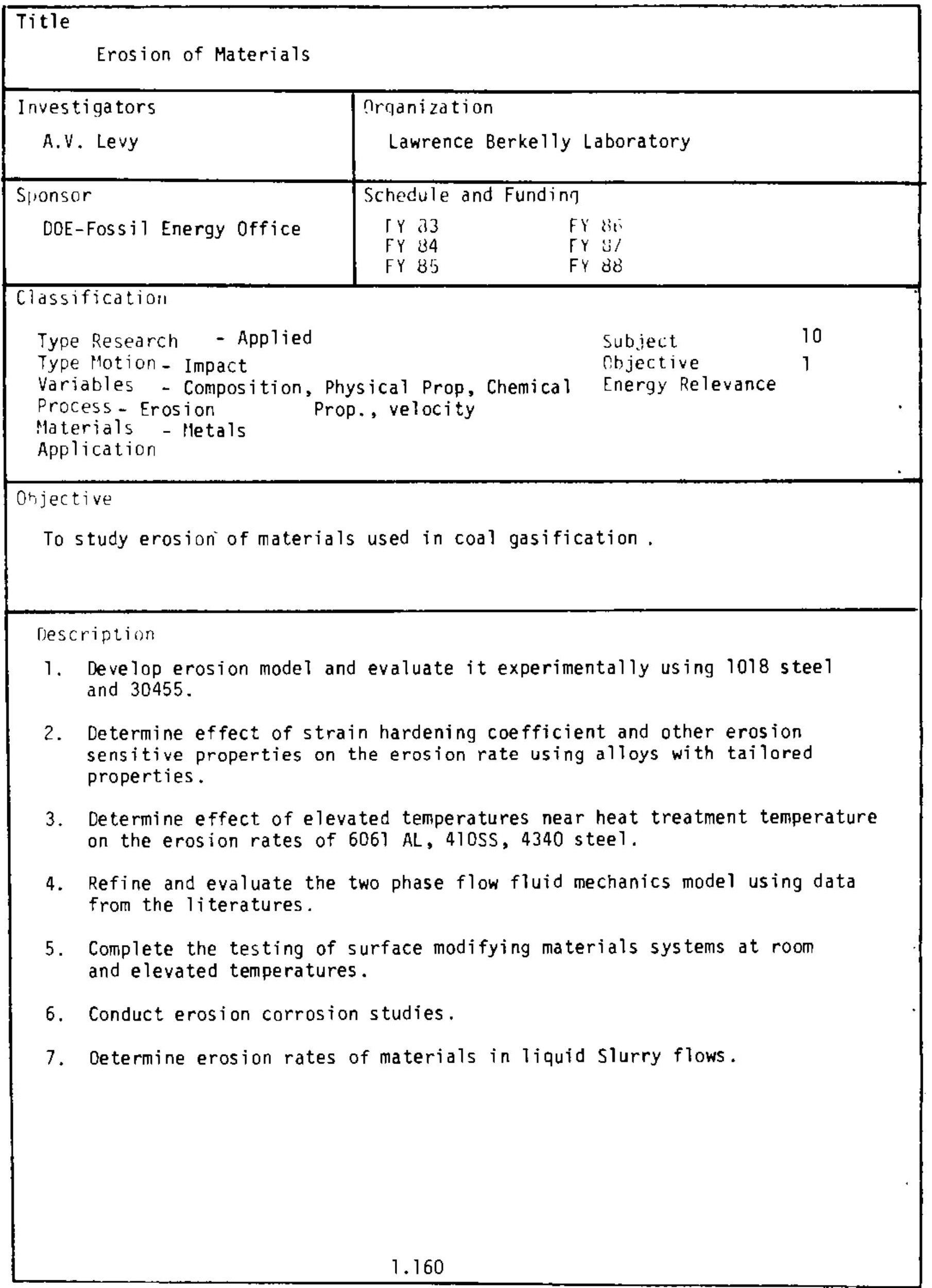




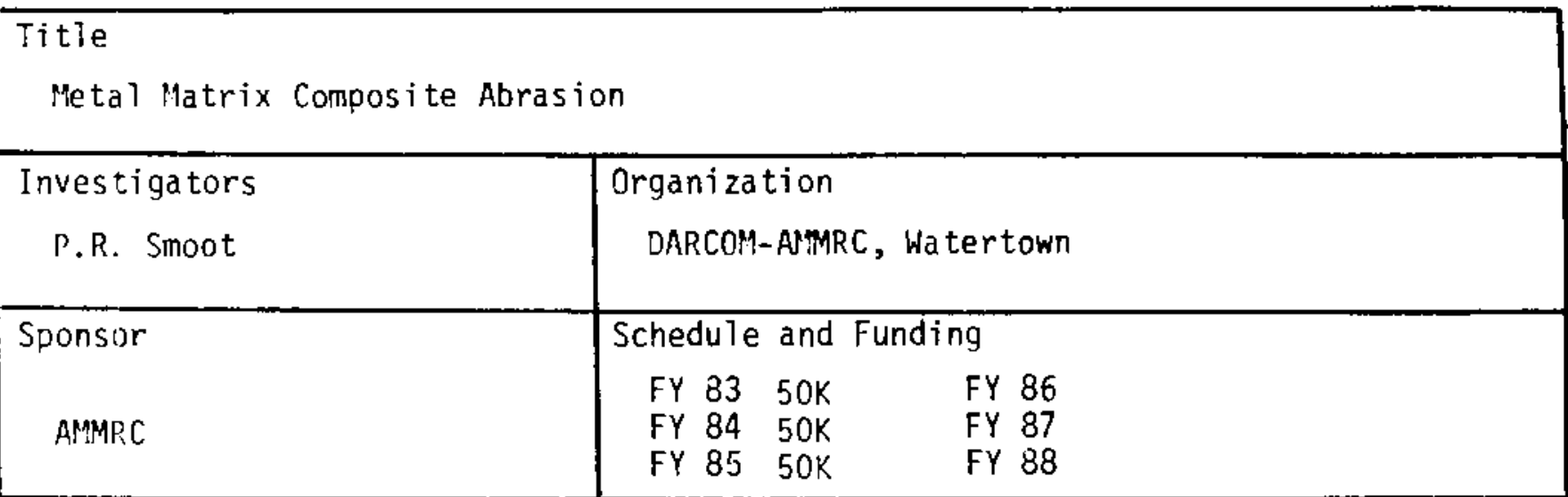

Classification

Type Research - Applied

Type Motion - Unlubricated Sliding

Variables - Compositions

Subject

Objective

10

Energy Relevance

Process - Abrasion

Materials - Metal Composites

Application - Sliding Contacts

Objective

To evaluate abrasion resistance of aluminum-silicon carbide metal matrix composites.

Description

A dry sand rubber wheel abrasion test is being used to evaluate $70 \mathrm{Al} / 30 \mathrm{SiC}$ metal matrix composites. Other mechanical properties such as tensile strength, fracture toughness, and corrosion resistance are also being measured. 


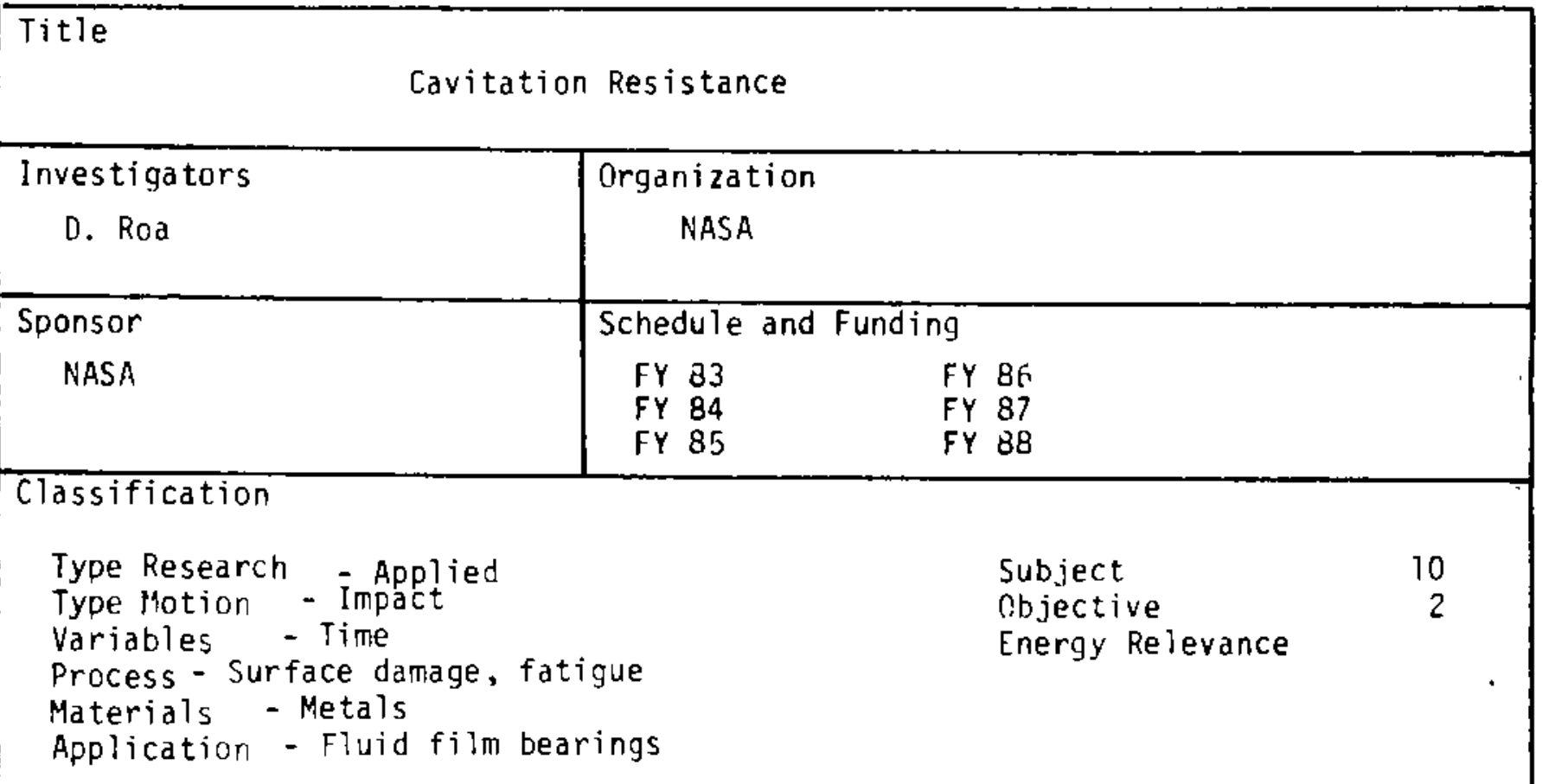

Objective

To determine the cavitation erosion mechanisms of different bearing metals and alloys in mineral oils.

Description

Experiments are carried out in an ultrasonic magnetostrictive oscillator. Surface profile measurements are taken of the worn surfaces of metals. Wear rates are determined in water and oils. 


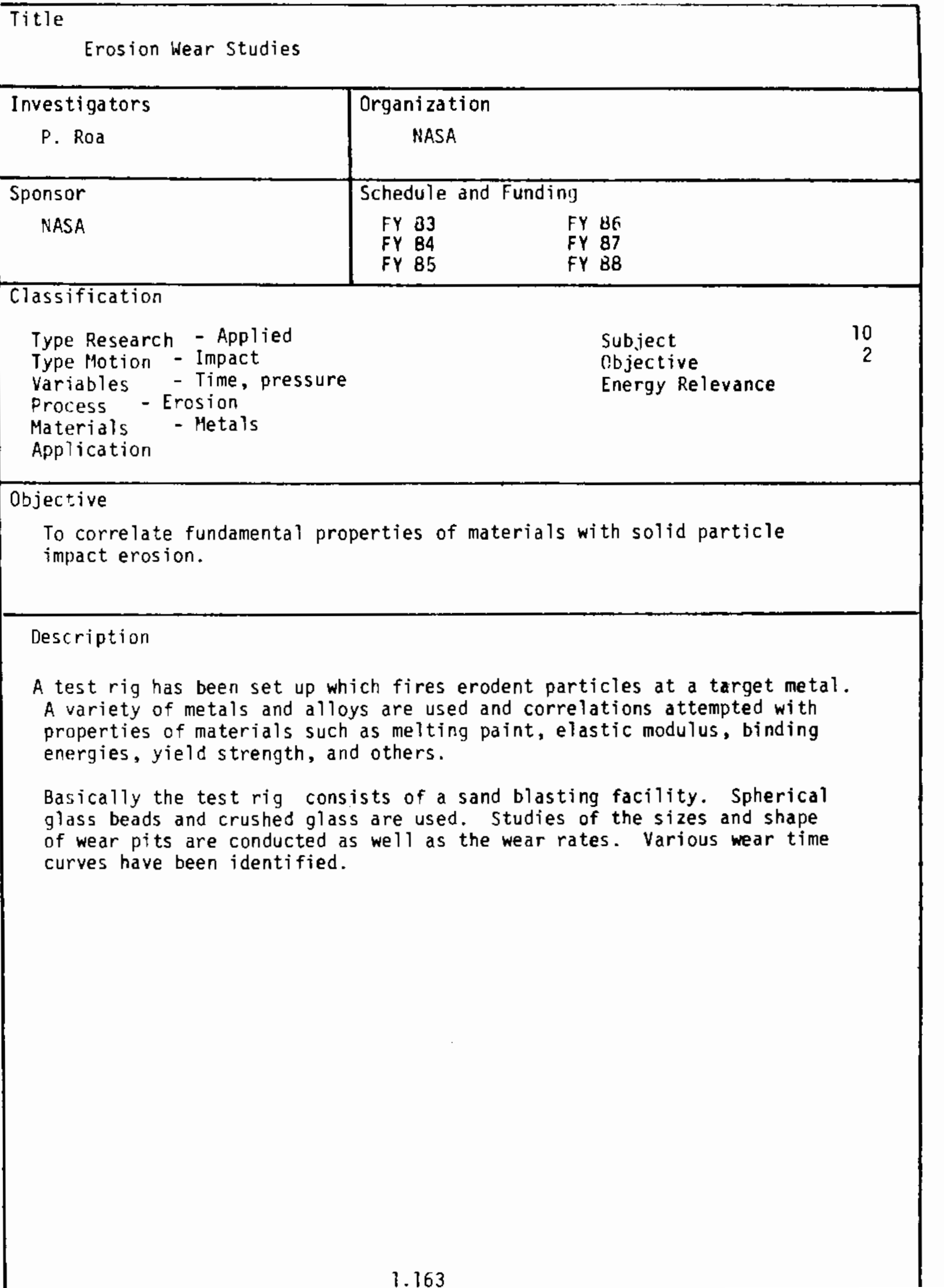


Title

Improved Turbine Engine Damper

Investigators

Organization

S. Orake

WPAFB - Propulsion Lab

Sironsor

WPAFB - APL

Schedute and Funding

I Y 33

ГY 314

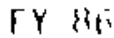

FY 85

TYY $: 3$

FY 88

Classification

Type Research - Technology Development

Type lotion - Reciprocating

variables

Process - Friction, Wear

Subject

Cbjective

Energy Relevance

Materials - Metals, ceramics

Application - Sliding contact

Onjective

To develop viscous damper technology.

Description

An analytical and experimental program is being conducted to develop viscous fluid film dampers for aircraft gas turbine bearings. 


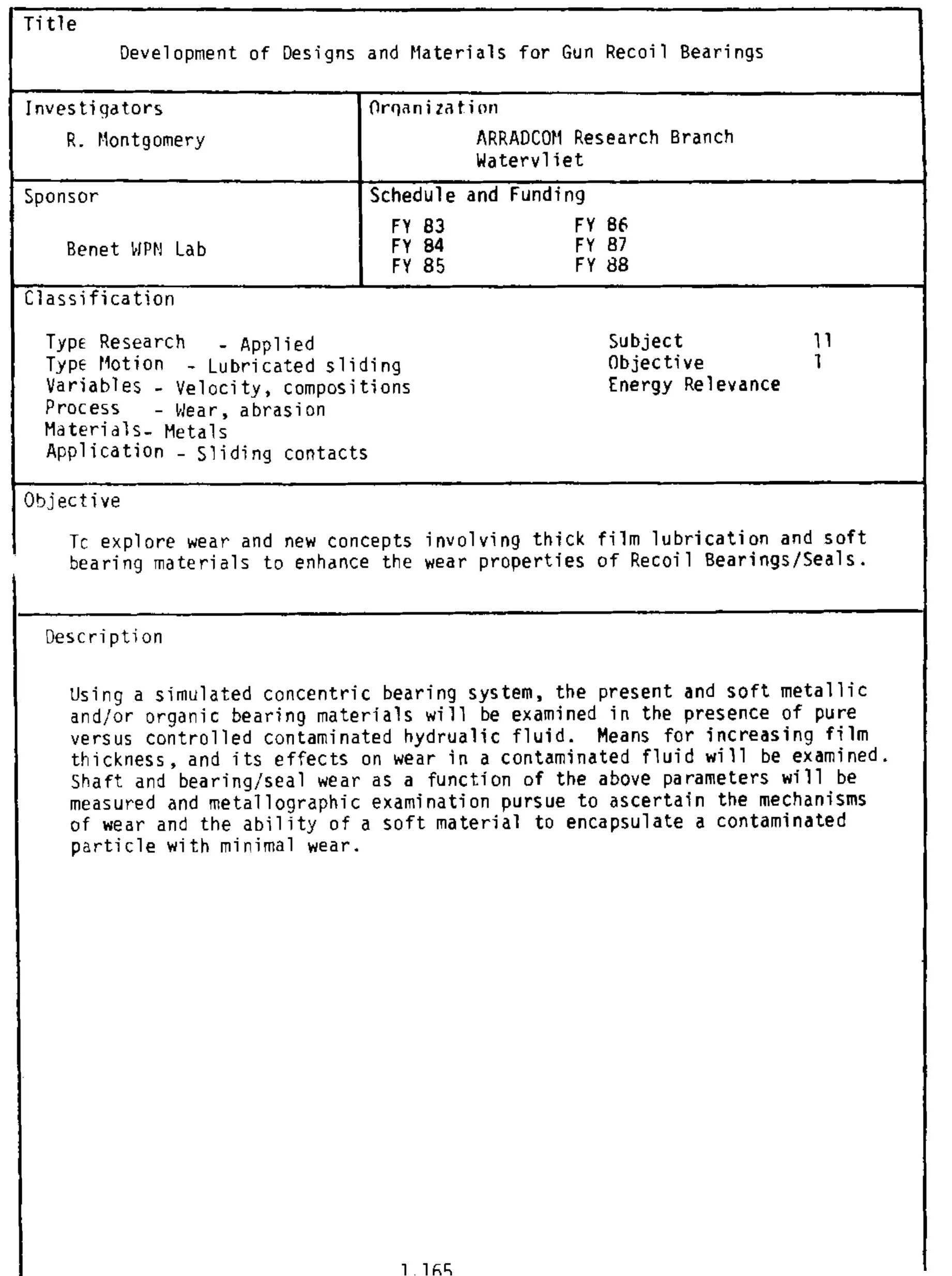




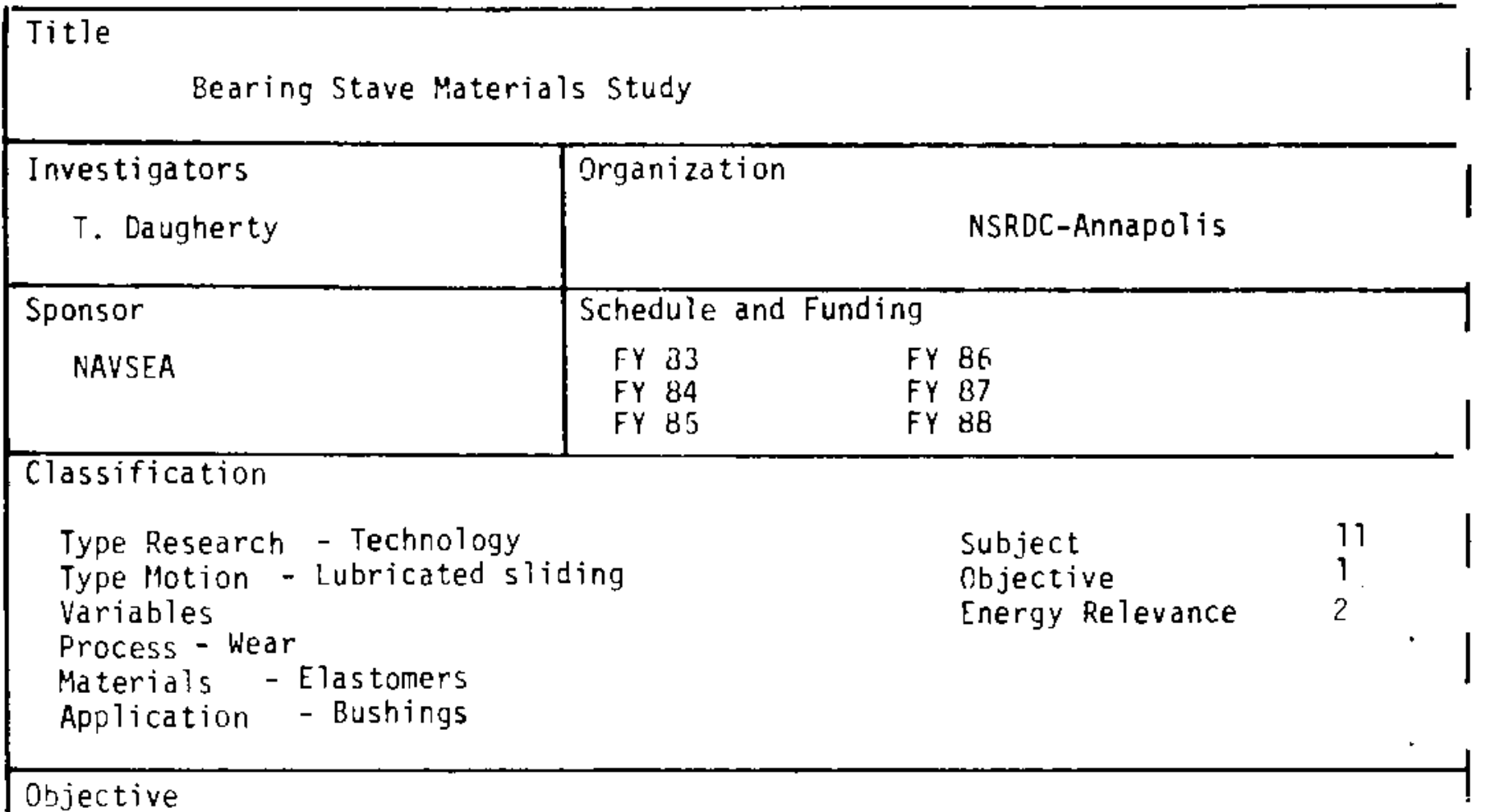

To improve military specifications for water lubricated bearings.

Description

A variety of bench tests are being used to select improved materials for main shaft stave materials. Experimental studies will also be conducted using a bearing test machines. Friction and vibration are monitored for each material. The primary variable is the rubber composition. Determinations are made as to how composition and finish influence stick slip behavior. 


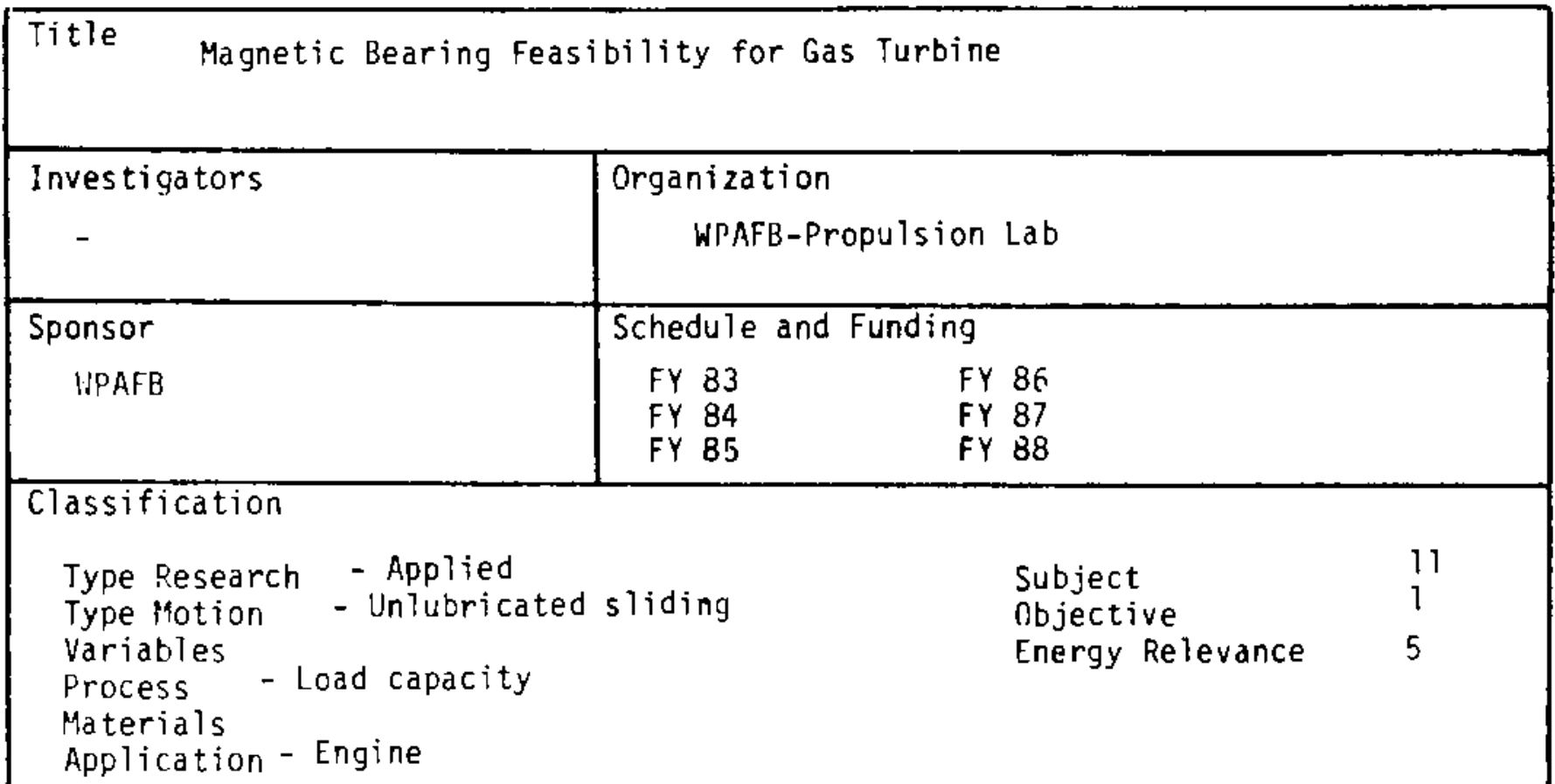

Objective

To determine the feasibility of using magnetic bearings in the aircraft gas turbine engine.

Description

This is a new program in the planning stages. 


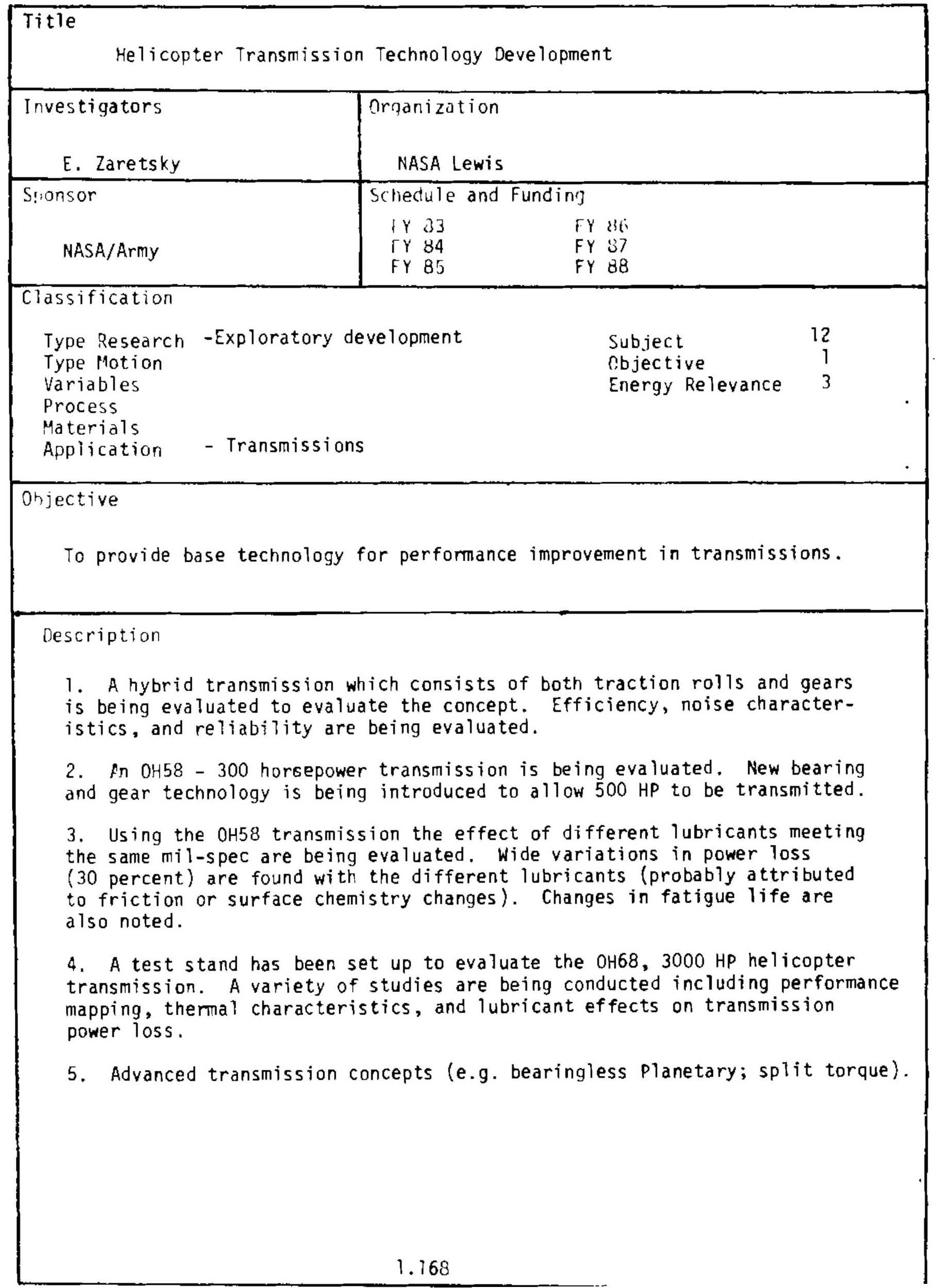




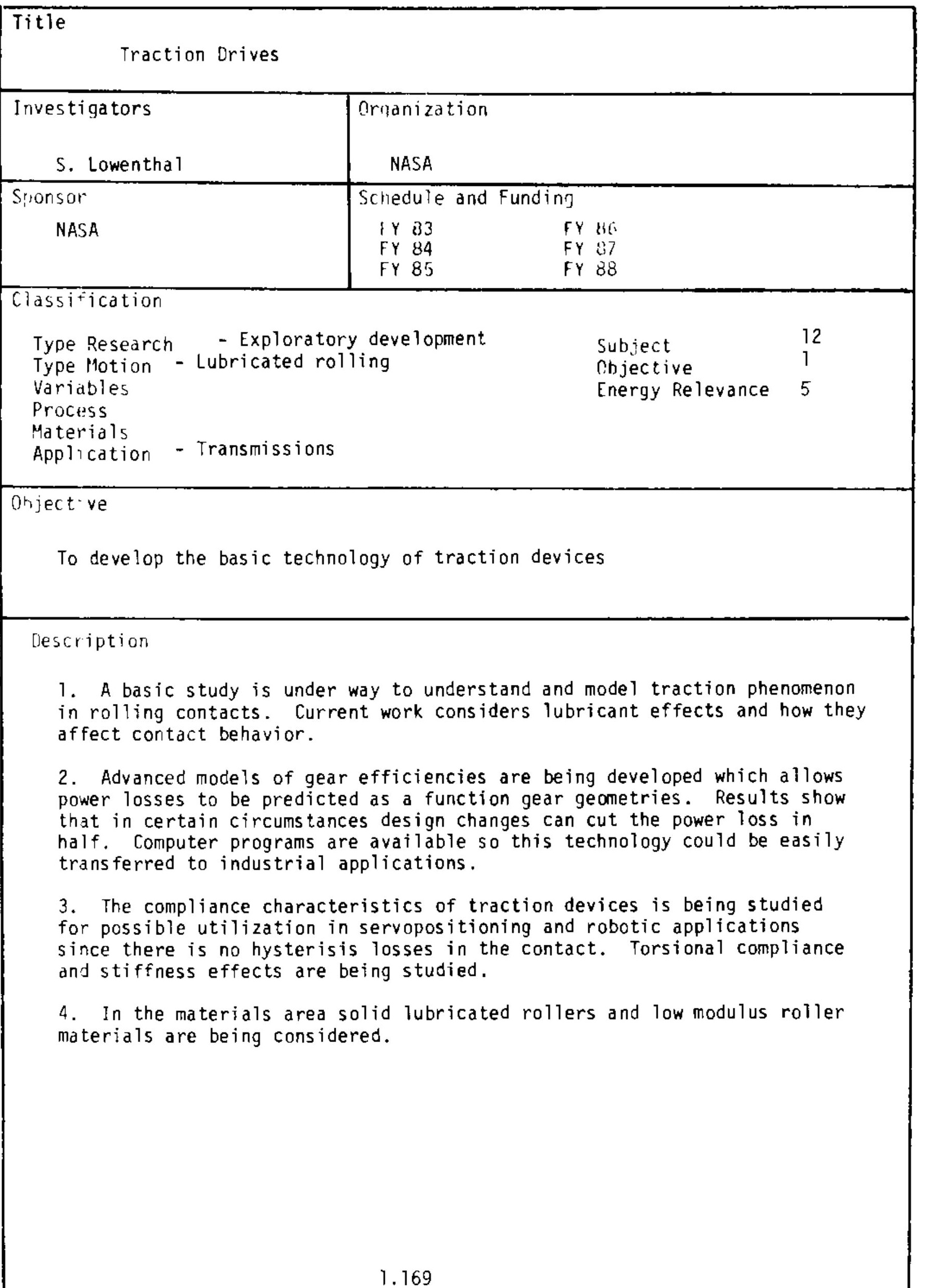




\begin{tabular}{|c|c|}
\hline \multicolumn{2}{|c|}{ Title Piston Ping Friction and Vehicle Fuel Economy } \\
\hline $\begin{array}{l}\text { Investigators } \\
\text { D.P. Hoult } \\
\text { J.J. Rife }\end{array}$ & $\begin{array}{l}\text { Organization } \\
\text { MIT - Energy Laboratory }\end{array}$ \\
\hline $\begin{array}{l}\text { Sponsor } \\
\text { DOE - Office of Energy } \\
\text { Research }\end{array}$ & $\begin{array}{l}\text { Schedule and Funding } \\
\text { FY } 83 \\
\text { FY } 84 \\
\text { FY } 85\end{array}$ \\
\hline $\begin{array}{l}\text { Classification } \\
\text { Type Research - Applied } \\
\text { Type Motion - Lubricate } \\
\text { Variables - } \\
\text { Process - Friction } \\
\text { Materials - Metals } \\
\text { Application - Rings }\end{array}$ & $\begin{array}{lll} & \text { Subject } & 15 \\
\text { Objective } & 6 \\
\text { Energy Relevance } & 5\end{array}$ \\
\hline \multicolumn{2}{|c|}{$\begin{array}{l}\text { Ohjective } \\
\text { Development of a physical model for piston ring-lubricant systems design. }\end{array}$} \\
\hline \multicolumn{2}{|c|}{$\begin{array}{l}\text { Description } \\
\text { This project addresses the development of a physical model for piston ring- } \\
\text { lubricant system design. The experimental base will come from a series of } \\
\text { experiments to be conducted in a high speed photographic rig, a friction } \\
\text { engine, and from flow visualization modeis. During the first year, a } \\
\text { theoretical model was developed to describe the motion of the piston ring } \\
\text { in a groove during the operation of a four cycle engine. This model is } \\
\text { based conceptually on the work of Rangert, and is three dimensional with three } \\
\text { degrees of freedom. The model predicts oil film thickness, oil consumption } \\
\text { and friction throughout the cycle. At present the calculations have been } \\
\text { in the quasi-steady regime. The turning points of the ring motion, when it } \\
\text { changes orientation, remain to be studied in detail. The second major area } \\
\text { of research was the design and construction of a test facility for the } \\
\text { visualization of piston ring motion. Preliminary runs have been made to } \\
\text { develop the experimental methodology. During the next year experiments will } \\
\text { be used to evaluate, calibrate and extend the model. }\end{array}$} \\
\hline
\end{tabular}




\begin{tabular}{|c|c|}
\hline \multicolumn{2}{|c|}{ Title Tribology in Automotive Fuel Economy } \\
\hline $\begin{array}{l}\text { Investiqators } \\
\text { W. O. Winer }\end{array}$ & $\begin{array}{l}\text { Organization } \\
\text { Georgia Tech - Mechanical Engineering }\end{array}$ \\
\hline Spronsor & $\begin{array}{cc}\text { Schedule and Funding } & \\
\text { TY } 33 & \text { FY } 83 \text { it } \\
\text { FY } 84 & \text { FY } 87 \\
\text { FY } 85 & \text { FY } 88\end{array}$ \\
\hline $\begin{array}{l}\text { Classification } \\
\text { Type Research - Applied } \\
\text { Type Hotion } \\
\text { Variasles } \\
\text { Process - Lubrication, fr } \\
\text { Materials - Coatings, fluic } \\
\text { Application - Engines }\end{array}$ & $\begin{array}{ll}\text { Subject } \\
\text { Objective } \\
\text { Energy Relevance }\end{array}$ \\
\hline \multicolumn{2}{|c|}{$\begin{array}{l}\text { Objective } \\
\text { Friction reduction in automotive applications with improved rheological } \\
\text { behavior and coatings. }\end{array}$} \\
\hline \multicolumn{2}{|c|}{$\begin{array}{l}\text { Description } \\
\text { An extensive program of study into several aspects of the role of tribology } \\
\text { in automotive fuel economy has recently been completed. The program had } \\
\text { two main aspects. These were the role of the lubricant rheology and the } \\
\text { potential role of hard and soft surface coatings. A significant portion of } \\
\text { the indicated horespower produced in the combustion process is dissipated } \\
\text { in tribocontacts by shearing the lubricant. The lubricant rheological } \\
\text { properties are a direct indication of the amount of energy that will be } \\
\text { dissipated for the kinematics of the tribocontact. The study was to } \\
\text { determine the rheological behavior of typical automotive lubricants and how } \\
\text { it depends on the composition of the lubricant. The second aspect of the } \\
\text { study was the development and evaluation of both hard and soft surface } \\
\text { coatings for automotive use. These coatings were put on current materials } \\
\text { of construction as well as on several lightweight and non-strategic materials. } \\
\text { Hard coats of titanium nitride were found to afford durable wear protection } \\
\text { on several substrates. }\end{array}$} \\
\hline
\end{tabular}


Title

Effect of Fuel Components on Engine Wear

\begin{tabular}{|c|c|}
\hline Investigators & $\begin{array}{l}\text { Organization } \\
\qquad \text { MERADCOH - F\&L }\end{array}$ \\
\hline Sponsor & $\begin{array}{c}\text { Schedule and Funding } \\
\text { FY } 83 \\
\text { FY } 84 \\
\text { FY } 85\end{array}$ \\
\hline
\end{tabular}

Classification

Type Research - Basic

Type Motion - Lubricated sliding

Variables - Environment

Subject

Objective

Energy Relevance
15

1

Process - wear

Materials - Metals

Application - Engine

Objective

To investigate the role of sulfur, oxygen, and nitrogen containing heteroatomic fuel components on compression-ignition engine deposits and wear.

Description

Operate a single-cylinder research engine using a highly controlled base fuel (JP-7) doped with specific heteroatomic compounds. Measure the differences in deposits and wear and investigate the related mechanisms. 


\section{Title}

Gas Film Bearings for High Temperature Engines

\begin{tabular}{|c|cc}
\hline $\begin{array}{c}\text { Investigators } \\
\text { R. Colshur }\end{array}$ & Organization \\
& Franklin Institute \\
\hline Sponsor & & \\
Curmins & Schedule and Funding \\
& FY 83 & FY 86 \\
& FY 84 & FY 87 \\
& FY 85 & FY 88
\end{tabular}

Classification

Type Research - Exploratory development

Subject

Type "lotion - Sliding

Variables -

Process - Load capacity

Objective

Energy Relevance

15

1

Materials -

Application - Gas film bearings

Objective

To develop gas film bearings for piston rings for adiabatic diesel.

Description

An analytical program was carried out to evaluate the potential of gas lubrication of piston rings in diesel engines. Three different designs were considered. One design was selected as having sufficient load capacity to warrant further development. 
Title Improved Shipboard Fuel Contimination Control for Gas Turbine
Engines

\begin{tabular}{|c|c|c|}
\hline $\begin{array}{c}\text { Investigators } \\
\text { P. Stande } 11\end{array}$ & \multicolumn{2}{|c|}{$\begin{array}{l}\text { Organization } \\
\text { MSROC-Annapolis }\end{array}$} \\
\hline Sponsor & \multicolumn{2}{|c|}{ Schedule and Funding } \\
\hline NAVSEA & $\begin{array}{ll}\text { FY } & 83 \\
\text { FY } & 84 \\
\text { FY } & 85\end{array}$ & 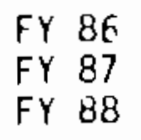 \\
\hline
\end{tabular}

Ciassification

Type Research - Technology development Subject

Type Motion

Objective

16

Variables

Process - Filtration

Energy Relevance

Materials - Fuels

Application - Engines

Objective

To define a prefilter necessary to meet LM2500 engine comtamination requirements.

Description

This program aims to optimize shipboard fuel purification systems. The program will take advantage of previous OTNSRDC and NAVSSES experience, plus the continuing investigations in fuel purification of other laboratories. 


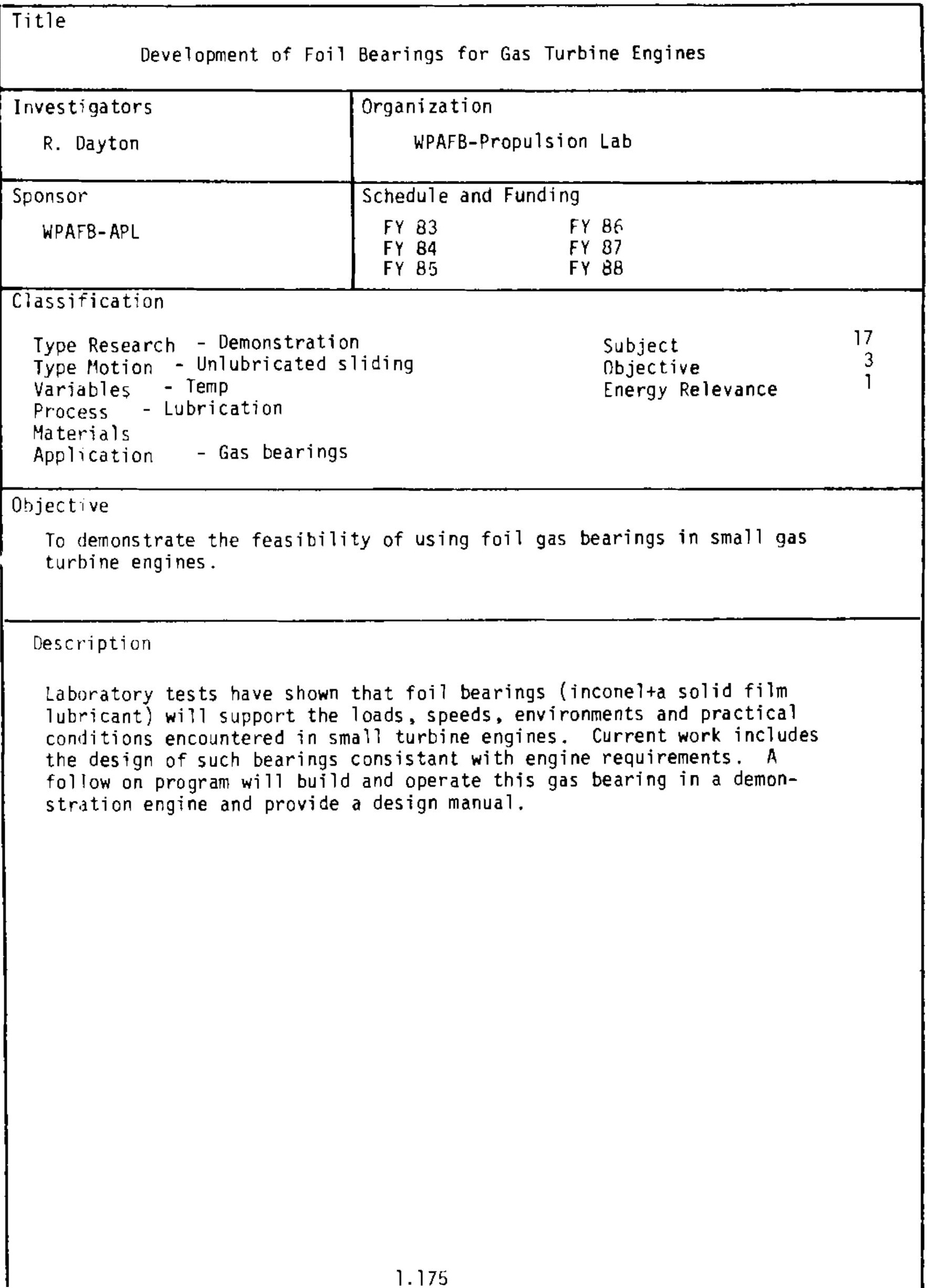




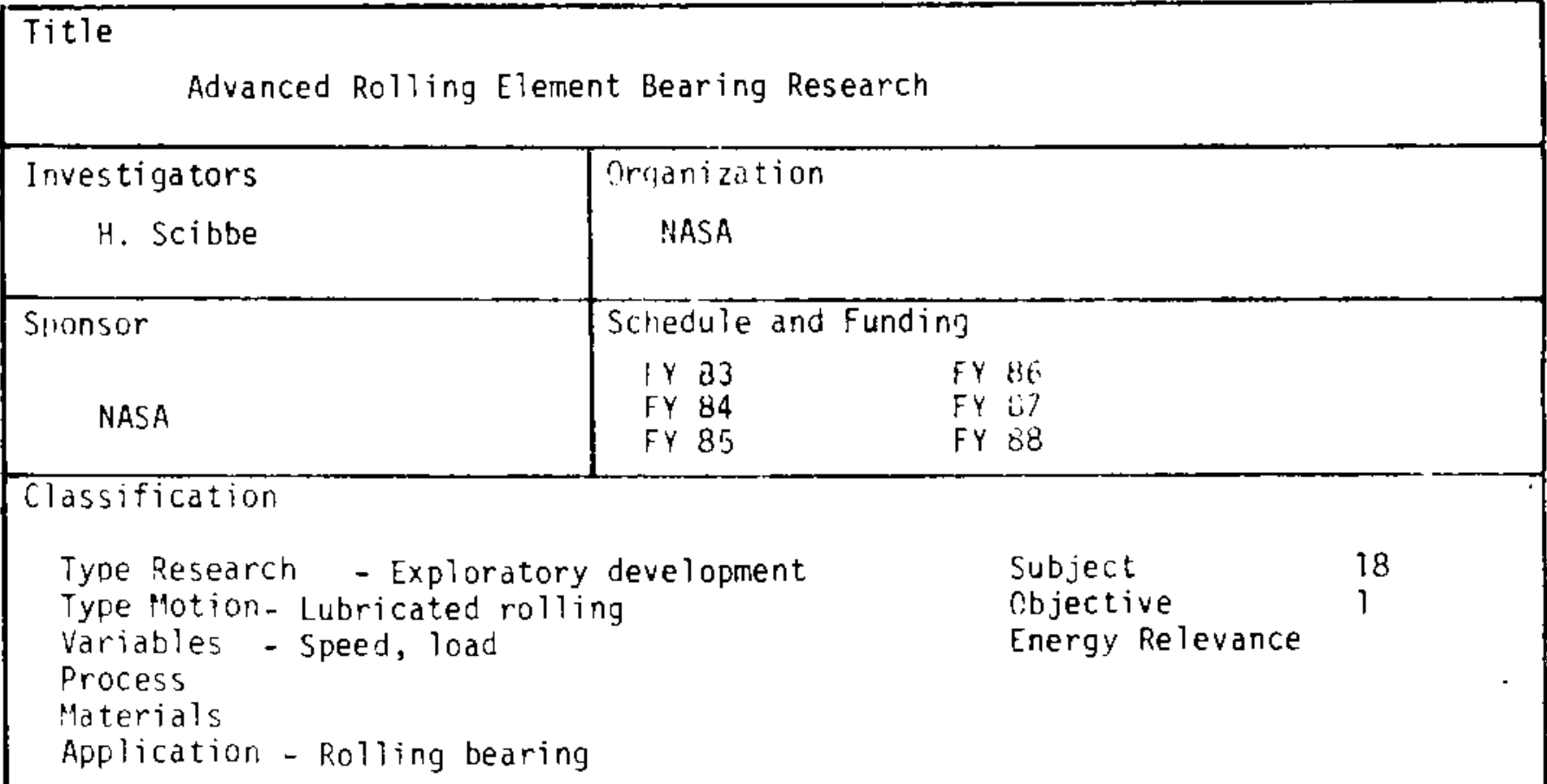

objective

To develop technology which will allow bearings to operate at higher speeds and loads, and lower temperatures.

Description

1. A transient thermal analys is has been developed which predicts temperature gradients in spherical roller bearings. This program allows engineers to modify designs to achieve minimum bearing operating temperatures. A rig is being build to compare theory with experiment.

2. A program is being conducted to increase the speed and temperature capabilities of tapered roller bearings.

3. A new bearing concept "three piece inner race" is being applied to high speed cylindrical roller bearings. The inner race (two flanges and contact surface) are made separately. This allows different materials to be used for different contact conditions; improved finishes; and different contact geometries. Such bearings are being evaluated.

4. An analytica) computer program (XCAV) has been developed which predicts bearing temperatures based upon the ratio of oil to air in the bearing cavity. Experimental results show that this is a critical factor in determining bearing temperatures. 


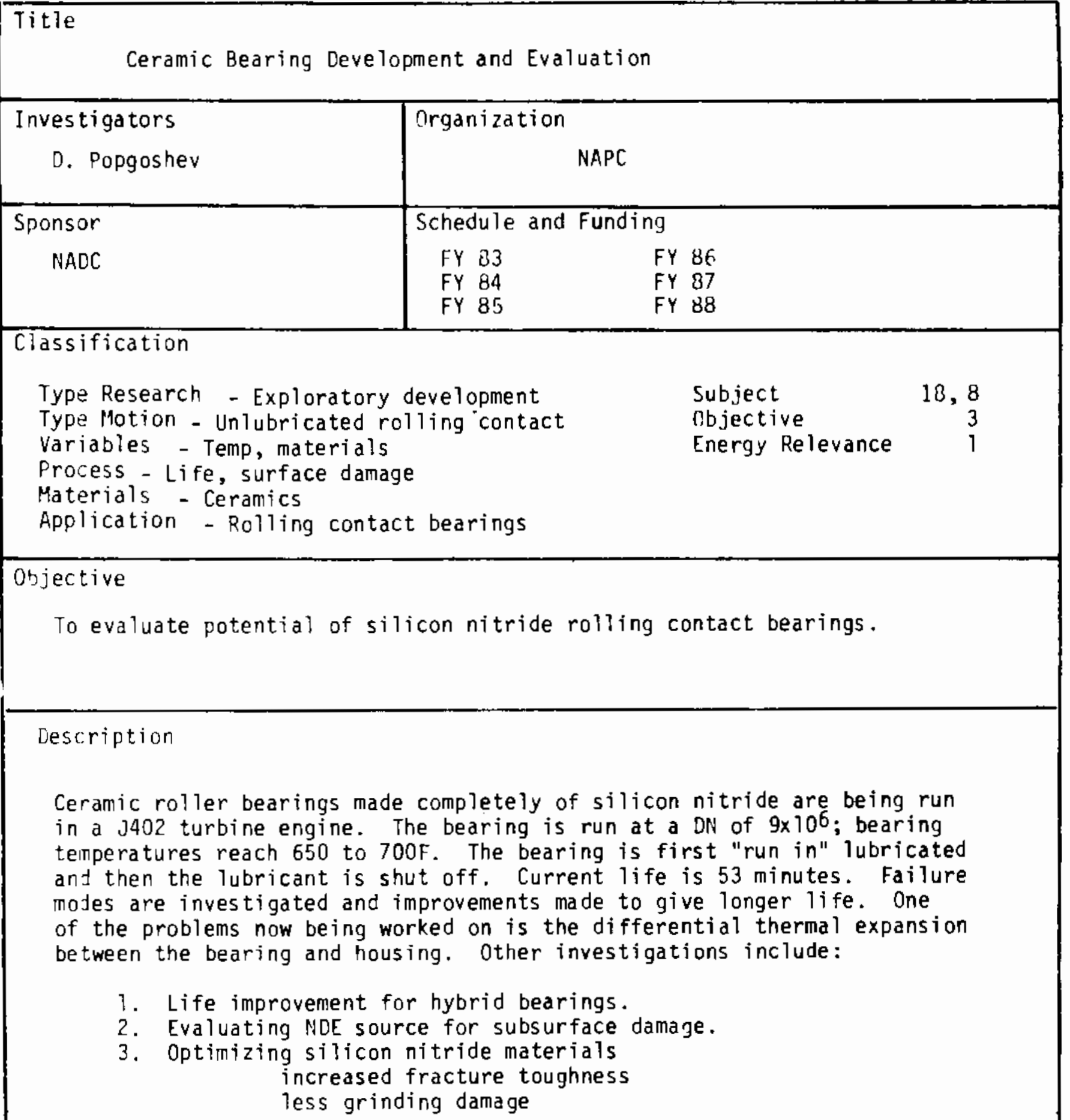


Title

Corrosion Resistant Bearings

Investigators

R. Valori

D. Popgoshev

Sponsor
Organization

NAPTC - Trenton

Schedule and Funding

FY 83

FY 84

FY 85

FY 86

FY 87

FY 88

Classification

Type Research - Exploratory research

Type Motion - Lubricated rolling; lubricated sliding

Variables - Environment

Process - Life

Materials - Metals, coatings

Application - Rolling contact bearings

objective

To develop bearings with improved corrosion and wear protection.

\section{Description}

Based on several programs, an implantation technique was developed. Ion implanted $M 50$ bearings were bench tested and engine tested and showed satisfactory performance. The 379 engine, the $T 58$ engine and the 446 hinge pin bearings are now being used for field evaluation. 


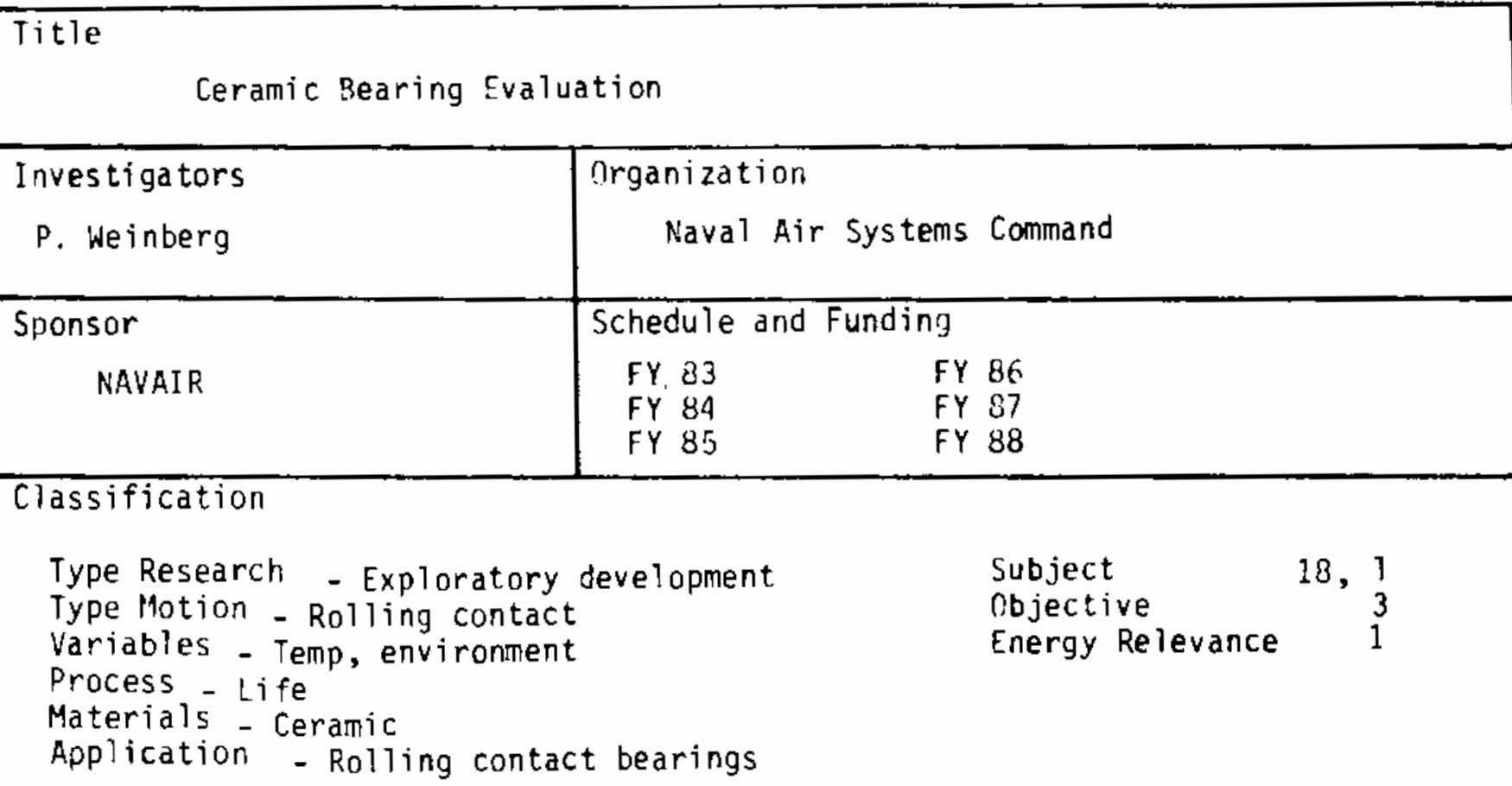

Objective

To evaluate the potential of $\mathrm{Si}_{3} \mathrm{~N}_{4}$ ceramic bearings.

Description

A continuing program has been conducted by SKF Industries to provide a data base for a complete $\mathrm{Si}_{3} \mathrm{~N}_{4}$ bearing. A carbon graphite cage is used to lubricate the bearing. A series of tests have been run to evaluate bearing life under a variety of conditions. The current investigation evaluates the effect of a sait water environment. 


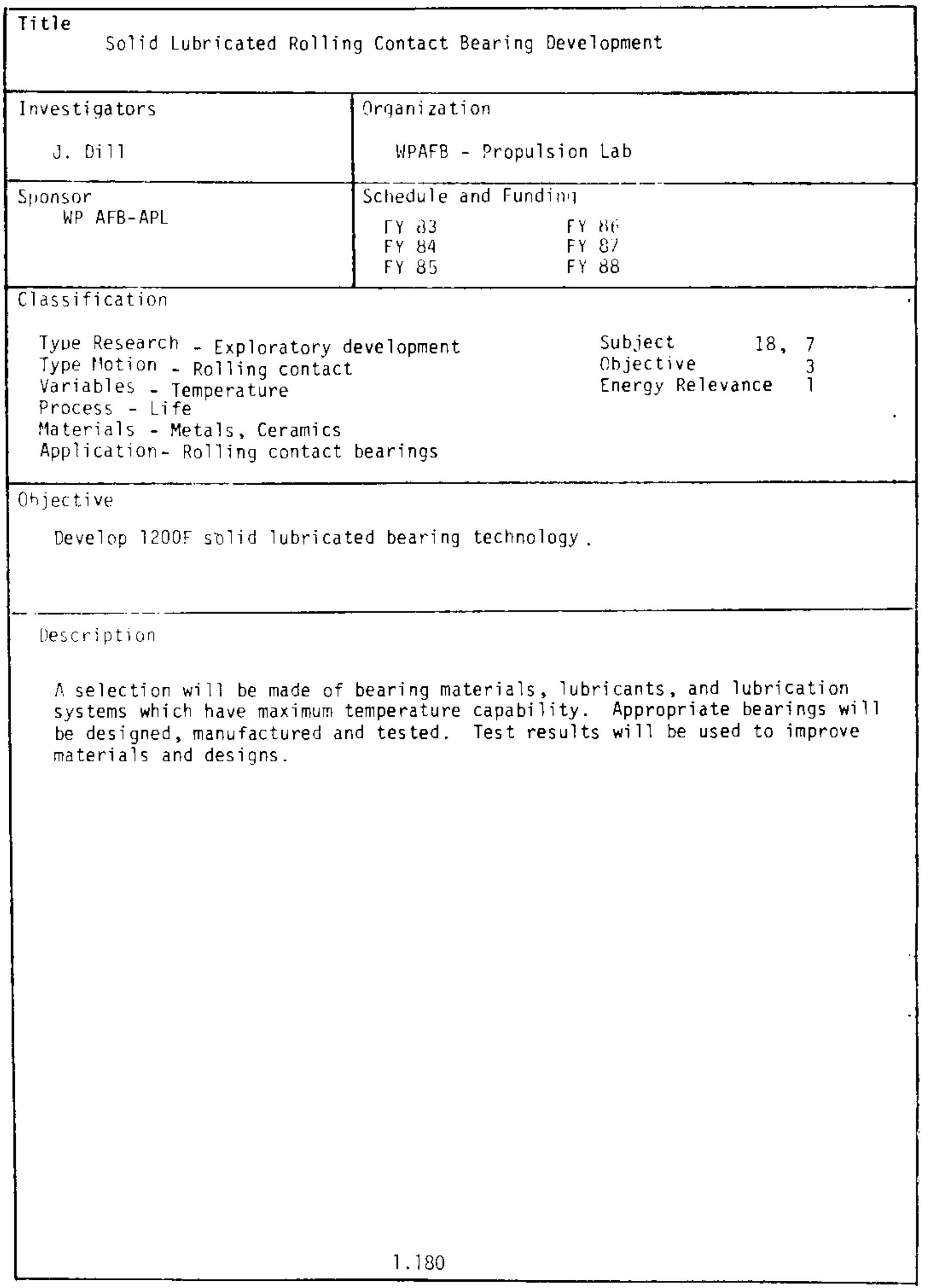




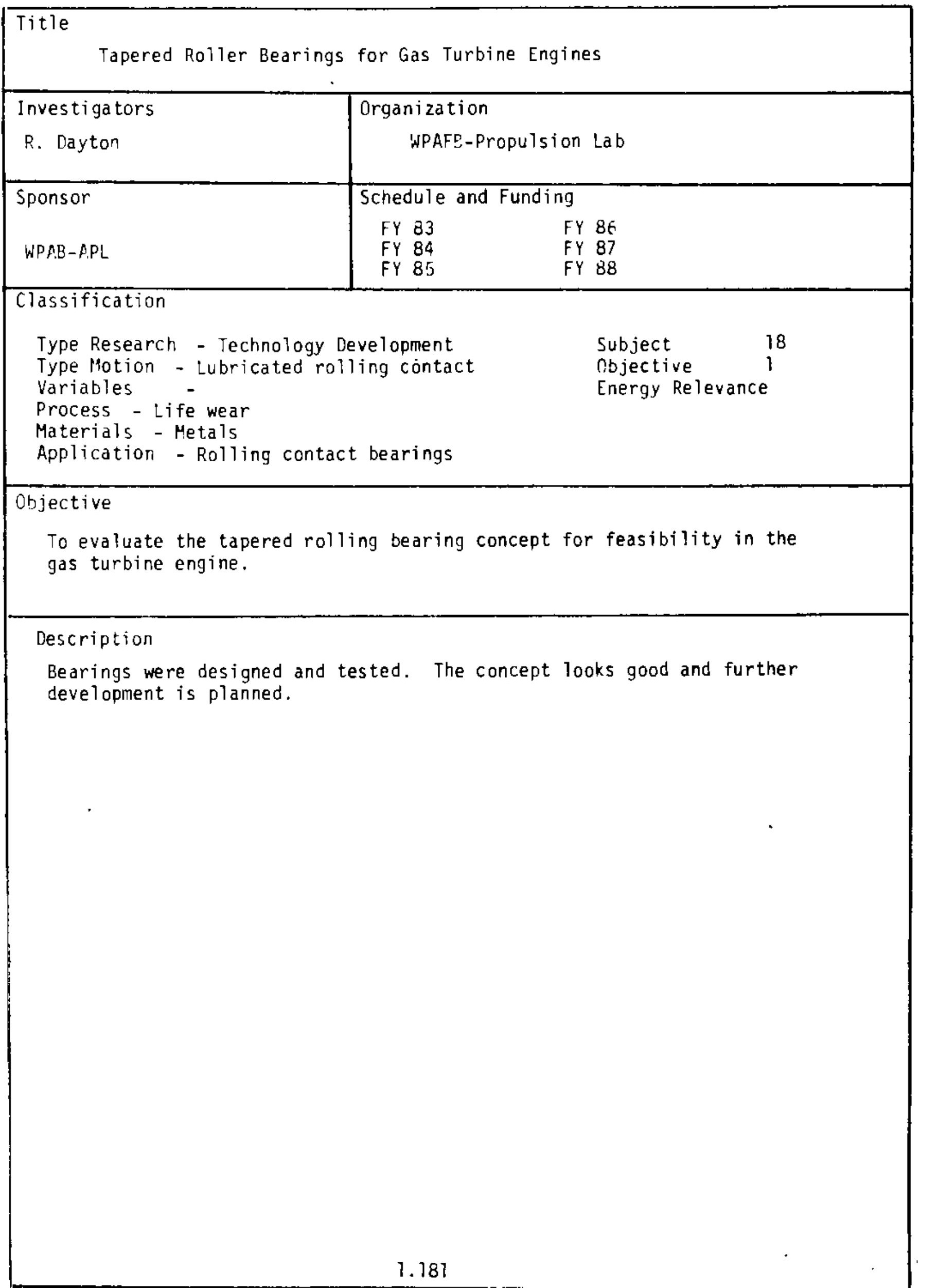


Title

High Speed Cylindrical Roller Bearing Development

\begin{tabular}{|c|c|c|c|}
\hline $\begin{array}{l}\text { Investigators } \\
\text { J. Schrand }\end{array}$ & $\begin{array}{l}\text { Orqanization } \\
\text { WPAFB - Propulsion } \\
\text { (Pratt \& Whitney Ai }\end{array}$ & $\begin{array}{l}\text { Lab } \\
\text { reraft) }\end{array}$ & \\
\hline $\begin{array}{l}\text { Sponsor } \\
\text { WPAFB-APL }\end{array}$ & $\begin{array}{l}\text { Schedule and Funding } \\
\text { IY } 33 \\
\text { Fy } 84 \\
\text { Fy } 85\end{array}$ & $\begin{array}{l}86 \\
37 \\
88\end{array}$ & \\
\hline \multicolumn{4}{|l|}{ Classification } \\
\hline $\begin{array}{l}\text { Type Research - Technology } \\
\text { Type Motion - Lubricated rollin } \\
\text { Variables - Velocity } \\
\text { Process - Life } \\
\text { Materials - Metals } \\
\text { Application - Rolling contact }\end{array}$ & bearing & $\begin{array}{l}\text { Subject } \\
\text { Objective } \\
\text { Energy Relevance }\end{array}$ & \\
\hline
\end{tabular}

Objective

To design a three million DN cylindrical roller bearing for turbomachinery applications.

\section{Description}

A new design is being prepared to avoid problem areas encountered in the original design. 
Title

Counter-Rotating Roller Bearing Development

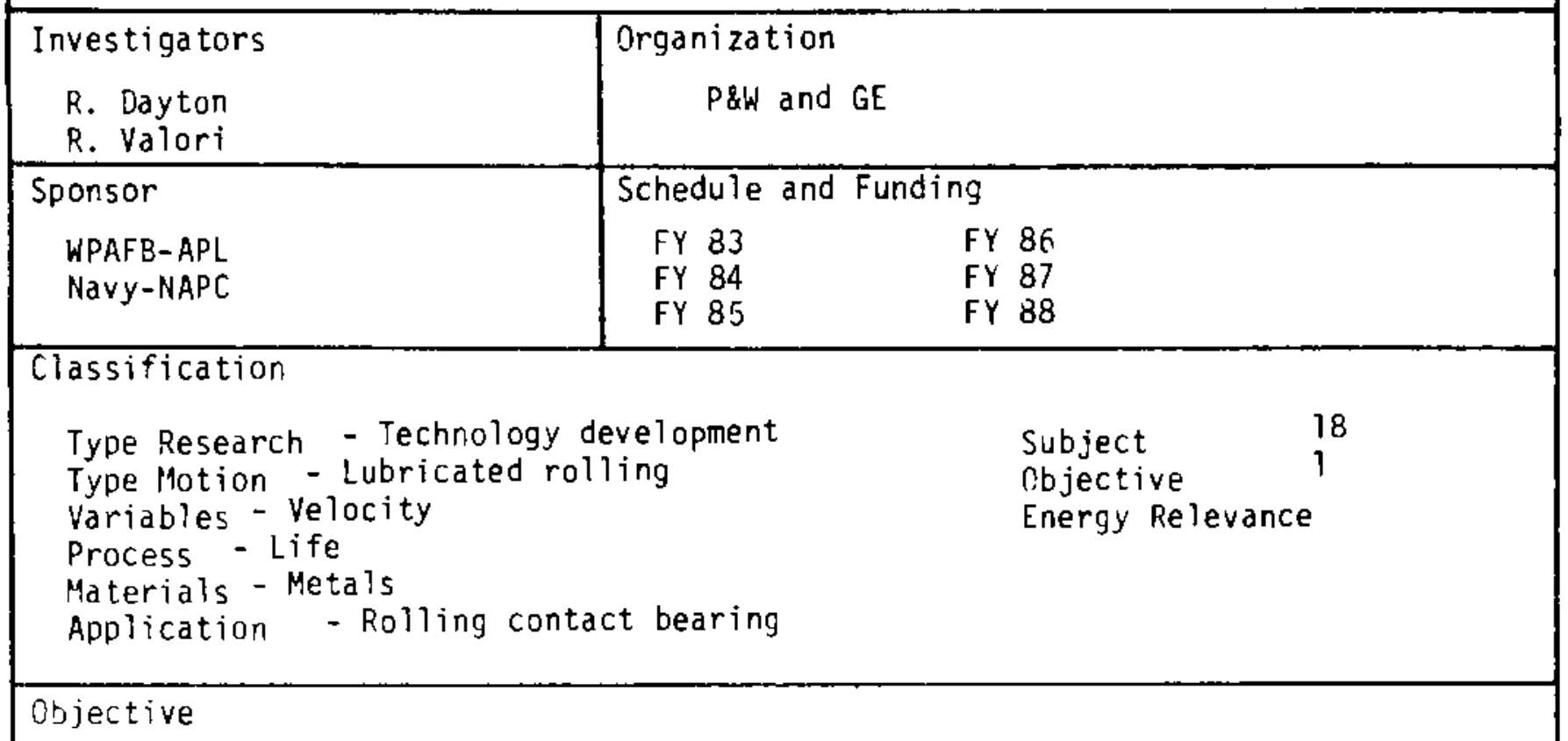

To design and evaluate a bearing system for a counter rotating shaft gas turbine engine.

Description

Advanced engine configuration studies conducted at P\&WA have shown large Life Cycle cost (LCC) advantages for an engine with contrarotating spools and a rotor support system in which the high rotor is straddle mounted with an intershaft support bearing downstream of the high pressure turbine. As a result, advanced engine designs are incorporating intershaft support bearings with operational requirements up to $3.7 \mathrm{million}$ DN, and roller rotational speeds up to $170,000 \mathrm{rpm}$ which is twice conventional levels.

The obiective of this program was to select an appropriate intershaft bearing size, mounting configuration and key design parameters for an advanced engine configuration, update bearing design analysis methodology to address intershaft bearings in contrarotation, and to conduct bearing tests on eight bearing configurations to evaluate two levels each of four key bearing geometry parameters relative to a baseline bearing.

Such bearings have been designed and operated in bearing tests. Long tem bearing tests (several thousand hours) to determine wear life are in progress. 


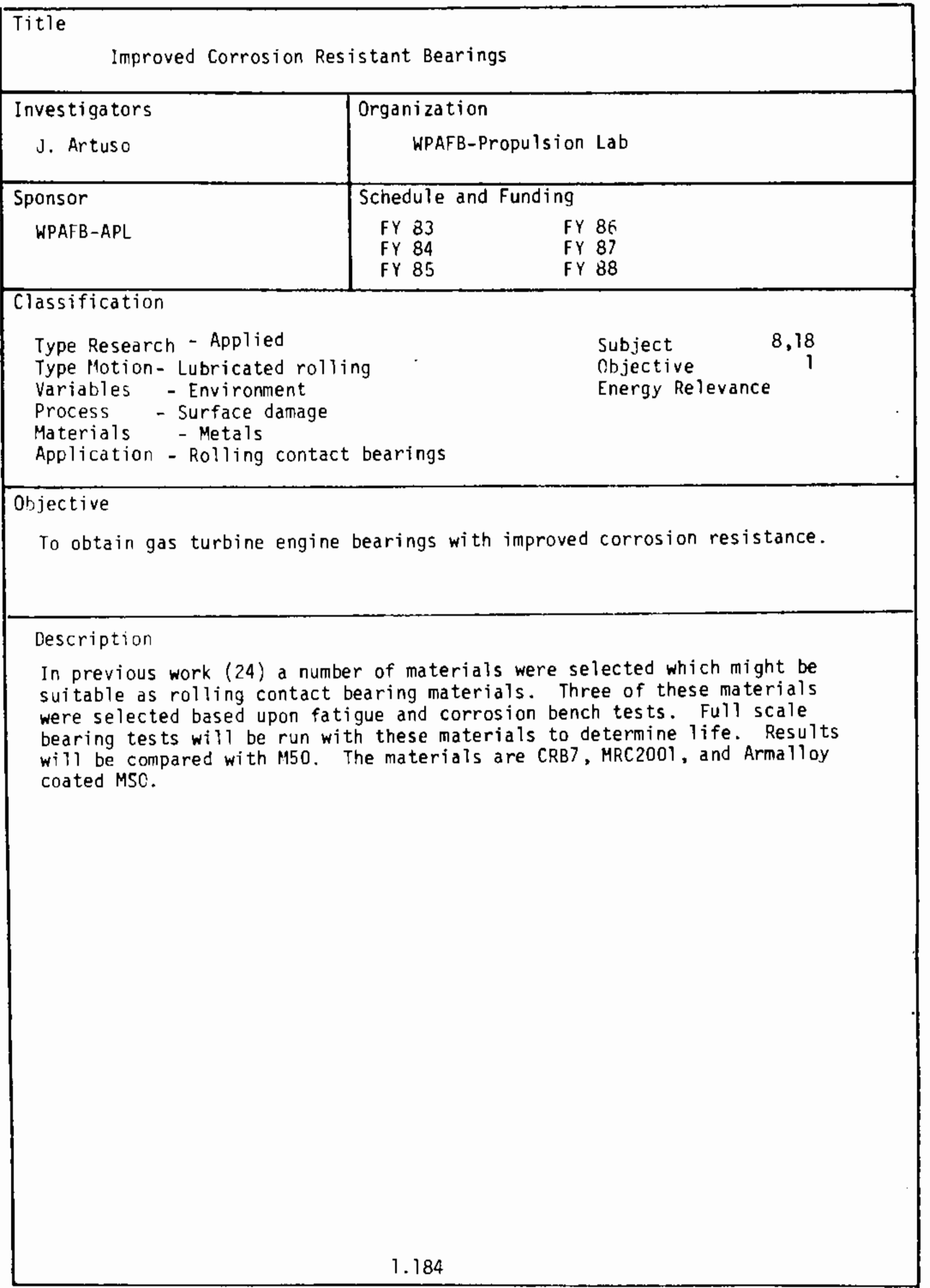


Title

Bearing Research for ROP Power Systems

\begin{tabular}{|c|c|}
\hline $\begin{array}{l}\text { Investigators } \\
\text { In - House }\end{array}$ & $\begin{array}{l}\text { Organization } \\
\qquad \text { WPAFB-Propulsion Lab }\end{array}$ \\
\hline Sponsor & Schedule and Funding \\
\hline WPAFB-APL & $\begin{array}{ll}\text { FY } & 83 \\
\text { FY } & 84 \\
\text { FY } & 85\end{array}$ \\
\hline
\end{tabular}

Classification

Type Research - Applied

Subject

Type Motion - Rolling contact

Objective

Variables

Process - Life

Energy Relevance

Materials - Metals, coatings

Application - Rolling contact bearings

\section{Objective}

In-house research to develop better bearing systems.

Description

A variety of investigations are conducted to improve understanding of materials and lubricants for engine rolling contact bearings:

1. Friction studies on lubricants

2. New and improved solid lubricant materials

3. Rolling contact fatigue tests on new materials

4. Full scale bearing dynamic studies (larger amplitudes) 


\section{Title}

NAVSEA Quiet Bearing Program

\begin{tabular}{|c|c|}
\hline $\begin{array}{l}\text { Investigators } \\
\text { R. Craig }\end{array}$ & $\begin{array}{l}\text { Organization } \\
\text { NAVSEA }\end{array}$ \\
\hline Sponsor & Schedule and Funding \\
\hline NAVSEA & $\begin{array}{ll}\text { Fy } & 83 \\
\text { Fy } & 84 \\
\text { Fy } & 85\end{array}$ \\
\hline
\end{tabular}

Classification

Type Research - Exploratory development

Type Hotion - Rolling

Subject

Objective

Variables - Finish, Geometry

Energy Relevance

Process - Noise

Materials

Application - Rolling Contact bearings

Objective

To better understand the nature of bearing noise (applicable to submarine machinery).

\section{Description}

NAVSEA is planning a major tribology program concerned with bearing noise. Low noise and vibration are needed in submarines to avoid detection. Noise requirement desired are specified in MILB 17931. Noise is usually classified as rigid body noise which relates to surface irregularities and elastic contact noise which relates to surface roughness. Noise is dependent upon both operating conditions and bearing geometries such as dimensional variations curvature, finish, tolerance, clearance, waviness, etc. This program will attempt to determine which variables are most important and what can be done to manufacture quiet bearings. 


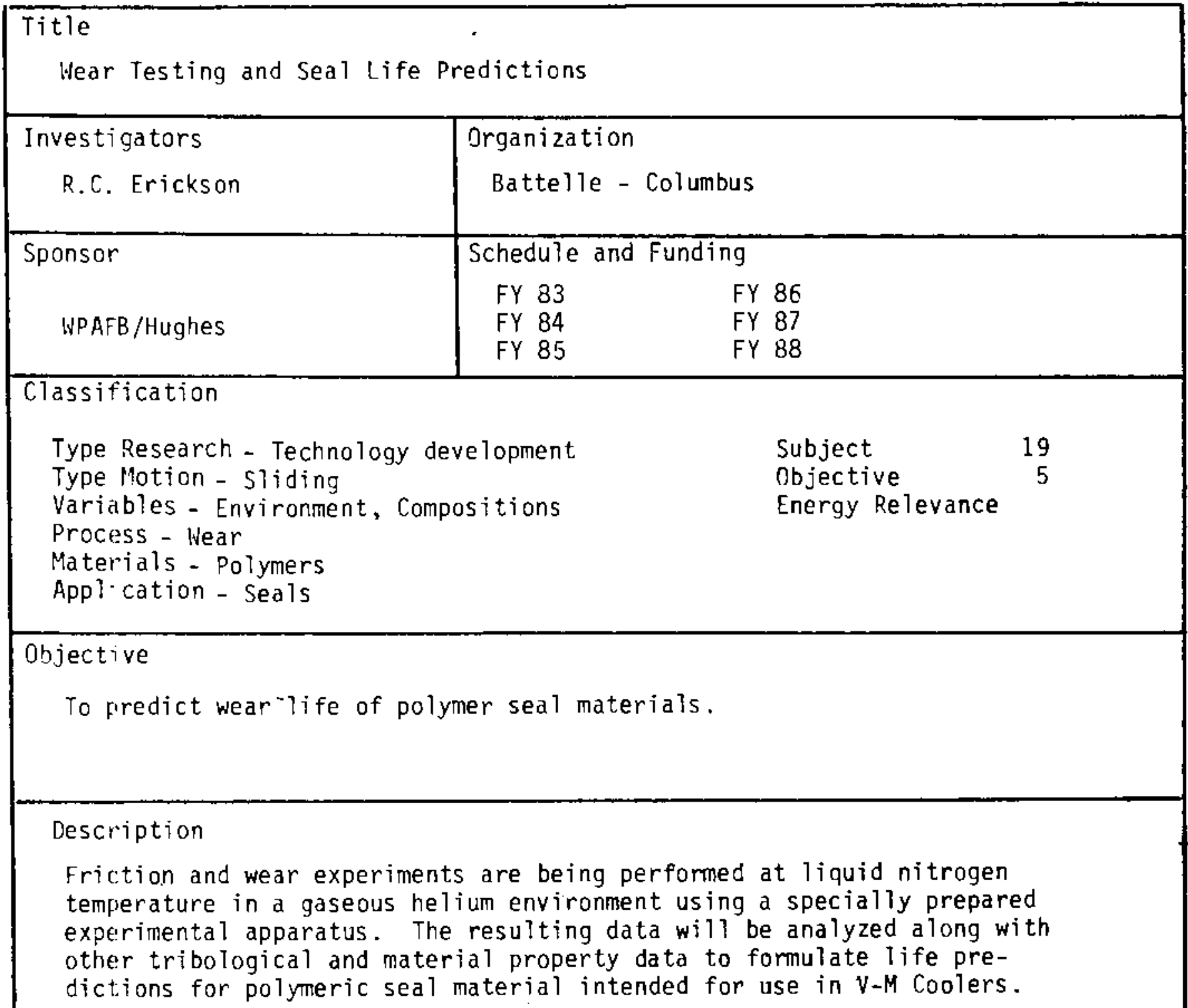




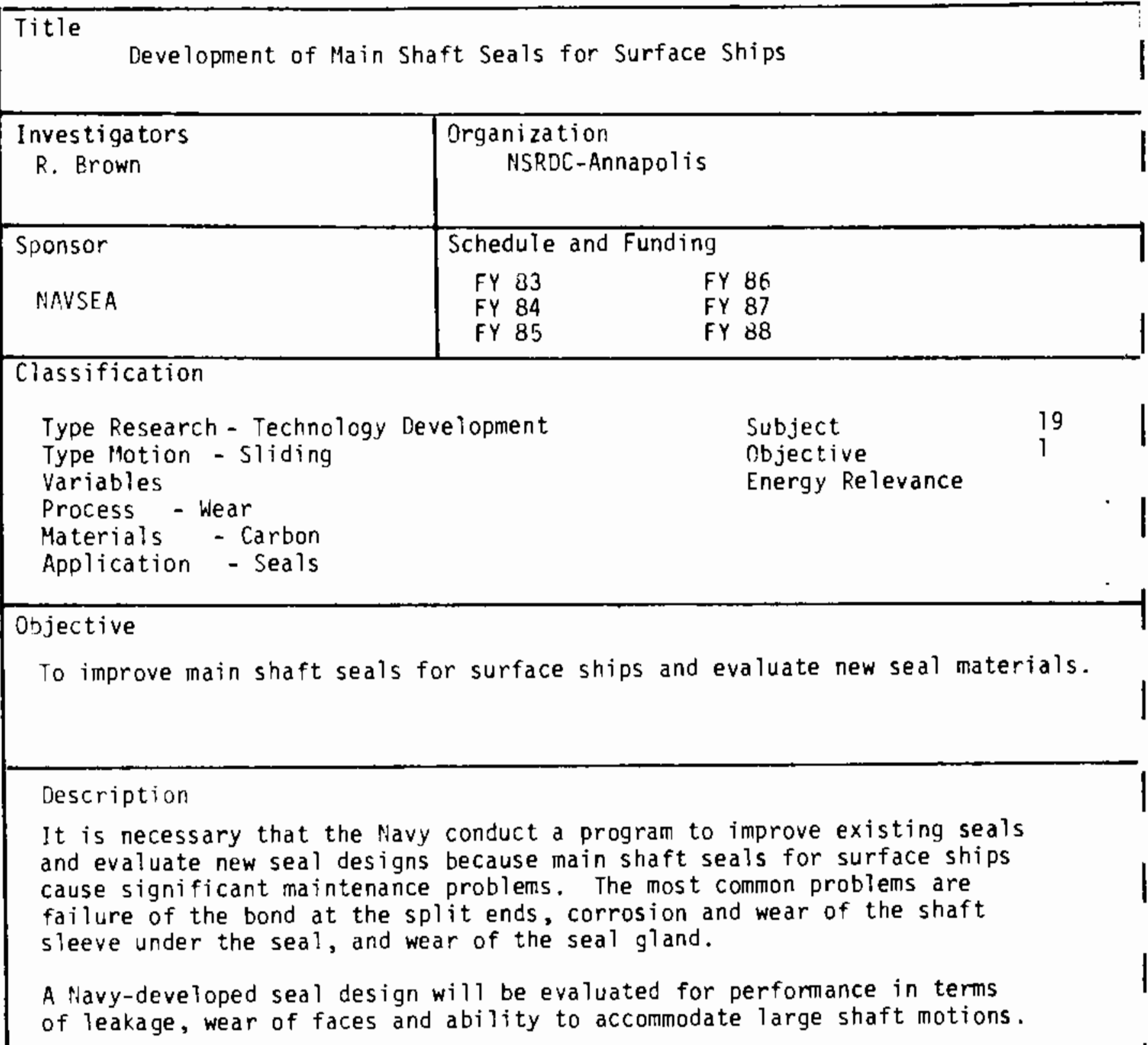




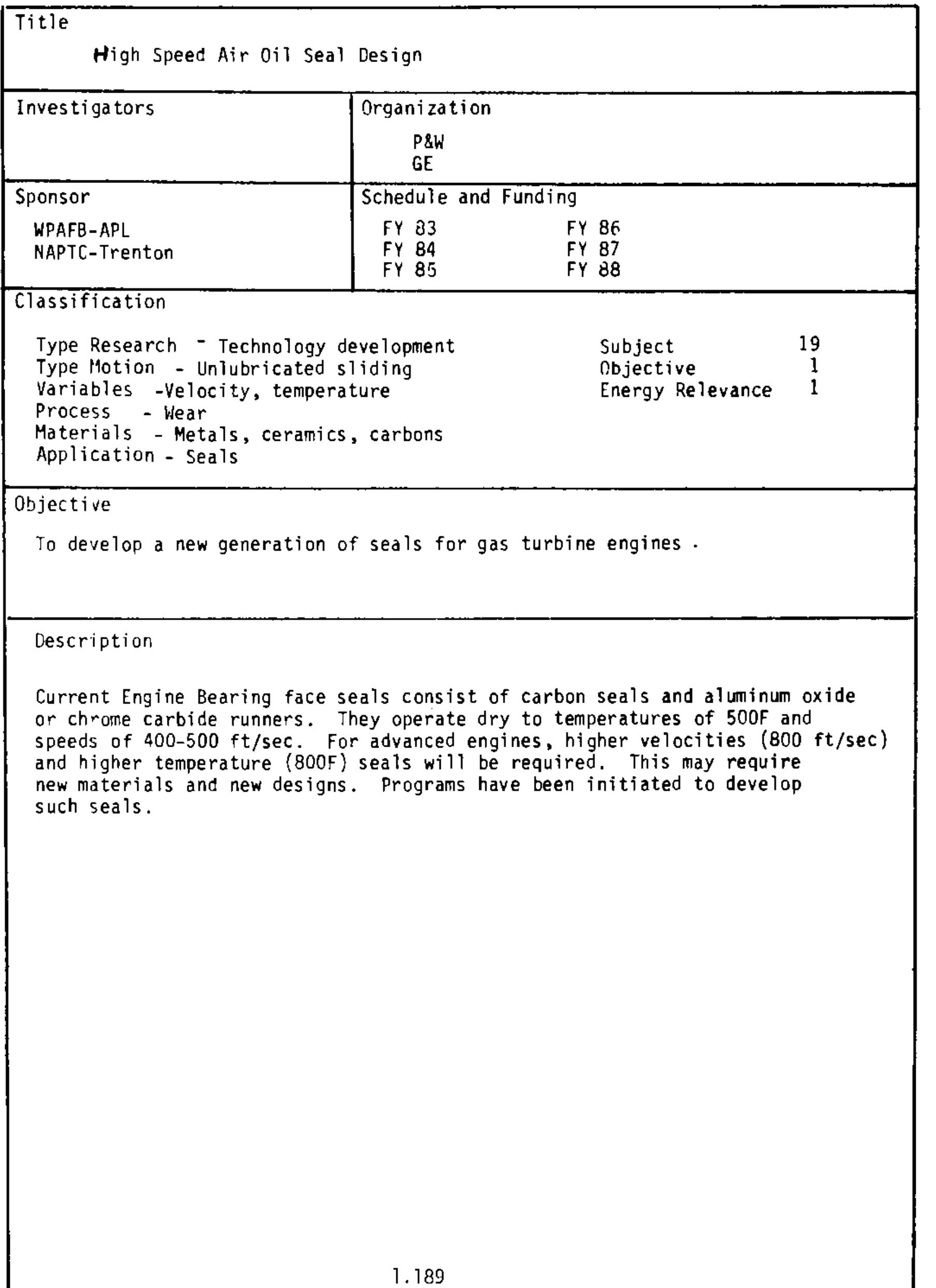




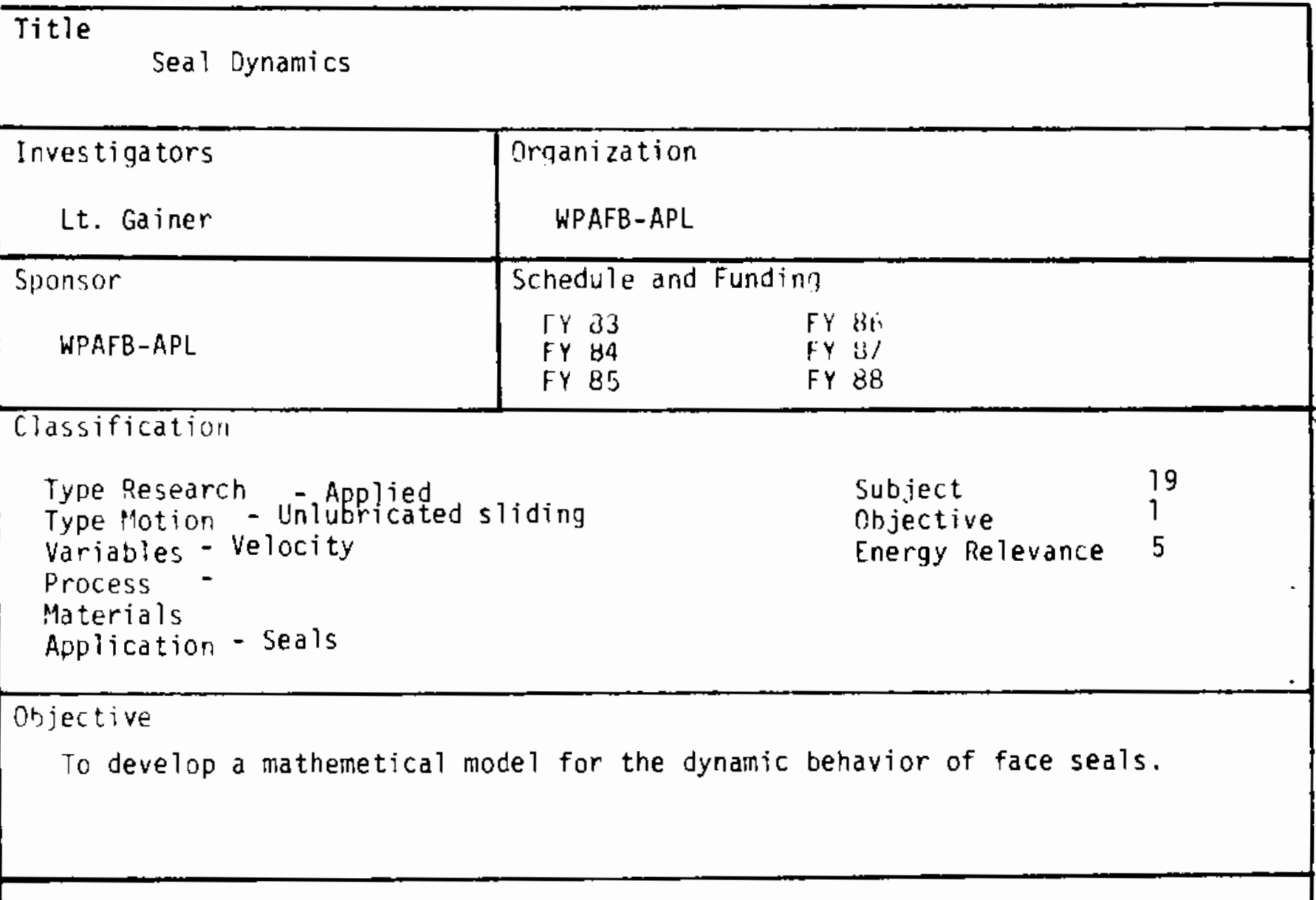

Description

An analytical model will be developed and correlated with experiment. 
Title

Tribological Research for Improved Aero-Engine Efficiency

\begin{tabular}{|c|c|}
\hline $\begin{array}{l}\text { Investigators } \\
\text { A.F. Emery } \\
\text { J. Wolak }\end{array}$ & $\begin{array}{l}\text { Orqanization } \\
\text { University of Washington }\end{array}$ \\
\hline Sponsor & Schedule and Funding \\
\hline NASA & $\begin{array}{ll}\text { FY } & 33 \\
\text { FY } & 84 \\
\text { FY } & 85\end{array}$ \\
\hline
\end{tabular}

Classification

Type Research - Applied

Subject

19

Type "otion - Sliding

Variables - Velocity \& Geometry

Objective

6

Process - Wear

Energy Relevance 5

Materials - Metals

Application - Seals

Orjective

To minimize the deleterious effects of blade tip/seal rub interactions in aero-turbine engines.

Description

Special apparatus has been constructed to permit experimental studies of similar high intensity rubbing processes under laboratory conditions. The controlled parameters associated with the blade tip specimen are its material, the geometry of the tip, and the speed of rubbing, which can be set between $0.01 \mathrm{~m} / \mathrm{s}$ to $150 \mathrm{~m} / \mathrm{s}$. The parameters associated with the seal are: $i$ ts material, the geometry of $i$ ts internal construction, the geometry of the path of rubbing, the depth of incursion, and the rate of incursion, which may oe set between $1.0 \times 10^{-5} \mathrm{~mm}$ and $0.1 \mathrm{~mm}$ per pass of the blade. The parameters measured experimentally are the forces of interaction, the temperatures at the blade-seal interface, and the wear of both specimens.

These studies are augmented with theoretical analyses of energy generation and dissipation during rubbing, of associated stress and temperature fields, and of the effect of temperature on the properties of materials adjacent

to the rub interface. 


\section{Titie}

Observations from a Five-inch Seal Test Machine

\begin{tabular}{|c|c|}
\hline $\begin{array}{c}\text { Investigators } \\
\text { S.A Karp } \\
\text { R.G. Brown }\end{array}$ & $\begin{array}{l}\text { Organization } \\
\text { DTMSRDC Annapolis }\end{array}$ \\
\hline Sponsor & Schedule and Funding \\
\hline NAVSEA & $\begin{array}{ll}F Y & 83 \\
\text { FY } & 84 \\
\text { FY } & 85\end{array}$ \\
\hline
\end{tabular}

Classification

Type Research - Applied

Type Motion - Sliding, lubricated

Variables - Composition

Subject

Objective

Energy Relevance

Process - llear, Teakage

Materials - Matals, ceramics

Application-Seal

Objective

To develop longer life submarine seal materials.

\section{Description}

A Navy submarine seal materials task was structured to provide inputs to a general program established to develop seals with a longer service life. one element of the task is to rank seal-face combinations having better resistance to wear than material combinations currently used. A test rig was developed for this purpose.

Data are being accumulated to provide a statistically sound basis to correlate the wear performance of the mating materials to material composition, structure, and properties. 


\section{Title \\ Influence of Thental Expansion and Wear on Contact of High Current Density Electric Brushes}

\begin{tabular}{|c|c|}
\hline $\begin{array}{l}\text { Investigators } \\
\text { T. Dow } \\
\text { D. Lawson }\end{array}$ & $\begin{array}{l}\text { Organization } \\
\text { North Carolina State }\end{array}$ \\
\hline Sponsor & $\begin{array}{l}\text { Schedule and Funding } \\
\text { FY } 83 \\
\text { FY } 84\end{array}$ \\
\hline $\begin{array}{l}\text { Classification } \\
\text { Type Research - Applied } \\
\text { Type llotion - Siiding } \\
\text { Variables - } \\
\text { Process- Temperatures, wear } \\
\text { Materials - Carbon } \\
\text { Application - Brushes }\end{array}$ & $\begin{array}{l}\text { Subject } \\
\text { Objective } \\
\text { Energy Relevance }\end{array}$ \\
\hline \multicolumn{2}{|c|}{$\begin{array}{l}\text { Objective } \\
\text { Deterinine the influence of thermal effects and interaction with viscosity, } \\
\text { thermal expansion, surface contact. }\end{array}$} \\
\hline \multicolumn{2}{|c|}{$\begin{array}{l}\text { Description } \\
\text { A research program is aimed at studying the influence of thermal effects } \\
\text { and interaction with: }\end{array}$} \\
\hline $\begin{array}{l}\text { 1. Lubricant viscosity } \\
\text { 2. Thermal expansion of } \\
\text { 3. Contact in uniubrica }\end{array}$ & $\begin{array}{l}\text { EHD contact } \\
\text { surface in EHD contact } \\
\text { ed or boundary lubricated sliding surfaces }\end{array}$ \\
\hline
\end{tabular}


Title

Improved Service Life of Transient Coach Brakes

\begin{tabular}{|c|cc|}
\hline Investigators & Organization \\
S.A. Barber & \multicolumn{2}{|c|}{ Battelle Columbus } \\
\hline Sponsor & Schedule and Funding \\
National Academy of & FY 83 & FY 86 \\
Science / NCTRP & FY 84 & FY 87 \\
& FY 85 & FY 88 \\
\hline
\end{tabular}

Classification

Type Research - Exploratory development

Type Motion- Uniubricated sliding

Variables - Temperature

Process - Life

Subject Objective

Energy Relevance

Materials - Polymer

Application-Brakes

Objective

To investigdte possible solution schemes toward reducing drum and lining temperatures.

Description

New Advanced Design Buses used in urban transit system now experience reduced brake lining life compared to older buses. Increased drum and lining temperature due to higher stopping speeds is suspected to be the main cause. This program is investigation possible solution schemes toward reducing drum and lining temperatures. 


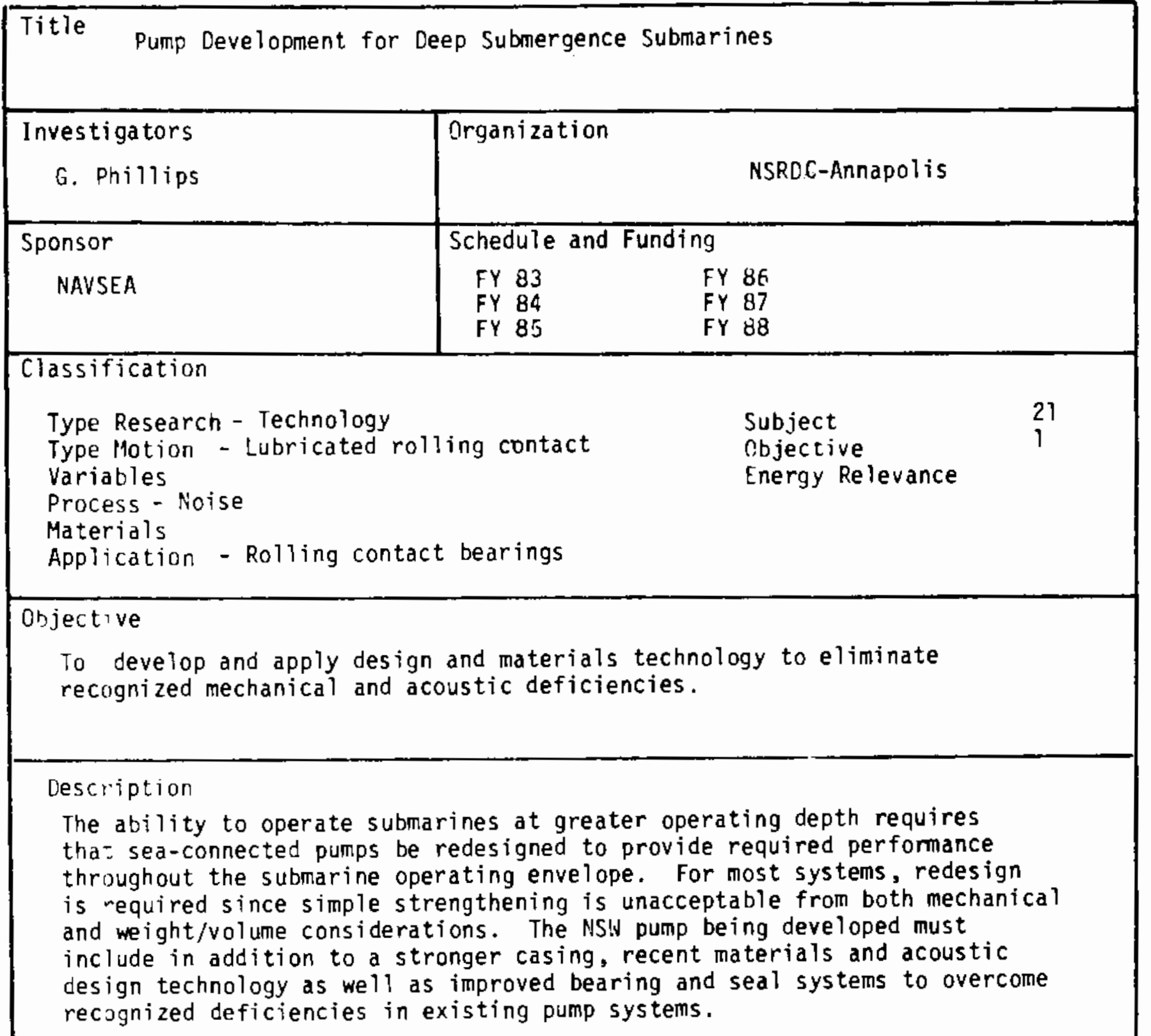




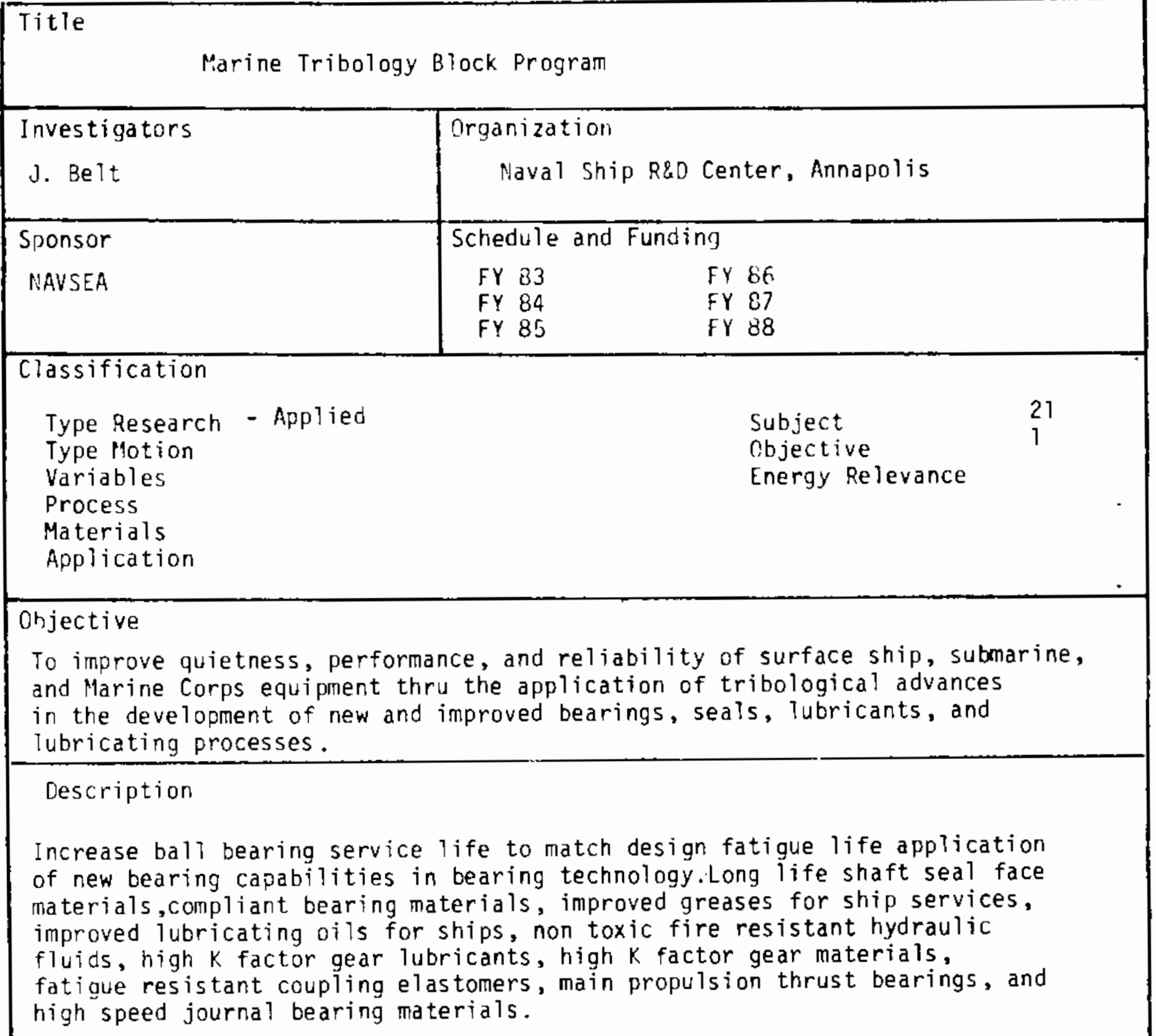




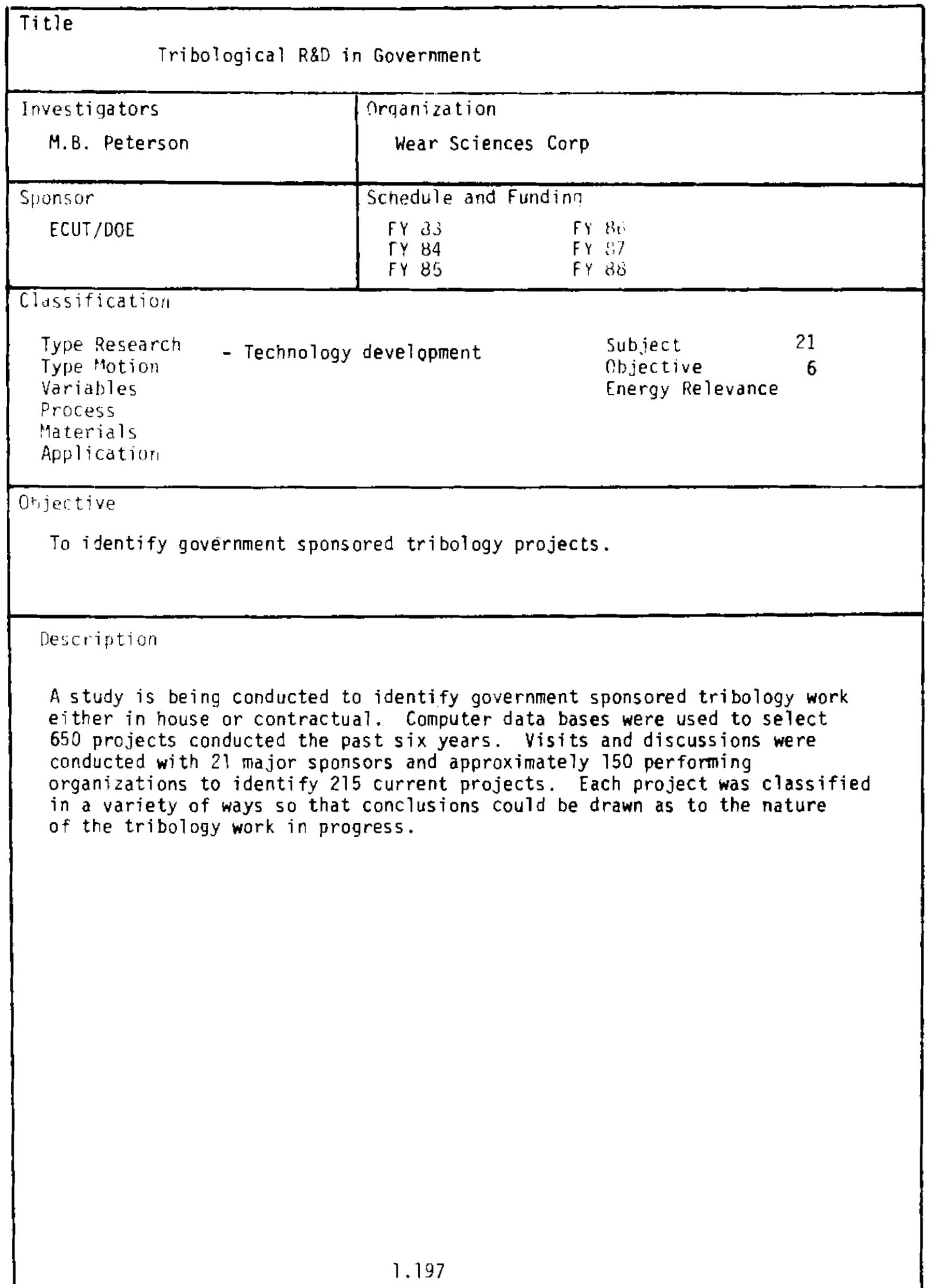




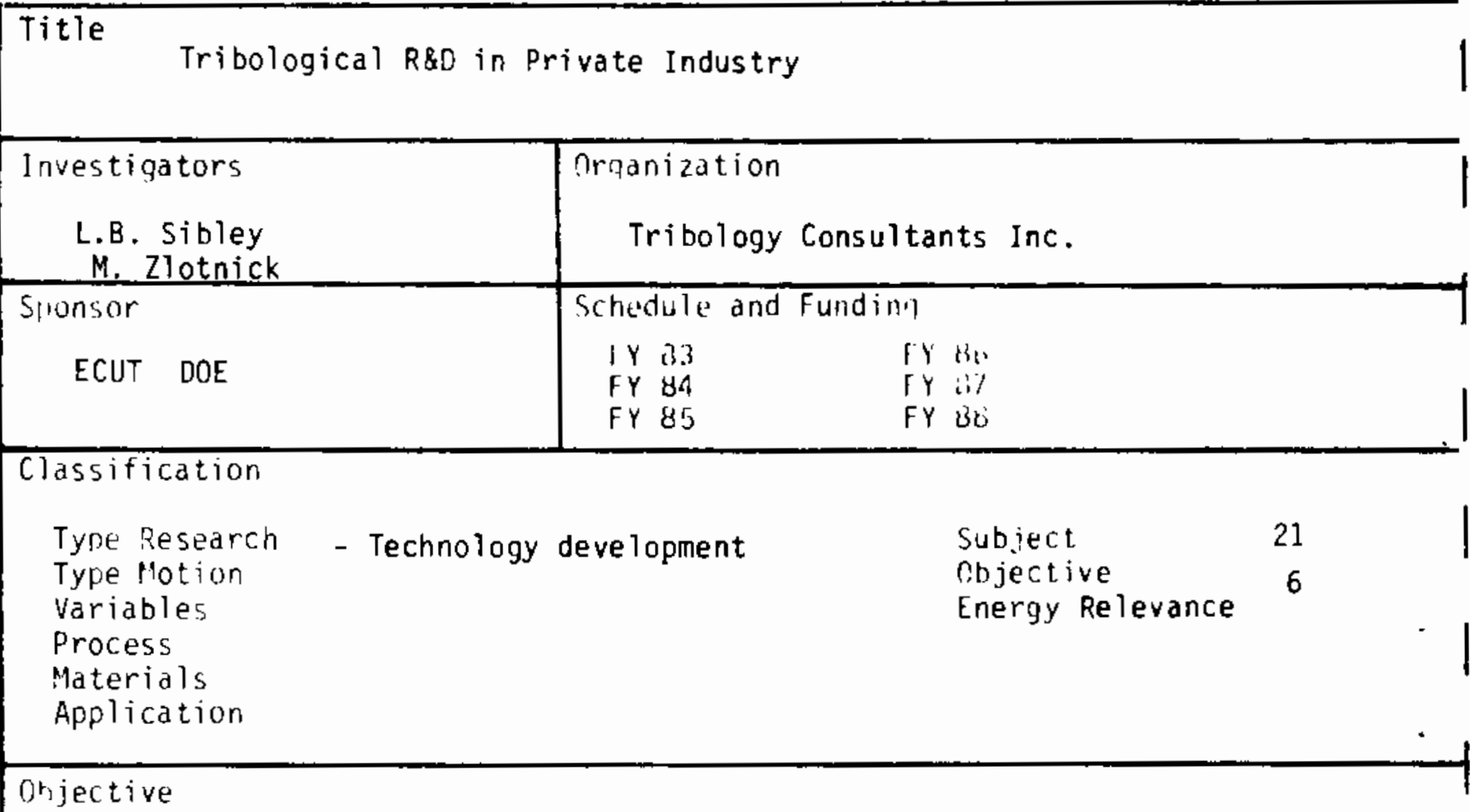

To obtain form industry their view on tribology research needs and determine research in progress.

Description

Visits were made to twenty selected industrial organizations to determine current tribology R\&D and to assess industrial conceptions of R\&D needs. Preliminary findings confirm the view that only a small amount of generic research in tribology is being conducted and that total expenditures by industry is smal1. Most of the work can be characterized as product development and testing. However the need for generic research was acknowledged, emphasizing fundamental mechanisms. 


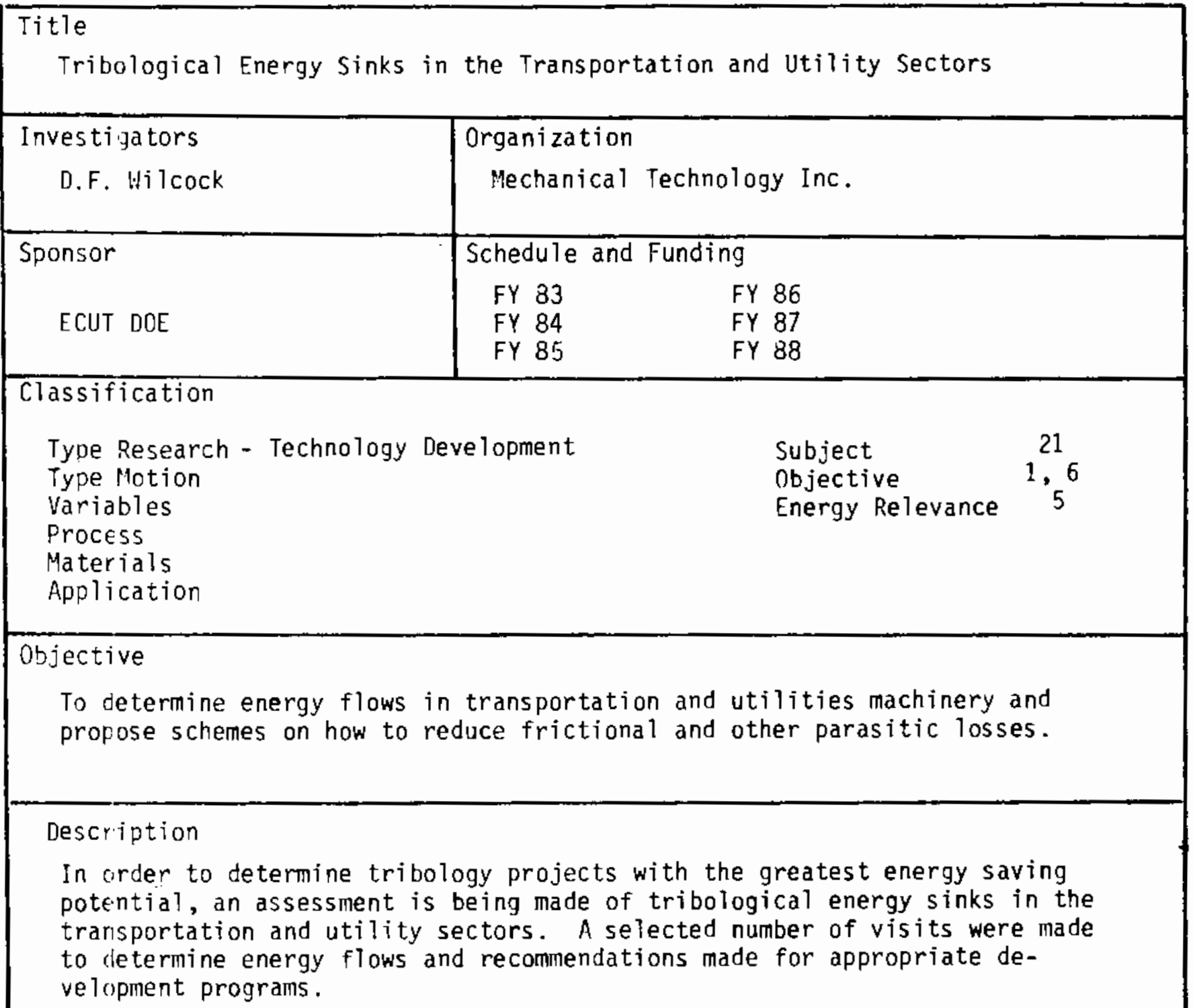




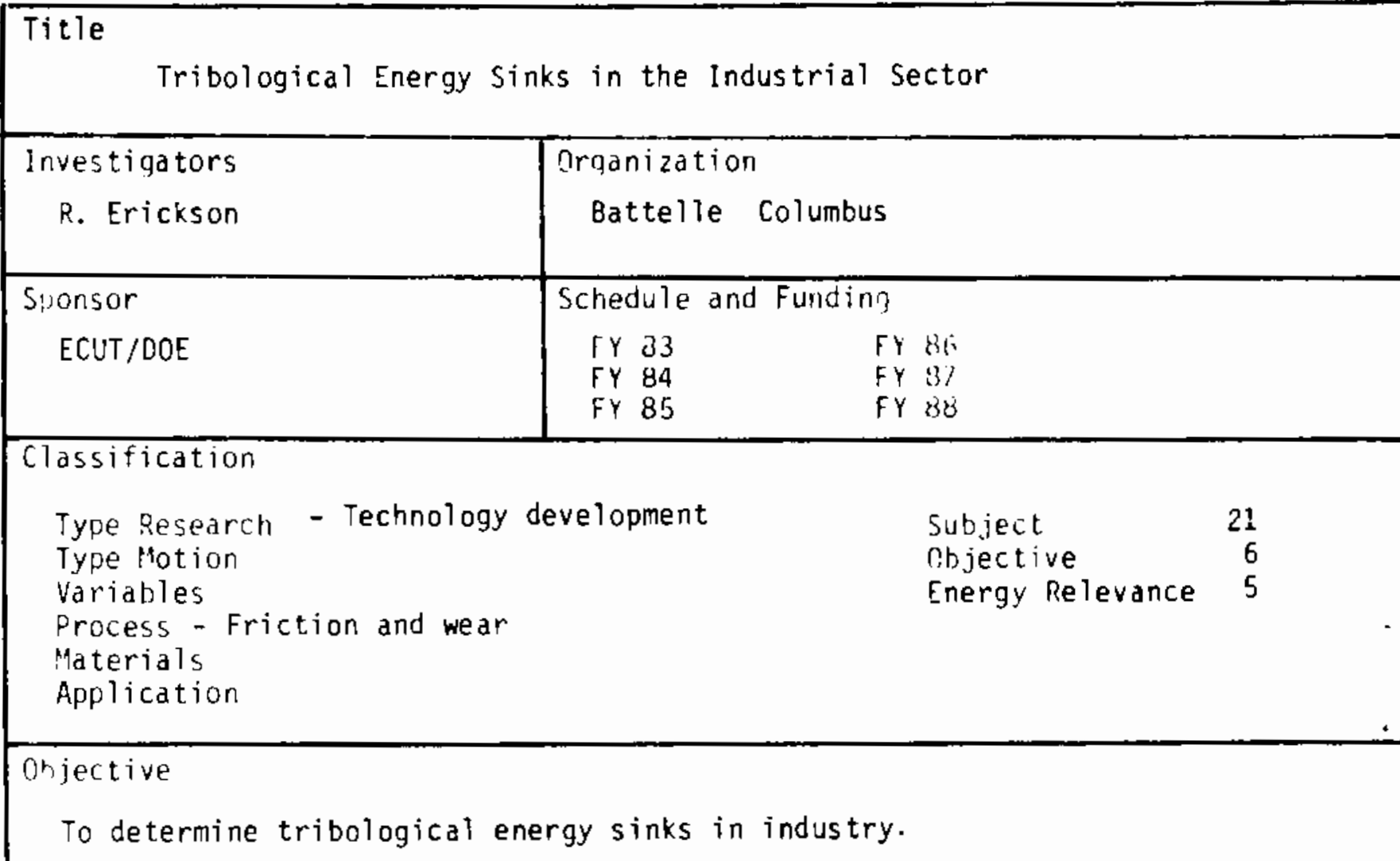

Nescriptinl

In order to determine tribology projects with the greatest energy saving potential an assessment is being made to quantify industrial energy sinks. Energy intensive industries were first selected followed by detailed reviews of different energy sectors. Different tribology contributions to each sector are being suggested. 


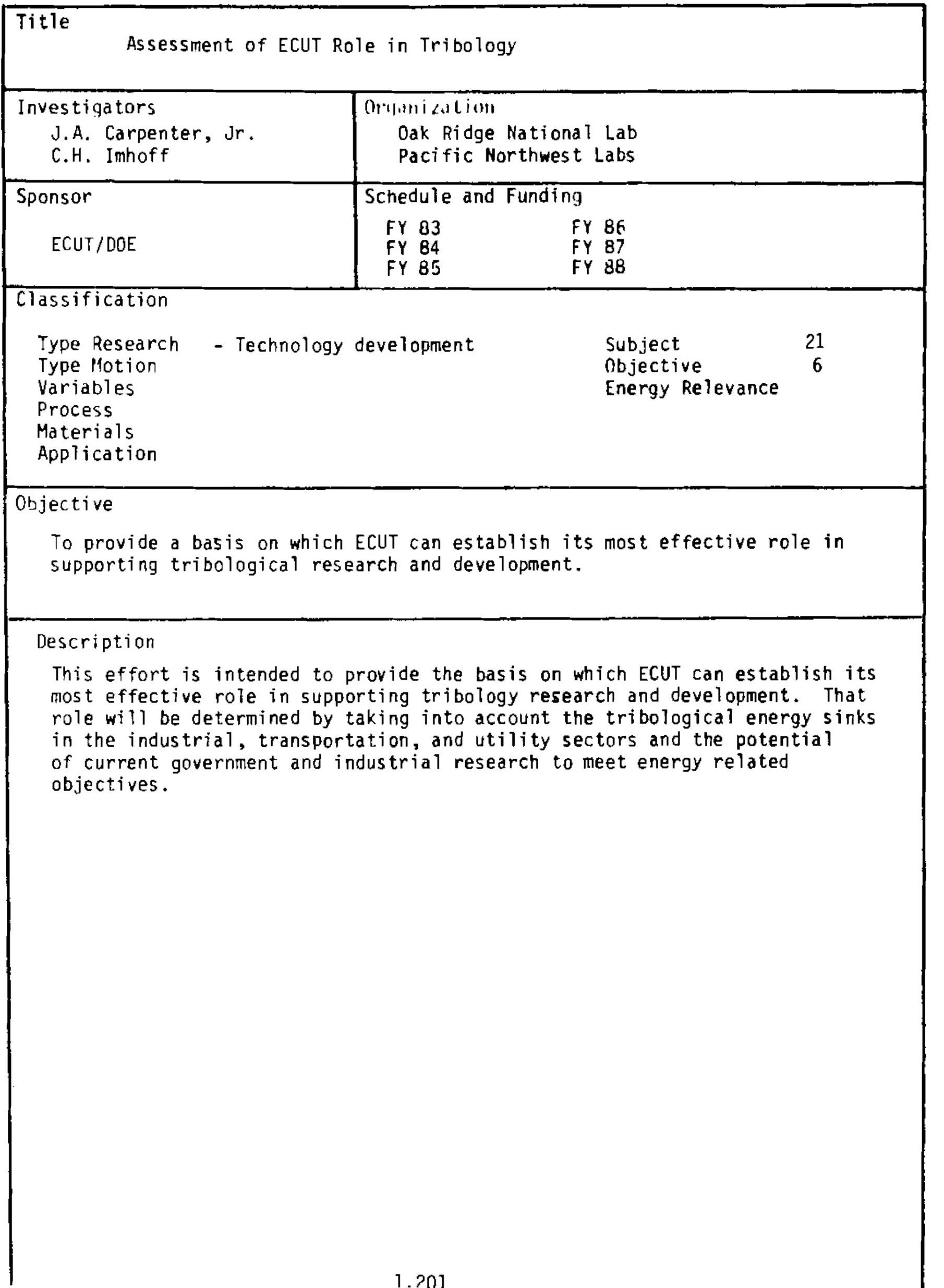




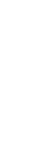


No. of

Copies

OFFSITE

12 T. Levinson

U.S. Department of Energy Forrestal Building CE-142

Washington, D.C. 20585

J. J. Eberhardt

U.S. Department of Energy

Forrestal Building

Mail Stop 6B025

Washingt on, D.C. 20585

30 DOE Technical Information Center

\section{A. Anderson}

Multi-Arc Vacuum Systems Inc.

261 East 5th Avenue

St. Pau1, MN 55101

C. Albertson

Borg-Warner Corporation

1200 South Woif Road

Des Plaines, IL 60018

A. Becker

Alurina, Chem. \& Ceramics Division

Alcoa Research Laboratories

Alcca Center, PA 15069

P. N. Blumberg

Integral Technologies, Inc.

415 East Plaza Drive

Westmont, IL 60559

L. I. Brombolich

Compu-Tec Engr. Inc.

300 Chesterfield Center, 205

Chesterfield, MO 63017

W. Bryzik

U.S. Army TACOM

AMSTA-RGR

Warren, MI 48090
No of

Copies

D. H. Buckley

NASA/Lewis Research Center

23-2

Cleveland, $\mathrm{OH} \quad 44135$

R. F. Bunshah

Department of Materials Science

University of California at

Los Angeles

6532 Boelter $\mathrm{Hall}$

Los Angeles, CA 90024

J. A. Carpenter, Jr.

Oak Ridge National Laboratory

P0 Box $X$, Building 4508

Oak Ridge, TN 37831

D. C. Classen

Caterpillar Tractor Co.

Mfg. Engr. Building W

600 West Washington Street

East Peoria, Il. 61630

F. J. Carignan

Advanced Mechanical

Technology Inc.

141 California Street

Newton, MA 02158

D. L. Cocke

Texas AsM University

Department of Chemistry

College Station, TX 77843-3255

H. S. Cheng

Dept. of Mechanical Engineering

Center for Engineering Tribology

Northwestern University

Evanston, IL 60201

G. H. Clark

Oak Ridge National Laboratory

PO Box $X$, Building 4508

Oak Ridge, TN 37831 
No of

Copies

G. Chang

29615 Lincoin Road

Bay Village, OH 44140

M. J. Cronin

Mechanical Technology, Inc.

968 Albany-Shaker Road

Lathan, NY 12110

J. L. Duda

Pennsylvania State University

133 Fenske Laboratory

University Park, PA 16802

S. K. Das

Materials Laboratory

Allied Corporation

P.0. Box $1021 \mathrm{R}$

Morristown, NJ 07960

J. F. Di11

Mechanical Technology Inc.

968 Albany-Shaker Road

Latham, NY 12110

R. L. DaSilveira

Eutectic Corp.

4040172 nd Street

Flushing, NY 11358

C. A. Ebel

High Performance Ceramics

Norton Company

1 New Bond Street

Worcester, MA 01606

R. Erickson

Battelle-Columbus Laboratory

$505 \mathrm{King}$ Avenue

Columbus, $\mathrm{OH}$ 43201-2693

L. L. Fehrenbacher

2002 Huntwood Drive

Huntington Woods

Gambrills, MD 21054
No of

Copies

D. G. Flom

General Electric Company

Corporate $\mathrm{R} \& \mathrm{D}, 4 \mathrm{~B} 4, \mathrm{~K}-1$

P.0. Box 8

Schenectady, NY 12301

T. Fischer

Exxon Research

Clinton Township Route 22 East

Annandale, NJ 08801

P. Grayson

Eagle Picher Industries, Inc.

P.0. Box 1090

Miami, OK 74354

J. Graham

Deere and Company

Technical Center

3300 River Drive

Moline, IL 61265

S. Goguen

U.S. Department of Energy, CE 131

Mailstop 5E 043

Forrestal Building

1000 Independence Ave., SW

Washington, D.C. 20585

R. M. Gresham

E/M Lubricants, Inc. P.0. Box 2200, Highway 52 N.W. West Lafayette, IN 47906
J. Horwath
Borg-Warner Corporation
Ingersoll Research Center
1200 S. Wolf Road
Des Plaines, IL 60018
S. M. Hsu
Room A257, Building 223
Inorganic Materials Division
National Bureau of Standards
Gaithersburg, MD 20899 
Vo of

Jopies

N. S. Hakim (R03B)

Detroit Diesel Allison Division

36880 Ecorse Road

Romulus, MI 48174

C. R. Houska

Dept. of Materials Engineering

Virginia Polytechnic Institute

Blacksburg, VA 24061

R. A. Harmon

25 Schalren Drive

Latham, NY 12110

J. K. Hirvonen

Spire Corporation

Patriots Park

Bedford, MA 07130

10 M. Kaminsky

Argonne National Laboratory

9700 South Cass

Argonne, IL 60439

E. E. Klaus

Dept. of Chemical Engineering

Pennsylvania State University

Iniversity Park, PA 16802

R. Krutenat, 102/D217

Exxon Research and

Engineering $\mathrm{Co}$.

Florham Park, NJ 07932

S. Knanna

Solid State Science Research Group

Jet Propulsion Laboratory

4800 0ak Grove Drive

MS 122-123

Pasajena, CA 91109

K. Ludema

University of Michigan

Dept. of Mechanical Engineering

2024 G. G. Brown

Ann Arbor, MI 48109-2125
No of

Copies

\author{
Librarian \\ Deere and Company \\ Technical Center \\ 3300 River Drive \\ Moline, IL 61265-1792 \\ F. F. Ling \\ Mechanical Engineering \\ Jonsson Engineering Center \\ Rensselaer Polytechnic \\ Institute \\ Troy, NY 12181
}

H. LeKhac

OHR Inc.

6849 0ld Dominion Drive

McLean, VA 22101

H. E. McCormick

Director of Engineering

Ramsey Piston Ring Division

TRW Automotive Products, Inc. 1233 Manchester Road

Manchester, M0 63011

C. Mecklenburg

AFWAL/MLBT

Wright Patterson AFB

Dayton, $\mathrm{OH}$ 45433-6533

J. $\mathrm{MCCOO}$

SKF Industries

1100 First Avenue

King of Prussia, PA 19406

R. W. Meyerhoff

Union Carbide Corporation

Coatings Service

1500 Polco Street

Indianapolis, IN 46224

J. R. Mullaly

Pratt \& Whitney Aircraft

P.0. Box 2691

MS 707-2B

West Palm Beach, FL 33402 
No of

Copies

P. Madden

SKF Industries

1100 First Avenue

King of Prussia, PA 19506

12 M. B. Peterson

Wear Sciences, Inc.

925 Mallard Circle

Arnold, MD 21012

0. Pinkus

Mechanical Technology Inc.

968 Albany-Shaker Road

Latham, NY 12110

T. F. J. Quinn

Tribology and Rheology

Laboratory

School of Mechanical

Engineering

Georgia Institute of Technology

Atlanta, GA 30332

R. C. Rosenberg

General Motors Research Laboratory

Fluid Mechanics Department

Warren, MI 48090

D. A. Rigney

The Ohio State University

Dept. of Metailurgical

Engineering

$141 \mathrm{~A}$ Font ana Laboratories

116 West 19th Avenue

Columbus, $\mathrm{OH}$ 43210-1179

A. W. Ruff

National Bureau of Standards

Metallurgy Division

Room B266-Materials Building

Gaithersburg, MD 20899

H. D. Sproul

Borg-Warner Corporation

1200 South wolf Road

Des Plaines, IL 60018
No of

Copies

P. Sutor

Midwest Research Institute

425 Volker Boulevard

Kansas City, M0 64110

L. B. Sibley

Tribology Consultants, Inc. 504 Foxwood Lane

Paoli, PA 19301

A. C. Schaffhauser

Oak Ridge National Laboratory

P.0. Box $X$

Dak Ridge, TN 37831

I. L. Singer

Naval Research Laboratory

Code 6170

Washington, D.C. 20375

G. L. Starr, Manager

Metallurgical Engineering

Cummins Engine Technical Center

Box 3005

Columbus, IN 47202-3005

R. Slone 50165

Cummins Engine Technical Center

Box 3305

Columbus, IN 47202-3005

T. C. Spalvins

NASA/Lewis Research Center

MS 23-2

Cleveland, $\mathrm{OH} 44135$

M. Shaw

Arizona State University

ECG 247, Mechanical Engineering

Tempe, AZ 85287

P. Swanson

John Deere Company

Technical Center

3300 River Drive

Moline, IL 61265 
No of

Copies

L. D. Wedeven

SKF Industries, Inc.

1100 First Avenue

King of Prussia, PA 19406

R. Ted Wimber

Deere and Company

Technical Center

3300 River Drive

Moline, IL 61265-2792

D. F. Wilcock, President

Trịbolock, Inc.

1949 Hexham Road

Schenectady, NY 12309

W. 0 . Winer

Tribology and Rheology Laboratory

School of Mechanical

Engineering

Georgia Institute of Technology

At lanta, GA 30332

D. Kuhlman-Wilsdorf

University of Virginia

Physics Department

McCormick Road

Charlottesville, VA 22901

W. H. Winnard

Battelle Memorial Institute

2030 M. Street NW

Washington, 0.C. 20036

C. S. Yust

Metals and Ceramics Division

Oak Ridge National Laboratory

P.0. Box $x$

Dak Ridge, TN 37831

T. M. Yonushonis

Cummins Engine

Mail Code 50183, Box 3005

Columbus, IN 47202-3005
No of

Copies

M. Zlotnick

141 East 88th Street

New York, NY 10028

C. A. Zanis

Department of the Navy

Naval Sea Systems Command

Research and Development Office

Washington, D.C. 20362

FORE IGN COUNTRIES

Or. Jochen P. Biersack

Hahn-Meitner-Institut

Glienicker Strabe 100

1000 Berlin 39

West Germany

Dr. Erich Bergmann

Balzers Aktiengesellschaft

FL-9496 Balzers

Furstentum, Liechtenstein

Professor Dr. H. Czichos

Federal Institute for Materials

Research and Testing

Unter den Eichen 87

D-1000 Berlin 45

West Germany

Or. Geoff Dearnaley

Nuclear Physics Division

Building $\mathrm{H} 8$

AERE Harwell

Didcot, Oxfordshire

United Kingdom OX 11 ORA

Dr. Hans E. Hintermann

Laboratoire Suisse de

Recherches Horlogeves

$\mathrm{CH}-2000$ Neuchatel

Switzerland 
No of

Copies

Dr. Richard Horton, Manager Energy Conservation Technology Centre

Engineering Sciences Division

B15l Harwell Laboratory

Oxfordshire OX 11 ORA

England

Dr. Boris Navinsek

Jozef Stefan Institute

61001 Ljubljana

Jamova 39

Yugoslavia

Prof. Dr. ir. J. Roos

Katholieke Universiteit Leuven

Departrent Metaalkunde

de Croylaan 2

B-3030 Leuven (Heverlee)

Beigium

Dr. S. Veprek

Anorganisch-Chemisches

Institut der Universitat Zurich

winterthurerstrasse 190

8057 Zurich

Switzerland
No. of

Copies

ONSITE

DOE Richland Operations Office

H. E. Ransom/D, R. Segna

12 Pacific Northwest Laboratory

D. L. Brenchley

C. H. Imhoff

D. C. Kuick

J. A. Russell

M. T. Thomas

Publishing Coordination MH (2)

Technical Information (5) 